\title{
MACHINING TECHNOLOGIES FOR SILICON-BASED NANOCHANNELS AND SOME PROPERTIES OF AQUEOUS SOLUTIONS CONFINED IN THESE CHANNELS
}

Hoang Thi Hanh

University of Twente 2012 
MACHINING TECHNOLOGIES FOR SILICONBASED NANOCHANNELS AND SOME PROPERTIES OF AQUEOUS SOLUTIONS

\section{CONFINED IN THESE CHANNELS}

Hoang Thi Hanh 
Graduation committee

\section{Chairman:}

Prof. dr. ir. A. J. Mouthaan

University of Twente

Secretary:

Prof. dr. ir. A. J. Mouthaan

University of Twente

\section{Promotor:}

Prof. dr. M. C. Elwenspoek

University of Twente

Assistant promotor:

Dr. ir. N. R. Tas

University of Twente

Members:

Prof. dr. L. Mercury

University of Orleans, France

Prof. dr. T. Hankemeier

Leiden University

Prof. dr. V. Subramaniam

University of Twente

Prof. dr. ir. J. Huskens

University of Twente

Prof. dr. J. C. T. Eijkel

University of Twente

Prof. dr. J. G. E. Gardeniers

University of Twente

The research in this thesis was carried out at the Transducers Science and Technology Group, the BIOS Lab-on-a-Chip Group, the NanoBioPhysics Group in University of Twente, and the Analytical BioSciences Group in Leiden University.

The work was financed by the NanoNed program through the Nanofluidics flagship under the project TET 6644 "Machining technologies for nanochannels and interfacing”.

Front cover: Signal from a single quantum dot moving inside $1 D$ nanochannels.

Back cover: Fluorescent signal inside 2D nanochannels. 


\section{MACHINING TECHNOLOGIES FOR SILICON-BASED \\ NANOCHANNELS AND SOME PROPERTIES OF AQUEOUS \\ SOLUTIONS CONFINED IN THESE CHANNELS}

DISSERTATION

to obtain

the degree of doctor at the University of Twente, on the authority of the rector magnificus,

Prof. dr. H. Brinksma,

on account of the decision of the graduation committee,

to be publicly defended

on Wednesday, January $25^{\text {th }} 2012$, at 12:45

by

Hoang Thi Hanh

born on December $28^{\text {th }} 1972$

in Hungyen, Vietnam 
This doctoral dissertation is approved by the promotor:

Prof. dr. M. C. Elwenspoek

and assistant promotor:

Dr. ir. N. R. Tas

Author: Hoang Thi Hanh

Title: Machining technologies for silicon-based nanochannels and some properties of aqueous solutions confined in these channels

$\mathrm{PhD}$ Thesis, University of Twente, Enschede, The Netherlands

ISBN: 978-90-365-3298-3

Copyright (c) 2012 by H. T. Hoang, Vienna, Austria 
I would like to dedicate this thesis to my wonderful mother for my upbringing and her support all the time, to my kind father for his pleasure of my achievements, to my sweetheart, Duy Ha for his extreme patience and unlimited encouragement and to my lovely daughter, Hoang Anh who makes my life overwhelmingly joyful and completely meaningful. 



\section{Contents}

1. Introduction 1

1.1. Fabrication of nanochannels 2

1.1.1. Nanostructured materials 2

1.1.2. 1D nanochannels 3

1.1.3. 2D nanochannels 6

1.2. Applications of nanochannels $\quad 8$

1.2.1. Fluid physics $\quad 8$

1.2.2. Nanobiotechnology 9

1.3. Aim of this thesis 11

1.4. Organization of this thesis 12

\begin{tabular}{ll} 
1.5. & References \\
\hline
\end{tabular}

2. Fabrication and interfacing of nanochannel devices for single-molecule 19 studies

$\begin{array}{ll}\text { 2.1. Introduction } & 20\end{array}$

2.2. Experimental section 23

2.2.1. Fabrication of 1D nanochannels by wafer bonding 23

2.2.2. Fabrication of transparent surface 2D nanochannels 25

2.2.3. Fabrication of fluidic inlet/outlet ports 30

2.3. Single molecule mobility studies 32

2.4. Conclusions 34

2.5. References 35

3. Wafer-scale thin encapsulated two-dimensional nanochannels and its 40 application toward visualization of single molecules

3.1. Introduction 41

3.2. Fabrication of thin encapsulated, 2D nanochannels 43

3.3. Fabricated nanochannels toward visualization of single molecules 46

3.4. Visualization of single Alexa molecule in confined channels 47

3.5. Conclusion 49

3.6. References 49

4. Solution titration by wall deprotonation during capillary filling of 1D $\mathbf{5 3}$ silicon oxide nanochannels

4.1. Introduction 
4.2. Experimental section $\quad 57$

4.2.1. Chip manufacture $\quad 57$

4.2.2. Fluorescence measurements $\quad 57$

4.2.3. Composition of the introduced solutions 59

4.3. Theory 59

4.3.1. Capillary filling $\quad 59$

4.3.2. Experimental amount of protons released 60

4.3.3. Theoretical amount of protons released 64

$\begin{array}{lll}\text { 4.4. } & \text { Results and discussion } & 67\end{array}$

$\begin{array}{ll}\text { 4.4.1. Theoretical results } & 67\end{array}$

4.4.2. Fitting results $\quad 68$

4.4.3. Buffer effects $\quad 69$

4.4.4. Fluorescence front $\quad 69$

$\begin{array}{lll}\text { 4.5. Conclusion } & 69\end{array}$

$\begin{array}{lll}\text { 4.6. } & \text { References } & 70\end{array}$

5. Analysis of single quantum-dot mobility inside 1D nanochannels devices $\mathbf{7 3}$

5.1. Introduction 74

5.2. Experimental details $\quad 75$

5.2.1. Fabrication of 1D nanochannel devices by wafer bonding 75

5.2.2. Materials and microscopy 75

5.2.3. Image analysis 76

5.3. Theory on Brownian motion 76

$\begin{array}{lll}\text { 5.4. Results and discussion } & 79\end{array}$

5.4.1. Visualization of single quantum dots $\quad 79$

5.4.2. Analysis of quantum-dot mobility 79

5.4.3. Discussion about observed reduced diffusion coefficient 82

5.5. Conclusions 85

5.6. References $\quad 85$

6. Conclusions and outlook 89

6.1. Conclusions 90

6.2. Outlook and recommendations 91

6.3. References 92 
$\begin{array}{ll}\text { Appendix } & 94\end{array}$

A2.1. Fabrication of 1D nanochannel devices 94

A2.2. Fabrication of 2D nanochannel devices 96

A2.3. Scanning confocal microscopy 98

A3.1. Fabrication of 2D encapsulated nanochannel devices 99

$\begin{array}{ll}\text { A4.1. Filling images of Alexa and Bodipy } & 100\end{array}$

A4.2. Process outline of 1D nanochannel devices for deprotonation studies $\quad 100$

A4.3. Fabrication of 1D nanochannel devices for deprotonation studies $\quad 100$

$\begin{array}{ll}\text { A4.4. Fluorescence experimental setup } & 102\end{array}$

A4.5. Raw data from a measurement with pure fluorescein 103

$\begin{array}{lr}\text { A5.1. Build matrix } & 103\end{array}$

$\begin{array}{ll}\text { A5.2. Quantum-dot tracking } & 104\end{array}$

$\begin{array}{ll}\text { A5.3. Brownian motion } & 106\end{array}$

$\begin{array}{ll}\text { A5.4a. Gaussian fitting } & 107\end{array}$

$\begin{array}{lr}\text { A5.4b. R-fitting } & 108\end{array}$

$\begin{array}{ll}\text { A5.5. MSD relation } & 109\end{array}$

$\begin{array}{ll}\text { A5.6. Distribution of diffusion coefficients } & 110\end{array}$

$\begin{array}{ll}\text { A5.7. Einstein-Stokes relation } & 111\end{array}$

A5.8. Random movements of suspended particles in liquids 112

$\begin{array}{ll}\text { A5.9. Solving diffusion equation } & 113\end{array}$

$\begin{array}{ll}\text { A5.10. Derivation of diffusion coefficient } & 115\end{array}$

$\begin{array}{ll}\text { A6.1. Nano-ITP chip, design and fabrication } & 116\end{array}$

$\begin{array}{ll}\text { A6.2. Modification and fabrication of 1D nanochannel devices } & 118\end{array}$

A6.3. Fabrication of 1D glass nanochannel devices 119

$\begin{array}{ll}\text { Summary } & 121\end{array}$

$\begin{array}{lr}\text { List of abbreviations and symbols } & 123\end{array}$

$\begin{array}{ll}\text { List of figures and tables } & 126\end{array}$

$\begin{array}{ll}\text { Publications } & 128\end{array}$

$\begin{array}{ll}\text { Acknowledgements } & 131\end{array}$

$\begin{array}{ll}\text { Biography } & 135\end{array}$ 



\section{Chapter 1}

\section{Introduction}

Recently, with advances in nanotechnology many scientists have focused their interest on fabrication of nanochannels and used them for both fundamental and applied studies. Nanochannel devices with controlled nanometer dimensions provide a novel tool for studying some properties of aqueous solutions and thus possibly new applications which are not available in the large scale. In this chapter, first diverse techniques to construct nanochannels are introduced, followed by a broad range of utilizations of nanochannels. Then, the aim and outline of the thesis is presented. 


\subsection{Fabrication of nanochannels}

\subsubsection{Nanostructured materials}

Zeolites and charcoal (carbons) have been well-known as naturally porous materials that are widely used in filtration, chromatography, (bio)chemical engineering, etc [1-5]. Based on advantages of their high porosity, researchers have created nanostructured materials that have other new applications along with their conventional applications. Zeolites were used as matrix materials that can host other guest molecules to create interesting properties for utilizations in microelectronic and medical diagnosis [6]. In another example [7], carbons with periodic porous nanostructures were used as electrode active materials to increase the charge-discharge capacities in battery applications. Moreover, porous carbons were created with different structures [8] and templates [9] to enlarge pore-size distribution for variant applications [10]. Another interesting material with nanostructures is glass nanocapillaries which were created from microcapillaries using mechanical pulling [11-12]. These nanocapillaries with cylindrical shape and dimensions from 5-100 $\mathrm{nm}$ were used to detect single $40 \mathrm{~nm}$ polystyrene nanoparticles. Also, Steinbock et al. [13] presented $45 \mathrm{~nm}$ diameter nanocapillaries that were pulled from quartz capillaries (outer diameter of $0.5 \mathrm{~mm}$ and inner diameter of $0.3 \mathrm{~mm}$ ) using a laser-equipped pipet puller. Final dimensions of the nanocapillaries depended on initial diameters of capillaries, temperature, and pulling force. These nanocapillaries were used to study DNA translocation using electrophoretic force.

Fluids confined in these nanostructured materials exhibited physical behaviors that were quite different from their bulk especially in presence of fluid-wall and fluid-fluid interactions. Gardeniers et al. [14] reviewed increasing of boiling temperature in micropores (diameters smaller than $2 \mathrm{~nm}$ ) materials. Furthermore, Zarragoicoechea et al. [15] presented a model for shifts in the critical temperature and the critical pressure using a non-wetting confined fluid in a nanopore. Water properties in confined structures have attracted the interest of many researchers. Among these properties is viscosity that was intensively studied. For instance, Derjaguin et al. [16] investigated physical behavior of the boundary layer of water near the surfaces in quartz capillaries with a diameter about a couple of hundred nanometers. In another study [17], frictionless flow of water molecules was observed through carbon nanotube membranes under an osmotic gradient. However, these nanostructured materials were randomly synthesized consequently their shape and dimensions were not highly uniform. There were also drawbacks in integration with other components. To overcome these limitations, silicon-based nanochannels have been introduced. They have precisely 

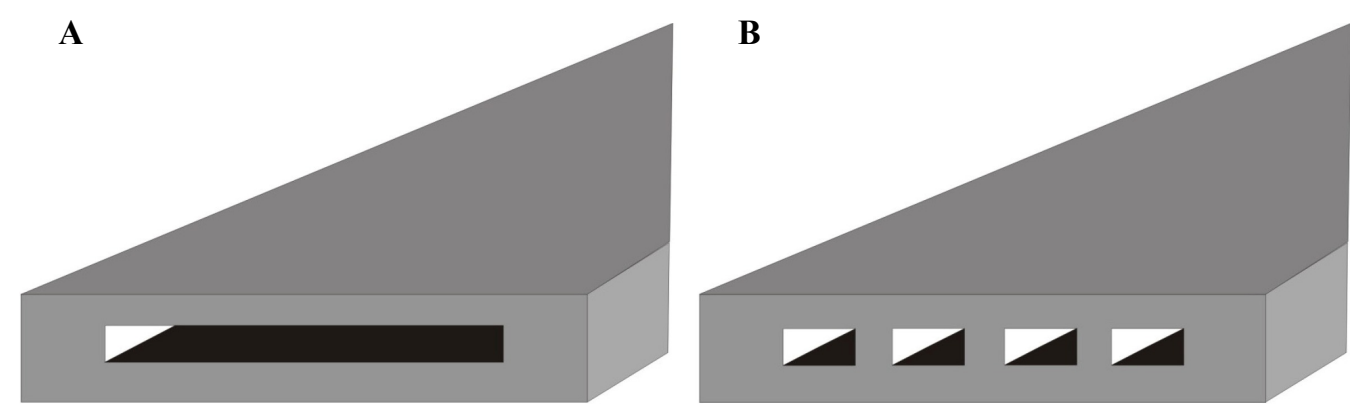

Figure 1.1. Definition of nanochannels. (A) a 1D nanochannel. (B) $2 D$ nanochannels.

defined sizes and can easily be integrated with other electrical and optical components like electrodes for conducting or mechanical parts for fluid guiding.

\subsubsection{D nanochannels}

Generally, nanochannels (NCs) having only their height or width (mostly the height) in the nanoscale range (commonly smaller than $100 \mathrm{~nm}$ ) are defined as one-dimensional (1D) NCs (figure 1.1A), while channels with both the height and the width are two-dimensional (2D) NCs (figure 1.1B). To create channels with the nanometer height, patterns are formed using standard photolithography. In case of both dimensions, patterns are constructed using nanolithography, micro-scale photolithography (in combination of other micromachining techniques) and bottom-up techniques. Fabrication is mainly based on surface-, bulk-, and bond-micromachining techniques.

Surface-micromachined NCs are formed by two common techniques known as spacer layer etching and sacrificial layer etching. In the spacer layer etching technique, channel patterns (figure 1.2B) are created on a substrate with a well-defined deposited layer by standard photolithography [18-20]. During photolithography, channel patterns are transferred by illumination with ultraviolet light through a designed photo-mask to a coated polymeric photoresist layer which is light sensitive. The patterns are then transferred to the deposited layer using wet chemical etching (WCE) or reactive ion etching (RIE). The channel height is controlled by the thickness of the deposited layer and the time needs to completely etch this layer. Then, this patterned substrate is closed by bonding with another substrate or covered by other layers. For instance, Haneveld et al. [21] fabricated sub-10 nm channels by controlling the thickness of the silicon oxide layer.

In the second approach, the sacrificial layer etching (figure 1.2C), channels are formed on a substrate with deposited layers (sacrificial and structural layers) by selective etching of the 



Figure 1.2. Brief description of fabrication of nanochannels (A) Bulk micromachining. (B) Spacer layer etching technique. (C) Sacrificial layer etching technique.

sacrificial layer. This technique is based on a proper selection of the two layers and the etchants to obtain a high selective etching of the sacrificial over the structural material. Channel height is controlled by the thickness of the sacrificial layer. Most common combination is $\mathrm{SiO}_{2}$ (sacrificial)/Si (structural) and $\mathrm{HF}$ etchant. Another combination with very good selectivity is $\mathrm{Si}$ (sacrificial)/ $\mathrm{SiN}$ or $\mathrm{SiO}_{2}$ (structural), and $\mathrm{KOH}\left(\mathrm{TMAH}, \mathrm{Xe}_{2} \mathrm{~F}\right.$ ) for Si etching [22]. For example, Tas et al. [23] created NCs on a fused silica substrate. A deposited tetra-ethyl-ortho-silicate (TEOS) silicon oxide layer as the structural and a polysilicon layer as the sacrificial was selected. Channels with $100 \mathrm{~nm}$ height and $375 \mu \mathrm{m}$ length were formed after etching of the polysilicon sacrificial layer in a 5\% TMAH solution. The sacrificial layer etching method produces slightly tapered channels of approximately 200 $\mathrm{nm}$ height at the channel entrance and $86 \mathrm{~nm}$ at the end. Another example is that of polyimide channels fabricated by Eijkel et al. [24]. The process was started by spinning of a polyimide layer on a silicon substrate (with a silicon oxide layer). Then, a sacrificial aluminum layer was deposited on the polyimide layer. A second layer of polyimide was used to cover the aluminum layer. The aluminum sacrificial layer was then etched by a wet chemical method. This technique has some drawbacks like long etching time to etch long channels subsequently variety in channel height and stress issues from the structural layer. To reduce the etching time, irrigation holes for the etchant were made [25], the sacrificial layer was removed 


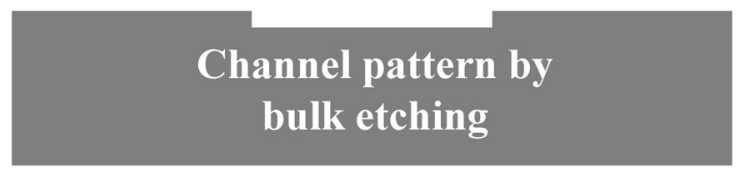

Bonding with cover substrate containing inlet access
Channel pattern by

spacer layer etching

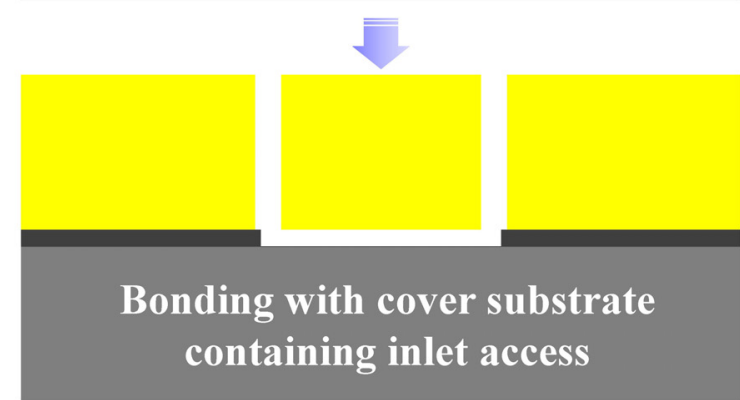

Figure 1.3. Brief description of fabrication of nanochannels using combination of bulk and bond micromachining (left images) and surface and bond micromachining (right images).

sideward [26] or heat decomposable polymers are used as the sacrificial layers [27-28]. Surface channels with very thin structural layers have a very low light absorbance but are relatively fragile which results in difficulties of integration with other fluidic components such as microchannels or macro inlet holes.

In bulk micromachining, NC structures (figure 1.2A) are formed out of a substrate by etching unwanted parts and leaving desired structures. NC patterns are created by photolithography then by short etching using either WCE [29-30] or RIE [31-32]. The height of the channels is well defined by tuning etching time using diluted wet etchants or optimizing the RIE parameters. Moreover, the shape of the channels can be precisely controlled with directional etching. For example, Han et al. [33] created $90 \mathrm{~nm}$ high channels in a silicon substrate using RIE for DNA separation.

Bond micromachining allows to form channels (figure 1.3) by bonding of two substrates with structures previously created by surface or bulk micromachining. Kutchoukov et al. [34] fabricated NCs on an intermediate layer of polysilicon from a glass substrate then bonded to another substrate. Mao et al. [32] presented detail parameters during processing to fabricate 1D NCs using silicon-glass and glass-glass bonding. NCs made by bonding technique are mechanically robust, since there is no issue related to the stress and fragility of the thin structural layer. However, the bonding process highly requires cleanliness of channel surfaces to avoid residue particles abrupting the bonding. 
During fabrication of NC devices, above techniques are combined. NCs are formed on a substrate by bulk micromachining then closed by another substrate using bonding. Surfacemachining NCs are integrated to bulk-machining inlet-ports to create a complete device.

\subsubsection{D nanochannels}

\section{Nanolithography}

2D NC patterns are generally obtained using nanolithographic techniques with a high resolution such as electron beam lithography (EBL) [35-37] and focused ion beam (FIB) lithography [38-39]. EBL is a technique using electro-beam to scan on a substrate with a coated resist layer. The patterns are directly written onto the resist without using a mask. Then, the exposure area is dissolved in a developer. WCE or RIE is followed to transfer the patterns with nanometer width from the resist layer to the substrate. And, channel height is defined by the etching time. FIB is a technique that used fine focused ion beams, commonly a beam of gallium ions, to directly etch materials away to form patterns. Very recently using FIB, sub-5 nm NCs were fabricated on substrates with insulating metal mask layers [39]. The advantages of the FIB are that no resist and develop process are needed. Although having the capability of making very small structures, both EBL and FIB are very slow process, thus expensive and not suitable for patterning in the large scale. A normal EBL system requires a long time to pattern a whole four-inch silicon substrate.

Nanoimprint lithography (NIL) is another technique that may overcome the low throughput drawbacks of the EBL and FIB. In NIL, a master with patterns is first made on a stamp substrate by the above high resolution lithography techniques. Then, the master was used to imprint on a resist layer, which is previously deposited (spun) on a substrate. Subsequently, an etching or a lift-off process is used to transfer the patterns from the resist layer to the substrate [40]. For example, Cao et al. [41] used NIL to fabricate nanofluidic channels with a cross section of $10 \mathrm{~nm}$ on an impressive large area of a four-inch substrate. As the master can be reused for many times, NIL offers a promising, inexpensive and simple way to form NCs.

Soft lithography is similar to NIL, but instead of transferring patterns from the master to a resist layer on a substrate, the master is used to make a cast in a soft elastomeric material mostly polydimethysiloxane (PDMS) [42]. However, soft lithography and NIL has had several inherent limitations such as: (1) the patterns of the master are only used for each fabrication; and (2) an intrusion of the material clogs the NCs. 
Introduction

\section{Photolithography (combination of micromachining techniques)}

A combination of standard techniques from micromachining such as photolithography, deposition and etching allows to fabricate 2D NCs avoiding using above mentioned expensive nanolithography. For example, 2D NC patterns can be created based on the asymmetry at the edge of a step known as edge lithography. Tas et al. [26] created sacrificial polysilicon nanowires on the sidewall of a step then encapsulated by a capping silicon nitride, and finally the sacrificial nanowires were etched to create NCs. Cho et al. [43] constructed $150 \mathrm{~nm}$ width silicon oxide channels using combination of WCE, RIE and local oxidation of silicon. This was a very simple method to create $2 \mathrm{D} \mathrm{NCs}$ at the wafer scale. Another combination of lithography and undercutting by isotropic wet etching was used to form 75 $\mathrm{nm}$ wide and $250 \mathrm{~nm}$ high channels [44].

Furthermore, other techniques were also employed for 2D NC fabrication. Letant et al. [45] created arrays of silicon channels by electrochemistry. Diameter of channels as small as $30 \mathrm{~nm}$ was defined by anisotropic etching (with V-shaped features) using $\mathrm{KOH}$ solutions from $2 \mu \mathrm{m} \times 2 \mu \mathrm{m}$ initial opening windows. Then, the $8 \mu \mathrm{m}$ deep channels were obtained by electrochemical etching ( $6 \% \mathrm{HF}$ solution and a breaking bias of $9 \mathrm{~V})$. Wang et al. [46] fabricated $20 \mathrm{~nm}$ diameter silica NCs using a scanned coaxial electrospinning. Channel shells (a silica sol-gel solution as the material) were deposited outside the core (motor oil) that is later removed during annealing to cross-link silica. In another study [47], 2D NCs with 100 $\mathrm{nm}$ height and $25 \mathrm{~nm}$ width were created using chemical mechanical polishing and thermal oxidation. The channel height was defined by thickness of a deposited amorphous silicon layer while the width was controlled by thickness of a grown silicon oxide as a buried layer. Chemical mechanical polishing was carried until surfaces of the buried silicon oxide layer were appeared to be ready for etching. These last techniques however had difficulty in precise control of channel sizes and integration with other fluidic components.

\section{Bottom-up techniques}

The above presented techniques are generally categorized as top-down techniques in which NC structures are created on substrates by deposition and etching using microfabrication techniques. In contrast, the bottom-up approach (self-assembly lithography) is to create small structures from molecules by building up into more complex assemblies. Based on chemical properties of the molecules, structures are formed by self-organizing or self-assembly [48-50]. For instance, single-walled carbon nanotubes bundles [51] were synthesized by laser 
ablation and purified by reflux in hydrogen peroxide and filtration then they were assembled on glass to control their orientation. In another study [52], $20 \mathrm{~nm}$ diameter nanowires of trimolybdate $\left(\mathrm{K}_{2} \mathrm{Mo}_{3} \mathrm{O}_{10} .3 \mathrm{H}_{2} \mathrm{O}\right)$ were chemically synthesized. These nanowires were manually loaded into desired positions and used as a sacrificial material to create $\mathrm{NCs}$ with $\mathrm{SiO}_{2}$ and $\mathrm{Cr}$ materials. NCs created by the bottom-up technique have very well-defined structures however they are difficult to integrate to other fluidic components since channels are randomly formed.

Fabrication of NCs has been intensively reviewed [53-55].

\subsection{Applications of nanochannels}

\subsubsection{Fluid physics}

Fluid transport in nanometer-sized channels exhibits physical properties that are completely changed and different from the macro world. For instance, the thickness of the electric double layer and channel dimensions are in the same order which can strongly affect fluid transport properties such as shaping the fluid velocity profile in electro-osmosis and local distribution of the electrolytes and charged analytes [56].

With decreasing of channel dimensions and related increase of the surface-to-volume ratio, surface charge has a strong effect on the fluid transport. When aqueous solutions containing diluted salts are introduced in confined channels, the surface charges of the channels can significantly influence the liquid behavior. Stein et al. [57] studied transport of low salt concentration in $70 \mathrm{~nm}$ high channels. They showed the surface charge governed ion transport, where the ionic conductance of NCs strongly deviates from the bulk conductance at low ion concentrations. Moreover, Heyden et al. [58] reported the prospect of using electrokinetic phenomena in NCs to convert hydrostatic energy to electrical power. It was suggested that the maximum energy conversion efficiency occurred at low salt concentration and depended on fluid viscosity, counter-ion mobility, ratio between channel height and Gouy-Chapman length. Pennathur et al. [59-60] demonstrated theoretical and experimental studies on the electrokinetic transport in $40 \mathrm{~nm}$ height NCs and developed a new electrophoresis separation method in the nanoscale. The model showed that effective mobility governing electrophoresis transport of charged species in NCs depended on electrolyte mobility, $\zeta$ potential, ion valence and background electrolyte concentration. The proposed model is valid for transport of individual (un)charged species over long distance in both cases of high and low $\zeta$ potential. 
Introduction

NCs are normally filled by pressure-driven flow or capillary flow. Studies related to pressure-driven flow have been reviewed in [61]. Capillary filling of liquids is an effective way to spontaneously flow liquids into NCs without using external forces. Liquids filling in nanospaces have very interesting properties. For instance, partially filled liquids inside NCs have lower pressure than the surrounding gas phase. Capillarity-induced negative pressures down to -17 bar have been demonstrated inside 1D surface NCs in quasi-static experiments [23]. In dynamic experiments, the position of the moving (liquid) meniscus is proportional to square root of time which is described by the Washburn equation [62]. Tas et al. [63] showed that capillary filling speed in $100 \mathrm{~nm}$ height NCs followed the Washburn equation; more important that the filling speed at low salt concentration was lower than the expected. This effect was explained by electroviscous effect. In another study, Han et al. [64] reported filling kinetics of in NCs as small as $27 \mathrm{~nm}$ height; the meniscus velocity slowed down due to decrease of the channel dimension, and the ratio between the surface tension and the viscosity. Haneveld et al. [21] investigated further the filling dynamics to qualitatively confirm the kinetic filling behavior in smaller NCs ( $5 \mathrm{~nm}$ height) in accordance with the Washburn equation. Delft et al. [65] studied the behavior of liquids using the integrated Fabry-Perot interferometer in glass NCs (6 nm height). Filling speed agreed to the Washburn equation, however, decreased in case of ethanol and increased in water. Van Honschoten et al. [66] studied elastocapillary phenomenon occurred in $80 \mathrm{~nm}$ high NCs capped by a thin flexible membrane. Deviation of filling speed in these channels compared to the conventional Washburn speed was due to the deformation of the thin channel membrane that was resulted from the difference in cross section of channels and meniscus curvatures. Furthermore, Phan et al. [67] developed a mathematical model for capillary filling in NCs including electroviscous effect. The apparent viscosity is increased with high zeta potential, low molar conductivity and low ion mobility.

\subsubsection{Nanobiotechnology}

The small volume inside NCs enables single-molecule experiments at relatively high concentrations compatible with normal single-molecule resolution. Additionally, NCs have essential advantages such as little samples consumption and reduced background signals in fluorescence applications due to their confined dimensions [68].

Recent advances in optical imaging and biomechanical techniques like optical tweezers [69] show great potentials for the investigation and observation of biological processes 
occurring at the molecular level. These techniques are increasingly used in both biological researches and biomedical applications. Besides that, nano/microfluidic systems have potentials for applications such as separation of biomolecules [70], enzymatic assays and immunohybridization reactions [71]. NCs are used as restricted spaces in order to decrease illumination volume and increase the working concentration at which the single-molecule level is reached. Foquet et al. [68] used $350 \mathrm{~nm}$ wide channels performing single-molecule detection at relatively high concentrations (micromolar). NCs with the small volume created high signal-to-noise ratio during measurements. In confinement, interactions from channel surfaces played a very important role in biomolecular behavior. Brownian motion of low molecular weight analytes is reduced and explained by electrostatic interactions with channel surfaces [72].

Furthermore, NCs have been also powerful tools in manipulation and analysis of important biomolecules, such as DNA and proteins [31]. For example, $90 \mathrm{~nm}$ height channels were used to separate long, DNA molecules by sized entropic traps [33]. The used NCs with their dimension closed to the persistence length of DNA around $100 \mathrm{~nm}$ offer a proper condition for physical confinement or stretching of biomolecules, so that it provides opportunities to reveal information of samples [35]. Especially, the utilization of 2D NCs with their extremely small volume offers several essential advantages in biological analysis. These advantages allow accurately recording and observing extremely small signals for studying biological samples at the desired molecular level. For instance, Sivanesan et al. [73] used $400 \mathrm{~nm}$ dimension polymer NCs to detect single protein molecules (prelabeled with Alexa Fluor dye) by using a confocal fluorescence microscope. Based on the burst intensities, evidence from single molecules traversing the detection region was confirmed. Wang et al. [74] showed another example of single DNA molecules (stained with intercalating fluorescent dye YOYO-1) manipulated into 2D NCs of $60 \mathrm{~nm}$ height $\times 40 \mathrm{~nm}$ width by capillary force and observed with fluorescence microscopy. Characteristics of DNA movement along the channels were discussed regarding to effects from buffer concentration, surface tension, viscosity, and channel dimensions. Furthermore, Stavis et al. [75] used $500 \mathrm{~nm}$ square crosssectional channels to isolate, detect and identify individual quantum dots conjugated with organic fluorophores. Detection of quantum dots as fluorescent labels in small fluidic channels was used for multiplexed single-molecule studies. In addition, Wang et al. [46] recorded photon signals from a single molecule of fluorescein at a $4.9 \mu \mathrm{M}$ concentration by 
Introduction

performing their experiments in $20 \mathrm{~nm}$ diameter NCs. Further review for applications in NCs is in Refs. [76-85].

\subsection{Aim of this thesis}

In the scenario of diverse techniques to create NCs, the demand for simple and straightforward techniques is still very strong. Fabrication of channels with both their width and height at nanometer scale by standard techniques from micromachining is a challenging task. Moreover, interfacing from the fabricated NCs to outer world is very essential to obtain complete devices ready for experiments. NC fabrication techniques based on simple and easy processes open variant platforms for fundamental studies and applications. Liquid transport inside NCs governed by surface-charge mechanism has some properties that occur only in nanoscale. More in general, water viscosity has been widely studied especially in physical chemistry to achieve better understanding of liquid behavior in nanoconfinement. The silicon-based NCs with their precise controlled dimensions can contribute to the experimental challenges in this field of research.

In this thesis large effort has been spent to develop simple, reliable processes to fabricate $\mathrm{NC}$ devices and to integrate from the fabricated NCs to outer world for different studies. For study of water viscosity in confined nanospaces, 1D NCs have been fabricated by direct bonding of a processed silicon wafer (containing NCs, microchannels and inlet/outlet ports) with a very thin glass wafer of $170 \mu \mathrm{m}$ thickness. Further, to create extreme confined spaces toward single-molecule studies, we constructed 2D NCs with a simple process using several common techniques of the conventional microfabrication like underetching of a sacrificial layer and vertically evaporation. Enclosed 2D NCs with both dimensions of their height and width down to sub-20 $\mathrm{nm}$ regimes were directly obtained without requiring nanolithography.

Liquid behavior in nanoconfinement has attracted the attention of researchers especially merging in achievements of nanofabrication techniques that enable to construct very welldefined NCs for restricted spaces. Water viscosity, one of the most interesting properties has been presented in this thesis by mobility study of single quantum dots inside 1D NCs. Furthermore, electroviscous is considered as the most disputed effect influenced on deviation of water viscosity in nanoconfinement compared to its bulk solution. Then, adding to interesting mechanisms from capillary filling dynamics, we study deprotonation during filling $50 \mathrm{~nm}$ deep channels in silicon oxide with sodium fluorescein solutions using capillary pressure. A distinct bisection was observed, the fluid near the entrance fluoresces while the 
fluid near the meniscus did not. Using a model of electric double layer, this phenomenon can be effectively modeled as titration of the solution by protons released from silanol groups on channel walls. These applications prove possibilities of using silicon-based NCs to broad understanding of liquid behavior in nanoconfinement.

\subsection{Organization of this thesis}

The thesis is beginning with introduction of fabrication and applications of NCs in chapter one. A straightforward technique to easily fabricate the thin glass capping 1D NCs with confinement in nanometer scale only in the height and the interfacing of these devices will be presented in chapter two. In chapter three, we present a new method to construct 2D NCs by a combination of underetching (edge lithography) and deposition techniques. These fabricated encapsulated NCs were confirmed to be hermetically closed. In chapter four we study the deprotonation phenomenon carried out in $50 \mathrm{~nm}$ high channels. During capillary filling, a bisection between fluorescence and liquid front was observed, and this phenomenon was modeled then explained by deprotonation of surface silanol groups. Furthermore, the water viscosity in confinement has been studied using mobility of quantum dots in chapter five. Diffusion coefficients were experimentally determined to be three-time reduced compared to bulk solutions. This thesis is completed with conclusions and outlook in chapter six to realize the importance of channel fabrication techniques for broad range of applications.

\subsection{References}

[1] Beck, J. S.; Vartuli, J. C.; Roth, W. J.; Leonowicz, M. E.; Kresge, C. T.; Schmitt, K. D.; Chu, C. T. W.; Olson, D. H.; Sheppard, E. W. A new family of mesoporous molecular sieves prepared with liquid crystal templates. J. Am. Chem. Soc. 1992, 114 (27), 10834-10843.

[2] Zhang, H. X.; Feng, P. X. Electrical and structural characterizations of one-dimensional carbon nanostructures synthesized at ambient pressure. J. Phys. D.: Appl. Phys. 2008, 41 (15), 155425 .

[3] Jha, A.; Barerjee, D.; Chattopadhyay, K. K. A comparative study of field-emission from different one dimensional carbon nanostructures synthesized via thermal CVD system. Appl. Surf. Sci. 2011, 257 (6), 1946-1951.

[4] Kyotani, T.; Nagai, T.; Inoue, S.; Tomita, A. Formation of new type of porous carbon by carbonization in zeolite nanochannels. Chem. Matter. 1997, 9 (2), 609-615.

[5] Mumpton, F. A. La roca magica: Uses of natural zeolites in agriculture and industry. Proc. Natl. Acad. Sci. USA. 1999, 96 (7) 3463-3470. 
Introduction

[6] Davis, M. E. Ordered porous materials for emerging applications. Nature 2002, 417 (6891), 813-821.

[7] Take, H.; Matsumoto, T.; Yoshino, K. Anodic properties of porous carbon with periodic nanostructure. Synthetic Met. 2003, 135-136, 731-732.

[8] Subramoney, S. Novel nanocarbons-structure, properties, and potential applications. Adv. Mater. 1998, 10 (15), 1157-1171.

[9] Sakintuna, B.; Yurum, Y. Templated porous carbons: a review article. Ind. Eng. Chem. Res. 2005, 44 (9), 2893-2902.

[10] Ryoo, R.; Joo, S. H.; Kruk, M.; Jaroniec, M. Ordered mesoporous carbon. Adv. Mater. 2001, $13(9), 677-681$.

[11] Zhang, B.; Wood, M.; Lee, H. A silica nanochannel and its applications in sensing and molecular transport. Anal. Chem. 2009, 81 (13), 5541-5548.

[12] Chowdhury, T. K. Fabrication of extremely fine glass micropipette electrodes. J. Phys. E: Sci. Instrum. 1969, 2 (12), 1087-1090.

[13] Steinbock, L. J.; Otto, O.; Chimerel, C.; Gornall, J.; Keyser, U. F. Detecting DNA folding with nanocapillaries. Nano Lett. 2010, 10 (7), 2493-2497.

[14] Gardeniers, H. J. G. E. Chemistry in nanochannel confinement. Anal. Bioanal. Chem. 2009, 394 (2), 385-397.

[15] Zarragoicoechea, G. J.; Kuz, V. A. Critical shift of a confined fluid in a nanopore. Fluid Phase Equil. 2004, 220 (1), 7-9.

[16] Derjaguin, B. V.; Churaev, N. V. Structure of water in thin layers. Langmuir 1987, 3 (5), $607-612$.

[17] Kalra, A.; Garde, S.; Hummer, G. Osmotic water transport through carbon nanotube membranes. Proc. Natl. Acad. Sci. USA 2003, 100 (18), 10175-10180.

[18] Persson, F.; Thamdrup, L. H.; Mikkelsen, M. B. L.; Jaarlgard, S. E.; Skafte-Pedersen, P.; Bruus, H.; Kristensen, A. Double thermal oxidation scheme for the fabrication of $\mathrm{SiO}_{2}$ nanochannels. Nanotechnology 2007, 18 (24), 245301.

[19] Kim, W. S.; Lee, J.; Ruoff. R. S. Nanofluidic channel fabrication and characterization by micromachining. Proceedings of IMECE'03 ASME International Mechanical Engineering Congress, Washington DC, USA 2003.

[20] Datta, A.; Gangopadhyay, S.; Temkin, H.; Pub, Q.; Liu, S. Nanofluidic channels by anodic bonding of amorphous silicon to glass to study ion-accumulation and iondepletion effect. Talanta 2006, 68 (3), 659-665. 
[21] Haneveld, J.; Tas, N. R.; Brunets, N.; Jansen, H. V.; Elwenspoek, M. C. Capillary filling of sub-10 nm nanochannels. J. Appl. Phys. 2008, 104 (1), 014309.

[22] Berenschot, J. W.; Tas, N. R.; Lammerink, T. S. J.; Elwenspoek, M.; van den Berg, A. Advanced sacrificial poly-Si technology for fluidic systems. J. Micromech. Microeng. 2002, $12(5), 621-624$.

[23] Tas, N. R.; Mela, P.; Kramer, T.; Berenschot, J. W.; van den Berg, A. Capillarity induced negative pressure of water plugs in nanochannels. Nano Lett. 2003, 3 (11), $1537-1540$.

[24] Eijkel, J. C. T.; Bomer, J.; Tas, N. R.; van den Berg, A. 1-D nanochannels fabricated in polyimide. Lab Chip 2004, 4 (3), 161-163.

[25] Foquet, M.; Korlach, J.; Zipfel, W.; Webb, W. W.; Craighead, H. G. DNA fragment sizing by single molecule detection in submicrometer-sized closed fluidic channels. Anal. Chem. 2002, 74 (6), 1415-1422.

[26] Tas, N. R.; Berenschot, J. W.; Mela, P.; Jansen, H. V.; Elwenspoek, M.; van den Berg, A. 2D-confined nanochannels fabricated by conventional micromachining. Nano Lett. 2002, 2 (9), 1031-1032.

[27] Li, W.; Tegenfeldt, J. O.; Chen, L.; R. H.; Austin, Chou, S. Y.; Kohl, P. A.; Krotine, J.; Sturm, J. C. Sacrificial polymers for nanofluidic channels in biological applications. Nanotechnology 2003, 14 (6), 578-583.

[28] Czaplewski, D. A.; Kameoka, J.; Mathers, R.; Coates, G. W.; Craighead, H. G. Nanofluidic channels with elliptical cross sections formed using a nonlithographic process. Appl. Phys. Lett. 2003, 83 (23), 4836-4838.

[29] Liao, K. P.; Yao, N. K.; Kuo, T. S. Sub-60 nm nanofluidic channels fabricated by glassglass bonding. Proceedings of the $28^{\text {th }}$ IEEE EMBS Annual International Conference, NY, USA 2006.

[30] Haneveld, J.; Jansen, H.; Berenschot, E.; Tas, N.; Elwenspoek, M. Wet anisotropic etching for fluidic 1D nanochannels. J. Micromech. Microeng. 2003, 13 (4), S62-S66.

[31] Tegenfeldt, J. O.; Prinz, C.; Cao, H.; Huang, R. L.; Austin, R. H.; Chou, S. Y.; Cox, E. C.; Sturm, J. C. Micro- and nanofluidics for DNA analysis. Anal. Bioanal. Chem. 2004, $378(7), 1678-1692$.

[32] Mao, P.; Han, J. Fabrication and characterization of $20 \mathrm{~nm}$ planar nanofluidic channels by glass-glass and glass-silicon bonding. Lab Chip 2005, 5 (8), 837-844.

[33] Han, J.; Craighead, H. G. Entropic trapping and sieving of long DNA molecules in a nanofluidic channel. J. Vac. Sci. Technol. A 1999, 17 (4), 2142-2147. 
Introduction

[34] Kutchoukov, V. G.; Laugere, F.; van der Vlist, W.; Pakula, L.; Garini, Y.; Bossche, A. Fabrication of nanofluidic devices using glass-to-glass anodic bonding. Sensor Actuat. A: Phys. 2004, 114 (2-3), 521-527.

[35] Reisner, W.; Beech, J. P.; Larsen, N. B.; Flyvbjerg, H.; Kristensen, A.; Tegenfeldt, J. O. Nanoconfinement-enhanced conformational response of single DNA molecules to changes in ionic environment. Phys. Rev. Lett. 2007, 99 (5), 058302.

[36] Turner, S. W.; Perez, A. M.; Lopez, A.; Craighead, H. G. Monolithic nanofluid sieving structures for DNA manipulation. J. Vac. Sci. Technol. B 1998, 16 (6), 3835-3840.

[37] Hibara, A.; Saito, T.; Kim, H. B.; Tokeshi, M.; Ooi, T.; Nakao, M.; Kitamori, T. Nanochannels on a fused-silica microchip and liquid properties investigation by timeresolved fluorescence measurements. Anal. Chem. 2002, 74 (24), 6170-6176.

[38] Wang, Y. M.; Tegenfeldt, J. O.; Reisner, W.; Riehn, R.; Guan, X. J.; Guo, L.; Golding, I.; Cox, E. C.; Sturm, J.; Austin, R. H. Single-molecule studies of repressor-DNA interactions show long-range interactions. Proc. Natl. Acad. Sci. USA 2005, 102 (28), 9796-9801.

[39] Menard, L. D.; Ramsey, J. M. Fabrication of sub-5 nm nanochannels in insulating substrates using focused ion beam milling. Nano Lett. 2011, 11 (2), 512-517.

[40] Guo, L. J. Recent progress in nanoimprint technology and its applications. J. Phys. D: Appl. Phys. 2004, 37 (11), R123-R141.

[41] Cao, H.; Yu, Z.; Wang, J.; Tegenfeldt, J. O.; Austin, R. H.; Chen, E.; Wu, W.; Chou, S. Y. Fabrication of $10 \mathrm{~nm}$ enclosed nanofluidic channels. Appl. Phys. Lett. 2002, 81 (1), $174-176$.

[42] Hug, T. S.; Parrat, D.; Kunzi, P. A.; Staufer, U.; Verpoorte, E.; de Rooij, N. F. Fabrication of nanochannels with PDMS, silicon and glass walls and spontaneous filling by capillary forces. $7^{\text {th }}$ International Conference on Miniaturized Chemical and Biochemical Analysts Systems, CA, USA 2003, 29-32.

[43] Cho, Y. H.; Lee, S. W.; Kim, B. J.; Fujii, T. Fabrication of silicon dioxide submicron channels without nanolithography for single biomolecule detection. Nanotechnology 2007, 18 (46), 465303.

[44] Love, J. C.; Paul, K. E.; Whitesides, G. M. Fabrication of nanometer-scale features by controlled isotropic wet chemical etching. Adv. Mater. 2001, 13 (8), 604-607.

[45] Letant, S. E.; van Buuren, T. W.; Terminello, L. J. Nanochannel arrays on silicon platforms by electrochemistry. Nano Lett. 2004, 4 (9), 1705-1707. 
[46] Wang, M.; Jing, N.; Su, C. B.; Kameoka, J.; Chou, C. K.; Hung, M. C.; Chang, K. A. Electrospinning of silica nanochannels for single molecule detection. Appl. Phys. Lett. 2006, 88 (3), 033106.

[47] Lee, C.; Yang, E. H.; Myung, N. V.; George, T. A nanochannel fabrication technique without nanolithography. Nano Lett. 2003, 3 (10), 1339-1340.

[48] Iijima, S. Helical microtubules of graphitic carbon. Nature 1991, 354 (6348), 56-58.

[49] Zhang, M.; Bando, Y.; Wada, K.; Kurashima, K. Synthesis of nanotubes and nanowires of silicon oxide. J. Mater. Sci. Lett. 1999, 18 (23), 1911-1913.

[50] Dai, H. Carbon nanotubes: opportunities and challenges. Surf. Sci. 2002, 500 (1-3), $218-241$.

[51] Shimoda, H. S.; Oh, S. I.; Geing, T. J. W.; Walker, R. J.; Zhang, X. B.; McNeil, L. E.; Zhou, O. Self-assembly of carbon nanotubes. Adv. Matter. 2002, 12, (18), 899-901.

[52] Gong, W.; Xue, J.; Zhuang, Q.; Wu, X.; Xu, S. Fabrication of nanochannels with waterdissolvable nanowires. Nanotechnology 2010, 21 (19), 195302.

[53] Mijatovic, D.; Eijkel, J. C. T.; van den Berg, A. Technologies for nanofluidic systems: top-down vs. bottom-up - a review. Lab Chip 2005, 5 (5), 492-500.

[54] Perry, J. L.; Kandlikar, S. G. Review of fabrication of nanochannels for single phase liquid flow. Microfluid. Nanofluid. 2006, 2 (3), 185-193.

[55] Abgrall, P.; Nguyen, N. T. Nanofluidic devices and their applications. Anal. Chem. 2008, 80 (7), 2326-2341.

[56] Qiao, R.; Aluru, N. R. Charge inversion and flow reversal in a nanochannel electroosmotic flow. Phys. Rev. Lett. 2004, 92 (19), 198301.

[57] Stein, D.; Kruithof, M.; Dekker, C. Surface-charge-governed ion transport in nanofluidic channels. Phys. Rev. Lett. 2004, 93 (3), 035901.

[58] van der Heyden, F. H. J.; Bonthuis, D. J.; Stein, D.; Meyer, C.; Dekker, C. Electrokinetic energy conversion effciency in nanofluidic channels. Nano Lett. 2006, 6 (10), 2232-2237.

[59] Pennathur, S.; Santiago, J. G. Electrokinetic transport in nanochannels. 1. Theory. Anal. Chem. 2005, 77 (21), 6772-6781.

[60] Pennathur, S.; Santiago, J. G. Electrokinetic transport in nanochannels. 2. Experiments. Anal. Chem. 2005, 77 (21), 6782-6789.

[61] Schoch, R. B.; Han, J.; Renaud, P. Transport phenomena in nanofluidics. Rev. Mod. Phys. 2008, 80 (3), 839-883.

[62] Washburn, E. W. The dynamics of capillary flow. Phys. Rev. Lett. 1921, 17 (3), 273-283. 
Introduction

[63] Tas, N. R.; Haneveld, J.; Jansen, H. V.; Elwenspoek, M.; Van den Berg, A. Capillary filling speed of water in nanochannels. Appl. Phys. Lett. 2004, 85 (15), 3274-3276.

[64] Han, A.; Mondin, G.; Hegelbach, N. G.; de Rooij, N. F.; Staufer, U. Filling kinetics of liquids in nanochannels as narrow as $27 \mathrm{~nm}$ by capillary force. J. Colloid Interf. Sci. 2006, 293 (1), 151-157.

[65] van Delft, K. M.; Eijkel, J. C. T.; Mijatovic, D.; Druzhinina, T. S.; Rathgen, H.; Tas, N. R.; van den Berg, A.; Mugele, F. Micromachined Fabry-Perot interferometer with embeded nanochannels for nanoscale fluid dynamics. Nano Lett. 2007, 7 (2), 345-350.

[66] van Honschoten, J. W.; Escalante, M.; Tas, N. R.; Jansen, H. V.; Elwenspoek, M. Elastocapillary filling of deformable nanochannels. J. Appl. Phys. 2007, 101 (9), 094310.

[67] Phan, V. N.; Yang, C.; Nguyen, N. T. Analysis of capillary filling in nanochannels with electroviscous effects. Microfluid. Nanofluid. 2009, 7 (4), 519-530.

[68] Foquet, M.; Korlach, J.; Zipfel, W. R.; Webb, W. W.; Craighead, H. G. Focal volume confinement by submicrometer-sized fluidic channels. Anal. Chem. 2004, 76 (6), $1618-1626$.

[69] McCauley, M. J.; Williams, M. C. Optical tweezers experiments resolve distinct modes of DNA-protein binding. Biopolymers 2008, 91 (4), 265-282.

[70] Hadd, A. G.; Jacobson, S. C.; Ramsey, M. Microfluidic assays of acetylcholinesterase inhibitors. Anal. Chem. 1999, 71 (22), 5206-5212.

[71] Thorsen, T.; Maerkl, S. J.; Quake, S. R. Microfluidic large-scale integration. Science 2002, 298 (5593), 580-584.

[72] Pappaert, K.; Biesemans, J.; Clicq, D.; Vankrunkelsven, S.; Desmet, G. Measurements of diffusion coefficients in 1-D micro- and nanochannels using shear-driven flows. Lab Chip 2005, 5 (10), 1104-1110.

[73] Sivanesan, P.; Okamoto, K.; English, D.; Lee, C. S.; DeVoe, D. L. Polymer nanochannels fabricated by thermomechanical deformation for single-molecule analysis. Anal. Chem. 2005, 77 (7), 2252-2258.

[74] Wang, K. G.; Yue, S.; Wang, L.; Jin, A.; Gu, C.; Wang, P. Y.; Feng, Y.; Wang, Y.; Niu, H. Manipulating DNA molecules in nanofluidic channels. Microfluid. Nanofluid. 2006, 2 (1), 85-88.

[75] Stavis, S. M.; Edel, J. B.; Samiee, K. T. Craighead, H. G. Single molecule studies of quantum dot conjugates in a submicrometer fluidic channel. Lab Chip 2005, 5 (3), $337-343$. 
[76] Daiguji, H.; Yang, P.; Majumdar, A. Ion transport in nanofluidic channels. Nano Lett. 2004, 4 (1), 137-142.

[77] Qiao, R.; Aluru, N. R. Scaling of electrokinetic transport in nanometer channels. Langmuir 2005, 21 (19), 8972-8977.

[78] Plecis, A.; Schoch, R. B.; Renaud, P. Ionic transport phenomena in nanofluidics: experimental and theoretical study of the exclusion-enrichment effect on a chip. Nano Lett. 2005, 5 (6), 1147-1155.

[79] Bhattacharyya, S.; Nayak, A. K. Electro-osmotic transport in charged cylindrical microand nano-channels. Intern. J. Eng. Sci. 2007, 45 (1), 55-74.

[80] Deladi, S.; Tas, N. R.; Berenschot, J. W.; Krijnen, G. J. M.; de Boer, M. J.; de Boer, J. H.; Peter, M.; Elwenspoek, M. C. Micromachined fountain pen for atomic force microscope-based nanopatterning. Appl. Phys. Lett. 2004, 85 (22), 5361-5363.

[81] Yuan, Z.; Garcia, A. L.; Lopez, G. P.; Petsev, D. N. Electrokinetic transport and separations in fluidic nanochannels. Electrophoresis 2007, 28 (4), 595-610.

[82] Sparreboom, W.; van den Berg, A; Eijkel, J. C. T. Transport in nanofluidic systems: a review of theory and applications. New J. Phys. 2010, 12, 015004.

[83] Baldessari, F.; Santiago, J. G. Electrophoresis in nanochannels: brief review and speculation. J. Nanobiotechnol. 2006, 4, 12.

[84] van Honschoten, J. W.; Brunets, N.; Tas, N. R. Capillarity at the nanoscale. Chem. Soc. Rev. 2010, 39 (3), 1096-1114.

[85] Eijkel, J. C. T.; van den Berg, A. Nanofluidics: what is it and what can we expect from it? Microfluid. Nanofluid. 2005, 1 (3), 249-267. 


\section{Chapter 2 \\ Fabrication and interfacing of nanochannel devices \\ for single-molecule studies}

Nanochannel devices have been fabricated using standard micromachining techniques such as optical lithography, deposition and etching. One-dimensional nanochannels with thin glass capping and through-wafer inlet/outlet ports were constructed. Two-dimensional nanochannels have been made transparent by oxidation of polysilicon channel wall for optical detection and these fragile channels were successfully connected to macro inlet ports. The interfacing from the macro world to the nanochannels was especially designed for optical observation of filling liquid inside nanochannels using an inverted microscope. Towards single-molecule studies, individual quantum dots were visualized in $150 \mathrm{~nm}$ height one-dimensional nanochannels. The potential of two-dimensional nanochannels for singlemolecule studies was shown from a filling experiment with a fluorescent dye solution.

This chapter is based on the paper "Fabrication and interfacing of nanochannel devices for single-molecule studies. J. Micromech. Microeng. 2009, 19, 065017" and the paper "Fabrication of 1D nanochannels with thin glass wafers for single-molecule studies. NSTI Nanotechnology Conference, CA, USA 2007, 260-263”. 


\subsection{Introduction}

Recently, several single-molecule studies using nanochannels (NCs) have been reported. For instance, single DNA fragments were confined and detected in $500 \mathrm{~nm}$ diameter silica capillaries [1]. Interactions of single DNA and protein molecules were studied in $120 \mathrm{~nm} \times$ $150 \mathrm{~nm}$ fused silica channels [2]. Single rhodamine labeled cellulase enzyme was detected in $100 \mathrm{~nm}$ diameter glass NCs [3]. In single-molecule studies, individual molecules need to be distinguished and identified. Discrimination of single molecules [4] can simply be achieved by preparing extremely dilute solutions, containing in average only one molecule per detection volume. However, for biological applications this is undesirable because usually biomolecules are only functional at much higher concentrations, similar to those present in a cellular environment [5]. Moreover, by extreme dilution the contribution of background signals from solvent molecules relative to the signals of the molecules of interest is enhanced. Another approach is to enable single-molecule studies by reduction of the detection volume. The detection volume can be significantly reduced by optical methods such as confocal fluorescence microscopy using small pinholes to minimize the detection of out-of-focus light [6]. Total internal reflection fluorescence microscopy (TIRFM) can also be used, where excitation only takes place in a limited field formed by evanescent waves [7]. Another option would be near-field scanning optical microscopy (NSOM) [8], where the detection volume is determined by the narrow aperture of an optical fiber probe. These optical techniques provide a detection depth as small as $100 \mathrm{~nm}$. If NCs are used for sample confinement, the channel height can be reduced even further towards detection depths as small as $5 \mathrm{~nm}$ [9-10]. As said the ultra small detection volume of NCs enables singlemolecule experiments at relatively high concentrations. Furthermore, carrying out singlemolecule experiments in NCs does not require immobilization of molecules and offers the possibility of exactly controlling and manipulating the sample conditions. In addition, the benefits of $\mathrm{NC}$ devices may be exploited for high-throughput applications.

NCs can be relatively easily fabricated using bulk, surface, mold, and bond micromachining techniques [43]. Using bulk and bond micromachining, NCs are created by etching trenches in a substrate that are closed by bonding to another substrate $[25,36]$. Surface channels can be formed on a substrate with deposited layers (sacrificial and structural layers) after selectively etching of the sacrificial layer [44-45]. In mold/bond micromachining, a mold formed on a substrate is filled by a desired layer, then the mold is 
Table 2.1. Overview of $1 D$ nanochannel fabrication methods

\begin{tabular}{|c|c|c|c|c|}
\hline Nanochannel pattern & Materials & Etching/deposition & Height & References \\
\hline Optical lithography & Silicon & "OPD solution, $\mathrm{HF}: \mathrm{NH}_{4} \mathrm{~F}: \mathrm{H}_{2} \mathrm{O}$ & $50 \mathrm{~nm}$ & {$[25-28]$} \\
\hline Optical lithography & Silicon & $\begin{array}{l}\text { BHF etching of } \quad \mathrm{SiO}_{2} \\
\text { + local oxidation }\end{array}$ & $70 \mathrm{~nm}$ & [29] \\
\hline Optical lithography & Silicon & RIE & $90 \mathrm{~nm}$ & {$[30]$} \\
\hline Optical lithography & $\begin{array}{l}\text { Silicon oxide, } \\
\text { amorphous } \mathrm{Si}\end{array}$ & BHF solution & $150 \mathrm{~nm}$ & $\begin{array}{l}{[31, \text { this }} \\
\text { work }]\end{array}$ \\
\hline Optical lithography & Silicon oxide & $\mathrm{BHF}+$ double thermal oxidation & $75 \mathrm{~nm}$ & {$[9]$} \\
\hline EBL & Silica & $\operatorname{RIE}\left(\mathrm{CHF}_{3} / \mathrm{O}_{2}\right)$ & $70 \mathrm{~nm}$ & {$[32]$} \\
\hline Optical lithography & Fused silica & RIE & $40 \mathrm{~nm}$ & {$[33-34]$} \\
\hline Optical lithography & Silicon, glass & RIE for silicon \& BOE for glass & $20 \mathrm{~nm}$ & {$[35-36]$} \\
\hline Optical lithography & Pyrex & $\mathrm{BHF}$ & $6 \mathrm{~nm}$ & {$[37]$} \\
\hline
\end{tabular}

removed to release channels which are closed by bonding the replica to another substrate (for a detailed review [11]). One-dimensional (1D) NCs are created by etching shallow trenches after standard lithography, while two-dimensional (2D) NC patterns are generally obtained using nanolithographic techniques such as focused ion beam (FIB) lithography [2, 12-13], electron beam lithography (EBL) [14-16], and nanoimprint lithography (NIL) [17-19]. Although NCs with two dimensions down to $10 \mathrm{~nm}$ have been successfully fabricated with nanolithography techniques, drawbacks are the high costs, low throughput and pattern limitations. Alternatively, other techniques like electrochemistry [20], electrospinning [21], mechanical deformation [22-23], and chemical mechanical polishing [24] are also employed for 2D NC fabrications. The latter techniques however have drawbacks such as precisely controlling channel sizes and integration with other fluidic components. Tables 2.1 and 2.2 give an overview of various methods applied for the construction of NCs.

In this chapter, we show that $150 \mathrm{~nm}$ height $1 \mathrm{D} \mathrm{NCs}$, created using the silicon oxide spacer layer method [46], can be bonded to blank thin glass wafers with suitable thickness for using high numerical aperture (NA) lenses. Fluidic filling holes for the 1D NCs were created on silicon wafers with NC structures to enable optical observation using a microscope with inverted configuration. Without using expensive nanolithography, but by a combination of standard micromachining techniques like optical lithography, deposition and selective etching, 2D NCs were created with well-controlled dimensions of $50 \mathrm{~nm}$ height and $400 \mathrm{~nm}$ 
Table 2.2. Overview of 2D nanochannel fabrication methods

\begin{tabular}{|c|c|c|c|c|}
\hline Nanochannel pattern & Materials & Etching/deposition & Dimensions & References \\
\hline$\overline{\text { FIB }}$ & $\begin{array}{l}\text { Silicon (nitride), glass, } \\
\text { quartz, fused silica }\end{array}$ & "FIB & $=50 \mathrm{~nm} \times 50 \mathrm{~nm}$ & {$[2,12-13]$} \\
\hline EBL & $\begin{array}{l}\text { Silicon (oxide, nitride), } \\
\text { fused silica }\end{array}$ & $\begin{array}{l}\mathrm{RIE}\left(\mathrm{CHF}_{3} / \mathrm{O}_{2},\right. \\
\left.\mathrm{CF}_{4}: \mathrm{CHF}_{3}\right)\end{array}$ & $50 \mathrm{~nm} \times 50 \mathrm{~nm}$ & {$[14-16]$} \\
\hline NIL & $\begin{array}{l}\text { Silicon (oxide), fused } \\
\text { silica }\end{array}$ & $\operatorname{RIE}\left(\mathrm{CHF}_{3} / \mathrm{O}_{2}\right)$ & $10 \mathrm{~nm} \times 50 \mathrm{~nm}$ & {$[17-19]$} \\
\hline $\begin{array}{l}\text { NIL + diffraction } \\
\text { gradient lithography }\end{array}$ & Silicon & $\operatorname{RIE}\left(\mathrm{CHF}_{3} / \mathrm{O}_{2}\right)$ & $10 \mathrm{~nm} \times 50 \mathrm{~nm}$ & {$[38]$} \\
\hline $\begin{array}{l}\text { Interferometic } \\
\text { lithography }\end{array}$ & Silicon & $\operatorname{RIE}\left(\mathrm{CHF}_{3} / \mathrm{O}_{2}\right)$ & $\begin{array}{l}100 \mathrm{~nm} \text { width, } \\
500 \mathrm{~nm} \text { height }\end{array}$ & [39] \\
\hline Sacrificial etching & $\begin{array}{l}\text { Silicon, silicon oxide, } \\
\text { polymer }\end{array}$ & (B)HF, RIE, heating & $\begin{array}{l}30 \mathrm{~nm} \text { height, } \\
200 \mathrm{~nm} \text { width }\end{array}$ & $\begin{array}{l}{[3,40, \text { this }} \\
\text { work }]\end{array}$ \\
\hline Local oxidation & Silicon oxide & $\operatorname{RIE}\left(\mathrm{CH}_{4}\right)$ & $\begin{array}{l}150 \mathrm{~nm} \times 200 \\
\mathrm{~nm}\end{array}$ & {$[41]$} \\
\hline Eletrochemistry & Silicon & $\mathrm{KOH}$ & $30 \mathrm{~nm}$ diameter & {$[20]$} \\
\hline $\begin{array}{l}\text { Scanned coaxial } \\
\text { electrospinning }\end{array}$ & Silica & Deposition & $20 \mathrm{~nm}$ diameter & {$[21]$} \\
\hline $\begin{array}{l}\text { Thermo mechanical } \\
\text { deformation and } \mathrm{CO}_{2} \\
\text { laser based puller }\end{array}$ & $\begin{array}{l}\text { Polymer and } \\
\text { silica glass capillaries }\end{array}$ & Pulling & $\begin{array}{l}400 \mathrm{~nm} \\
\text { diameter }\end{array}$ & {$[22-23]$} \\
\hline $\begin{array}{l}\text { Chemical mechanical } \\
\text { polishing }\end{array}$ & Silicon oxide & $\mathrm{BOE}$ & $\begin{array}{l}25 \mathrm{~nm} \text { width, } \\
100 \mathrm{~nm} \text { height }\end{array}$ & {$[24]$} \\
\hline $\begin{array}{l}\text { Nonconformal } \\
\text { deposition }\end{array}$ & Polymer & Deposition & 100 nm size & {$[42]$} \\
\hline
\end{tabular}

width. Fabricated 2D NCs were integrated with inlet ports and made transparent for optical detection by oxidizing the polysilicon channel wall. Deep reactive ion etching (DRIE) was used to fabricate inlet/outlet ports for 1D and 2D NCs. Towards single-molecule applications individual quantum dots (QDs) in a $12 \mathrm{nM}$ concentration solution were visualized in 1D NCs; filling and observation of 2D NCs with a micromolar concentration of fluorescent solutions was shown. 


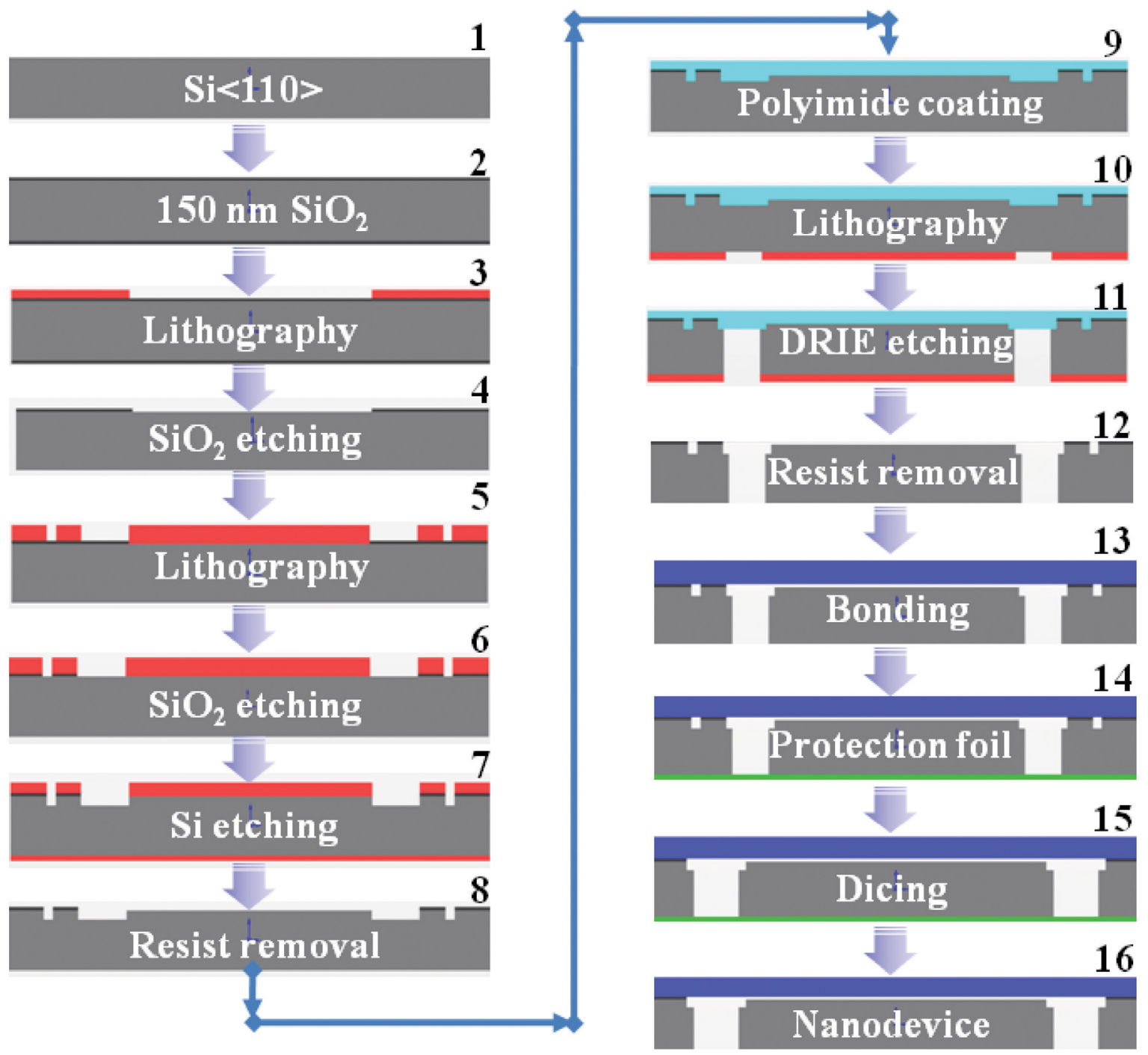

Figure 2.1. Process outline for fabrication of $1 D$ nanochannel devices (details of processing steps in appendix 2.1).

\subsection{Experimental section}

\subsubsection{Fabrication of 1D nanochannels by wafer bonding}

Fabrication of 1D NCs was based on the approach of Haneveld [46] (figure 2.1). The process was started on a $<110>$ silicon wafer (Okmetic) with $380 \mu \mathrm{m}$ thickness and $100 \mathrm{~mm}$ diameter (step 1). First standard cleaning was applied to the wafer $\left(10 \mathrm{~min}\right.$ in fuming $(100 \%) \mathrm{HNO}_{3}$, 10 min in boiling $\left.(69 \%) \mathrm{HNO}_{3}\right)$. A $150 \mathrm{~nm}$ thick silicon oxide layer was grown by thermal 


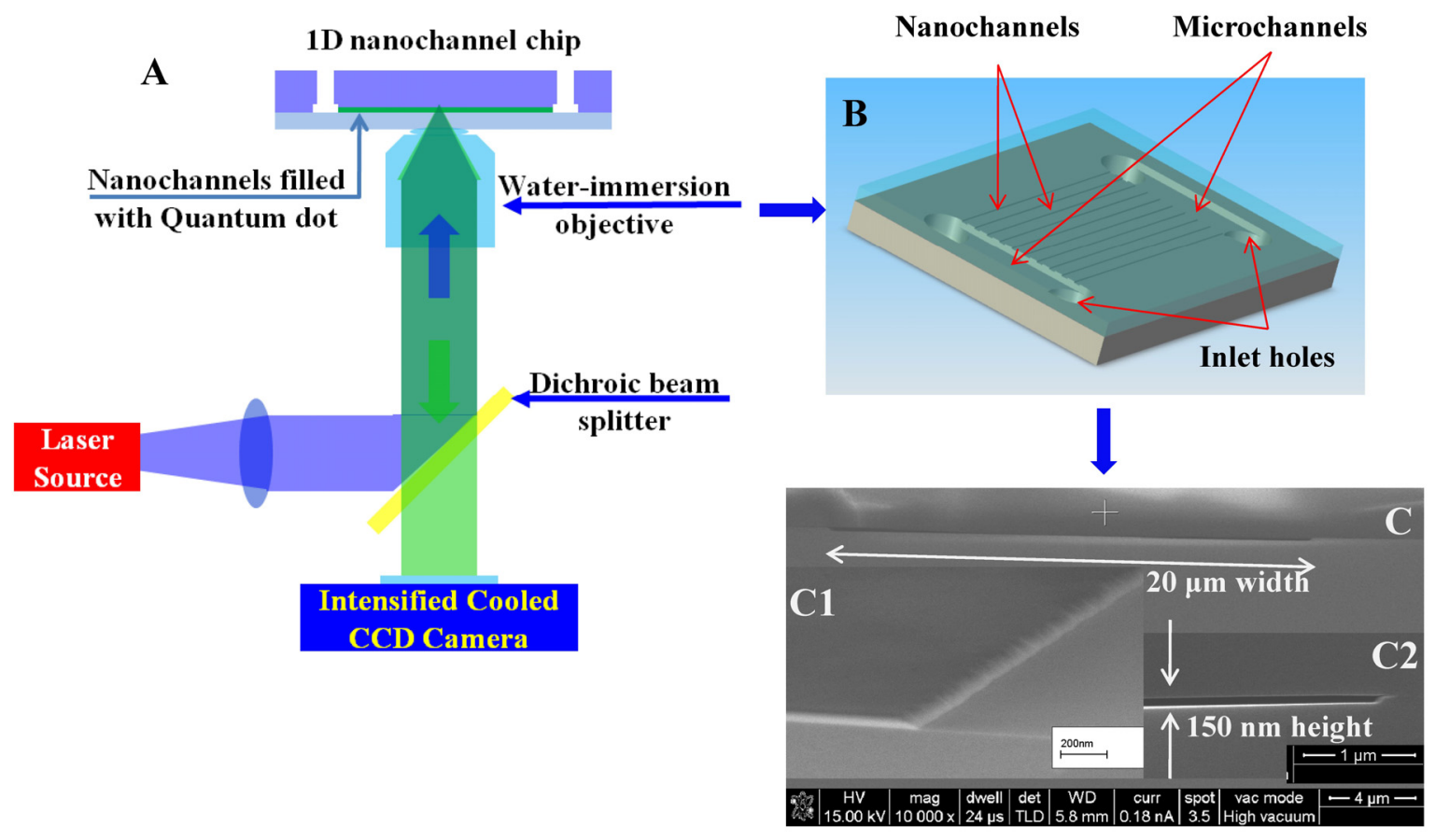

Figure 2.2. (A) Schematic of the experimental set-up. (B) An artist's drawing of a 1D nanochannel device. (C) SEM cross section of a $20 \mu \mathrm{m}$ width nanochannel bonded between a silicon wafer and a thin glass wafer. Inset figure C1: channel wall morphology of the nanochannel formed by wet chemical etching. Inset figure C2: SEM cross section of a $150 \mathrm{~nm}$ height nanochannel.

dry oxidation with oxygen flow of $41 . \mathrm{min}^{-1}$ at $950{ }^{\circ} \mathrm{C}$ in $7 \mathrm{~h}$ (Amtech Tempress Omega Junior, step 2). The thickness of the silicon oxide was measured by an ellipsometry (Plasmos SD 2002). NC structures with $20 \mu \mathrm{m}$ width were created by a standard lithography procedure (step 3) consisting of: a dehydration step (5 min, $120{ }^{\circ} \mathrm{C}$ ), spin coating of a hexamethyldisilazane (HMDS) adhesion promotor and Olin 907-12 photoresist (20 s, 4000 $\mathrm{rpm})$, softbake $\left(1 \mathrm{~min}, 95^{\circ} \mathrm{C}\right)$, exposure (3 s using a $12 \mathrm{~mW} \cdot \mathrm{cm}^{-2}$ Electro Vision exposure apparatus (EVG 620)), post-exposure bake $\left(1 \mathrm{~min}, 120{ }^{\circ} \mathrm{C}\right)$ and development $(1 \mathrm{~min}$ in an OPD 4262 developer). The structures were transferred to the silicon oxide layer (step 4) by wet chemical etching (WCE, $3 \mathrm{~min}$ ) in a buffered hydrofluoric acid (BHF) solution (Merck). Using this silicon oxide spacer layer method [46], the channel height was controlled by the thickness of the silicon oxide layer and by the time to completely etch this layer. For silicon oxide etching, BHF or $1 \%$ HF solutions can be used. In case of channel heights larger than $50 \mathrm{~nm}$, the BHF solution is preferred because of its "resist friendly" properties. However, BHF also etches silicon, although only at a very low rate [10]. Therefore, if the channel heights are below $20 \mathrm{~nm}$, the $1 \%$ HF solution is selected due to its very high selectivity between the etch rates of silicon and silicon oxide. This means that, when using the $1 \% \mathrm{HF}$, 
the etching stops exactly on the silicon/silicon oxide interface, and the channel height is more precisely controlled.

To create fluidic interfacing to the NCs, microchannels were created on the wafer with NC structures. After resist lithography (step 5), the microchannel structure was transferred to the silicon oxide layer by WCE in a BHF solution (4 min, step 6), then to the silicon layer by reactive ion etching (RIE, step 7) (Oxford Plasmalab 100). The main etching parameters were a power of $600 \mathrm{~W}, 120 \mathrm{sccm} \mathrm{SF}_{6}$ flow, $-110{ }^{\circ} \mathrm{C}$ substrate temperature, $10 \mathrm{mTorr}$ process pressure, and time of $40 \mathrm{~s}$ for $2 \mu \mathrm{m}$ depth. Next, resist was removed (step 8) for further processing. For use on an inverted microscope (figure 2.2A), inlet ports were also fabricated on the silicon wafer from the backside, connected to the microchannels (details of inlet-hole fabrication in part 2.2.3).

For optimal collection of fluorescent signals, high NA water-immersion lenses are commonly used, optically corrected for use with $170 \mu \mathrm{m}$ thick cover glasses. Therefore, we covered the 1D NCs by bonding them to special, $170 \mu \mathrm{m}$ thin, blank glass wafers (Borofloat, Mark Optics). Hence, using an inverted microscope, observation of the NCs from the bottom and filling of the channels through inlet ports from the top was possible. Before bonding, channel height was measured by a mechanical surface profiler (Dektak 8, Veeco Instruments Inc.). Both wafers were cleaned by standard cleaning and Piranha cleaning $\left(20 \mathrm{~min}, 120{ }^{\circ} \mathrm{C}\right.$, solution of $\mathrm{H}_{2} \mathrm{SO}_{4}: \mathrm{H}_{2} \mathrm{O}_{2}=3: 1$ ) to obtain clean hydroxylated surfaces before fusion bonding. The final cleaning step was extremely difficult because the thin glass wafer is very fragile. The cleaning was performed in a rinsing bath in which water flow-up and nitrogen bubbles could be reduced. For drying a spinner at low speed or a nitrogen spray gun was used. Broad plastic tip tweezers were preferred to handle this thin wafer.

The silicon wafer with all structures was directly bonded to the blank thin glass wafer (step 13). Then the bonded wafers were annealed in a program furnace $\left(4 \mathrm{~h}, 400{ }^{\circ} \mathrm{C}\right)$ with a controller C 250 (Nabertherm) to enhance the bond between the silicon and the glass wafer. The bonded wafers were diced (step 15) into smaller sized chips with a protection step (14).

\subsubsection{Fabrication of transparent surface 2D nanochannels}

\section{Channel fabrication}

In this chapter, we adapted and extended our previously reported surface-micromachining procedure to create transparent 2D NCs [43]. Figure 2.3 shows a brief process flow to realize 


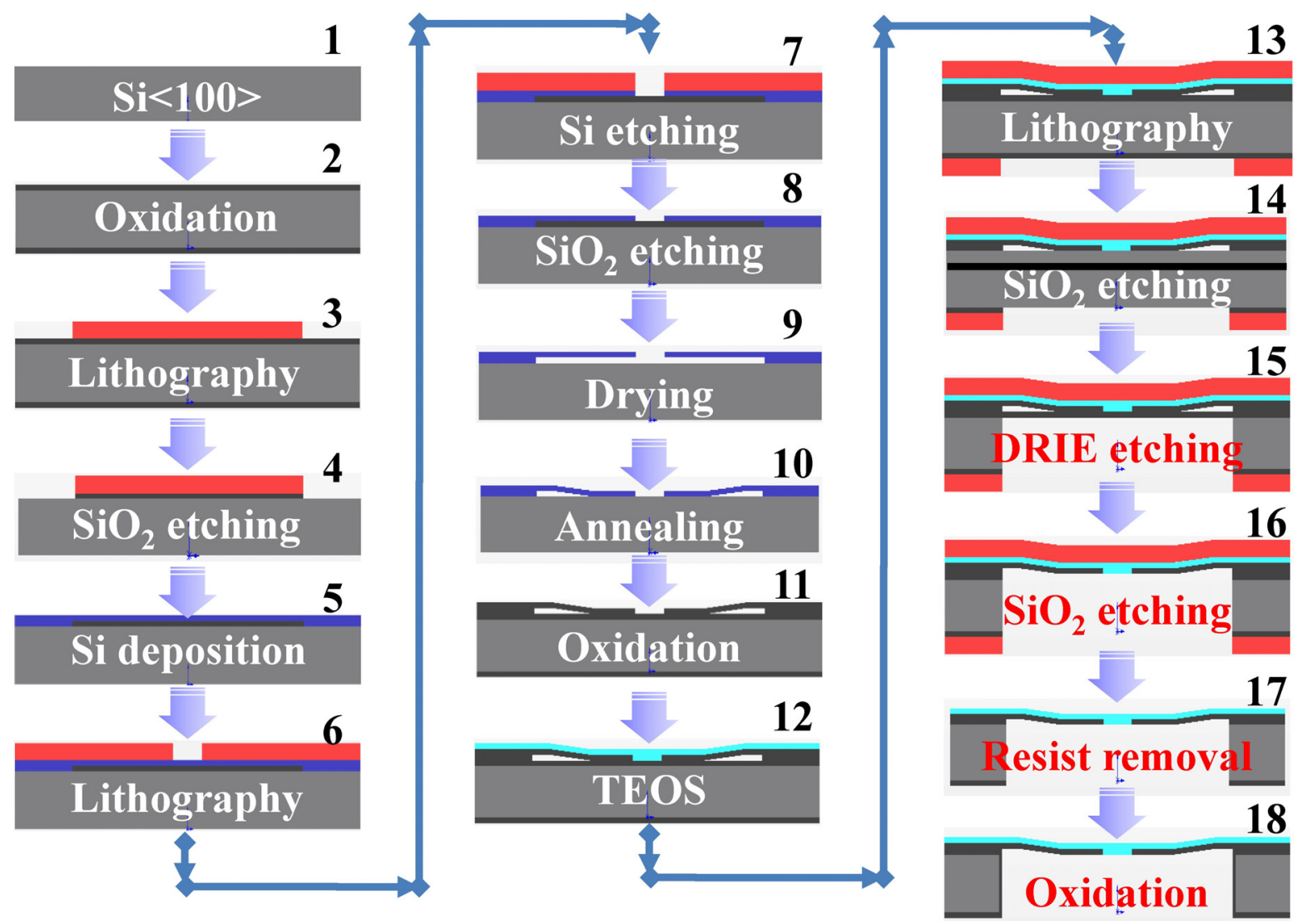

Figure 2.3. Process outline for fabrication of $2 D$ nanochannel devices (details of processing steps in appendix 2.2).

the NCs. A starting substrate is a $<100>$ silicon wafer with a $525 \mu \mathrm{m}$ thickness (step 1). The wafer is thermally dry oxidized $\left(41 \cdot \mathrm{min}^{-1} \mathrm{O}_{2}\right.$ flow, $\left.950{ }^{\circ} \mathrm{C}, 2 \mathrm{~h}\right)$ to realize a $50 \mathrm{~nm}$ silicon oxide sacrificial layer (step 2). Afterward, a standard optical lithography was carried out to create $14 \mu \mathrm{m}$ wide lines in an Olin 907-12 photoresist layer (step 3). Then this pattern was transferred into the silicon oxide layer by RIE etching (step 4, $5 \mathrm{~min}$ ) using a $75 \mathrm{~W}$ power, 25 sccm $\mathrm{CHF}_{3}$ flow and $10 \mathrm{mTorr}$ pressure. After photoresist stripping, the patterned oxide layer was capped by a $20 \mathrm{~nm}$ thick polysilicon layer deposited by low-pressure chemical vapor deposition (LPCVD) with $50 \mathrm{sccm} \mathrm{SiH}_{4}$ flow at $590{ }^{\circ} \mathrm{C}$ and $200 \mathrm{mTorr}$ pressure in $7 \mathrm{~min}$ (Amtech Tempress Omega Junior, step 5). After a second lithographic step (6), a second RIE etching (100 W power, $30 \mathrm{sccm} \mathrm{SF}_{6}, 7 \mathrm{sccm} \mathrm{CHF}_{3}, 11 \mathrm{sccm} \mathrm{O}, 100$ mTorr pressure and, 2 min etching time) was carried out to open windows (step 7). Then through these windows, the sacrificial oxide layer was etched away in a 50\% HF solution for $2 \min$ (step 8). The etching time was short because the sacrificial layer was removed sideward. In this etching step, the sacrificial layer was partly or completely removed to give different possibilities for 

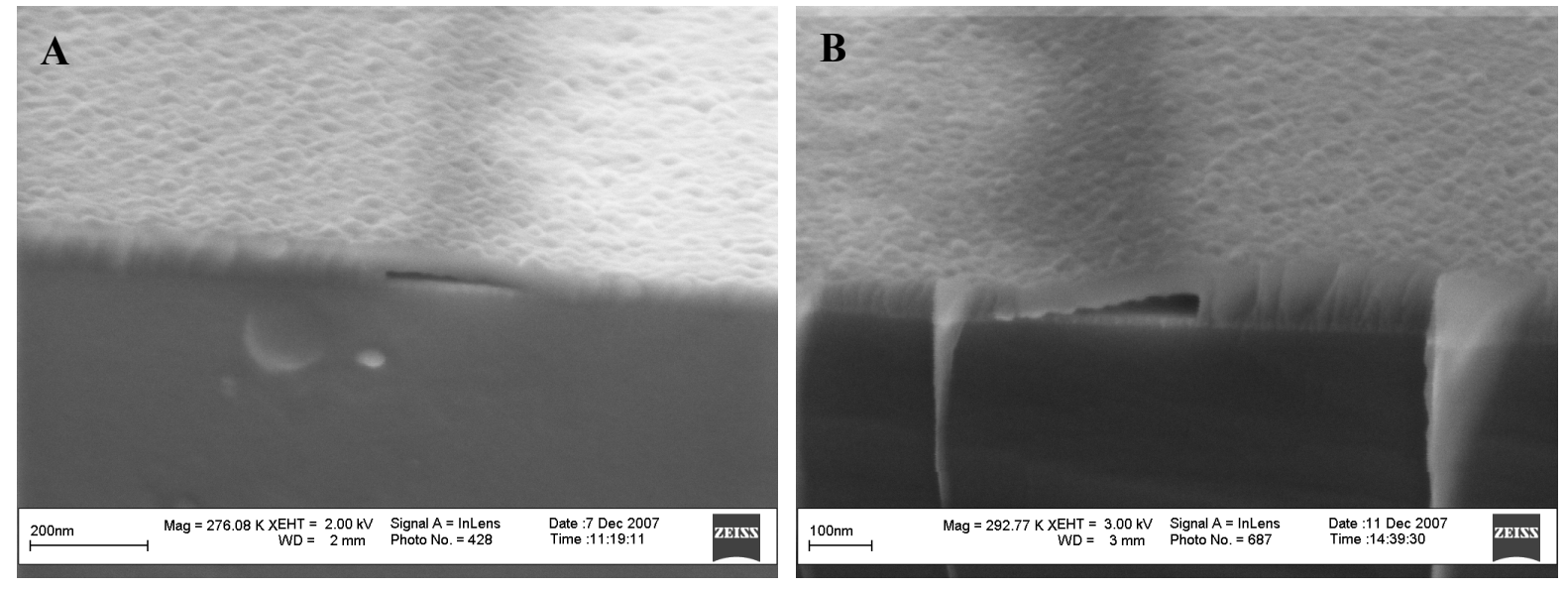

Figure 2.4. SEM cross-sectional images of $2 D$ nanochannels fabricated with different thicknesses of the sacrificial layer, corresponding with the initial gap between capping layer and substrate of (A) $30 \mathrm{~nm}$ and (B) $50 \mathrm{~nm}$.

the shape of the NCs (figure 2.5). Subsequently, the wafer was spin dried (step 9), and during these crucial steps, the capping polysilicon layer was pulled down and adhered to the bearing silicon substrate, thus forming closed NCs. Then, the wafer was thermally annealed (step 10) at $1150{ }^{\circ} \mathrm{C}$ in $\mathrm{N}_{2}$ environment (1 $1 . \mathrm{min}^{-1}$ flow) for $2 \mathrm{~h}$ to strengthen the bond between the polysilicon and the substrate, realizing better sealed channels. Afterwards, the channels were completely oxidized (step 11) to make the capped polysilicon layer optically transparent and to create a $100 \mathrm{~nm}$ silicon oxide layer as a stop layer underneath the channels.

\section{Controlling of channel-fabrication process}

\section{Selection of materials}

2D NCs were formed by adhesion of the capping layer to the substrate after removing the sacrificial layer. In sacrificial layer etching technique, silicon oxide and polysilicon layers are a common combination for sacrificial and capping layers because WCE of silicon oxide using a HF solution has high selectivity over silicon [47]. Additionally in our work, the sacrificial silicon oxide layer is preferred because of its smoothness. This leads to smooth bottom surface of the polysilicon layer which serves as the top NC surface. Also, the high uniform surface of the silicon oxide layer defined the smoothness of the silicon, which forms the bottom NC surface. As the NCs are formed by deformation and adhesion of the polysilicon film to the silicon substrate, the highly smooth surface of the used layers is a 


\section{Partly etched silicon oxide}

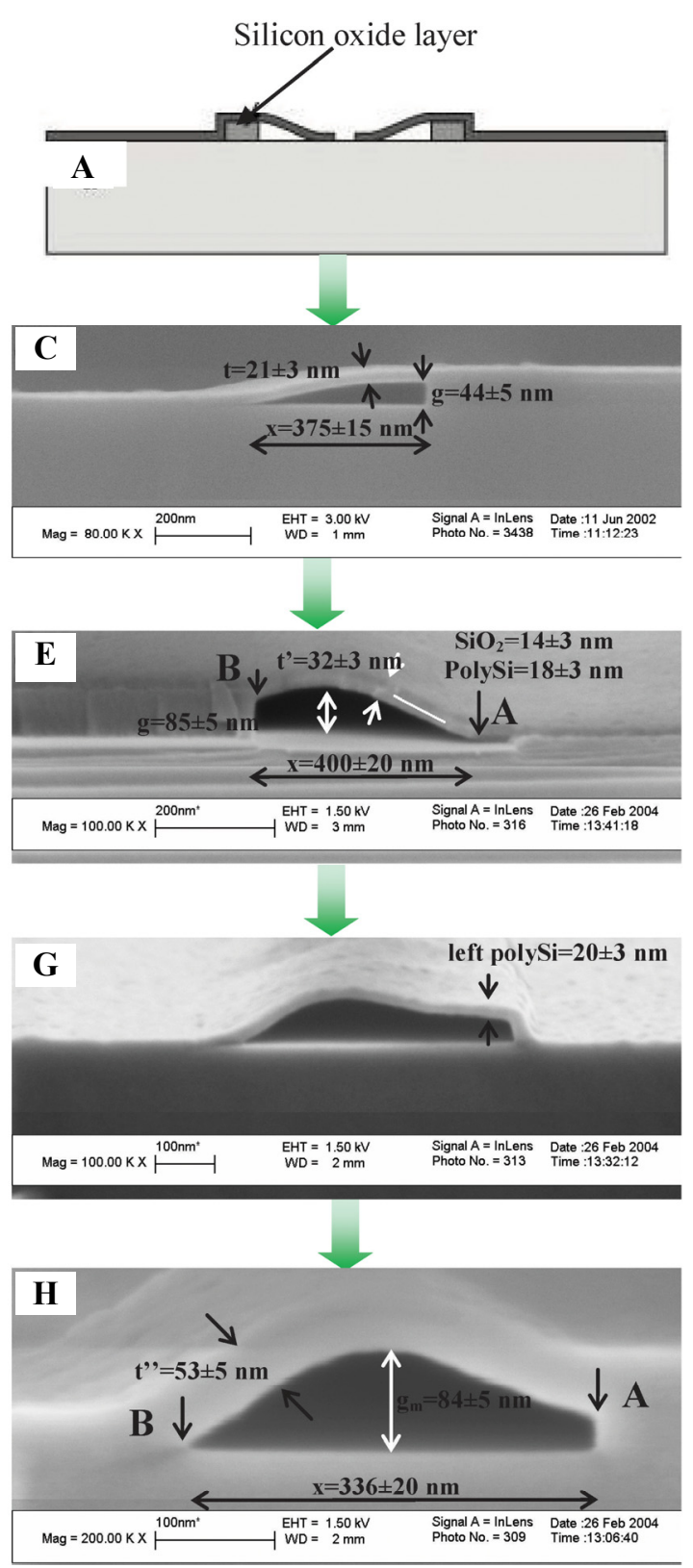

\section{Completely etched silicon oxide}
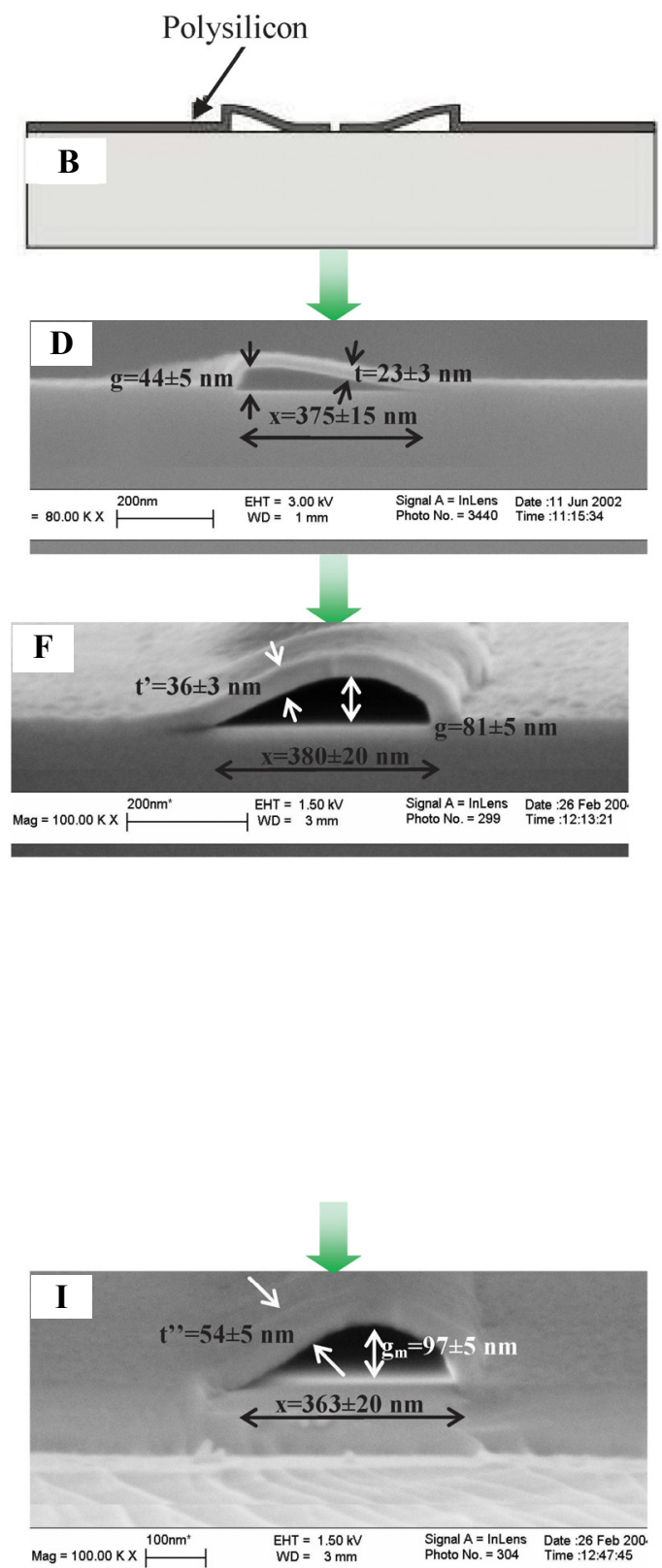

Figure 2.5. Cross-sectional SEM images of 2D nanochannels during processing with two etching possibilities of the sacrificial layer. Left images: remained silicon oxide and right images: completely etched silicon oxide. (A), (B) Sketched finished process steps. (C), (D) Nanochannels just after formation. (E), (F) Nanochannels after partly oxidized the polysilicon capping layer. $(G)$ A nanochannel after the oxidized polysilicon capping layer was removed. (H), (I) Nanochannels after completely oxidizing the polysilicon capping layer.

crucial factor to create strong bonding between the two materials composing the channels, creating completely sealed NCs. 


\section{Channel dimensions after fabrication}

NCs were formed by the elastic deformation and adhering of the capping layer to the substrate after removal of the sacrificial layer. Therefore, both the channel height and width are strongly determined by the thickness and mechanical properties of the used sacrificial and capping layers. Firstly, the height of the channels was exactly equal to the thickness of the sacrificial layer. We observed channels with $27 \pm 3 \mathrm{~nm}$ height (figure $2.4 \mathrm{~A}$ ) and $48 \pm 3 \mathrm{~nm}$ (figure 2.4B) height, in correspondence with to the initial gap of $30 \mathrm{~nm}$ and $50 \mathrm{~nm}$ (measured by ellipsometry) between capping layer and the substrate.

The channel width is depending on thicknesses of both layers. Because the NCs were created due to deformation of the capping layer, the channel width also depends on mechanical properties of the capping layer as well as the adhesion energy of the capping layer to the substrate. The channel width $x$ is found by energy minimization [48]:

$$
x=\sqrt[4]{\frac{3}{2} \frac{E t^{3} g^{2}}{\gamma}}
$$

where $E$ is the Young's modulus of the capping layer, $t$ - the thickness of the capping layer, $g$-the thickness of the sacrificial layer, and $\gamma$-the adhesion energy. From equation 2.1, one can see that the thinner layers create more narrow NCs. From a fabricated channel (figure 2.5C) with width $x=375 \pm 15 \mathrm{~nm}$, thickness $g=44 \pm 5 \mathrm{~nm}$, thickness $t=21 \pm 3 \mathrm{~nm}$, the adhesion energy $E=150 \mathrm{GPa}, \gamma$ of the bond between the capping layer and the substrate was about $0.2 \mathrm{~J} . \mathrm{m}^{-2}$, which is calculated from equation 2.1 and confirmed to be in the range of the adhesion energy of silicon-silicon bonds [43, 49].

\section{Preservation of channel features after post-processes}

For optical detection, transparent channels are required therefore the fabricated channels were oxidized to transform the polysilicon layer which forms channel walls to a transparent silicon oxide layer. It is desired that features of the fabricated channels such as shape and sizes are preserved after post processes. Therefore, an investigation of the oxidation of the fabricated channels was carried out. The polysilicon capping layer was partly oxidized and figure $2.5 \mathrm{E}$ shows the capping layer with an interface (indicated by white dots) between oxidized polysilicon (14 $\pm 3 \mathrm{~nm}$ thick) and the remaining polysilicon (18 $\pm 3 \mathrm{~nm}$ thick) layers with a total thickness of $32 \pm 3 \mathrm{~nm}$. To prove this observation, the oxidized polysilicon layer was removed by HF 50\% to reveal the remaining polysilicon layer $(20 \pm 3 \mathrm{~nm}$ thick in figure 
2.5G). Furthermore, we observed that the capping layer was pushed up due to the volume expansion during transformation of polysilicon to silicon oxide. It was indicated by an increase in channel height from $44 \pm 5 \mathrm{~nm}$ (before oxidation in figure 2.5C) to $84 \pm 5 \mathrm{~nm}$ (after oxidation in figure 2.5H). During oxidation, the capping polysilicon layer (from point A to point $\mathrm{B}$ in figure $2.5 \mathrm{C}$ and figure $2.5 \mathrm{H}$ ) was elongated from $370 \pm 15 \mathrm{~nm}$ to $374 \pm 15$ $\mathrm{nm}$. Also, the capping layer became thicker, from $21 \pm 3 \mathrm{~nm}$ to $53 \pm 3 \mathrm{~nm}$. From its thickness and length expansion, the volume ratio of the capping layer after and before oxidation was determined to be about 2.6, which is in the same range as the ratio in bulk-silicon oxidation [50]. Surely, the most important observation is the oxidized polysilicon that hangs over channel areas rather than collapsing or blocking the channels, which confirms the preservation of the fabricated channels.

For integration of the fabricated NCs to the outer world, a thicker layer such as silicon oxide or silicon nitride was deposited on top of the channels. This layer mechanically protects for the fragile channels from damage. Figure 2.8A shows the fabricated channels with a deposited silicon oxide layer of $500 \mathrm{~nm}$ thickness without any collapse.

\subsubsection{Fabrication of fluidic inlet/outlet ports}

In NC devices interfacing from macro inlet ports to the NCs is necessary for proper delivery of liquid into the NCs. Inlet ports can be created by different processes, such as powder blasting and DRIE etching [51]. For 1D bonded NCs, powder blasting is commonly selected to form inlet ports on glass wafers [25]. In order to use an inverted microscope, inlet ports formed on silicon wafers containing the nano/microchannel structures, DRIE etching was a preferred alternative method to avoid damage of NCs. Protection of the NCs against damage was crucial. The fabricated channels were protected by coating with various materials such as TI35, SU-8 (Micro Chemicals), unfortunately all resulting in cracking and peeling-off during the cryogenic DRIE step. Durimide 7500 series polyimide (Arch) successfully protected the fabricated structures during etching through the wafer, exhibiting the proper combination of thermal stability and mechanical toughness. Polyimide was coated (figure 2.1, step 9) on the front side containing NC structures by a lithography procedure (step 9): dehydration (5 min, $\left.120{ }^{\circ} \mathrm{C}\right)$, spin coating $(20 \mathrm{~s}, 6000 \mathrm{rpm})$, softbake $\left(1 \mathrm{~min}, 95{ }^{\circ} \mathrm{C}\right)$, flood exposure $(3 \mathrm{~s})$, postbake in Leybold Heraeus vacuum oven $\left(1 \mathrm{~h}, 350{ }^{\circ} \mathrm{C}, 2\right.$ mbar). After a standard lithography step (10), inlet-port patterns were created on the back side of the wafer. Next, these patterns were transferred to the silicon substrate by DRIE etching (step 11) with an etch rate of $6 \mu \mathrm{m} \cdot \mathrm{min}^{-1}$. The main etching parameters were a power of $600 \mathrm{~W}, 200 \mathrm{sccm} \mathrm{SF}$ fow 

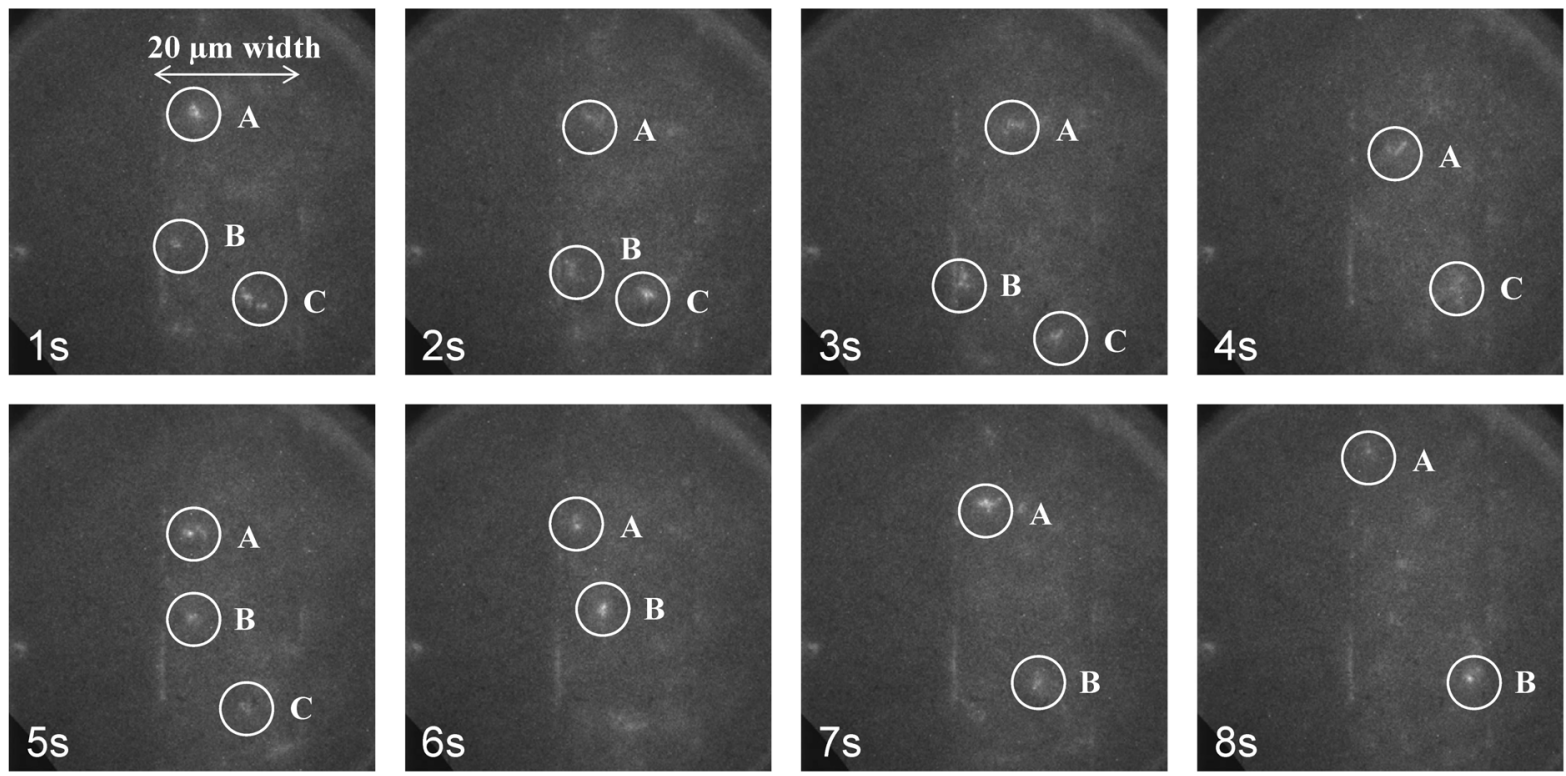

Figure 2.6. Blinking behavior of individual quantum dots visualized inside 1D nanochannels (150 nm height, 20 $\mu \mathrm{m}$ width). Interfacing of the nanochannels is indicated by the white arrow. "On" and "off" states were observed in the quantum dot marked B (inside the white circle) whose fluorescence disappeared at the 4s-image then reappeared in the 5 -image.

$1.0 \mathrm{sccm} \mathrm{O}_{2}$ flow, $-110{ }^{\circ} \mathrm{C}$ substrate temperature, $10 \mathrm{mT}$ Torr process pressure and $65 \mathrm{~min}$ etching time. After etching, the polyimide layer was removed (step 12) by Piranha cleaning.

For the enclosed 2D NCs, DRIE was absolutely preferred over powder blasting. In powder blasting the high-pressure flow of aluminum oxide will damage the fragile channels. Therefore, DRIE was used to create inlet ports for 2D NCs. The fabricated NCs were protected by a $500 \mathrm{~nm}$ thick silicon oxide layer deposited at $700{ }^{\circ} \mathrm{C}$ and $400 \mathrm{mTorr}$ in $70 \mathrm{~min}$ (Tempress Systems Furnace) from tetraethoxysilane (TEOS) and nitrogen (figure 2.3, step 12). This layer served as a protective layer during further processing and provided a transparent layer for optical observation as well. Inlet ports were integrated with the channels (figure 2.8B) from the back side to avoid interference with the objective, a problem may occur when filling and observation takes place at the same side. A standard lithographic step (13) was applied to form patterns of inlet ports on the backside of the wafer and to coat the front side with a photoresist layer to protect the NC structures. Next, the inlet-port patterns were transferred to the oxide layer by WCE in a BHF solution (10 min, step 14). Inlet ports were etched almost through the wafer by the DRIE etching (90 min, step 15) using the same parameters as presented for fabrication of the 1D NCs. Etching of the silicon was stopped on 

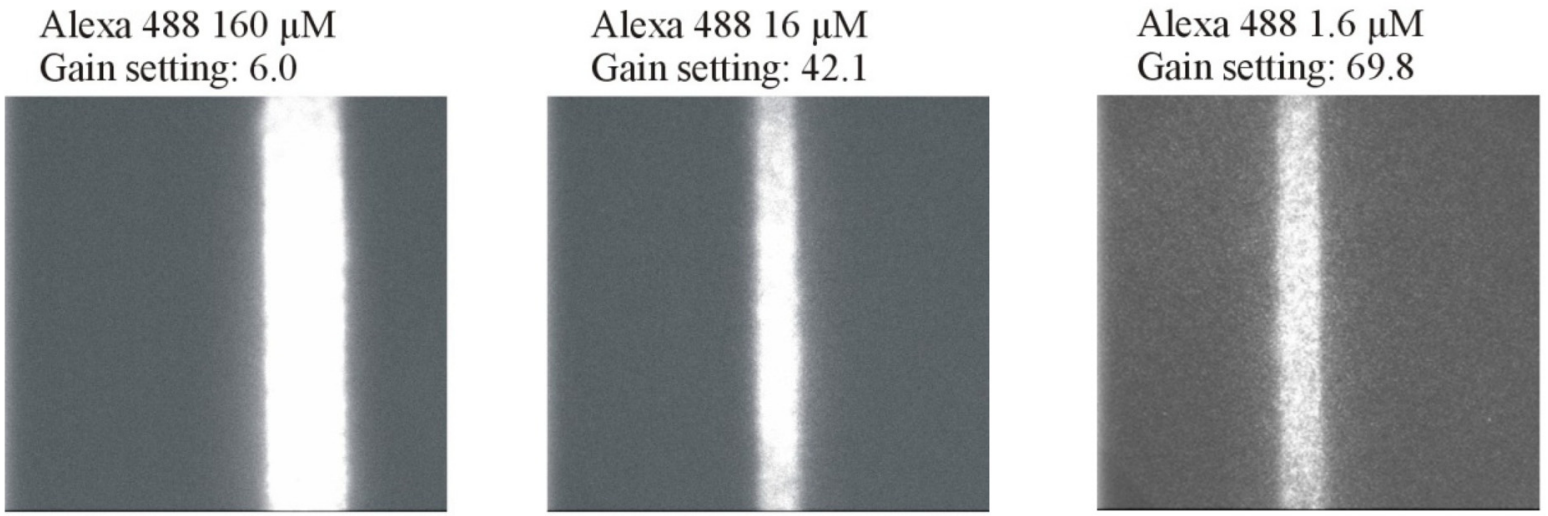

Figure 2.7. $1 D$ nanochannels filled with different concentrations of Alexa 488 in water. Exposure time was 200 ms. Image size is $50 \mu m \times 50 \mu m$ with 512 pixels $\times 512$ pixels.

the stop layer introduced by the oxidation step (11) after fabrication of the channels. The stop layer was removed by RIE etching in $3 \mathrm{~min}$ and the channels were partly opened in the inletport area (step 16). The photoresist layers from both sides were removed (step 17) by oxygen plasma (20 min, Tepla 300E). In a final step (18), thermal dry oxidation at $950{ }^{\circ} \mathrm{C}$ in $15 \mathrm{~min}$ the surfaces and side walls of the inlet ports were made hydrophilic to facilitate filling of the channels.

\subsection{Single molecule mobility studies}

The $150 \mathrm{~nm}$ high 1D NCs (figure 2.2C) were used for observation of single QDs. The experiments were carried out on an upgraded inverted fluorescence microscope (Zeiss, Axiovert, Oberkochen, Germany) (figure 2.2A) [52]. For excitation $488 \mathrm{~nm}$ Argon laser light was focused into the NCs by using a 100×, $1.20 \mathrm{NA}$, water-immersion objective (Leica Planachromat, Wetzlar, Germany). For detection of fluorescence intensities the microscope was equipped with an air-cooled intensified CCD camera (Pentamax, Roper Scientific, NJ). Emission was detected with a $610 / 75 \mathrm{~nm}$ band pass filter and a notch filter was used to remove residual excitation intensities. Images of $50 \mu \mathrm{m} \times 50 \mu \mathrm{m}(512$ pixels $\times 512$ pixels $)$ were recorded by using the WinSpec 32 program (Roper Scientific). A series of 40 sequential images were acquired at a rate of 5 frames per second (200 ms exposure time).

By capillary force the NCs were filled with a $12 \mathrm{nM}$ QD solution (Evitag Fort Orange, type T2-MP, carboxyl, CdSe/ZnS, $\sim 25 \mathrm{~nm}$ diameter, emission $600 \pm 10 \mathrm{~nm}$, Evident Technologies). Imaging was started only after the equilibrium state was reached indicated by an absence of flow inside the channels. QDs performed the well-known Brownian motion 

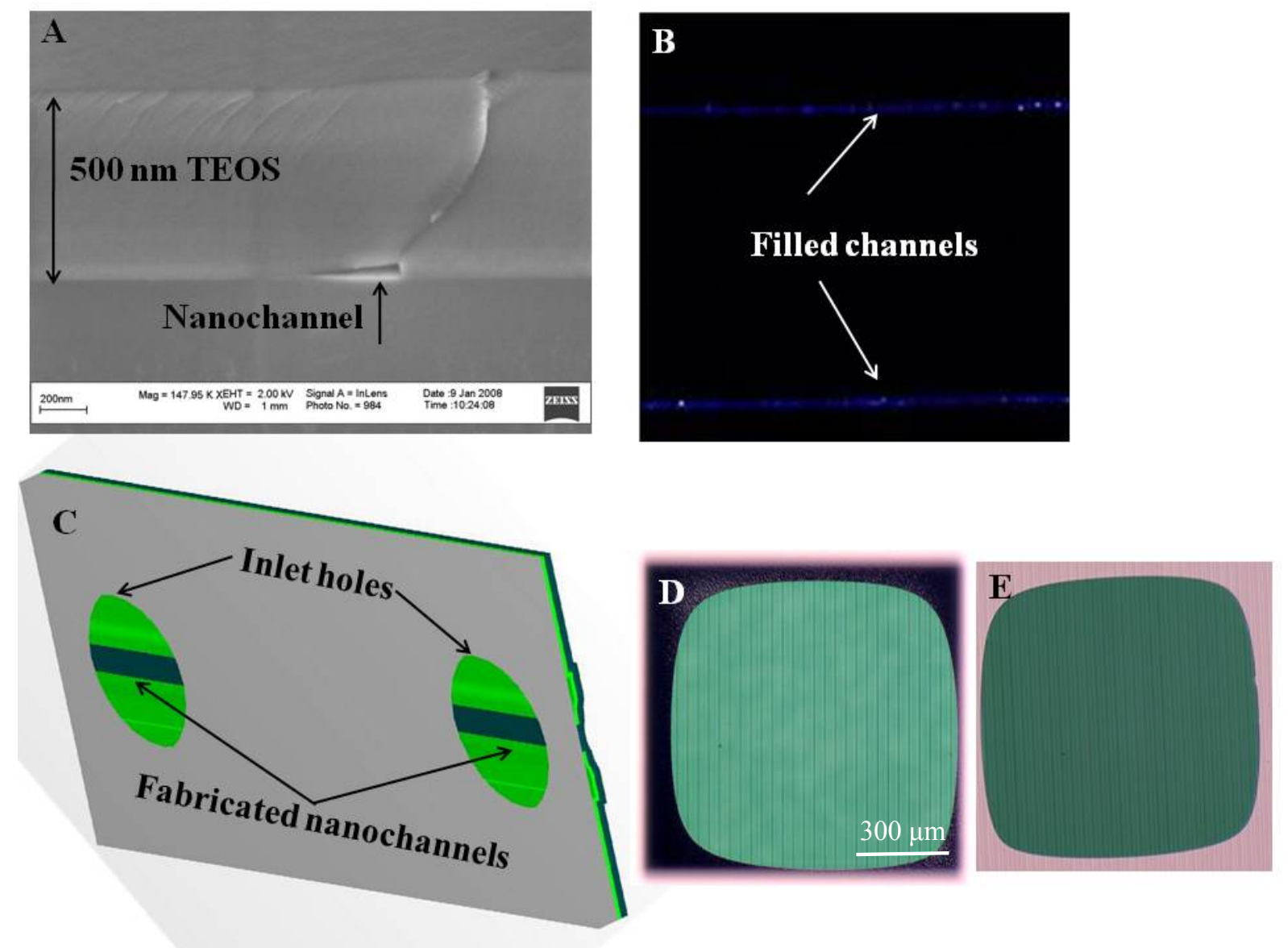

Figure 2.8. (A) A preserved nanochannel with $500 \mathrm{~nm}$ TEOS protection layer. (B) A confocal fluorescence image of $4 \mu \mathrm{M}$ Alexa Fluor 488 solution in $50 \mathrm{~nm}$ height and $400 \mathrm{~nm}$ width $2 \mathrm{D}$ nanochannels. Image size is 43.4 $\mu m \times 43.4 \mu m .(C)$ An artist's drawing of a 2D nanochannel device including inlet holes connected to channels for filling. (D), (E) Optical microscope images of $0.9 \mathrm{~mm}$ diameter inlet holes, observed on top of the inlet hole and above the channels.

that a quantitative analysis is presented in chapter five. In the Brownian motion of single QDs, the average of its displacements tends to zero value which means there is no flow. Individual QDs could be visualized by virtue of the nanoconfinement in the channels in combination with the high NA objective and the sensitive detection camera. The sequences of images (figure 2.6) identified the presence of individual QDs from the instantaneous appearance and disappearance of fluorescence, a demonstration of the well-known blinking behavior, characteristic for single fluorescent molecules. In every image of the series, dots could be recognized that were already present in the first image (dots $\mathrm{A}-\mathrm{C}$ ) and could be followed over several consecutive images (2s-, 3s-images); other dots disappeared (dot B in 
4s-image) and reappeared (dot B in 5s-image) during imaging. Note that the number of QDs in the observation window is two orders of magnitude smaller than the calculated number corresponding to the original QD solution. Therefore, the observed concentration corresponds to $\sim 0.01 \mathrm{nM}$.

In other experiments, the NCs were filled with solutions of Alexa Fluor 488 (Molecular Probes, Eugene, OR) in water. We started with a high concentration of $160 \mu \mathrm{M}$ Alexa 488, and gradually diluted this solution. Figure 2.7 shows that a concentration as low as $1.6 \mu \mathrm{M}$ has been observed in the NCs. A simple calculation shows how far the concentrations have to be reduced to reach the single-molecule level. Assume we have one molecule in a channel volume $V=h \times A$, where $h(\mathrm{~m})$ is the channel height and $A\left(\mathrm{~m}^{2}\right)$ is the lateral channel area occupied by the molecule. The required molarity is then given by $C=1 /\left(N_{A} \times V \times 1000\right)$, Avogadro number $\left(N_{A}=6.02 \times 10^{23} \mathrm{~mol}^{-1}\right)$. For $A=10 \mu \mathrm{m}^{2}$ and $h=50 \mathrm{~nm}$ this results in $C=$ $3 \mathrm{nM}$. This means that a further reduction by three orders of magnitude is required compared the lowest concentration $(1.6 \mu \mathrm{M})$ achieved in our imaging experiments. One way to make the concentration requirement less stringent is the use of confined 2D NCs [43]. Technologically, it is possible to reduce the channel width and thus channel area $A$ by a factor of 100. Another possibility is to detect the fluorescence not by using an imaging method, but by applying fluorescence correlation spectroscopy (FCS) [53]. FCS measurements can be performed with confocal fluorescence microscopy, where the fluorescence is detected from individual molecules during passage through a sub-femtoliter confocal volume. The application of 1D NCs will reduce the detection volume even further and enable FCS measurements at physiologically relevant concentrations. The performance of the 2D NCs was only tested regarding their filling capability. For visualization a homebuilt scanning confocal fluorescence microscope (appendix 2.3) was used [54-55]. Briefly, $488 \mathrm{~nm} \mathrm{Ar} / \mathrm{Kr}$ laser light was used for excitation in combination with a $63 \times, 1.20 \mathrm{NA}$ water immersion objective, a 525/50 $\mathrm{nm}$ band pass emission filter and an avalanche photodiode detector. Application of $4 \mu \mathrm{M}$ Alexa 488 solution confirmed that filling of the $2 \mathrm{D}$ NCs indeed can be properly accomplished (figure $2.8 \mathrm{C}$ ). The concentration of $4 \mu \mathrm{M}$ was still three orders higher than the concentration required for the single-molecule level [56]. Furthermore, the visualization of fluorescent dye molecules at $\mathrm{nM}$ concentration inside another type of $2 \mathrm{D}$ NCs (thin encapsulated channels) is presented in chapter three. 


\subsection{Conclusions}

We fabricated 1D NCs using thin glass wafers as cover especially for observation with high NA lenses. Inlet ports for these 1D channels were constructed on silicon wafers for use in an inverted microscope configuration. 2D fragile NCs were successfully fabricated and made transparent for optical observation by oxidation then they were integrated to macro world by through-wafer inlet ports. Inlet/outlet ports integrated with the fabricated NCs were created using DRIE at cryogenic temperature. The performance of the 1D NCs in single-molecule fluorescence detection was demonstrated from visualization of single QDs from a $12 \mathrm{nM}$ solution. These results indicate promising prospects for utilization of the NCs for various applications, like e.g. single-molecule position tracking at physiologically relevant concentrations. Testing of the $2 \mathrm{D}$ NCs showed adequate performance in filling with a fluorescent solution.

\subsection{References}

[1] Lyon, W. A.; Nie, S. Confinement and detection of single molecules in submicrometer channels. Anal. Chem. 1997, 69 (16), 3400-3405.

[2] Wang, Y. M.; Tegenfeldt, J. O.; Reisner, W.; Riehn, R.; Guan, X. J.; Guo, L.; Golding, I.; Cox, E. C.; Sturm, J.; Austin, R. H. Single-molecule studies of repressor-DNA interactions show long-range interactions. Proc. Natl. Acad. Sci. USA 2005, 102 (28), 9796-9801.

[3] Verbridge, S. S.; Edel, J. B.; Stavis, S. M.; Moran-Mirabal, J. M.; Allen, S. D.; Coates, G.; Craighead, H. G. Suspended glass nanochannels coupled with microstructures for single molecule detection. J. Appl. Phys. 2005, 97 (12), 124317.

[4] Nie, S.; Zare, R. N.; Optical detection of single molecules. Annu. Rev. Biophys. Biomol. Struct. 1997, 26, 567-596.

[5] Levene, M. J.; Korlach, J.; Turner, S. W.; Foquet, M.; Craighead, H. G.; Webb, W. W. Zero-mode waveguides for single-molecule analysis at high concentrations. Science 2003, 299 (5607), 682-686.

[6] Semwogerere, D.; Weeks, E. R. Confocal Microscopy. Encyclopedia of Biomaterials and Biomedical Engineering, Taylor Francis: NY 2005.

[7] Jin, S.; Huang, P.; Park, J.; Yoo, J. Y.; Breuer, K. S. Near-surface velocimetry using evanescent wave illumination. ASME International Mechanical Engineering Congress and Exposition, Washington DC, USA 2003, 44015. 
[8] Mooren, O. L.; Erickson, E. S.; Dickenson, N. E.; Dunn, R. C. Extending near-field scanning optical microscopy for biological studies. J. Assoc. Lab. Autom. 2006, 11 (4), 268-272.

[9] Persson, F.; Thamdrup L. H.; Mikkelsen, M. B. L.; Jaarlgard, S. E.; Skafte-Pedersen, P.; Bruus, H.; Kristensen, A. Double thermal oxidation scheme for the fabrication of $\mathrm{SiO}_{2}$ nanochannels. Nanotechnology 2007, 18 (24), 245301.

[10] Haneveld, J.; Tas, N. R.; Brunets, N.; Jansen, H. V.; Elwenspoek, M. Capillary filling of sub-10 nm nanochannels. J. Appl. Phys. 2008, 104 (1), 014309.

[11] Mijatovic, D.; Eijkel, J. C. T.; Van den Berg, A. Technologies for nanofluidic systems: top-down vs. bottom-up - a review. Lab Chip 2005, 5 (5), 492-500.

[12] Alarie, J. P.; Hmelo, A. B.; Jacobson, S. C.; Baddorf, A. P.; Feldman, L.; Ramsey, J. M. Fabrication and evaluation of 2D confined nanochannels. $7^{\text {th }}$ International Conference on Miniaturized Chemical and Biochemical Analysts Systems, CA, USA 2003, 9-12.

[13] Riehn, R.; Lu, M.; Wang, Y. M.; Lim, S. F.; Cox, E. C.; Austin, R. H. Restriction mapping in nanofluidic devices. Proc. Natl. Acad. Sci. USA 2005, 102 (29), 10012-10016.

[14] Turner, S. W.; Perez, A. M.; Lopez, A.; Craighead, H. G. Monolithic nanofluid sieving structures for DNA manipulation. J. Vac. Sci. Technol. B 1998, 16 (6), 3835-3840.

[15] Hibara, A.; Saito, T.; Kim, H. B.; Tokeshi, M.; Ooi, T.; Nakao, M.; Kitamori, T. Nanochannels on a fused-silica microchip and liquid properties investigation by timeresolved fluorescence measurements. Anal. Chem. 2002, 74 (24), 6170-6176.

[16] Reisner, W.; Beech, J. P.; Larsen, N. B.; Flyvbjerg, H.; Kristensen, A.; Tegenfeldt, J. O. Nanoconfinement-enhanced conformational response of single DNA molecules to changes in ionic environment. Phys. Rev. Lett. 2007, 99 (5), 058302.

[17] Cao, H.; Yu, Z.; Wang, J.; Tegenfeldt, J. O.; Austin, R. H.; Chen, E.; Wu, W.; Chou, S. Y. Fabrication of $10 \mathrm{~nm}$ enclosed nanofluidic channels. Appl. Phys. Lett. 2002, 81 (1), 174-176.

[18] Guo, L. J.; Cheng, X.; Chou, C. F. Fabrication of size-controllable nanofluidics channels by nanoimprinting and its applications for DNA stretching. Nano Lett. 2004, 4 (1), 69-73.

[19] Liang, X.; Morton, K. J.; Austin, R. H.; Chou, S. Y. Single sub-20 nm wide, centimeterlong nanofluidic channel fabricated by novel nanoimprint mold fabrication and direct imprinting. Nano Lett. 2007, 7 (12), 3774-3780. 
[20] Letant, S. E.; Van Buuren, T. W.; Terminello, L. J. Nanochannel arrays on silicon platforms by electrochemistry. Nano Lett. 2004, 4 (9), 1705-1707.

[21] Wang, M.; Jing, N.; Su, C. B.; Kameoka, J.; Chou, C. K.; Hung, M. C.; Chang, K. A. Electrospinning of silica nanochannels for single molecule detection. Appl. Phys. Lett. 2006, 88 (3), 033106.

[22] Sivanesan, P.; Okamoto, K.; English, D.; Lee, C. S.; DeVoe, D. L. Polymer nanochannels fabricated by thermomechanical deformation for single-molecule analysis. Anal. Chem. 2005, 77 (7), 2252-2258.

[23] Huh, D.; Mills, K. L.; Zhu, X.; Burns, M. A.; Thouless, M. D.; Takayama, S. Tuneable elastomeric nanochannels for nanofluidic manipulation. Nature Mater. 2007, 6 (6), $424-428$.

[24] Lee, C.; Yang, E. H.; Myung, N. V.; George, T. A nanochannel fabrication technique without nanolithography. Nano Lett. 2003, 3 (10), 1339-1340.

[25] Haneveld, J.; Jansen, H.; Berenschot, E.; Tas, N.; Elwenspoek, M. Wet anisotropic etching for fluidic 1D nanochannels. J. Micromech. Microeng. 2003, 13 (4), S62-S66.

[26] Pappaert, K.; Biesemans, J.; Clicq, D.; Vankrunkelsven, S.; Desmet, G. Measurements of diffusion coefficients in 1-D micro- and nanochannels using shear-driven flows. Lab Chip 2005, 5 (10), 1104-1110.

[27] Durand, N. F. Y.; Bertsch, A.; Todorova, M.; Renaud P. Direct measurement of effective diffusion coefficients in nanochannels using steady-state dispersion effects. Appl. Phys. Lett. 2007, 91 (20), 203106.

[28] Mannion, J. T.; Reccius, C. H.; Cross, J. D.; Craighead, H. G. Conformational analysis of single DNA molecules undergoing entropically induced motion in nanochannels. Biophys. J. 2006, 90 (12), 4538-4545.

[29] Wu, C.; Jin, Z.; Wang, H. Q.; Ma, H.; Wang, Y. Design and fabrication of a nanofluidic channel by selective thermal oxidation and etching back of silicon dioxide made on a silicon substrate. J. Micromech. Microeng. 2007, 17 (12), 2393-2397.

[30] Han, J.; Craighead, H. G. Entropic trapping and sieving of long DNA molecules in a nanofluidic channel. J. Vac. Sci. Technol. A 1999, 17 (4), 2142-2147.

[31] Parikesit, G. O. F.; Markesteijn, A. P.; Kutchoukov, V, G.; Piciu, O.; Bossche, A.; Westerweel, J.; Garini, Y.; Young, I. T. Electroosmotic flow analysis of a branched Uturn nanofluidic device. Lab Chip 2005, 5 (10), 1067-1074. 
[32] Stein, D.; Kruithof, M.; Dekker, C. Surface-charge-governed ion transport in nanofluidic channels. Phys. Rev. Lett. 2004, 93 (3), 035901.

[33] Pennathur, S.; Santiago, J. G. Electrokinetic transport in nanochannels. 1. Theory. Anal. Chem. 2005, 77 (21), 6772-6781.

[34] Pennathur, S.; Santiago, J. G. Electrokinetic transport in nanochannels. 2. Experiments. Anal. Chem. 2005, 77 (21), 6782-6789.

[35] Pu, Q. S.; Yun, J. S.; Temkin, H.; Liu, S. R. Ion-enrichment and ion-depletion effect of nanochannel structures. Nano Lett. 2004, 4 (6), 1099-1103.

[36] Mao, P.; Han, J. Fabrication and characterization of $20 \mathrm{~nm}$ planar nanofluidic channels by glass-glass and glass-silicon bonding. Lab Chip 2005, 5 (8), 837-844.

[37] van Delft, K. M.; Eijkel, J. C. T.; Mijatovic, D.; Druzhinina, T. S.; Rathgen, H.; Tas, N. R.; Van den Berg, A.; Mugele, F. Micromachined Fabry-Pérot interferometer with embedded nanochannels for nanoscale fluid dynamics. Nano Lett. 2007, 7 (2), 345-350.

[38] Cao, H.; Tegenfeldt, J. O.; Austin, R. H.; Chou, S. Y. Gradient nanostructures for interfacing microfluidics and nanofluidics. Appl. Phys. Lett. 2002, 81 (16), 3058-3060.

[39] O’Brien, M. J.; Bisong, P.; Ista, L. K.; Rabinovich, E. M.; Garcia, A. L.; Sibbett, S. S.; Lopez, G. P.; Brueck, S. R. J. Fabrication of an integrated nanofluidic chip using interferometric lithography. J. Vac. Sci. Technol. B 2003, 21 (6), 2941-2945.

[40] Han, A.; Mondin, G.; Hegelbach, N. G.; de Rooij, N. F.; Staufer, U. Filling kinetics of liquids in nanochannels as narrow as $27 \mathrm{~nm}$ by capillary force. J. Colloid Interf. Sci. 2006, 293 (1), 151-157.

[41] Cho, Y. H.; Lee, S. W.; Kim, B. J.; Fujii, T. Fabrication of silicon dioxide submicron channels without nanolithography for single biomolecule detection. Nanotechnology 2007, 18 (46), 465303.

[42] Ilic, B.; Czaplewski, D.; Zalalutdinov, M.; Schmidt, B.; Craighead, H. G. Fabrication of flexible polymer tubes for micro and nanofluidic applications. J. Vac. Sci. Technol. B 2002, 20 (6), 2459-2465.

[43] Tas, N. R.; Berenschot, J. W.; Mela, P.; Jansen, H. V.; Elwenspoek, M.; Van den Berg, A. 2D-confined nanochannels fabricated by conventional micromachining. Nano Lett. 2002, 2 (9), 1031-1032.

[44] Eijkel, J. C.; Bomer, J.; Tas, N. R.; Van den Berg, A. 1-D nanochannels fabricated in polyimide. Lab Chip 2004, 4 (3), 161-163.

[45] French, P. J. Development of surface micromachining techniques compatible with onchip electronics. J. Micromech. Microeng. 1996, 6 (2), 197-211. 
[46] Haneveld, J. Nanochannel Fabrication and Characterization Using Bond Micromachining, PhD thesis, University of Twente, The Netherlands 2006.

[47] Elwenspoek, M.; Jansen, H. V. Silicon Micromachining, Cambridge University Press: Cambridge 1998.

[48] Tas, N.; Sonnenberg, T.; Jansen, H.; Legtenberg, R.; Elwenspoek, M. Stiction in surface micromachining. J. Micromech. Microeng. 1996, 6 (4), 385-397.

[49] Backlund, Y.; Hermansson, K.; Smith, L. Bond strength related to silicon surface hydrophilicity. J. Electrochem. Soc. 1992, 139 (8), 2299-2301.

[50] Chen, X.; Lin, J.; Xu, S.; Xin, P.; Wang, L. Oxidation of high area ratio silicon microchannels fabricated by electrochemical etching. Proceedings of the $3^{\text {rd }}$ IEEE International Conference on Nano/Micro Engineered and Molecular Systems, Sanya, China 2008, 78-81.

[51] Polyakov, A.; Grob, T.; Hovenkamp, R. A.; Kettelarij, H. J.; Eidner, I.; de Samber, M. A.; Bartek, M.; Burghartz, J. N. Comparison of via-fabrication techniques for throughwafer electrical interconnect applications. IEEE Electronic Components and Technology Conference, NV, USA 2004, 1466-1470.

[52] Snijder-van As, M. I.; Rieger, B.; Joosten, B.; Subramaniam, V.; Figdor, C. G.; Kanger, J. S. A hybrid total internal reflection fluorescence and optical tweezers microscope to study cell adhesion and membrane protein dynamics of single living cells. J. Microsc. 2009, 233 (1), 84-92.

[53] Medina, M. A.; Schwille, P. Fluorescence correlation spectroscopy for the detection and study of single molecules in biology. BioEssays 2002, 24 (8), 758-764.

[54] Kassies, R., Lenferink, A., Segers-Nolten, I.; Otto, C. Prism-based excitation wavelength selection for multicolor fluorescence coincidence measurements. Appl. Opt. 2005, 44 (6), 893-897.

[55] Segers-Nolten, G. M. J., Wyman, C., Wijgers, N., Vermeulen, W., Lenferink, A. T., Hoeijmakers, J, H., Greve, J.; Otto, C. Scanning confocal fluorescence microscopy for single molecule analysis of nucleotide excision repair complexes. Nucleic Acids Res. 2002, 30 (21), 4720-4727.

[56] In a 2D channel volume $V=h \times w \times l$, where $h, w, l$ is the height, width and length of the channel; $h=50 \mathrm{~nm}, w=400 \mathrm{~nm}, l=50 \mu \mathrm{m}$. In order to have one molecule in this volume, concentration $C$ of solution should be: $C=1 /\left(1000 \times V \times N_{A}\right)=1.7 \mathrm{nM} . N_{A}$ is Avogadro number $\left(N_{A}=6.02 \times 10^{23} \mathrm{~mol}^{-1}\right)$. 


\section{Chapter 3}

\section{Wafer-scale thin encapsulated two-dimensional nanochannels and its application toward visualization of single molecules}

We present a new and simple approach to fabricate wafer-scale, thin encapsulated, twodimensional nanochannels by using conventional surface-micromachining technology and thin-film evaporation. The key steps to the realization of two-dimensional nanochannels are a fine etching of a sacrificial layer to create underetching spaces at the nanometer regime, and an accurate thin-film evaporation for encapsulation. Well-defined cross-sectional, encapsulated nanochannel arrays with dimensions as small as $20 \mathrm{~nm}$ in both width and height have been realized at the wafer-scale. The fabricated nanochannels with a channel length of $10 \mathrm{~mm}$ have been used as a suitable fluidic platform for confining a solution containing nanomolar concentrations of Alexa fluorescent molecules. Initial results toward visualization of single Alexa molecules in the confined solution are reported.

This chapter is based on the paper "Wafer-scale thin encapsulated two-dimensional nanochannels and its application toward visualization of single molecules. J. Colloid Interf. Sci. 2012, 367 (1), 455-459”. 


\subsection{Introduction}

Generally, nanochannels with either width or depth in the nanometer range $(1-100 \mathrm{~nm})$ are defined as one-dimensional nanochannels (1D NCs), while channels with both dimensions in the nanometer range are defined as two-dimensional nanochannels (2D NCs). NCs provide a novel tool for studying new phenomena and properties of fluids at the nanometer scales, and thus possibly new applications in diverse fields, ranging from nanofluidics to nanochemistry, nanomedicine, and nanobiotechnology [1-5]. Especially, synthetic NCs are vital platforms for experimental research in nanofluidics, concerning the behavior, manipulation, and control of fluids confined to nanometer dimensions. Fluids confined in these structures exhibit physical behaviors not observed in larger structures, such as those of micrometer dimensions and above, because the characteristic physical scaling lengths of the fluid, e.g. Debye length, hydrodynamic radius [6-7], are closely coincided with the dimensions of the nanostructure itself. For example, confinement of matters on the nanometer scale induces phase transitions that are different from the ones observed in bulk systems [8], or a supercooling of almost $20 \%$ below the bulk freezing point is reported for liquid oxygen in the pore or channels with diameter of $2.2 \mathrm{~nm}$ [9]. A similar relationship holds for the boiling-point elevation in pores, and the relation in that case turns out to be a combination of the Clausius-Clapeyron and Kelvin equations. The Kelvin equation predicts that the boiling temperature for water in pores a few nm wide may rise to above $300{ }^{\circ} \mathrm{C}[10-11]$.

In the newly emerging field of nanobiotechnology, NCs have been also powerful tools in manipulation and analysis of vital biomolecules such as DNA and proteins etc. [12-13]. In commonly used fluorescence experiments for biochemical reaction and analysis, the utilization of 2D NCs with an ability to separate, isolate, and investigate a small number of molecules in a nanoscale-confined environment offers several essential advantages such as: a little consumption of expensive analytical agents; a small observed confocal volume enabling single-molecule experiments at relatively high concentrations; and a significant reduction of background signal. These advantages may allow accurate recording and observation of extremely small signals from biological samples at the desired single-molecule level [4]. More fundamental research and promising applications of NC-based devices have been recently reviewed by Eijkel et al., Han et al., and others [14-20].

Until now, several methods have been reported for the fabrication of NCs in various materials, including silicon, glass and even polymeric substrates. Generally, we may divide the reported NC fabrication techniques into two major approaches: (1) the use of sacrificial 
layers, which is also referred to as surface micromachining; and (2) constructing the NCs in the bulk of the substrate itself, which is referred to as bulk micromachining. With surface micromachining, NCs can be made using nanometer-thick sacrificial layers and nanowires defining the male form of the $\mathrm{NCs}$, followed by removal in order to open the aperture [21-22]. Tas et al. [22] adhered a top capping (polysilicon) layer to the substrate after the removal of a sacrificial strip to form NCs with a width around $100 \mathrm{~nm}$. Generally, utilization of surface micromachining offers several advantages such as: (1) its relatively simple and inexpensive; and (2) only a submicron film separates the biomolecule containing solutions inside NCs and the device surface, allowing accurate observation and interpretation of the experiments. However, the surface-micromachining approach also poses several inherent limitations. For example, a diffusion-limited removal of the sacrificial layer in NCs is very time consuming, e.g. channels $0.64 \mathrm{~mm}$ long required $15 \mathrm{~h}$ of etching [22]. To reduce the etching time, dedicated irrigation holes for the etchant have to be made [23], or heat decomposable polymers need to be used as the sacrificial layer [24]. Also, etchants and reactants may remain inside the (long) channels after the etching step, potentially posing undesirable influences on the subsequent experiments. The technique reported by Tas et al. [22] avoids the above mentioned problems because the sacrificial layer is removed from sideward. However, as the capping layer should be made long enough for being pulled down to the bearing substrate, this thus implies a difficulty to realize very narrow NCs, i.e. channels with widths smaller than $100 \mathrm{~nm}$.

In the second NC-fabrication approach of using bulk micromachining, nanolithographic techniques such as focused ion beam (FIB) lithography [25-26], electron beam lithography (EBL) [27], and nanoimprint lithography (NIL) [28] are first used to create NC patterns on a polymeric film, previously spin coated on bearing wafers. Then, wet chemical etching or reactive ion etching is used to transfer the patterns from the polymeric film into nanometer width recesses on the substrates. To enclose the bulk-machined NCs, bonding and sealing with another capping substrate has to be performed. Although NCs with two dimensions down to $10 \mathrm{~nm}$ have been successfully fabricated, main drawbacks are the high costs and low throughput of the involved nanolithography patterning. Recently, several innovative fabrication methods have been reported for the fabrication of sub-10 nm NCs. However, the utilized fabrication techniques are expensive and involve complex steps [28-29]. Generally speaking, although NCs can now be fabricated by various reported approaches, a simple 
method to fabricate thin encapsulated, very narrow 2D NCs at the wafer-scale is still very desirable.

In this chapter we present a new but simple approach to fabricate the desired 2D NCs by using conventional surface-micromachining technology and thin-film evaporation. The essences of the method are a fine etching of a sacrificial layer to form underetching spaces at the nanometer regime, and accurate thin film evaporation for encapsulation. In this way, welldefined cross-sectional, thin encapsulated, very narrow NC arrays with dimensions as small as $20 \mathrm{~nm}$ in both width and height have been successfully realized at the wafer-scale length. The initial research results toward confining and visualization of single fluorescent molecules in the fabricated channels are reported.

\subsection{Fabrication of thin encapsulated, 2D nanochannels}

The process steps for fabrication of the NCs are shown in figure 3.1, and are as follows: a 4in., $<100>-\mathrm{Si}$ wafer (step 1) is coated with $35 \mathrm{~nm}$ of thermally grown silicon oxide $\left(\mathrm{SiO}_{2}\right)$ (dry oxidation) (step 2) and $30 \mathrm{~nm}$ of low-stress silicon-rich nitride (SiRN) (step 3) layers by means of low-pressure chemical vapor deposition (LPCVD). Conventional lithography is carried out to open a pattern on photoresist (step 4), followed by reactive ion etching $\left(\mathrm{CHF}_{3}+\right.$ $\mathrm{O}_{2}$ ) of $\mathrm{SiRN}$ and $\mathrm{SiO}_{2}$ layers (step 5). The etching procedure is stopped when the bearing silicon substrate is over etched a little. Afterwards, the photoresist layer is removed and the sacrificial layer of $\mathrm{SiO}_{2}$ is etched in $1 \% \mathrm{HF}$ solution at an etching rate of about $2.5 \mathrm{~nm}$ per minute to create underetching of the SiRN layer to form nanospaces (step 6). Subsequently, dry oxidation is performed at $950{ }^{\circ} \mathrm{C}$ for $7 \mathrm{~min}$ to grow $10 \mathrm{~nm} \mathrm{SiO}_{2}$ to create hydrophilic surfaces for filling. Then, a $200 \mathrm{~nm}$ thick $\mathrm{SiO}_{2}$ layer is deposited by using e-beam evaporation (step 7) at an evaporated rate of $0.8 \AA . \mathrm{s}^{-1}$ to seal the nanospaces, thus forming the encapsulated NCs. Also during this evaporation process, entries and exits of the channels are created using a simple micromachined shadow mask to protect intended area from being closed by the evaporated material.

Figure 3.2 is a high resolution scanning electron microscopy image (HRSEM: LEO Gemini 1550, $2 \mathrm{~nm}$ lateral resolution) of the fabricated NCs. As shown, the obtained NCs are very small with dimensions of around $20 \mathrm{~nm}$ by $40 \mathrm{~nm}$ and with an almost rectangular cross section due to our advanced combination of dry etching and wet etching of $\mathrm{SiO}_{2}$ (steps 5-6). Practically, etchant (HF) diffuses, thus etching $\mathrm{SiO}_{2}$, a little faster at an interface between LPCVD SiRN/SiO 2 than that of high temperature thermally grown $\mathrm{SiO}_{2} / \mathrm{Si}$. This issue is 


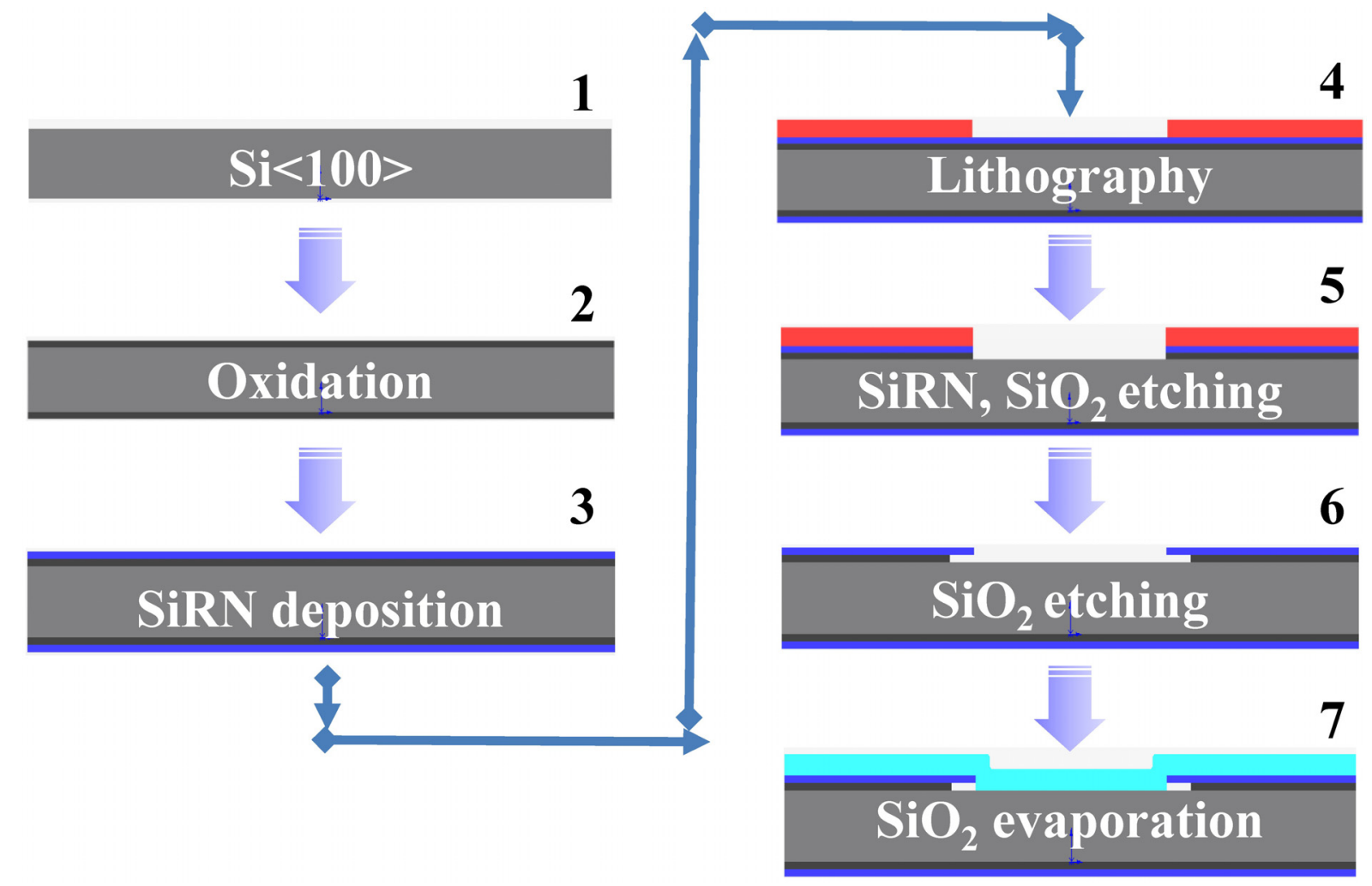

Figure 3.1. Process outline for fabrication of $2 D$ nanochannels (details of processing steps in appendix 3.1).

normally neglected in fabrication of large cross-sectional NCs, but should be taken into account when one would like to realize very narrow 2D NCs with a really well-defined cross section. Moreover, by varying the $\mathrm{SiO}_{2}$ evaporated angles we obtain NCs with different and smaller cross sections. For instance, upper inset in figure 3.2 shows an almost triangle shaped cross-sectional NC with effective dimension of ca. $20 \mathrm{~nm}$, realized by performing the evaporation of $\mathrm{SiO}_{2}$ at an angle of ca. $30^{\circ}$. According to our best knowledge, this is one of the smallest 2D NCs that could have been simply and directly fabricated by using the surfacemicromachining strategy so far. In our approach, the channel depth is controlled by the thickness of the thermal silicon oxide, which can be in a range of few nanometers [16]. While the channel width, the essential parameter needs for being well controlled at nanometer regime, is controlled by a combination of a slow and accurate etching of the sacrificial $\mathrm{SiO}_{2}$ with a well-determined position of the arrived evaporation $\mathrm{SiO}_{2}$ [31]. For example, detailed analysis of images of figure 3.2 shows that the difference between the designed arrived positions and the as-deposited positions of the evaporated $\mathrm{SiO}_{2}$ is only of ca. $5 \mathrm{~nm}$ (figure 3.3). This difference is caused by several reasons such as: (1) practically experimental errors in predetermine the thickness of the sacrificial $\mathrm{SiO}_{2}$, the widths of the nanospaces, and the 




Figure 3.2. A $20 \mathrm{~nm}$ deep and $40 \mathrm{~nm}$ wide nanochannel made with a $35 \mathrm{~nm}$ sacrifical $\mathrm{SiO}_{2}$ film and capped by a layer of $200 \mathrm{~nm}$ of e-beam evaporation $\mathrm{SiO}_{2}$, evaporated at a setup angle of $0^{\circ}$ (scale bar: $100 \mathrm{~nm}$ ). Upper inset, a triangle cross-sectional nanochannel with dimension of around $20 \mathrm{~nm}$, sealed by evaporated $\mathrm{SiO}_{2}$ at the angle of $30^{\circ}$ (scale bar: $20 \mathrm{~nm}$ ). In both images, the channel depth is smaller than the thickness of the sacrificial $\mathrm{SiO}_{2}$ layer due to the formation of the $\mathrm{SiO}_{2}$ layer created in the second oxidation step.

evaporation angles; (2) deposition of $\mathrm{SiO}_{2}$ material into the nanospaces due to reflection and scattering from the overhanging $\mathrm{SiRN}$; and (3) a diffusion of the arrived evaporated $\mathrm{SiO}_{2}$ on the wafer surface [31], which also migrates $\mathrm{SiO}_{2}$ into the nanospaces. However, because the utilized $\mathrm{SiO}_{2}$ evaporation beam has low kinetic energy [30-31], thus restricting the reflection, scattering and diffusion of $\mathrm{SiO}_{2}$ within a few nm distance, e.g. ca. $5 \mathrm{~nm}$ as observed in our experiments (figure 3.3) can be reached, therefore allowing a realization of well-defined cross-sectional and narrow NCs.

We also tried to cap the created nanospaces by using sputtering technique, but the arrived sputter materials have relatively high energies [30-31], thus a total effect of several processes like reflection, scattering, and diffusion of the sputtered materials clogged the nanospaces completely. Han et al. [16], also created nanospaces by surface-micromachining technique, but used plasma-enhanced chemical vapor deposition (PECVD) to deposit $\mathrm{SiO}_{2}$ for capping the nanospaces to form NCs. Probably, difficulties in accurate control at nanometer-scale of the arrived positions of the $\mathrm{PECVD} \mathrm{SiO}_{2}$ (due to its relatively high kinetic energy and high 


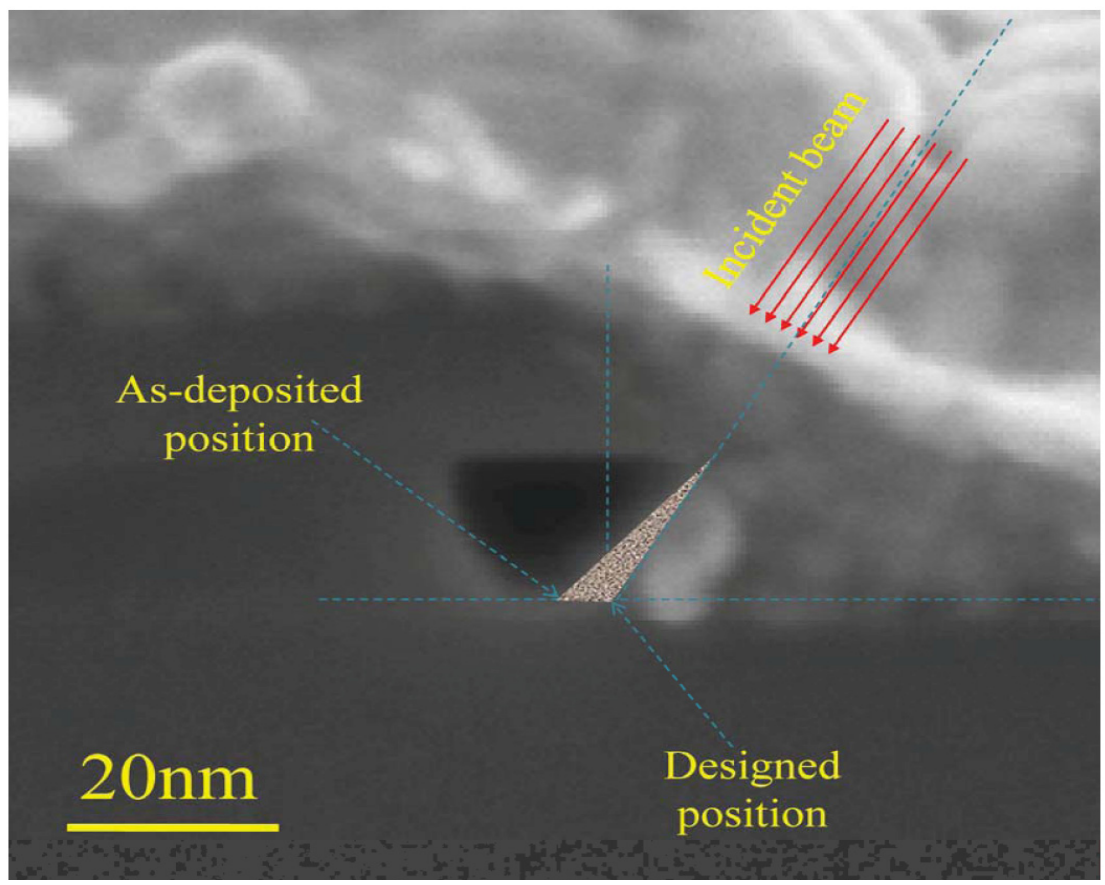

Figure 3.3. A small difference of ca. $5 \mathrm{~nm}$ between the designed arrived positions and the as-deposited positions of the evaporated $\mathrm{SiO}_{2}$. This difference caused by several factors, including reflection, scattering, and diffusion etc., of the evaporation beam. The use of evaporation technique with a low kinetic energy of the evaporated beam helps to restrict the total undesirable closing effect to within a few $\mathrm{nm}$, allows the successful creation of well-defined and narrow cross-sectional nanochannels.

substrate temperatures [30]) resulted in NCs with channel widths of $100 \mathrm{~nm}$ or larger [16, 20].

Besides the capability of simple realization of narrow 2D NCs with well-defined cross sections, other advantages of our channel fabrication approach are that: (1) the realized NCs are sealed by a relatively thin $\mathrm{SiO}_{2}$ layer, which is a favorable condition for accurate signal recording and direct observation of experimental phenomena taken place inside the channels; (2) the reported process can be modified to produce 2D NCs on various substrates like quartz and glass etc., thus providing $\mathrm{NC}$ availability in various materials for meeting diverse research requirements; and (3) the planar format of the reported channels is very suitable for the integration of analytical tools that can be scaled, using modern fabrication tools, to match the dimensions of the NCs.

\subsection{Fabricated nanochannels toward visualization of single molecules}

Visualization or observation of single molecules is very important in many fields such as molecular dynamics, chemical analysis, DNA sequencing, and clinical diagnostics. It offers 
new insights into behavior of molecules and interactions between molecules that was previously only possible by indirect approaches [33-37]. However, visualization of single molecule fluorescence is complicated by the presence of an enormous number of individual solvent molecules, and noises from the measurement itself [29, 32-34, 37]. Therefore, it is essential to develop detection methods that provide an increase in signal-to-noise ratio. 2D NCs with the ability to spatially separate, isolate, and investigate a small number of molecules in an extremely small volume or nanoscale-confined environment may be a suitably analytical platform for single-molecule observation. Here, we report initial results of utilizing the fabricated $2 \mathrm{D} \mathrm{NCs}$ as a confined platform toward observation of single molecules in the confined (static) solution. The channel chips containing an array of one hundred of 2D NCs with $10 \mathrm{~mm}$ length, $20 \mathrm{~nm}$ height and $40 \mathrm{~nm}$ width were used in all the reported experiments. Polydimethylsiloxane (PDMS) structures were prepared by SU-8 moulding and sealed irreversibly to the access openings to serve as liquid reservoirs.

First of all, the fabricated NCs were tested for its hermetic to liquid; the fabricated 2D NCs were filled with a solution of $1.33 \mathrm{mM}$ fluorescein sodium (Sigma-Aldrich, St. Louis, MO) and observed by a $40 \times$ objective in a DM Leica microscope. In our experiment the interface movements of the liquid flow could not be dynamically observed because of the high magnification used and very small cross section $(20 \mathrm{~nm} \times 40 \mathrm{~nm})$ but an interface between bright and dark areas [38] of channel sections was clearly observed after filling experiment (see figure 3.4A). Basic functioning of the fabricated 2D NCs is proven by the filling of the fluorescent solutions.

\subsection{Visualization of single Alexa molecule in confined channels}

For observation of fluorescent signals from molecules confining inside the NCs, an upgraded inverted fluorescence microscope (Zeiss, Axiovert, Oberkochen, Germany) with a $100 \times, 1.20$ NA, water-immersion objective (Leica Planachromat, Wetzlar, Germany) was used. For excitation, $488 \mathrm{~nm}$ Argon laser line with excitation intensity of about $100 \mathrm{~W} . \mathrm{cm}^{-2}$ was focused into the NCs and detection of fluorescence intensities was performed using an aircooled intensified CCD camera (Pentamax, Roper Scientific, NJ). A 525/50 nm band pass emission filter and a notch filter were used to remove residual excitation intensities. Images 

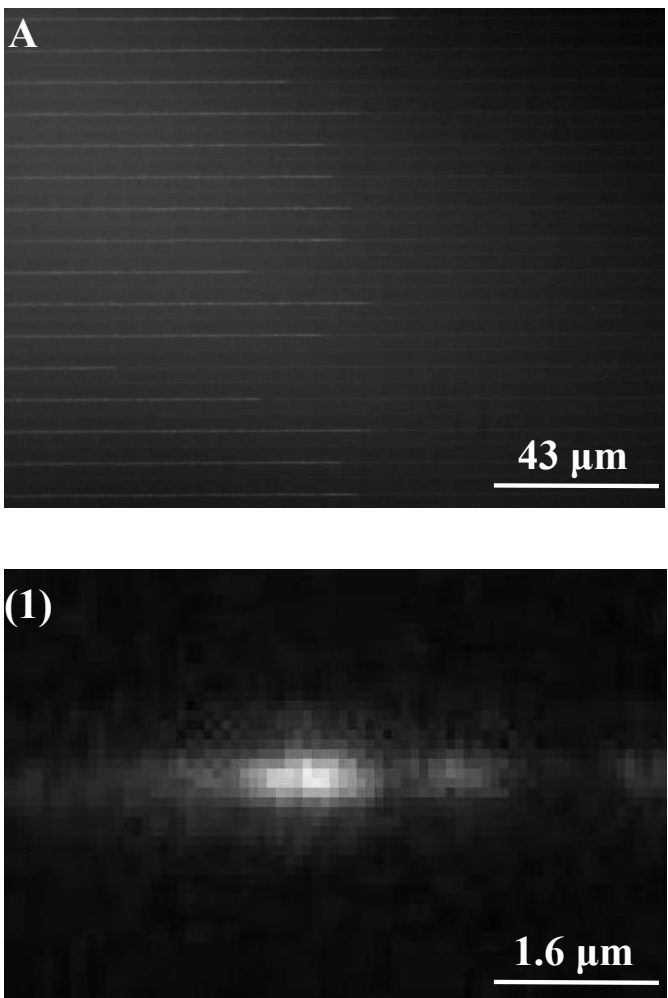


Figure 3.4. Fluorescence intensity images of fluorescent molecules filled in nanochannels. (A) $1.33 \mathrm{mM}$

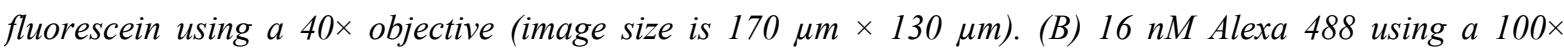
objective (image size is $32 \mu \mathrm{m} \times 24 \mu \mathrm{m}$ ). (1), (2) Magnification of areas indicated by dashed boxes in figure $3.4 B$ (image size is $6.8 \mu \mathrm{m} \times 4.5 \mu \mathrm{m}$ ).

of $50 \mu \mathrm{m} \times 50 \mu \mathrm{m}(512$ pixels $\times 512$ pixels $)$ were recorded using the WinSpec 32 program (Roper Scientific). Sequential images were acquired at a rate of 5 frames per second.

A $16 \mathrm{nM}$ Alexa Fluor 488 (Alexa molecules with ca. $1.4 \mathrm{~nm}$ diameters from Molecular Probes, Eugene, OR) solution was prepared. In a channel of cross-sectional area $A=800 \mathrm{~nm}^{2}$, this corresponds with eight molecules per $1 \mathrm{~mm}$ channel length. A $4 \mu 1$ drop of fluorescence solution was placed in the PDMS entrance reservoir and solution filled naturally into the channel by capillary forces. The channel chip was then brought for further observation by using the above mentioned microscope for further observation. Normally, it takes ca. $30 \pm 5$ min from the filling moment to the first and clear images to be recorded due to adjusted and focused procedures. Figure 3.4B shows an image of 2D NCs filled with a $16 \mathrm{nM}$ Alexa 488 solution. This image was taken in the strong fluorescent signal region of the channels. Along the NCs, a sequence of bright spots can be seen and magnified in figures 3.4(1) and 3.4(2). The discrete nature of the bright spot in those images might suggest the presence and observation of single molecules. Following this hypothesis, the blurring in the length direction could be caused by Brownian motion during the $200 \mathrm{~ms}$ exposure time. Prolonged 
observation of the bright spots, however, shows that they remain in the same position for at least tens of seconds, which is inconsistent with the presence of mobile single molecules. Additionally, we calculated the integral of the intensities over a sufficient large area around and including the spots. This integral of the emitted light over the observed area shows differences of a factor of three between different spots, which does not support the hypothesis of mobile single molecules. The above mentioned observations point in the direction of pockets liquid separated by air bubbles which can be formed during the capillary filling of small NCs containing sharp corners [39]. The liquid pockets most likely contain multiple molecules, which is quite surprising based on the expected average number of eight molecules per $1 \mathrm{~mm}$ channel length. A possible explanation for the enhanced concentration of Alexa is the adsorption of Alexa at the liquid-air interface. In the traditional picture, the interface is free of ions, however it was shown recently [40] that larger polarizable ions may have a propensity for the interface. The liquid pockets in our experiment are the results of transport through the channel corners, which involves a large surface-to-volume ratio and therefore can contribute the concentration of species that are adsorbed at the interfaces. In future experiments this hypothesis will be further tested.

\subsection{Conclusion}

We have presented a new but simple approach to fabricate wafer-scale, thin encapsulated 2D NCs with both dimensions down to $20 \mathrm{~nm}$. In addition, the fabricated NCs have well-defined cross sections, and are surrounded by the same material. The experiments proved that channels can be filled by capillary action and that fluorescent visualization at concentrations close to the single-molecule level is possible. Finally, the NC fabrication process is entirely based on the planar and conventional silicon technology, thus allowing the possibility of direct integration of the fabricated NCs with other silicon-based components to create complex systems for both fundamental and applied studies in various fields.

\subsection{References}

[1] Sivanesan, P.; Okamoto, K.; English, D.; Lee, C. S.; DeVoe, D. L. Polymer nanochannels fabricated by thermomechanical deformation for single-molecule analysis. Anal. Chem. 2005, 77 (7), 2252-2258.

[2] Wang, K. G.; Yue, S.; Wang, L.; Jin, A.; Gu, C.; Wang, P. Y.; Feng, Y.; Wang, Y.; Niu, H. Manipulating DNA molecules in nanofluidic channels. Microfluid. Nanofluid. 2006, 2 (1), 85-88. 
[3] Stavis, S. M.; Edel, J. B.; Samiee, K. T.; Craighead, H. G. Single molecule studies of quantum dot conjugates in a submicrometer fluidic channel. Lab Chip 2005, 5 (3), $337-343$.

[4] Wang, M.; Jing, N.; Su, C. B.; Kameoka, J.; Chou, C. K.; Hung, M. C.; Chang, K. A. Electrospinning of silica nanochannels for single molecule detection. Appl. Phys. Lett. 2006, 88 (3), 033106.

[5] Wang, Y. M.; Tegenfeldt, J. O.; Reisner, W.; Riehn, R.; Guan, X. J.; Guo, L.; Golding, I.; Cox, E. C.; Sturm, J.; Austin, R. H. Single-molecule studies of repressor-DNA interactions show long-range interactions. Proc. Natl. Acad. Sci. USA 2005, 102 (28), 9796-9801.

[6] Brenner, H. The slow motion of a sphere through a viscous fluid towards a plane surface. Chem. Eng. Sci. 1961, 16 (3-4), 242-251.

[7] Pu, Q.; Yun, J.; Temkin, H.; Liu, S. Ion-enrichment and ion-depletion effect of nanochannel structures. Nano Lett. 2004, 4 (6), 1099-1103.

[8] Gelb, L. D.; Gubbins, K. E.; Radhakrishnan, R.; Sliwinska, M. Phase separation in confined systems. Rep. Prog. Phys. 1999, 62 (12), 1573-1659.

[9] Warnock, J.; Awschalom, D. D.; Schafer, M. W. Geometrical supercooling of liquids in porous glass. Phys. Rev. Lett. 1986, 57 (14), 1753-1756.

[10] Fisher, L. R.; Gamble, R. A.; Middlehurst, J. The Kelvin equation and the capillary condensation of water. Nature 1981, 290 (5807), 575-576.

[11] Gardeniers, H. J. G. E. Chemistry in nanochannel confinement. Anal. Bioanal. Chem. 2009, 394 (2), 385-397.

[12] Han, J.; Craighead, H. G. Separation of long DNA molecules in a microfabricated entropic trap array. Science 2000, 288 (5468), 1026-1029.

[13] Reisner, W.; Beech, J. P.; Larsen, N. B.; Flyvbjerg, H.; Kristensen, A.; Tegenfeldt, J. O. Nanoconfinement-enhanced conformational response of single DNA molecules to changes in ionic environment. Phys. Rev. Lett. 2007, 99 (5), 058302.

[14] Eijkel, J. C. T.; van den Berg, A. Nanofluidics: what is it and what can we expect from it? Microfluid. Nanofluid. 2005, 1 (3), 249-267.

[15] Whitesides, G. M. The origins and the future of microfluidics. Nature 2006, 442 (7101), $368-373$.

[16] Han, A.; de Rooij, N. F.; Staufer, U. Design and fabrication of nanofluidic devices by surface micromachining. Nanotechnology 2006, 17 (10), 2498-2503. 
[17] Perry, J. L.; Kandlikar, S. G. Review of fabrication of nanochannels for single phase liquid flow. Microfluid. Nanofluid. 2006, 2 (3), 185-193.

[18] Austin, R. Nanofluidics: A fork in the nano-road. Nat. Nanotechnol. 2007, 2 (2), 79-80.

[19] Schoch, R. B.; Han, J.; Renaud, P. Transport phenomena in nanofluidics. Rev. Mod. Phys. 2008, 80 (3), 839-883.

[20] Abgrall, P.; Nguyen, N. T. Nanofluidic devices and their applications. Anal. Chem. 2008, 80 (7), 2326-2341.

[21] Desai, T. A.; Hansford, D. J.; Kulinsky, L.; Nashat, A. H.; Rasi, G.; Tu, J.; Wang, Y.; Zhang, M.; Ferrari, M. Nanopore technology for biomedical applications. Biomed. Microdevices 1999, 2 (1), 11-40.

[22] Tas, N. R.; Mela, P.; Kramer, T.; Berenschot, J. W.; van den Berg, A. Capillarity induced negative pressure of water plugs in nanochannels. Nano Lett. 2003, 3 (11), $1537-1540$.

[23] Foquet, M.; Korlach, J.; Zipfel, W.; Webb, W. W.; Craighead, H. G. DNA fragment sizing by single molecule detection in submicrometer-sized closed fluidic channels. Anal. Chem. 2002, 74 (6), 1415-1422.

[24] Li, W.; Tegenfeldt, J. O.; Chen, L.; Austin, R. H.; Chou, S. Y.; Kohl, P. A.; Krotine, J.; Sturm, J. C. Sacrificial polymers for nanofluidic channels in biological applications. Nanotechnology 2003, 14 (6), 578-583.

[25] Alarie, J. P.; Hmelo, A. B.; Jacobson, S. C.; Baddorf, A. P.; Feldman, L.; Ramsey, J. M. Fabrication and evaluation of 2D confined nanochannels. $7^{\text {th }}$ International Conference on Miniaturized Chemical and Biochemical Analysts Systems, CA, USA 2003, 9-12.

[26] Riehn, R.; Lu, M.; Wang, Y. M.; Lim, S. F.; Cox, E. C.; Austin, R. H. Restriction mapping in nanofluidic devices. Proc. Natl. Acad. Sci. USA 2005, 102 (29), $10012-10016$.

[27] Turner, S. W.; Perez, A. M.; Lopez, A.; Craighead, H. G. Monolithic nanofluid sieving structures for DNA manipulation. J. Vac. Sci. Technol. B 1998, 16 (6), 3835-3840.

[28] Xia, Q.; Morton, K. J.; Austin, R. H.; Chou, S. Y. Sub-10 nm self-enclosed self-limited nanofluidic channel arrays. Nano Lett. 2008, 8 (11), 3830-3833.

[29] Sordan, R.; Miranda, A.; Traversi, F.; Colombo, D.; Chrastina, D.; Isella, G.; Masserini, M.; Miglio, L.; Kern, K.; Balasubramanian, K. Vertical arrays of nanofluidic channels fabricated without nanolithography. Lab Chip 2009, 9 (11), 1556-1560.

[30] Ohring, M. The Materials Science of Thin Films, Academic Press: NY 1992. 
[31] Rossnagel, S. M.; Cuomo, J. J.; Westwood, W. D. Handbook of Plasma Processing Technology: Fundamentals, Etching, Deposition and Surface Interactions, Noyes Publications 1990.

[32] Ying, L. Single molecule biology: Coming of age. Mol. BioSyst. 2007, 3 (6), 377-380.

[33] Moerner, W. E. Those blinking single molecules. Science 1997, 277 (5329), 1059-1060.

[34] Tokunaga, M.; Kitamura, K.; Saito, K.; Iwane, A. H.; Yanagida, T. Single molecule imaging of fluorophores and enzymatic reactions achieved by objective-type total internal reflection fluorescence microscopy. Biochem. Biophys. Res. Commun. 1997, 235 (1), $47-53$.

[35] Han, J.; Craighead, H. G. Entropic trapping and sieving of long DNA molecules in a nanofluidic channel. J. Vac. Sci. Technol. A 1999, 17 (4), 2142-2147.

[36] Huang, W. H.; Zinchenko, A. A.; Pawlak, C.; Chen, Y.; Baigl, D. Dynamic conformational behavior and molecular interaction discrimination of DNA/binder complexes by single-chain stretching in a micro-device. Chem. Bio. Chem. 2007, 8 (15), $1771-1774$.

[37] Kumbhakar, M.; Nath, S.; Mukherjee, T.; Mittal, J. P.; Pal. H. Single-molecule detection in exploring nanoenvironments: an overview. J. Photochem. Photobiol. C 2004, 5 (2), $113-137$.

[38] Hoang, T. H. Segers-Nolten, I. M.; Tas, N. R.; van Honschoten, J. W.; Subramaniam, V.; Elwenspoek, M. C. Analysis of single quantum-dot mobility inside 1D nanochannel devices. Nanotechnology 2011, 22, 275201.

[39] van Honschoten, J. W.; Brunets, N.; Tas, N. R. Capillarity at nanoscale. Chem. Soc. Rev. 2010, 39 (3), 1096-1114.

[40] Jungwirth, P.; Tobias, D. J. Ions at the air/water interface. J. Phys. Chem. B. 2002, 106 (25), 6361-6373. 


\section{Chapter 4}

\section{Solution titration by wall deprotonation during capillary filling of 1D silicon oxide nanochannels}

This chapter describes a fundamental challenge when using silicon oxide nanochannels for analytical systems, namely the occurrence of a strong proton release or proton uptake from the walls in any transient situation such as channel filling. Experimentally, when fluorescein solutions were introduced into silicon oxide nanochannels through capillary pressure, a distinct bisection of the fluorescence was observed, the zone of the fluid near the entrance fluoresced, while the zone near the meniscus, was dark. The ratio between the zones was found to be constant in time and to depend on ionic strength, $\mathrm{pH}$ and the presence of a buffer and its characteristics. Theoretically, using the Gouy-Chapman-Stern model of the electrochemical double layer, we demonstrate that this phenomenon can be effectively modeled as a titration of the solution by protons released from silanol groups on the walls, as a function of the $\mathrm{pH}$ and ionic strength of the introduced solution. The results demonstrate the dominant influence of the surface on the fluid composition in nanofluidic experiments, in transient situations such as filling, and changes in solvent properties such as filling, and changes in solvent properties such as the pH or ionic strength. The implications of these fundamental properties of silicon oxide nanochannels are important for analytical strategies and in particular the analysis of complex biological samples.

This chapter is based on the paper "Solution titration by wall deprotonation during capillary filling of silicon oxide nanochannels. Anal. Chem. 2008, 80, 8095-8101". 


\subsection{Introduction}

The fabrication and applications of nanochannels (NCs) have gained considerable interest in the past few years. Using bonding, one-dimensional (1D) NCs are mostly formed by shallow etching of trenches in silicon (or glass) wafers followed by bonding to glass (or silicon) cover wafers to form enclosed channels [1-2]. 2D NCs can be fabricated using nanolithography [3-5], surface and bulk machining [6-7], and electrospinning [8]. NCs are created in various types of materials such as silicon (silicon oxide, silicon nitride), glass, and polymers [9-10]. An extensive review on fabrication was made by Mijatovic et al. [11]

Channels with such small dimensions have interest properties because the extremely high surface to volume ratio, (electrical) interface effects between the fluid and channel wall surfaces become dominant [12]. For example, Pennathur et al. [13-14] described a novel nanoscale electrophoretic separation method in a theoretical and experimental study on the electrokinetic transport in NCs. Pu et al. [15] demonstrated an ion-enrichment and iondepletion effect when an electric field was applied across two reservoirs connected by $60 \mathrm{~nm}$ deep channels.

Less known, the surface chemistry of silicon oxide has a large influence on solutions in NCs. It has been known for a very long time that the silanol groups present on silica are capable of protonating the solution in contact with it. Actually, this effect has been used to assess the presence of silanol groups on silica beads in chromatographic columns via the indicator methyl red which colors red at a $\mathrm{pH}$ below 4.4 [16].

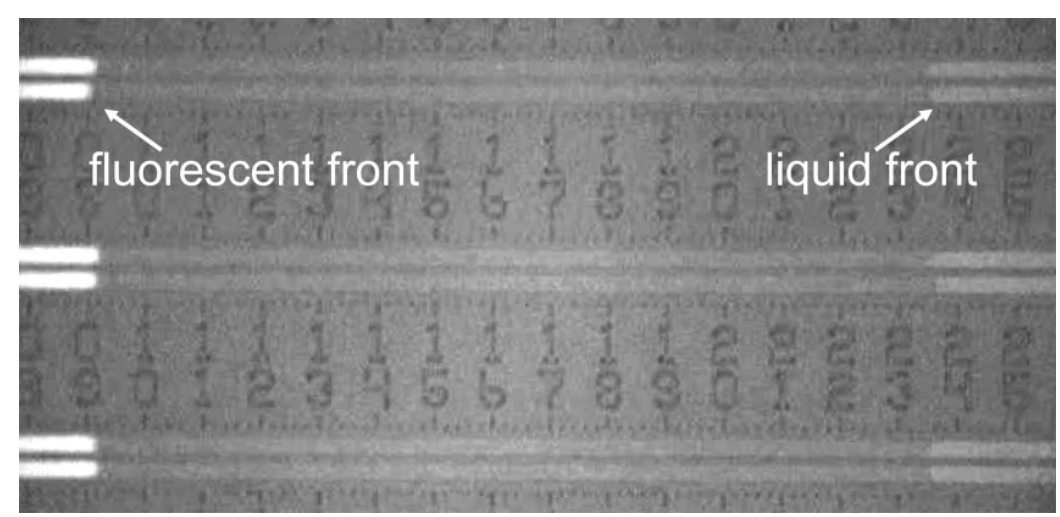

Figure 4.1. Typical image of fluorescence observed in nanochannels during filling. In this experiment, (experiment no. 1 of table 4.1, figure 4.2), the partial filling of parallel channels, $20 \mu \mathrm{m}$ width and $40.5 \mathrm{~nm}$ height, taken at $t=5 \mathrm{~s}$, are shown. From left to right the channel is filling from the reservoir, which is outside the image shown. Fluorescence is observed in the filled zone, from $x=0$ to $x=0.92 \mathrm{~mm}$, but not in the zone from $x=0.92 \mathrm{~mm}$ to $2.36 \mathrm{~mm}$. 

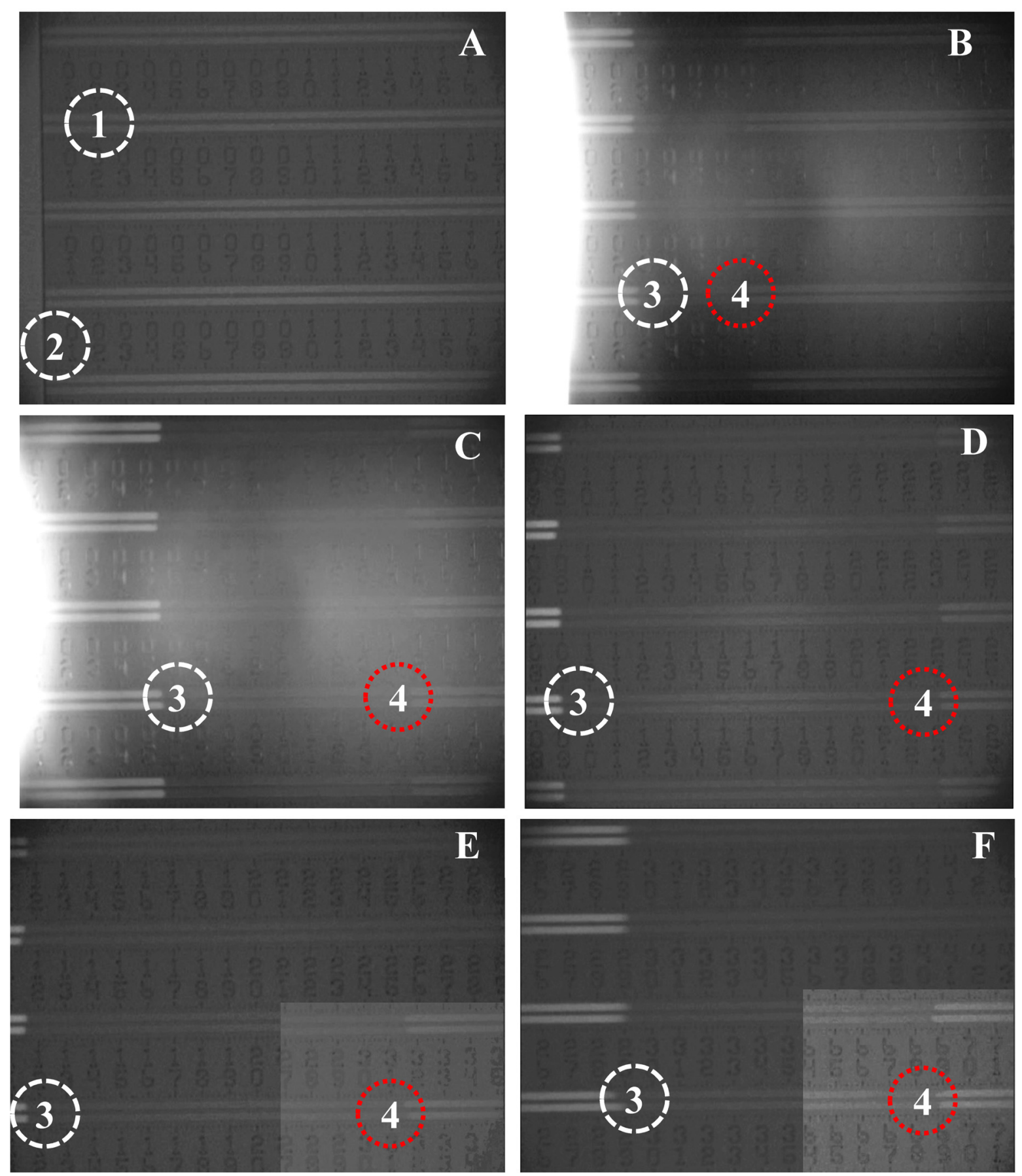

Figure 4.2. Sequence of fluorescence images during filling of a pure fluorescein sodium solution into $50 \mathrm{~nm}$ height and $20 \mu \mathrm{m}$ width nanochannels indicates the increasing of distance $d$ between fluorescence and liquid fronts $\left(d=x_{2}-x_{1}\right)$. (A) Os-image with empty nanochannels before filling. (B) 1 s-image after 1 s filling indicated by very bright fluorescence signals from the microchannel with $d=0.5 \mathrm{~mm}$. (C) 3 s-image with $d=$ $0.9 \mathrm{~mm}$. (D) 5 s-image with $d=1.4 \mathrm{~mm}$. (E) $7 \mathrm{~s}$-image, there is only the fluorescence front and the liquid front out of the image area therefore indicated by an inset figure. (F) 40s-image with $d \sim 4.0 \mathrm{~mm}$ shows fluorescence front and liquid front in an inset figure. (1) Nanochannels. (2) A microchannel. (3) $x_{1}$ position: fluorescence front. (4) $x_{2}$ position: liquid front. 


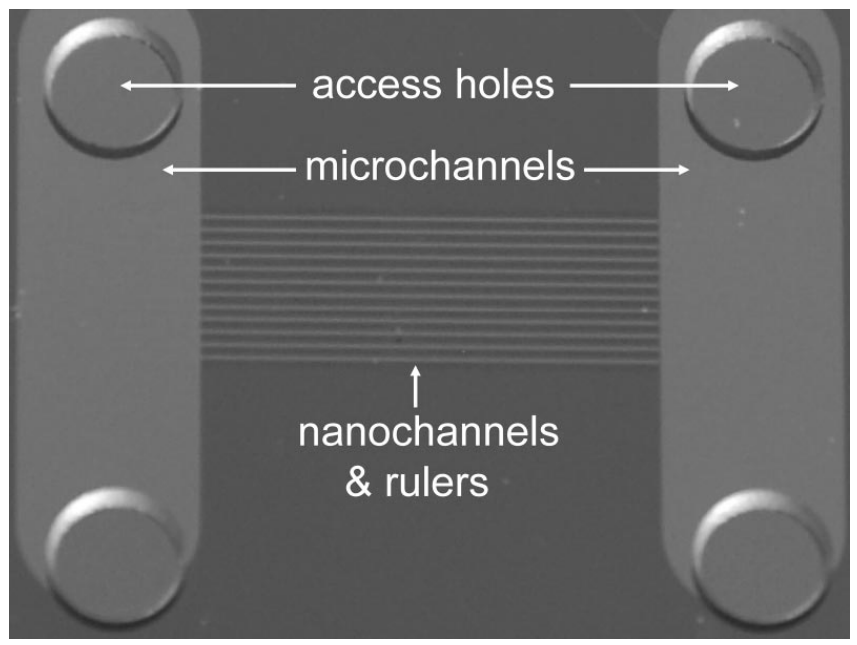

Figure 4.3. Chip layout seen from the top. Vertically, the microchannels connecting the two pairs of access holes can be seen and between them the rulers positioned along the nanochannels are visible. The nanochannels are $50 \mathrm{~nm}$ high and $20 \mu \mathrm{m}$ wide, the microchannels are $20 \mu \mathrm{m}$ high, $15 \mathrm{~mm}$ long, and $4 \mathrm{~mm}$ wide.

\section{General description of the phenomenon and hypothesis}

In this chapter we demonstrate that a solution introduced into an empty silicon oxide $\mathrm{NC}$ is acidified and dissolved substances protonated. For this purpose we measured the fluorescence of solutions of fluorescein, which has a strong $\mathrm{pH}$-dependent fluorescence, introduced in empty channel through capillary pressure. During filling, two distinct zones were observed, with the zone of the solution starting from the entrance showing fluorescence, while in the zone near the flow front no fluorescence was observed, as shown in figure 4.1. Figure 4.2 belonging to this experiment, showing of the $\mathrm{NC}$ and the progression in time of the two zones.

To study this phenomenon in more detail, we varied $p H$, buffer concentration, and ionic strength and determined for various solution compositions the ratio of the lengths of fluorescing and dark zones. From this ratio we calculated the number of proton released per $\mathrm{m}^{2}$ and compared these data with a model based on oxide surface chemistry theory [17] which predicts the amount of released protons. The results obtained describe an effect relevant for nanofluidic experiments because they indicate the influence of the surface chemistry on fluid composition such as the $p H$ and wall charge in transient situations.

\section{Consideration of relevance of other nanochannel effects}

Ion exclusion of the negatively charged fluorescein was first considered as a possible explanation of the observed phenomenon, but discarded since the phenomenon became more 
pronounced with increasing ionic strength. For the same reason also the generation of a streaming potential was discarded as an explanation. Straightforward retention due to adsorption to the wall, as in thin layer chromatography, which could become significant due to the high surface to volume ratio, can also be ruled out. Pennathur et al. [14] in fact demonstrated experimentally that fluorescein effectively travels faster instead of slower through silicon oxide NCs as compared to microchannels, due to exclusion of the negative ion from the double layer. A final argument to support the titration theory is that experiments we performed with a $p H$-insensitive dye (Alexa) showed no significant lagging of the fluorescent front (appendix 4.1).

\subsection{Experimental section}

\subsubsection{Chip manufacture}

Chip devices containing micro- and nanochannels were fabricated based on the approach of Haneveld et al. [2]. NCs and microchannels (including rulers for filling observation) were manufactured in the bottom-side silicon wafers by wet chemical etching and reactive ion etching, respectively. After etching, a dry thermal oxide of $20 \mathrm{~nm}$ thickness was grown on the silicon wafers to ensure adequate surface hydrophilicity for capillary filling of the NCs. The etch depths of the channel structures were measured with a mechanical surface profiler (Veeco Dektak 8, Veeco Instruments Inc., Plainview, NY). The processing of the top-side Borofloat glass wafers consisted of powder blasting of access holes followed by thorough wafer cleaning to remove residue from the abrasive powder blasting particles. Prior to prebonding, the top and bottom wafers were Piranha cleaned. This step was followed by fusion bonding at $400{ }^{\circ} \mathrm{C}$ for $4 \mathrm{~h}$. A layout of the channel structure is shown in figure 4.3; detail processing steps and a process outline for fabrication of NC devices is given in appendices 4.2 and 4.3. Directly prior to the experiments the wafers were conditioned by heating for $2 \mathrm{~h}$ at $400{ }^{\circ} \mathrm{C}$, to ensure identical starting conditions for the experiments.

\subsubsection{Fluorescence measurements}

To probe the $p H$ in NCs, we used the fluorescent activity of disodiumuorescein (SigmaAldrich, St. Louis, MO). Depending on the $p H$, fluorescein can have a double or single negative charge or be neutral; the single negatively charged form has a $p K_{a}$ of 6.68 and the neutral form has an apparent $p K_{a}$ of 4.34 [18]. When molecule is excited at $488 \mathrm{~nm}$ and emission is measured at $514 \mathrm{~nm}$, the molar response of the ions having a valence of -1 is 
Table 4.1. Composition of the solution, the height (h) of the channel, and the measured pH for the various experiments

\begin{tabular}{|c|c|c|c|c|c|c|}
\hline Expt & Tris $\left(\right.$ mol. $\left.L^{-l}\right)$ & $\mathbf{H C l}\left(\mathrm{mol} . L^{-l}\right)$ & $\mathbf{K C l}\left(\right.$ mol. $\left.L^{-l}\right)$ & $\boldsymbol{h}(n m)$ & $p H$ & Meniscus ratio* \\
\hline 1 & 0 & 0 & 0 & 40.5 & 7.3 & 0.420 \\
\hline 2 & 0 & 0 & 0 & 49.0 & 7.4 & 0.589 \\
\hline 3 & 0 & 0 & 0.1 & 48.0 & 7.1 & 0.784 \\
\hline 4 & 0 & 0 & 0.1 & 49.0 & 7.2 & 0.771 \\
\hline 5 & 0 & 0 & 0.2 & 52.8 & 7.2 & 0.803 \\
\hline 6 & 0 & 0 & 0.2 & 44.0 & 7.1 & 0.823 \\
\hline 7 & 0 & 0 & 0.5 & 47.8 & 7.1 & 0.832 \\
\hline 8 & 0 & 0 & 0.5 & 47.0 & 7.0 & 0.857 \\
\hline 9 & 0.2 & 0.073 & 0 & 50.0 & 8.6 & 0.296 \\
\hline 10 & 0.2 & 0.073 & 0 & 50.3 & 8.4 & 0.268 \\
\hline 11 & 0.2 & 0.073 & 0.1 & 49.8 & 8.4 & 0.267 \\
\hline 12 & 0.2 & 0.073 & 0.2 & 50.3 & 8.4 & 0.292 \\
\hline 13 & 0.2 & 0.073 & 0.5 & 45.5 & 8.5 & 0.313 \\
\hline 14 & 0.2 & 0.073 & 0.5 & 48.4 & 8.4 & 0.352 \\
\hline 15 & 1 & 0.364 & 0 & 49.5 & 8.5 & 0.082 \\
\hline
\end{tabular}

*Meniscus ratio is defined by difference between liquid meniscus and fluorescence meniscus over liquid meniscus

only $5.7 \%$ and that of the neutral form $0.8 \%$ in comparison to the ion having valence -2 [19]; therefore the emission can be used as an indicator of the local $\mathrm{pH}$.

Measurements were done on a fluorescence microscope (Leica DM LM, Wetzlar, Germany), using a $100 \mathrm{~W}$ mercury lamp, an I3 filter cube, a $510 \mathrm{~nm}$ dichromatic mirror. Movies were taken with a CCD camera to record the movement of the solutions entering the empty NCs and analyzed using Pinnacle software (Pinnacle, Mountain View, CA). From the parallel channels one was selected for measurement, as differences between parallel channels were small (see figure 4.1) (more detail about fluorescence experimental setup and data analysis in appendices 4.4 and 4.5). 


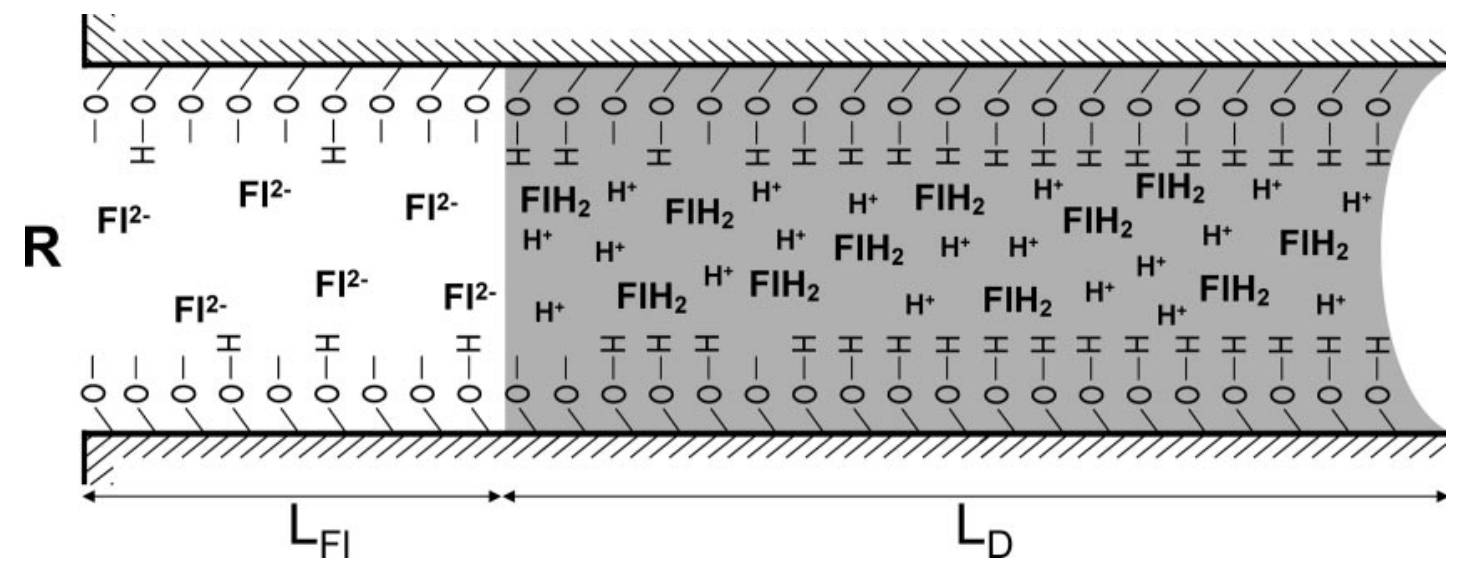

Figure 4.4. Axial cross-section of a filling nanochannel. $R$ indicates the reservoir from which the nanochannel is filled. $L_{F l}$ and $L_{D}$ correspond to the fluorescent and dark zone of the channel, respectively. In the fluorescent zone the $\mathrm{pH}$ is that of the introduced solution where fluorescein is present mainly as doubly charged anions $\left(\mathrm{Fl}^{-}\right)$. The fluid in the dark zone contains an excess of protons, with $\mathrm{pH}=p H_{p z c}$ and fluorescein is mainly present as the uncharged fluorescein molecule $\left(\mathrm{FlH}_{2}\right)$, having negligible fluorescence.

\subsubsection{Composition of the introduced solutions}

To buffer the solutions, 2-amino-2-(hydroxymethyl)propane-1,3-diol (TRIS) was used, having a $p K a$ of 8.06 (Merck \& Co., Inc., Whitehouse Station, NJ). To influence the ionic strength, various amounts of potassium chloride $(\mathrm{KCl})$ (Sigma-Aldrich) were added. The composition of the solutions introduced in the channels were all made in deionized water $(0.7$ $\mu \mathrm{S} . \mathrm{cm}^{-1}$ ) and are described in table 4.1 .

\subsection{Theory}

\subsubsection{Capillary filling}

The walls of the NCs in the chip device are assumed to have hydrophilic silanol groups. When liquid comes into contact with such a $\mathrm{NC}$, the liquid is pulled into the empty channel by capillary forces creating a pressure gradient $\triangle P(\mathrm{~Pa})$,

$\Delta P=-2 \gamma \cos \theta / h$

with $\gamma$ the gas liquid surface tension $\left(\mathrm{N} . \mathrm{m}^{-1}\right), \theta$ - the contact angle, and $h$ - the channel height. The position, $x(\mathrm{~m})$, of the liquid front in a $\mathrm{NC}$ at any point in time, $t(\mathrm{~s})$, is given in accordance with the Washburn equation for a rectangular channel with the condition: width $>>$ height $[20-21]$,

$x=\sqrt{\frac{\gamma h t \cos \theta}{3 \mu}}$ 
where $\mu$ is the viscosity (Pa.s).

\subsubsection{Experimental amount of protons released}

We explain the phenomenon observed in figure 4.4, as follows. As the aqueous solution is introduced into the $\mathrm{NC}$ from the reservoir, protons are released from channel walls into the solution, lowering the $\mathrm{pH}$ as well as protonating compounds in the solution. When the fluid came along the channel, the front of the fluid continuously comes into contact with a new section of the wall, with which it anew establishes equilibrium, again taking up protons. This process continues until the fluid in the liquid front reaches a $\mathrm{pH}$ corresponding to the point of zero charge (pzc) of $\mathrm{SiO}_{2}$, which is on the order of $\mathrm{pH}_{p z c}=2-3$. At a $\mathrm{pH}$ of the fluid below this $p H_{p z c}$ the wall will no longer release protons. On the other hand, the zone of fluid behind the front comes into contact with a wall already in equilibrium with a solution of this composition. As a result, the fluorescein is no longer protonated, and the zone near the entrance will maintain its fluorescent activity (see figure 4.4).

We assume infinitely fast (de)protonation reactions ( $\propto$ fs) and we calculated the diffusion time, from the wall to the center of the channel, using Einstein-Smoluchowski [22], to be 35 ns. Therefore, for our experiments we assume the onset of radial equilibrium due to the small dimension of the channel to be infinitely fast. The time scale of the axial diffusion of protons ( $\propto 1000 \mathrm{~s}$ for an average diffusion distance of half the channel length) is one order of magnitude larger than the time scale of filling the channel ( $\propto 100 \mathrm{~s}$ ). For our calculations we will assume that the $p H$ change from that of the introduced solution to the $p H_{p z c}$ occurs abruptly at the fluorescent front. In part 4.4 we will show the validity of this assumption based on experimental results.

We denote the length of the fluorescent and dark zone as $L_{F l}$ and $L_{D}$ respectively as shown in figure 4.4. The protons released from the walls in the fluorescent zone of the channel are responsible for protonating the fluorescein in the dark zone, so that $L_{F l}$ can be used to deduce

the released number of protons, $N_{H_{\text {released }}^{+}}$via

$$
N_{H_{\text {released }}^{+}}=N_{S} \Theta^{-} L_{F l} 2(h+w)
$$

where $\Theta^{-}$is the fraction of the charged surface groups that is negatively charged, $N_{S}$ is the total number of $\mathrm{SiOH}$ sites, taken to be $4.6 \times 10^{18}$ groups per $\mathrm{m}^{2}$ [23], $h$ (in $\mathrm{m}$ ) is the measured height, and $w$ (in $\mathrm{m}$ ) is the width of the channel; see also table 4.2 for a description 
Table 4.2. Constants and parameters used in fitting the data

Constants Description

\begin{tabular}{ll}
\hline \hline$q$ & Elementary charge \\
$k$ & Boltzmann's constant \\
$\varepsilon_{0}$ & Permittivity of free space \\
$N_{A}$ & Avogadro's constant
\end{tabular}

\section{Experimental variables}

T Temperature

$\varepsilon \quad$ Relative permittivity of water

$N_{S} \quad$ Silanol groups per $\mathrm{m}^{2}$

$h \quad$ Measured channel height

$p_{B} \quad$ Measured bulk $p H$ of introduced solutions

$L_{D} \quad$ Length of dark zone

$L_{F l} \quad$ Length of fluorescent zone

\section{Calculated variables}

$p H_{S} \quad$ Calculated $p H$ at the surface

pHpzc $\quad$ pH at point of zero charge of $\mathrm{SiO}_{2}$

$n^{0} \quad$ Ionic strength in the bulk

$B_{S} \quad$ Required protons to titrate from $p H_{B}$ to $p H_{p z c}$, includes fluorescein, and any buffer, mol. $\mathrm{m}^{-3}$

$\mathrm{NH}_{\mathrm{exp}}^{+} \quad$ Amount of protons released per $\mathrm{m}^{2}$ of wall

$\Psi_{0} \quad$ Surface potential in $V$, calculated with fitted variables and table 4.1

$\phi_{2} \quad$ Potential at the Stern plane in $V$ calculated with fitted variables and table 4.1

$\sigma_{0} \quad$ Surface charge in C.m ${ }^{-2}$, calculated with fitted variables and table 4.1

$N_{H_{\text {theory }}^{+}} \quad$ Theoretical amount of released protons per $\mathrm{m}^{2}$ of wall
Value

$1.6022 \times 10^{-19} \mathrm{C}$
$1.38 \times 10^{-23} \mathrm{~J} . \mathrm{K}^{-1}$
$8.8542 \times 10^{-12} \mathrm{C}^{2} \cdot \mathrm{N}^{-1} \cdot \mathrm{m}^{-2}$
$6.022 \times 10^{23} \mathrm{~mol}^{-1}$

\section{Remarks}

$297 \mathrm{~K}$

80 , in presence of salt

$4.6 \times 10^{18}[23]$

Table 4.1

Table 4.1

Figure 4.5

Figure 4.5

Equation 4.9

Average of $p K_{a 1} \& p K_{a 2}$

$\mathrm{m}^{-3}$, derived from table 4.1

Derived from table 4.1 and $p H_{p z c}$

Calculated from experiment, equation 4.5

Solved numerically [28]

Solved numerically [28]

Solved numerically [28]

Derived from $\sigma_{0}$ equation 4.16

\section{Fitted variables}

$p K_{a l} \quad$ Dissociation constant equation 4.6

Chosen as -1.9 for the fitting of figure 4.8

$p K_{a 2} \quad$ Dissociation constant equation 4.7

Fitted

$C_{\text {Stern }}$

Stern capacitance in F.m ${ }^{-2}$, affects $N_{H_{\text {theory }}^{+}}$, equation 4.16

Fitted 


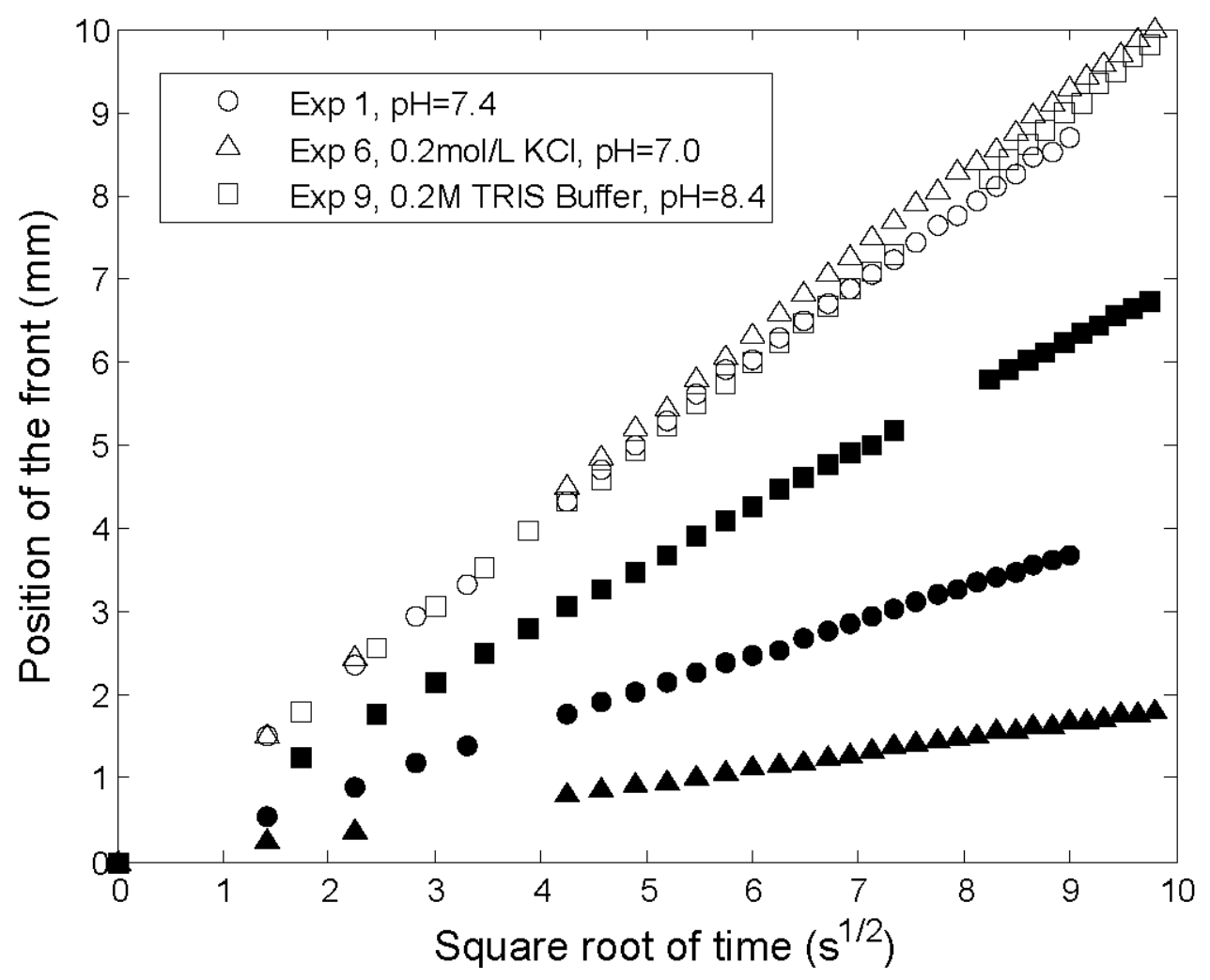

Figure 4.5. Position of the meniscus (empty symbols) and the fluorescent front (filled symbols) versus the square root of time for experiments 1, 6, and 9. All graphs could be linearly fitted using a least-squares method with a value of $R^{2}>0.99$.

of the general variables in the equations.

The amount of protons absorbed by the solution in the dark zone $\left(L_{D}\right), N_{H_{\text {absorbed }}^{+}}$, can then be expressed using the number of protons necessary to change the $p H$ from its initial value to the point of zero charge, $B_{S}\left(\right.$ in mol.m $\mathrm{m}^{-3}$ ), as

$N_{H_{\text {absorbed }}^{+}}=N_{A} B_{S} L_{D} h w$

with $N_{A}$ Avogadro's constant. $B_{S}$ includes the concentration of protons needed to protonate fluorescein and the concentration required to establish a $p H$ equal to $p H_{p z c}$. If a buffer is present, the concentration of protons needed to protonate the buffer is calculated based on the composition according to table 4.1. e.g., 0.2 mol. $\mathrm{L}^{-1}$ Tris buffer brought to $p H 8.4$ with 0.072 mol. $\mathrm{L}^{-1} \mathrm{HCl}$ required $0.128 \mathrm{~mol} . \mathrm{L}^{-1}$ of protons. 


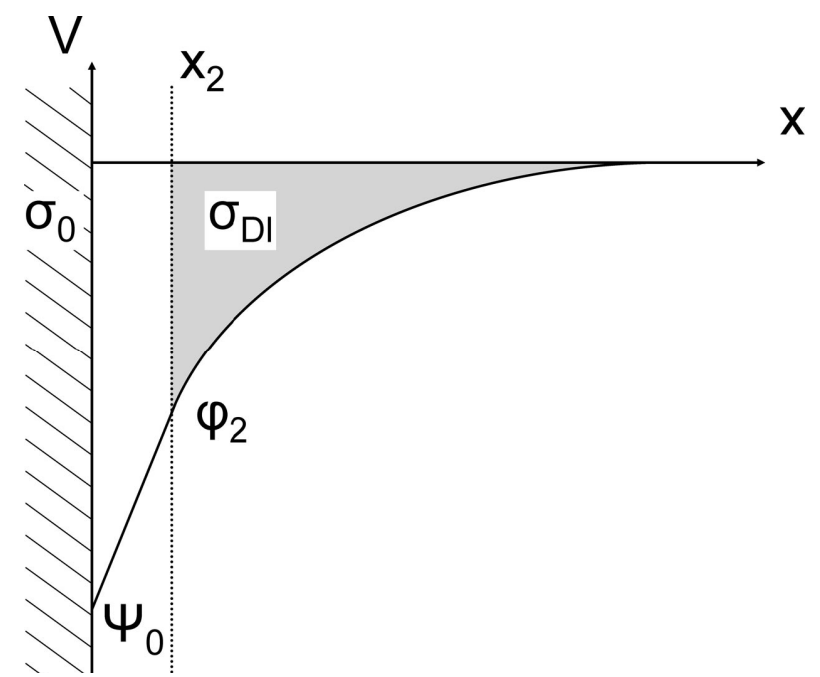

Figure 4.6. Schematic representation of potential V versus the distance $x$ from the silicon oxide wall. $\Psi_{0}$ is the potential at the wall. $x_{2}$ is the position of the Stern plane, the plane of closest approach of ions towards the surface, having the potential $\phi_{2}$. The region from the wall to the Stern plane is called the Stern layer. $\sigma_{0}$ (equations 4.8 and 4.13) indicates the surface charge per $m^{2}$ from deprotonated silanol groups at $x=0 . \sigma_{D l}$ is the countercharge to $\sigma_{0}$ per $\mathrm{m}^{2}$ (equation 4.11), composed of ions located in the area beyond the Stern plane, the so-called diffuse part of the double layer (gray region).

Typical results for the position of the fluid front and fluorescent front are given in figure 4.5. The linear relationship between the position of the fluid front and the square root of time is in good agreement with the Washburn equation (equation 4.2) and earlier results reported by Tas et al. [21]. A constant ratio between the positions of the meniscus and the fluorescent front is observed, with the fluorescing zone of the channel linearly dependent on the amount of channel filled. This means that the ratio $L_{D} / L_{F l}$ is constant per experiment and can be used to characterize it. For example, the experiments 1, 6 and 9 (shown in figure 4.5) have a ratio of $0.41,0.18$ and 0.70 , respectively. This actually supports our assumption that axial proton diffusion does not have a significant effect on our experiments. If this would be the case, this would show up as a nonlinearity of the plot of the fluorescent front against time towards the end of the experiment, which is not seen in the data. We can derive the number of protons released per area of wall, $N_{H_{\exp }^{+}}$, as a function of the observed ratio of dark and fluorescent zones, by equating the absolute amounts of released and absorbed protons (equations 4.3 and 4.4) and using $h<<w$ : 


$$
N_{H_{\exp }^{+}}=N_{S} \Theta^{-}=N_{A} B_{S} h \frac{1}{2} \frac{L_{D}}{L_{F l}}
$$

Equation 4.5 provided an experimental expression for the amount of released protons.

\subsubsection{Theoretical amount of protons released}

We will now construct a theoretical model to describe the theoretical amount of released protons which can be verified by comparing it to the experimental data. When the channel is filled with an aqueous solution, it interacts with the silanol groups as described by the following surface reactions:

$\mathrm{SiOH}_{2}^{+} \Leftrightarrow \mathrm{SiOH}+\mathrm{H}_{S}^{+}$

characterized by the dissociation constant $K_{a 1}$ and

$\mathrm{SiOH} \Leftrightarrow \mathrm{SiO}^{-}+H_{S}^{+}$

characterized by the dissociation constant $K_{a 2}$ and with $H_{S}^{+}$the concentration of protons at the surface. $p K_{a 2}$ has been reported to be 6.7 [24] and $p K_{a 1}$ has been reported to be -1.9 [25].

When protons are released into solution, this induces a negative potential on the siliconoxide surface, $\Psi_{0}$, and a surface charge $\sigma_{0}$. The surface charge depends on the amount of SiOH sites, $N_{S}$, the dissociation constants $K_{a 1}$ and $K_{a 2}$ and the proton activity at the surface $a_{H_{S}^{+}}$and was given by [17]:

$\sigma_{0}=q N_{S}\left[\frac{a_{H_{S}^{+}}^{2}-K_{a 1} K_{a 2}}{a_{H_{S}^{+}}^{2}+K_{a 1} a_{H_{S}^{+}}+K_{a 1} K_{a 2}}\right]$

The negative potential affects the distribution of ions in the solution directly near this surface such that there is a region containing its counter charge. This system of charged wall and the region containing the counter charge density of ions in solution is known as the electrical double layer (figure 4.6).

At some distance from the surface, at least several Debye lengths, the bulk solution is characterized by its bulk number concentration of ions, $n^{0}\left(\mathrm{~m}^{-3}\right.$, for a $1: 1$ ion equal to the ionic strength) and bulk $p H, p H_{B}$. The difference in proton activity between surface and electroneutral bulk was according to Boltzmann: 


$$
p H_{S}=p H_{B}+\Psi_{0} \frac{q}{2.3 k T}
$$

with $k$ Boltzmann's constant, $q$ elementary charge, and $T$ temperature. This equation can be used to express measured bulk $p H$ into $\sigma_{0}$ via equation 4.8 and demonstrates the dependence of $\sigma_{0}$ on $p H_{B}$. The combination of Poisson's equation with Boltzmann's equation also gives an expression for the surface charge [26]:

$$
\sigma_{0}=\left(8 k T \varepsilon \varepsilon_{0} n^{0}\right)^{1 / 2} \sinh \left(\frac{q \Psi_{0}}{2 k T}\right)
$$

This equation demonstrates the dependence of $\sigma_{0}$ on the ionic strength $n^{0}$ and it can be used to calculate $\Psi_{0}$. The charge on the electrolyte side of the double layer, $\sigma_{D L}$ is equal and of opposite sign to the surface charge $\sigma_{0}$ and can be described as a function of a double layer capacitance $C_{D L}\left(\right.$ in F. $\mathrm{m}^{-2}$ ) and the surface potential $\Psi_{0}$ :

$$
\sigma_{D L}=-C_{D L} \Psi_{0}=-\sigma_{0}
$$

For our model we make use of the refinement of double layer theory as proposed by Stern [26]. Ions have a finite size and the closest distance they can approach the surface, equal to the radius of the ions, is the so-called Stern plane. This causes the potential drop across the double layer to have a discontinuity (figure 4.6). Directly near the surface the double layer is described by the potential drop across the Stern plane from $\Psi_{0}$ to $\phi_{2}$. The capacitance of the Stern layer, $C_{\text {Stern }}\left(\right.$ in F.m ${ }^{-2}$ ) is therefore given by:

$$
C_{\text {Stern }}=\frac{\sigma_{0}}{\Psi_{0}-\phi_{2}}
$$

Beyond the Stern plane, the surface charge density in the diffuse layer of counterions is now described by:

$$
\sigma_{0}=\left(8 k T \varepsilon \varepsilon_{0} n^{0}\right)^{1 / 2} \sinh \left(\frac{q \phi_{2}}{2 k T}\right)
$$

and the capacitance of the diffuse part of the double layer, $C_{D i f f}$ is given by:

$$
C_{\text {Diff }}=\frac{\sigma_{0}}{\phi_{2}}
$$

The double layer capacitance is given by the Stern and diffuse layer capacitances in series [26]: 


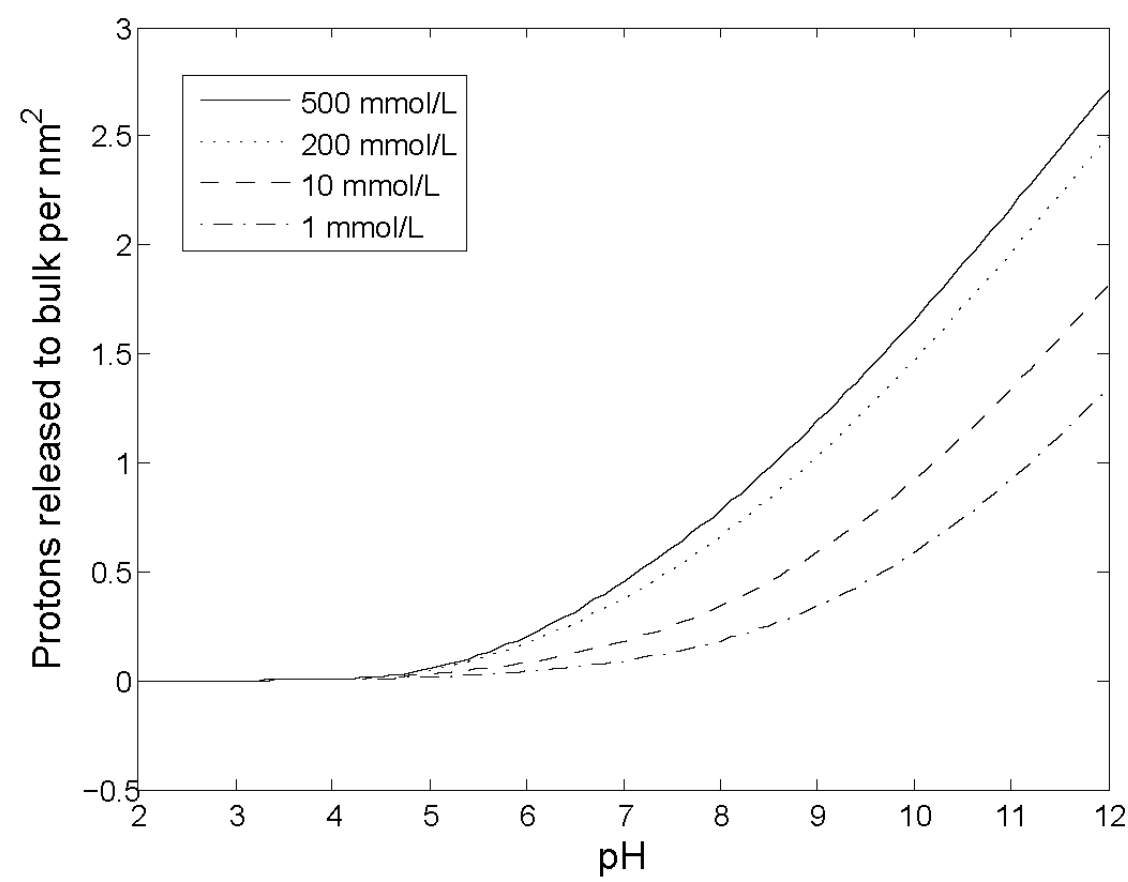

Figure 4.7. Theoretical amount of deprotonated silanol groups per $\mathrm{nm}^{2}$ as a function of $\mathrm{pH}$. The different curves, belonging to 1, 10, 200 and 500 mmol. $L^{-1}$ of $\mathrm{KCl}$, show the effect of the ionic strength on proton release, with more salt inducing a higher release, which will be observed as a shorter fluorescent zone.

$C_{D L}=\frac{1}{C_{\text {Stern }}^{-1}+C_{\text {Diff }}^{-1}}$

To describe titration experiments of $\mathrm{SiO}_{2}$ surfaces, colloid experiments typically take values for $C_{\text {Stern }}$ of 0.8 to $1.4 \mathrm{~F} . \mathrm{m}^{-2}$ [27]. It has also been argued that for a porous well ordered planar surfaces, values for $C_{\text {Stern }}$ between 0.8 to $1.7 \mathrm{~F} . \mathrm{m}^{-2}$ should be assumed [27]. As these values for $C_{\text {Stern }}$ considerably vary and strongly affect our model, we used $C_{\text {Stern }}$ to fit the measurement results (5), with the constraint of one $C_{\text {Stern }}$ for all experiments.

From the above equations 4.8 to 4.15 , we can derive $\sigma_{0}$ via an iteration procedure given [28] and therefore the amount of protons released per surface area into the bulk solution:

$N_{H_{\text {theory }}^{+}}=\frac{\sigma_{0}}{q}$

which can be fitted to $N_{H_{\text {exp }}^{+}}$(equation 4.5). An overview of constants and parameters used for fitting is given in table 4.2 . 




Figure 4.8. Results of the experiments, $N_{H_{\mathrm{exp}}^{+}}$, fitted with the model, $N_{H_{\text {theory }}^{+}}$. Fits were made using the input and fitting parameters from tables 4.1 and 4.2 , with the dissociation constants $p K_{a 1}=6.77$ and $p K_{a 2}=-1.90$ and therefore a $p H_{p z c}=2.44$. A value of $C_{S t e r n}=2.30 \mathrm{~F} . \mathrm{m}^{-2}$ led to the optimal fit with $R^{2}=0.93$ for the unbuffered solutions and $R^{2}=0.37$ for buffered solutions. The data point for the buffered solution at an ionic strength of 386 mmol. $L^{-1}$ has a buffer strength of $1 \mathrm{~mol} . \mathrm{L}^{-1}$, the others $0.2 \mathrm{~mol} . \mathrm{L}^{-1}$. The dashed lines indicate the modeled values corresponding to the extremes of $\mathrm{pH}$ in the introduced solutions, from top to bottom, $\mathrm{pH}=$ 8.6, $p H=8.4, p H=7.4$ and $p H=7.0$.

\subsection{Results and discussion}

\subsubsection{Theoretical results}

Our theoretical model shows how the capacity of the solution to take up protons, via a buffer and via fluorescein itself, affects the position of the fluorescent front. More buffer for this reason leads to a larger fluorescent zone. The model shows how a higher $p H$ of the introduced solution increases the amount of protons per $\mathrm{nm}^{2}$ to be released (equation 4.9, a higher $p H$ induces a more negative surface potential effectuated by proton release). It also shows how the ionic strength affects proton release (equation 4.13; for a more in depth explanation see ref. [29]) as is seen in our experiments. Hereby the buffer ions are incorporated in the determination of the ionic strength. Figure 4.7 shows the theoretically calculated amount of deprotonated groups as a function of $p H$ and ionic strength. Using this model we fitted our experimental results. 


\subsubsection{Fitting results}

The parameter space we investigated to fit the data was $p K_{a 2}=\left[4\right.$ to 7.5] and $p K_{a 1}=[-2.4$ to $0]$. Each pair of $p K_{a}$ values was used to fit the date of the unbuffered and buffered results, under the constraint that $C_{\text {Stern }}$ was equal for all data, using equations 4.8 to 4.15 according to the iteration procedure described in ref. [28]. As a side note, interestingly, it appears that the fitting results could be described by the empirical relation $C_{S t e r n}=2.32 \times 10^{-4} \mathrm{e}^{3.77 p H p z c}\left(R^{2}=\right.$ $0.99)$ and therefore many pairs of dissociation constants $p K_{a 1}$ and $p K_{a 2}$ yielded a good fit as long as they gave the same $p H_{p z c}$.

Figure 4.8 shows measured data points as well as fitted curves, displaying the amount of released protons as a function of ionic strength. To generate figure 4.8, we chose $p K_{a l}=-1.9$ based on literature [25], which yielded a dissociation constant $p K_{a 2}=6.77$ close to the literature value of 6.7 reported by Davis et al. [24], accepting a somewhat high $C_{\text {Stern }}$ of 2.30 F. $\mathrm{m}^{-2}$.

High values of $C_{\text {Stern }}$ (greater than $1.7 \mathrm{~F} . \mathrm{m}^{-2}$ ) for a nonporous surface can be attributed to complexation of ions in solution with silanol groups [24]. This is because ionic complexation has been reported to shift the point of zero charge [30] from its value as the mean of the $p K a$ 's, when only protons are the potential determining ions, to another value. According to our empirical relation, a slight difference in $p H_{p z c}$ results in a significant change in $C_{\text {Stern }}$, e.g.,

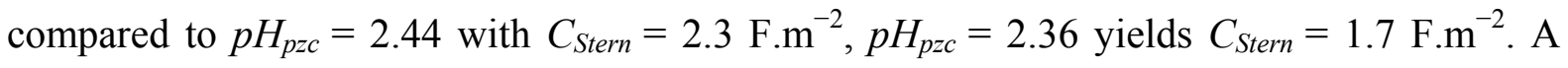
second explanation for high values of $C_{\text {Stern }}$, according to Hiemstra et al. [27] is the silicon oxide surface having a less condensed surface structure and the presence of reactive surface groups protruding from the surface.

A good fit was achieved for the solutions containing fluorescein and $\mathrm{KCl}, R^{2}=0.93$, and a lesser fit was found for the solutions containing TRIS buffer $R^{2}=0.37$, due to the spread in experimental results (see variation in duplicate experiments in figure 4.8).

Figure 4.8 shows that the variation in amount of released protons is reasonably explained by the variation in ionic strength and the $p H$ of the filling fluid. On the other hand, the buffer concentration in the filling fluid does not affect the released amount of protons per wall area (apart from its contribution to the ionic strength). This is indeed expected since the model gives an amount of protons released per wall area based only on the equilibrium with an infinite solution of the initial $\mathrm{pH}$ and ionic strength. Though the buffer concentration affects 
the ratio between dark and the fluorescent zone, this is incorporated in equation 4.5, leading to an amount of protons released per wall area independent from buffer concentration.

\subsubsection{Buffer effects}

Figure 4.8 shows a large spread in the duplicate measurements of several buffered solutions. This is probably caused by substantial variations in the buffer composition. Inspection of table 4.1 shows that the measured $p H$ of the TRIS-buffered solutions varied between 8.4 and 8.6, though all solutions were prepared by adding 0.072 mol. $\mathrm{L}^{-1} \mathrm{HCl}$ to a $0.2 \mathrm{mol.L}{ }^{-1} \mathrm{TRIS}$ solution. These $p H$ differences would indicate substantial differences in buffer capacity of the resulting solutions, affecting the value of $B_{S}$ and $N_{H_{\exp }^{+}}$(equation 4.5).

\subsubsection{Fluorescence front}

The results show a release of approximately 0.8 protons per $\mathrm{nm}^{2}$ for the solutions around $\mathrm{pH}$ $=8.5$ and 0.4 protons per $\mathrm{nm}^{2}$ for the unbuffered solutions, $p H=7-7.4$. We would like to stress the effect that such an amount of released protons has in shallow channels of $50 \mathrm{~nm}$ in height and arbitrary width. For a released amount of 0.5 protons per $\mathrm{nm}^{2}, 1$ proton was released into the $50 \mathrm{~nm}^{3}$ between the two walls or 0.02 protons per $\mathrm{nm}^{3}$ (corresponding to a concentration of $\left.60 \mathrm{mmol} . \mathrm{L}^{-1}\right)$. To titrate a solution of 0.6 molecules per $\mathrm{nm}^{3}\left(1 \mathrm{~mol} . \mathrm{L}^{-1}\right)$ the solution therefore has to pass only $30 \mathrm{~nm}$ of channel.

Together with the very fast equilibration in radial direction, this can explain our observation of a sharp fluorescence boundary for example in figure 4.1. The argumentation for this is as follows: the protons diffusing axially into the fluorescent zone will be buffered by the solution, whereas fluorescein and/or buffer molecules that diffuse into the dark zone will be instantly protonated. Even if axial diffusion contributes significantly to proton transport relative to the flow of solution, this transient zone between dark and fluorescent regions will be the first to be in contact with undeprotonated wall, and become protonated to $p H_{p z c}$. This effectively conserves the sharpness of the boundary between the dark and fluorescent zones, as is observed in our experiments.

\subsection{Conclusion}

A new phenomenon was observed unique to nanofluidics, namely a decrease in the fluorescent activity of fluorescein during capillary filling. The observed dark and fluorescent regions can be explained by acidification of the solution via deprotonation of the silanol groups at the wall. This mechanism could be verified by establishing a model based on the 
double layer theory and fitting this to the data. This mechanism represents a unique way to titrate a solution without adding additional counterions and to study the properties of a surface.

As chemical analysis in NCs is a growing field of research, the understanding of the effects of the nanostructure walls, due to a high surface to volume ratio, on the solution $\mathrm{pH}$ and the resulting changes in wall potential are of great significance. Importantly, this will occur in all transient cases, which means not only during filling but also when the solution $p H$ or ionic strength is changed. This will be especially important for the analysis of biological samples because of its complex matrix composition. Fortunately, these effects can be modeled as demonstrated in this chapter.

\subsection{References}

[1] Han, J.; Craighead, H. G. Entropic trapping and sieving of long DNA molecules in a nanofluidic channel. J. Vac. Sci. Technol. A 1999, 17 (4), 2142-2147.

[2] Haneveld, J.; Jansen, H.; Berenschot, E.; Tas, N.; Elwenspoek, M. Wet anisotropic etching for fluidic 1D nanochannels. J. Micromech. Microeng. 2003, 13 (4), S62-S66.

[3] Alarie, J. P.; Hmelo, A. B.; Jacobson, S. C.; Baddorf, A. P.; Feldman, L.; Ramsey, J. M. Fabrication and evaluation of 2D confined nanochannels. $7^{\text {th }}$ International Conference on Miniaturized Chemical and Biochemical Analysts Systems, CA, USA 2003, 9-12.

[4] Harnett, C. K.; Coates, G. W.; Craighead, H. G. Heat-depolymerizable polycarbonates as electron beam patternable sacrificial layers for nanofluidics. J. Vac. Sci. Technol. B 2001, $19(6), 2842-2845$.

[5] Cao, H.; Yu, Z.; Wang, J.; Tegenfeldt, J. O.; Austin, R. H.; Chen, E.; Wu, W.; Chou, S. Y. Fabrication of $10 \mathrm{~nm}$ enclosed nanofluidic channels. Appl. Phys. Lett. 2002, 81 (1), 174-176.

[6] Tas, N. R.; Berenschot, J. W.; Mela, P.; Jansen, H. V.; Elwenspoek, M.; Van den Berg, A. 2D-confined nanochannels fabricated by conventional micromachining. Nano Lett. 2002, $2(9), 1031-1032$.

[7] Chen, X.; Ji, R.; Steinhart, M.; Milenin, A.; Nielsch, K.; Gösele, U. Aligned horizontal silica nanochannels by oxidative self-sealing of patterned silicon wafers. Chem. Mater. 2007, $19(1), 3-5$.

[8] Wang, M.; Jing, N.; Su, C. B.; Kameoka, J.; Chou, C. K.; Hung, M. C.; Chang, K. A. Electrospinning of silica nanochannels for single molecule detection. Appl. Phys. Lett. 2006, 88 (3), 033106. 
[9] Eijkel, J. C.; Bomer, J.; Tas, N. R.; Van den Berg, A. 1-D nanochannels fabricated in polyimide. Lab Chip 2004, 4 (3), 161-163.

[10] Müller-Buschbaum, P.; Bauer, E.; Maurer, E.; Schlögl, K.; Roth, S. V.; Gehrke, R. Route to create large-area ordered polymeric nanochannel arrays - a high-resolution investigation. Appl. Phys. Lett. 2006, 88 (8), 083114.

[11] Mijatovic, D.; Eijkel, J. C. T.; Van den Berg, A. Technologies for nanofluidic systems: top-down vs. bottom-up - a review. Lab Chip 2005, 5 (5), 492-500.

[12] Eijkel, J. C. T.; Van den Berg, A. Nanofluidics: what is it and what can we expect from it? Microfluid. Nanofluid. 2005, 1 (3), 249-267.

[13] Pennathur, S.; Santiago, J. G. Electrokinetic transport in nanochannels. 1. Theory. Anal. Chem. 2005, 77 (21), 6772-6781.

[14] Pennathur, S.; Santiago, J. G. Electrokinetic transport in nanochannels. 2. Experiments. Anal. Chem. 2005, 77 (21), 6782-6789.

[15] Pu, Q. S.; Yun, J. S.; Temkin, H.; Liu, S. R. Ion-enrichment and ion-depletion effect of nanochannel structures. Nano Lett. 2004, 4 (6), 1099-1103.

[16] Ahuja, S. Selectivity and Detectability Optimizations in HPLC, John Wiley \& Sons, Inc.: NY 1986.

[17] Van Hal, R. E. G.; Eijkel, J. C. T.; Bergveld, P. A general model to descibe the electrostatic potential at electrolyte oxide interface. Adv. Colloid Interface Sci. 1996, 69 (1-3), 31-62.

[18] Smith, S. A.; Pretorius, W. A. Spectrophotometric determination of $\mathrm{pKa}$ values for fluorescein using activity coefficient corrections. Water $S A$ 2002, 28 (4), 395-402.

[19] Diehl, H.; Markuszewski, R. Studies on fluorescein-VII. The fluorescence of fluorescein as a function of $\mathrm{pH}$. Talanta 1989, $36(3), 416-418$.

[20] Washburn, E. W. The dynamics of capillary flow. Phys. Rev. Lett. 1921, 17 (3), $273-283$.

[21] Tas, N. R.; Haneveld, J.; Jansen, H. V.; Elwenspoek, M.; Van den Berg, A. Capillary filling speed of water in nanochannels. Appl. Phys. Lett. 2004, 85 (15), 3274-3276.

[22] Atkins, P. W. Physical Chemistry, Oxford University Press: Oxford 1998.

[23] Armistead, C. G.; Tyler, A. J.; Hambleton, F. H.; Mitchell, S. A.; Hockey, J. A. Surface hydroxylation of silica. J. Phys. Chem. 1969, 73 (11), 3947-3953.

[24] Davis, J. A.; James, R. O.; Leckie, J. O. Surface ionization and complexation at the oxide/water interface: I. Computation of electrical double layer properties in simple electrolytes. J. Colloid Interf. Sci. 1978, 63 (3), 480-499. 
[25] Bousse, L. The Chemical Sensitivity of Electrolyte/Insulator/Silicon Structures: Fundamentals of ISFET Operation, $\mathrm{PhD}$ thesis, University of Twente, The Netherlands 1982.

[26] Bard, A. J.; Faulkner, L. R. Electrochemical Methods, Fundamentals and Applications, John Wiley \& Sons, Inc.: NY 1980.

[27] Hiemstra, T.; Van Riemsdijk, W. H. Physical chemical interpretation of primary charging behaviour of metal (hydr) oxides. Colloids Surf. 1991, 59 (C), 7-25.

[28] The iteration procedure has the ionic strength and measured $\mathrm{pH}$ (table 4.1), as well as the surface properties stated above (table 4.2), as input parameters. Choosing a starting value for $\Psi_{0}$, it is entered into Boltzmann equation (equation 4.9) giving the surface activity of protons, which is used to calculate $\sigma_{0}$ (equation 4.8) and subsequently applied to yield $\phi_{2}$ (equation 4.13). Finally a new value for $\Psi_{0}$ is calculated from $\Psi_{0}=\phi_{2}+\sigma_{0} / C_{\text {Stern }}$ (equation 4.12) and reentered into Boltzmann (equation 4.9). The stable value for $\sigma_{0}$ is then used for equation 4.16.

[29] The effect of the ionic strength is demonstrated by the Debye-Huckel approximation of $C_{D i f f}$ as $C_{D i f f}=\varepsilon / \lambda_{D}$, with $\lambda_{D}$ the Debye length. A higher ionic strength, $n_{0}$, decreases the Debye length and increases $C_{D i f f}$, leading to a larger negative surface charge density and a larger proton release to titrate the solution.

[30] Bogdanova, N. F.; Klebanov, A. V.; Ermakova, L. E.; Sidorova, M. P. Electrosurface characteristics of (hydr)oxides and oxide nanostructures in $1: 1$ electrolyte solutions. 3 . calculation of the electrical double layer parameters for boehmite, goethite, and silicon oxide according to adsorption and electrokinetic data. Colloid J. 2002, 64 (4), 389-395. 


\section{Chapter 5 \\ Analysis of single quantum-dot mobility inside \\ 1D nanochannels devices}

We visualized individual quantum dots using a combination of a confining nanochannel and an ultra-sensitive microscope system, equipped with a high numerical aperture lens and a highly sensitive camera. The diffusion coefficients of the confined quantum dots were determined from the experimentally recorded trajectories according to the classical diffusion theory for Brownian motion in two dimensions. The calculated diffusion coefficients were three times smaller than those in bulk solution. These observations confirm and extend the results of Eichmann et al. [19] to smaller particle diameters and more narrow confinement. A detailed analysis shows that the observed reduction in mobility can not be explained by conventional hydrodynamic theory.

This chapter is based on the paper "Analysis of single quantum-dot mobility inside 1D nanochannel devices. Nanotechnology 2011, 22, 275201". 


\subsection{Introduction}

Nanochannel (NC) devices have been used for single-molecule studies because of their extremely small volume. The confining effect of the NCs allows single-molecule studies at relative high concentration, without requiring immobilization of molecules to keep them in focus. The benefits of NC devices may be exploited for single-molecule applications in many fields such as single-molecule physics, chemistry and biology [1-6]. Single-molecule experiments in NCs offer the possibility of exquisite control and manipulation of the sample conditions. These studies reveal information that is otherwise hidden within an ensemble of molecules or only can be addressed by indirect approaches [7-9]. Not only have individual fluorescent molecules been observed and identified, but typical single-molecule characteristics, like blinking and bleaching, have been extensively studied [10]. Functional studies of molecular, interaction and binding studies have been performed [11]. Investigations of physical properties at the single-molecule level, like mobility, provide new insights into the properties of individual molecules in nanometer-scale environments.

In this chapter we address the important issue of the viscosity of confined water by measuring the mobility of fluorescent quantum dots. The viscosity of water in confinement is a long disputed subject since the measurements by Churaev et al. [12] in quartz microcapillaries. They found an elevation of the (apparent) viscosity by as much as $40 \%$ in 0.04 $\mu \mathrm{m}$ radius capillaries. These results could not be reproduced in nanometer thin films in the Surface Forces Apparatus (SFA). A dynamic SFA technique revealed a viscosity of water equal to the bulk viscosity, even in $2 \mathrm{~nm}$ thin films and under high salt concentrations sufficient to induce a strong repulsive hydration force between mica surfaces [13]. In recent years, silicon-based nanotechnology offers new routes to study the viscosity of liquids in confinement [14-15]. The measurement of quantum-dot mobility inside nanochannels is expected to provide relative direct information on liquid viscosity, through application of the Einstein-Stokes relation.

For spheres moving in close proximity parallel to solid surfaces Goldman et al. [16] modeled the viscous drag, leading to a reduced mobility which deviated from the Einstein-Stokes equation. Banerjee et al. [17] and Choi et al. [18] confirmed the theory for nanoparticles (down to $100 \mathrm{~nm}$ radius) by tracking their three-dimensional motion using total internal reflection fluorescence microsopy. The lateral mean square displacements (MSD) in the near-wall region were shown to follow the model of Goldman. 
In this chapter, we determine the diffusion coefficients $(D)$ from the Brownian motion of single quantum dots inside $150 \mathrm{~nm}$ high NCs, visualized by using a high numerical aperture (NA) lens and a sensitive charge-coupled device (CCD) camera. The $D$ values were found to be about three times $(60-70 \%)$ reduced compared to bulk solution. This is much more than can be explained by the Goldman model. Our result is in qualitative correspondence with the findings of Eichmann [19] who found a 50\% reduction of the lateral mobility for $57 \mathrm{~nm}$ gold nanoparticles confined between glass surfaces (340 nm separated). Kaji et al. [20] found a three times lower than expected diffusion coefficients for $50 \mathrm{~nm}$ carboxylated polystyrene nanospheres in $400 \mathrm{~nm}$ high NCs. In the latter case the reduced mobility observed was attributed to an enhanced viscosity of water in nanoconfinement. We will review and analyze in detail different mechanisms that can contribute to the observed decrease in quantum-dot mobility.

\subsection{Experimental details}

\subsubsection{Fabrication of $1 D$ nanochannel devices by wafer bonding}

1D NC devices were fabricated based on the approach of Haneveld et al. $[14,21]$. The process was started on a $<110>$ silicon wafer. A $150 \mathrm{~nm}$ thick silicon oxide layer was grown by dry thermal oxidation and its thickness was measured by ellipsometry (Plasmos SD 2002). Next, a standard lithography step was applied to create NC structures of $20 \mu \mathrm{m}$ width. These structures were transferred to the silicon oxide layer by wet chemical etching in BHF solution. Channel height was controlled by the thickness of the silicon oxide layer and by the time to completely etch this layer. For connection of the NCs to the macro world, microchannels were added which were realized using reactive ion etching. For use on an inverted microscope, inlet/outlet ports were fabricated from the back side of the silicon wafer using deep reactive ion etching at cryogenic temperature. Finally, the NCs were covered by a blank glass wafer of $170 \mu \mathrm{m}$ thickness by direct bonding at $400{ }^{\circ} \mathrm{C}$ in order to enable observation on the inverted microscope. Before bonding, both wafers were cleaned in Piranha solution $\left(\mathrm{H}_{2} \mathrm{SO}_{4}: \mathrm{H}_{2} \mathrm{O}_{2}=3: 1\right)$. An artist's drawing of a completely 1D NC device, SEM crosssectional images of the fabricated channels and detail processing steps were shown in figures 2.1 and 2.2 from chapter two.

\subsubsection{Materials and microscopy}

A quantum-dot (QD) solution (Evitag Fort Orange, type T2-MP, carboxyl, CdSe/ZnS, 25 $\mathrm{nm}$ diameter, emission $600 \pm 10 \mathrm{~nm}$ (Evident Technologies, NY)) was used for experiments. 
A $12 \mu \mathrm{M}$ [22-23] stock solution was diluted in MilliQ water $\left(0.7 \mu \mathrm{S} . \mathrm{cm}^{-1}\right)$ to the required concentration of $12 \mathrm{nM}$. The diameter of the quantum-dot particles given by the supplier was confirmed to be $25 \pm 6 \mathrm{~nm}$ using dynamic light scattering. Experiments were carried out on custom-modified inverted fluorescence microscope (Zeiss, Axiovert) (figure 2.2A, chapter two ) at room temperature $\left(21 \pm 1^{\circ} \mathrm{C}\right)$ [24]. For excitation a $488 \mathrm{~nm}$ Argon laser line was focused into the NCs by using a $100 \times, 1.20 \mathrm{NA}$, water-immersion objective (Leica Planachromat). Fluorescence emission was detected by an air-cooled, intensified CCD camera (Pentamax). Emission was detected with a 610/75 nm band pass filter and a notch filter was used to remove any residual excitation light. Images of $50 \mu \mathrm{m} \times 50 \mu \mathrm{m}$ (512 pixels $\times 512$ pixels) were recorded by using the WinSpec 32 program (Roper Scientific). A series of 40 sequential images were acquired at a rate of 5 frames per second corresponding to $200 \mathrm{~ms}$ exposure time. The NCs were filled with the QD solution by capillary forces using a macro inlet hole and a microchannel to couple to the NCs. Under the influence of these forces, the solution went through the NCs and then quickly stopped when the meniscus reached another microchannel at the distal end of the NCs.

\subsubsection{Image analysis}

The images recorded by the Winspec program were converted to text-image files by ImageJ software [25]. The text-image files were digitized and redrawn in a user-written Matlab program [26] (appendix 5.1). Positions of single QDs were manually determined (appendix 5.2) from the Matlab images, which were recorded as a set of coordinates $\left\{x_{i}, y_{i}\right\}$, where the index $i$ indicates the order of an image in a sequence. Two-dimensional movements were recorded during three-dimensional trajectories of single QDs. The confinement of the NCs in vertical direction prevented movements out of the focus of the objective lens.

The precise position of a single QD, defined by the center of the diffraction-limited fluorescence spot, was determined using two-dimensional Gaussian fitting. Trajectories were terminated when the QD disappeared due to bleaching or moved out of the tracking window.

\subsection{Theory on Brownian motion}

In 1827, Brown [27] observed that small pollen grains suspended in water exhibit a very animated and irregular state of motion. A satisfactory explanation of the Brownian motion did not appear until 1905, when Einstein [28] showed that macroscopic particles suspended in 
liquids must perform unceasing motions. The Brownian motion was maintained by collisions with surrounding liquid molecules in the absence of external forces. Based on the Stokes equation, describing the force resisting the motion of a spherical particle in a liquid, Einstein presented the relation between the macroscopic diffusion coefficient and microscopic parameters. The diffusion coefficient $D$ of particles depends on their radius, the temperature and the coefficient of viscosity of the surrounding liquid, and is given by the Einstein-Stokes relation [29] (appendix 5.7):

$D=\frac{R T}{N_{A}} \frac{1}{6 \pi \eta r}$

where $R$ is the gas constant, $T$ - the temperature, $N_{A}$ - the Avogadro number, $\eta$ - the viscosity of solvent and $r$-the radius of the particles.

Einstein inferred from the kinetic theory that an ensemble of small suspended particles had to possess osmotic pressure. If this pressure is distributed in a spatially inhomogeneous way, it gives rise to a compensatory diffusion process. He obtained an expression for the diffusion coefficient, written in the form of a partial differential equation describing the relation between the spatial and temporal change of the probability density function $p(\vec{r}, t)$ of the particles in the solution [29] (appendix 5.8):

$$
\frac{\partial p(\vec{r}, t)}{\partial t}=D \nabla^{2} p(\vec{r}, t)
$$

where $\vec{r}(x, y)$ or $\vec{r}(x, y, z)$ and $\nabla^{2}=\partial_{x}^{2}+\partial_{y}^{2}$ or $\nabla^{2}=\partial_{x}^{2}+\partial_{y}^{2}+\partial_{z}^{2}$ for two or three dimensions, respectively. Equation 5.2 is Fick's second law, which applies for systems containing many particles. Furthermore, Einstein showed in his theory of Brownian motion that this equation also applies for one particle. Assuming that all the particles are in the same coordinate system, Einstein applied equation 5.2 to determine the probability distribution of irregularly moving particles. Einstein identified the irregular motion of suspended particles as governed by a stochastic process using the probability function $p(x, y, t)$. By solving equation 5.2 (appendix 5.9) the probability distribution as a function of time is obtained, which yields for one and two dimensions:

$$
\begin{aligned}
& p(x, t)=\frac{1}{\sqrt{4 \pi D t}} e^{-x^{2} / 4 D t} \\
& p(x, y, t)=\frac{1}{\sqrt{4 \pi D t}} e^{-\left(x^{2}+y^{2}\right) / 4 D t}
\end{aligned}
$$




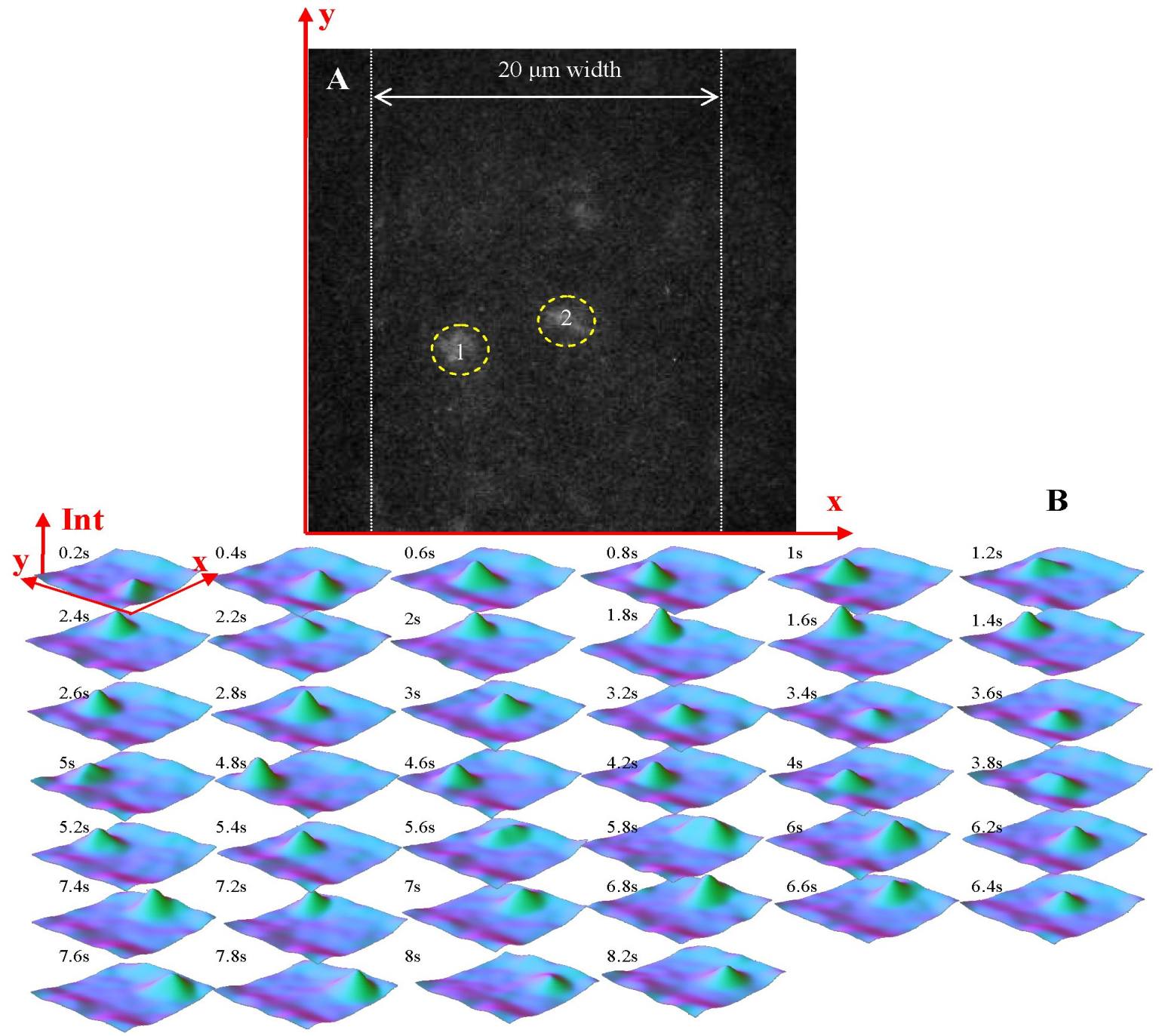

Figure 5.1. (A) Fluorescence images of single quantum dots observed in a $150 \mathrm{~nm}$ high and $20 \mu \mathrm{m}$ wide nanochannel; the dotted white lines indicate the channel walls. Quantum dots were marked inside the dashed yellow circles. (B) Surface plots which indicate fluorescence intensity of a single quantum dot performing the Brownian motion inside the confined nanochannel.

From comparing the probability density of particle positions with equation 5.3, the diffusion coefficient can be determined. Furthermore, we can derive the diffusion coefficient of the Brownian particles from the relation between the MSD and the time $t$ [30] (appendix 5.10):

$<x^{2}>=2 D t$

$<x^{2}+y^{2}>=4 D t$

where the notation $<\cdot>$ represents the mean square displacements, averaged over many particles, or averaged using the probability function in the case of a single particle. 


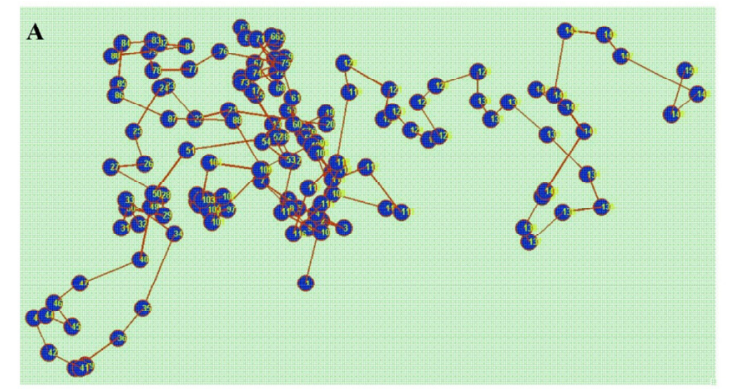

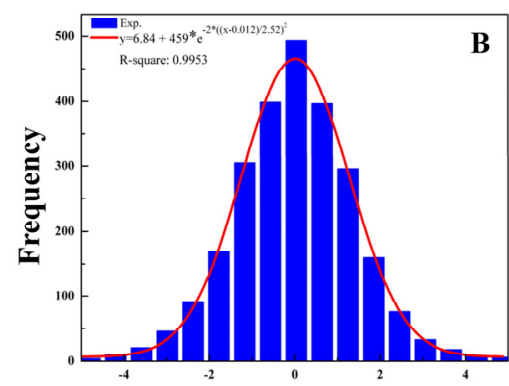

x-displacement

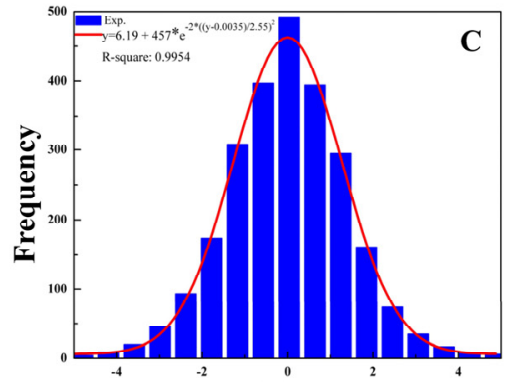

-displacement



R-displacement

Figure 5.2. (A) A trajectory (appendix 5.3) of a quantum dot inside a $150 \mathrm{~nm}$ high and $20 \mu \mathrm{m}$ wide nanochannel. (B) and (C) Histograms of $x, y$ displacements of 65 trajectories with 40 steps each in a time lag of $200 \mathrm{~ms} ; x$ axis is displacements in $\mu \mathrm{m}$ and $y$ axis is frequency; Experimental data (bar graphs) are fitted by a Gaussian function indicated by red curves. (D) Histogram of $R$ displacements $R^{2}=x^{2}+y^{2}$; experimental data are fitted by nonlinear least square regression function.

\subsection{Results and discussion}

\subsubsection{Visualization of single quantum dots}

The fabricated NCs were filled with a $12 \mathrm{nM}$ QD solution. Figure 5.1A shows that much fewer QDs were observed than expected based on concentration and volume [31]. Although there is no satisfactory explanation for this phenomenon, ion exclusion [32] has been considered as an effect. The sequences of images (presented in the figure 2.6 from chapter two) identified the presence of individual QDs from the instantaneous appearance and disappearance of fluorescence, a demonstration of the well-known blinking behavior, characteristic for single QDs.

\subsubsection{Analysis of quantum-dot mobility}

Figure 5.1B shows the fluorescence surface plots of a single QD within 40 sequentially acquired images. Analysis of QD mobility was based on two-dimensional projections of 
Table 5.1. D values in $\mu m^{2} . s^{-1}$

$D_{x}(x$ displacement $)$

Fitting

MSD
$D_{y}(y$ displacement $)$

5.54

$5.39 \pm 1.29$
$D_{R}(R$ displacement $)$

4.88

$5.13 \pm 1.29$

three-dimensional trajectories using histograms of displacements with an interval time of $\tau=$ $200 \mathrm{~ms}$. Figures 5.2B and 5.2C show histograms of displacements in $x$ and $y$ directions $(x$ : across channels, $y$ : along channels). Distributions of $x, y$ displacements satisfied the zero mean.

These experimental data (bar graph) were then fitted by Gaussian distributions (solid lines in figures 5.2B and 5.2C, appendix 5.4a) [33]. $D$ values were extracted from equation 5.3a which is the Gaussian function. $D_{x}, D_{y}$ values were calculated from the standard deviation $\sigma$ of the Gaussian distribution, $D_{x, y}=\sigma^{2} / 2 \tau$, yielding 5.47 and $5.54 \mu \mathrm{m}^{2} . s^{-1}$ respectively with $\mathfrak{R}^{2}=0.99$ ( $\mathfrak{R}$ is coefficient of variation). Figure 5.2D presents histograms of $R$ displacements in both dimensions. The experimental data were fitted based on equation $5.3 \mathrm{~b}$ by a nonlinear least square regression fitting (appendix 5.4b) as follows:

$$
p^{*}(R) d R=(R / 2 D t) \exp \left[\frac{-R^{2}}{4 \pi D t}\right] d R
$$

The $D_{R}$ value was extracted to be $4.88 \mu \mathrm{m}^{2} . \mathrm{s}^{-1}$ with $\mathfrak{R}^{2}=0.98$.

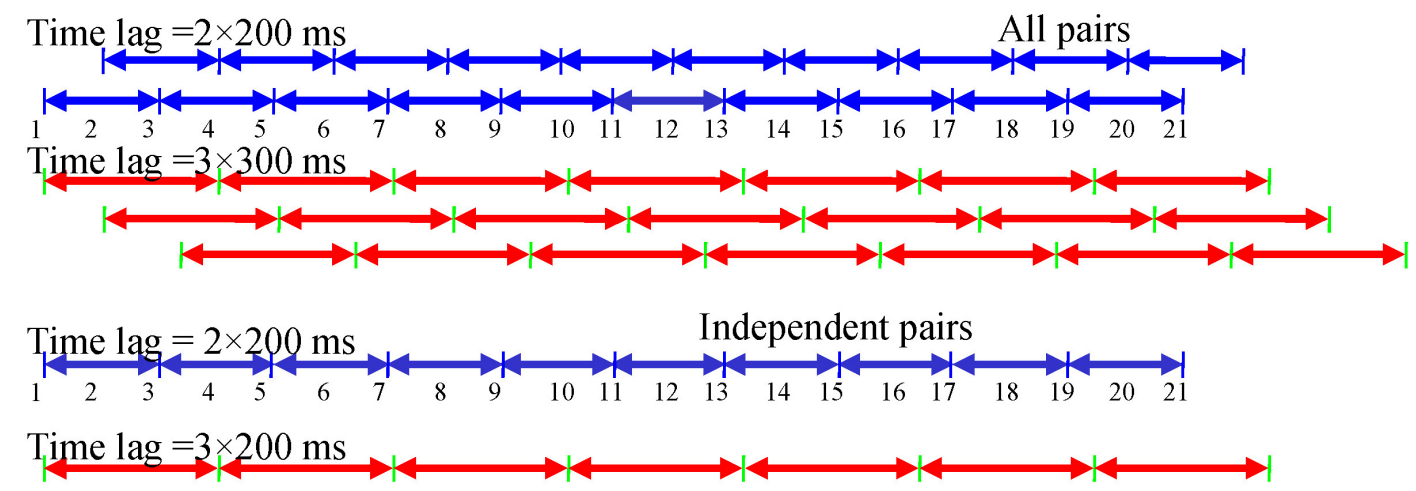

Figure 5.3. Displacements determination methods for moving positions from 1 to $N_{s}$; $N_{s}$ : number of images in one movie recording the movement of a single quantum dot. 


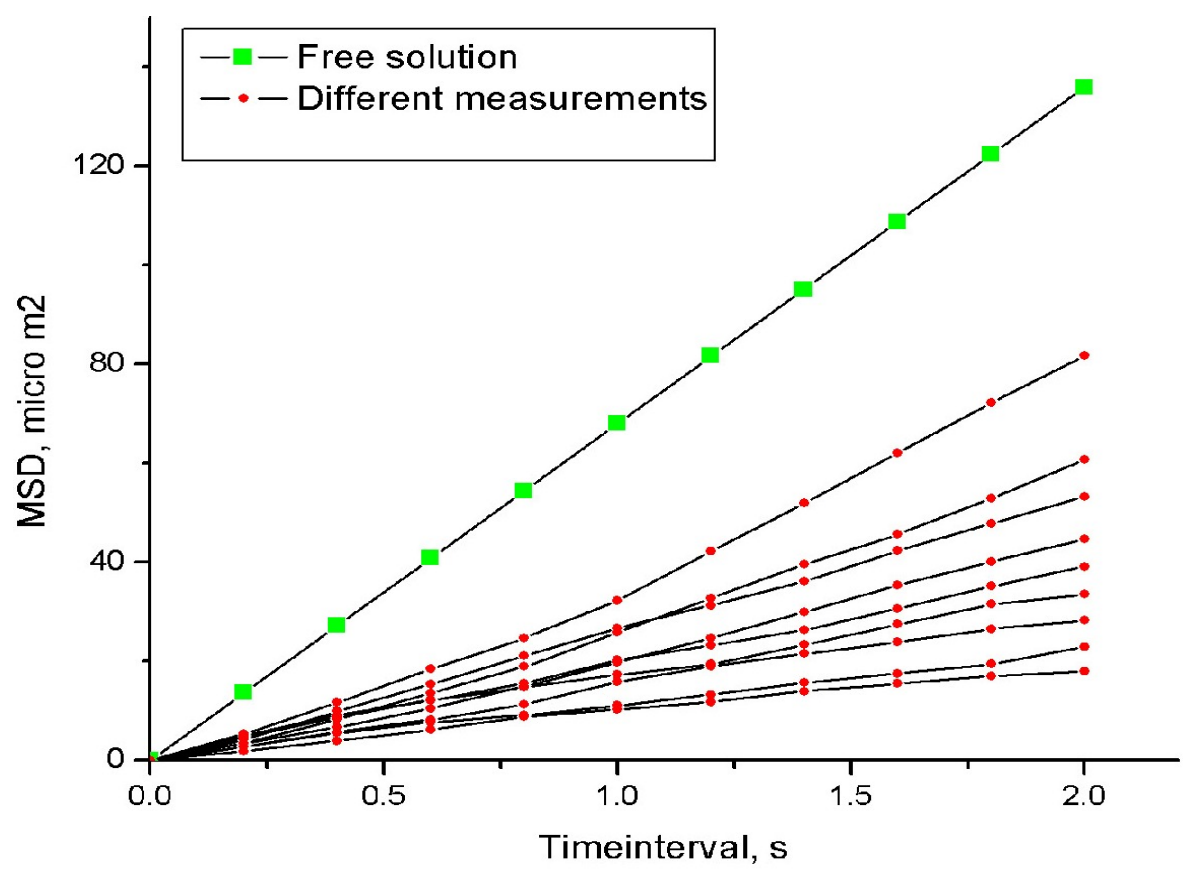

Figure 5.4. Mean square displacements of the first ten steps of ten trajectories in $150 \mathrm{~nm}$ high and $20 \mu \mathrm{m}$ wide nanochannels.

Next, the relation between MSDs $\left(<x^{2}>,<y^{2}>\right.$ and $\left.<R^{2}>\right)$ and time lags was constructed. For a time lag $t(t=m \tau)$, MSDs can be determined in two ways: by averaging over all pairs of $<M S D>=<R^{2}>(t=m \tau)=\frac{1}{N_{s}-m} \sum_{i=1}^{N_{S}-m} R_{i}^{2}(m \tau)$

steps or over independent pairs of steps [34]. In one movie, there are $N_{s}$ images, separated by an exposure time of $200 \mathrm{~ms}$. Displacements are defined $R^{2}(t=m \tau)=\left(x_{i+m}-x_{i}\right)^{2}+$ $\left(y_{i+m}-y_{i}\right)^{2} . R(t)$ for defining movements of single QDs in both dimensions is calculated by averaging over all pair of steps [34] in a time lag $t$ (figure 5.3); Figure 5.4 shows the relation between MSDs and lag times $t$ (appendix 5.5). The obtained proportional relationship between MSDs and $t$ proved that the Brownian motion of the QDs followed classical diffusion. The diffusion coefficient was calculated from the slope of the straight line fitted to the experimental data.

The distribution of $D$ values calculated from MSD- $t$ curves from 65 different measurements is shown in figure 5.5 (appendix 5.6). The measured $D$ values (table 5.1) were about 5-6 $\mu \mathrm{m}^{2} . \mathrm{s}^{-1}$, which is three times smaller than the expected value of $17 \mu \mathrm{m}^{2} . \mathrm{s}^{-1}$ in bulk solution [35]. 


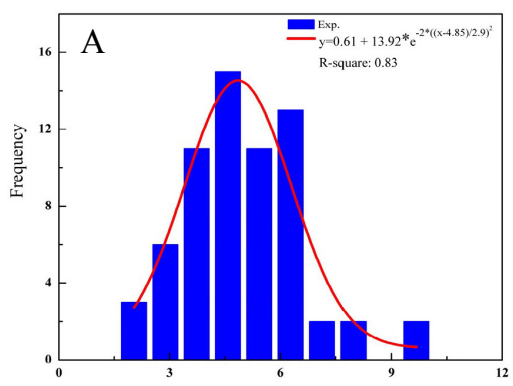

$D_{x}, \mu m^{2} \cdot s^{-1}$

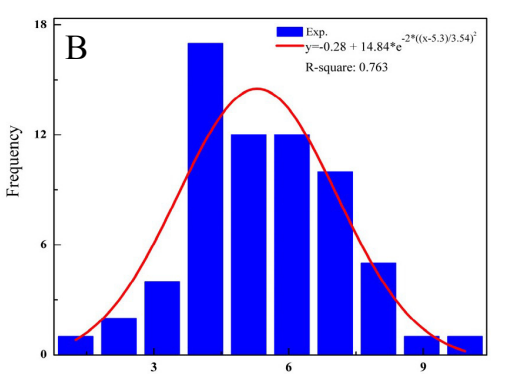

$D_{y}, \mu m^{2} \cdot s^{-1}$

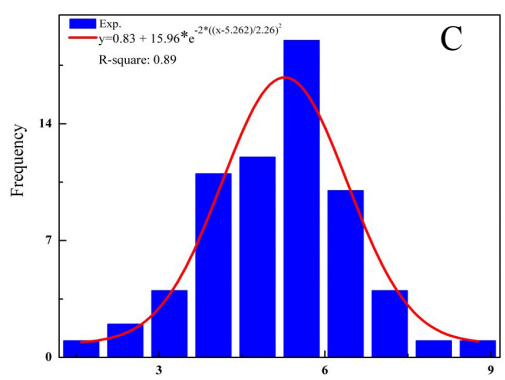

$D_{R}, \mu m^{2} \cdot s^{-1}$

Figure 5.5. Distribution of diffusion coefficient values of quantum dots in nanochannels (height of 150 $\mathrm{nm}$, width of $20 \mu \mathrm{m}$ and length of $50 \mu \mathrm{m})$ with 65 measurements. The bar graphs are experimental data; the red curves are Gaussian fitting functions. Most frequent values are from $5.5 \mu \mathrm{m}^{2} . \mathrm{s}^{-1}$ to $6 \mathrm{\mu m}^{2} . \mathrm{s}^{-1}$. (A) $D_{x},(B) D_{y}$ and (C) $D_{R}$.

\subsubsection{Discussion about observed reduced diffusion coefficient}

A reduction of $D$ values in NCs compared to bulk solution has been observed in different studies. Lyon et al. [36] studied the motion of single R6G molecules inside $500 \mathrm{~nm}$ diameter capillary channels. Experimental results showed $D$ values which were 50 times lower than in bulk solution. This effect was explained by electrostatic interactions of the charged R6G molecules with the capillary wall. Furthermore, Pappaert et al. [37] measured the molecular $D$ of fluorescent molecules in NCs. The $D$ values for DNA oligomers in $260 \mathrm{~nm}$ deep channels were $30 \%$ lower than in $2.95 \mu \mathrm{m}$ channels. Moreover, the reduction of $D$ values inside the NCs appeared to correlate with the size of the diffusing molecules, as indicated by a reduction of only $5 \%$ for small fluorescein isothiocyanate molecules. Here, the effect was attributed to the presence of the channel walls which increases the number of interactions with the analyte molecules significantly in the case of nanometer-sized channels. In another study, Durand et al. [38] measured diffusion coefficients of a protein (38 KDa molecular weight) in $50 \mathrm{~nm}$ high NCs and found $D$ values four orders of magnitude lower than in bulk solution. This was explained by dynamic adsorption and desorption of molecules on glass surfaces.

The slower diffusion coefficients observed inside NCs have been attributed to hydrodynamic and electrostatic interactions [36] of the molecules with the channel walls, and to absorption of molecules on the channel walls. More specifically, focusing on nanoparticles of similar size as in our study there are a few studies reporting a reduced mobility. Eichmann et al. [19] captured trajectories of $50 \mathrm{~nm}$ gold nanoparticles confined between glass surfaces separated by $350 \mathrm{~nm}$ silica colloid spacers. Observed lateral 
diffusion coefficients as small as $50 \%$ of predicted values were explained by hydrodynamic interactions with the confining walls and electroviscous effect, possibly being intensively enhanced due to overlap of electrostatic double layers around the particles and wall surfaces. Kaji et al. [20] observed a three times reduced mobility of 50 $\mathrm{nm}$ polystyrene beads (carboxylated) in water confined in a $400 \mathrm{~nm}$ tall $\mathrm{NC}$. The reduced mobility was explained by an increase of the water viscosity due to confinement.

To explain the deviation of the $D$ values in our experiments with QDs moving in 150 $\mathrm{nm}$ high NCs, we considered effects such as the modified Stokes drag in confinement and electrostatic interactions. Even though sticking or adsorption of the QDs to the channel walls was considered to contribute to a decrease of $D$ values [36-37], it was rejected because of the expected repulsion of the QDs from the channel walls since both are negatively charged in our experiments.

From the ratio of the modified Stokes force in confinement and the Stokes force in bulk solution, the expected deviation from the Einstein-Stokes relation can be extracted [16]:

$\frac{\mu_{\text {confinement }}}{\mu_{\text {bulk }}}=\left[1-\frac{9}{16}\left(\frac{r}{d}\right)+\frac{1}{8}\left(\frac{r}{d}\right)^{3}-\frac{45}{256}\left(\frac{r}{d}\right)^{4}-\frac{1}{6}\left(\frac{r}{d}\right)^{5}\right]$

where $\mu$ is mobility of the particle, $r$-the radius of the particle and $d$-the average distance from the particles to the channel walls. From equation 5.7, assuming an average distance $d=65 \mathrm{~nm}$ (the distance for the QDs staying at the centre plane of the channel), the ratio between the mobility in confinement and in bulk solution appears to be about 0.88 , indicating a decrease of mobility due to hydrodynamic interactions between particles and channel walls. Although the generated reduction is only moderate, we consider hydrodynamic effects as partially responsible for the three times lower mobility observed in our experiments. Note that equation 5.7 is valid for the ratios $d / r$ ranging from 1 to 10 .

Kaji et al. [20] suggested a change of the bulk viscosity of water due to confinement to be responsible for the reduced mobility. Note that the possible increased viscosity of water near polar or charged walls is a long-disputed subject. Some suggest an increased viscosity that extends in the order of $10 \mathrm{~nm}$ into the liquid [12], while other experimental studies indicate that there is no such effect and water retains its bulk viscosity within less than a nanometer distance from the wall [13]. Recent atomic force mircoscopy (AFM) 
measurements indicate that there is a repulsive structural force and an associated increased viscosity of water which extends about $1 \mathrm{~nm}$ into the liquid [15]. This result is consistent with viscosity measurements through analysis of the capillary filling dynamics of NCs with a typical diameter of $10 \mathrm{~nm}$ [14]. Based on the latter two studies one should conclude that it is unlikely that a real viscosity effect is responsible for the reduced mobility of the QDs confined to a $150 \mathrm{~nm}$ tall spacing.

Next, the electroviscous effect was considered. The mechanism is that, when a suspended particle is randomly moving in a quiescent liquid due to thermal motion, surrounding ions in the electrical double layer of this particle are dragged along due to the motion of the other particle. This effect has been described before in the work of Ohshima et al. [39] and Cox [40] who studied the electroviscous effects on the motion of sedimented particles. Here, the charged particles were sedimented in a liquid without wall present and the electrical double-layer thickness was very much smaller than the particle size. The ratio between the drag and ideal Stokes drag is as follows [40]:

$$
\frac{\mu_{E V E}}{\mu_{\text {bulk }}}=4\left[\frac{\left(\varepsilon \varepsilon_{o}\right)^{2}(k T)^{3}}{(z e)^{4} \eta n_{\infty} r^{2}}\right]\left(G^{2}+H^{2}\right)
$$

where $G$ and $H$ are defined as [40]

$$
\begin{aligned}
& G=\ln \frac{1}{2}\left[1+\exp \left(-\frac{1}{2} \widetilde{\psi}_{p}\right)\right], \\
& H=\ln \frac{1}{2}\left[1+\exp \left(\frac{1}{2} \widetilde{\psi}_{p}\right)\right] .
\end{aligned}
$$

Here $k$ is the Boltzmann constant, $z$-the ionic valence, $e$-the charge of a proton, $n_{\infty}$-the ionic concentration, $\widetilde{\psi}_{p}$-the dimensionless surface potential of particles. Derivation of equation 5.8 was based on the assumption that the Debye length, a measure for the electrical double-layer thickness, is smaller than the particle radius. In our experiments however, the Debye length is probably larger than the particle radius and therefore we have to use the numerical calculation presented in figure 1 from Ohshima et al. [39], resulting in a reduction of $D$ values of about $10 \%$. Note that these models have been derived for particles in bulk solution. It has been suggested by Eichmann et al. [19] that, in the presence of a wall and in conditions of double-layer overlap, the reduction of mobility is much greater than predicted by the Ohshima and Cox models. However, so far this hypothesis is not supported by a quantitative model and has not been systematically 
tested. A logical step to test this hypothesis is to study the dependence of the effect on the electrolyte concentration and zeta potential of the particles. Altogether, we should conclude that at this moment there is no sound theory existing to explain the reduced mobility by us and by other teams.

\subsection{Conclusions}

We fabricated NCs of $150 \mathrm{~nm}$ height that were connected to microchannels and macro inlet ports using a bond-micromachining technique. The NCs were used to carry out filling experiments. Visualization of single quantum-dot nanoparticles was realized after filling with a $12 \mathrm{nM}$ solution. The combination of a NC, a high NA lens and a sensitive intensified CCD camera established a platform for single-molecule studies at relatively high concentration. Random movements of single QDs were observed consistent with the classical Brownian motion theory. We experimentally determined the diffusion coefficients of single QDs by image analysis revealing the mean square displacements. The diffusion coefficients of single QDs moving inside NCs were found to be three times smaller than theoretically expected for $12.5 \mathrm{~nm}$ radius of particles in bulk solution. The observed reduced mobility confirms and extends the results of Eichmann who found a $50 \%$ reduced mobility of $50 \mathrm{~nm}$ particles in a $350 \mathrm{~nm}$ confinement. The observed reduce mobility cannot be explained by conventional hydrodynamic and electroviscous theories. Follow-up studies should concentrate on modeling of the electroviscous effect under conditions of double-layer overlap, and on experiments in which the dependence of the particle mobility on electrolyte concentration is measured.

\subsection{References}

[1] Cosentino, C.; Amato, F.; Walczak, R.; Boiarski, A.; Ferrari. M. Dynamic model of biomolecular diffusion through two-dimensional nanochannels. J. Phys. Chem. B 2005, 109 (15), 7358-7364.

[2] Wang, M.; Jing, N.; Su, C. B.; Kameoka, J.; Chou, C. K.; Hung, M. C.; Chang, K. A. Electrospinning of silica nanochannels for single molecule detection. Appl. Phys. Lett. 2006, 88 (3), 033106.

[3] Kievsky, Y. Y.; Carey, B.; Naik, S.; Mangan, N.; Ben-Avraham D.; Sokolov, I. Dynamics of molecular diffusion of rhodamine $6 \mathrm{G}$ in silica nanochannels. J. Chem. Phys. 2008, 128 (15), 151102. 
[4] Douville, N.; Huh, D.; Takayama, S. DNA linearization through confinement in nanofluidic channels. Anal. Bioanal. Chem. 2008, 391 (7), 2395-2409.

[5] Stavis, S. M.; Edel, J. B.; Li, Y.; Samiee, K. T.; Luo, D.; Craighead. H. G. Singlemolecule mobility and spectral measurements in submicrometer fluidic channels. J. Appl. Phys. 2005, 98 (4), 044903.

[6] Pennathur, S.; Baldessari, F.; Santiago, J. G.; Kattah, M. G.; Steinman, J. B.; Utz, P. J. Free-solution oligonucleotide separation in nanoscale channels. Anal. Chem. 2007, 79 (21), 8316-8322.

[7] Bai, C.; Wang, C.; Xie, X. S.; Wolynes. P. G. Single molecule physics and chemistry. Proc. Natl. Acad. Sci. USA 1999, 96 (20), 11075-11076.

[8] Craighead, H. Future lab-on-a-chip technologies for interrogating individual molecules. Nature 2006, 442 (7101), 387-393.

[9] Ying, L. Single molecule biology: Coming of age. Mol. BioSyst. 2007, 3 (6), 377-380.

[10] Moerner, W. E. Those blinking single molecules. Science 1997, 277 (5329), 1059-1060.

[11] Baer, R.; Rabani, E. Theory of resonance energy transfer involving nanocrystals: the role of high multipoles. J. Chem. Phys. 2008, 128 (18), 184710.

[12] Churaev, N. V.; Soboley, V. D.; Zorin, Z. M. Special Discussion on Thin Liquid Films and Boundary Layers, Academic Press: NY 1971, 213-220.

[13] Israelachvili, J. N. Measurement of the viscosity of liquids in very thin films. J. Colloid Interf. Sci. 1986, 110 (1), 263-271.

[14] Haneveld, J.; Tas, N. R.; Brunets, N.; Jansen, H. V.; Elwenspoek, M. Capillary filling of sub-10 nm nanochannels. J. Appl. Phys. 2008, 104 (1), 014309.

[15] Li, T. D.; Gao, J.; Szoszkiewicz, R.; Landman U.; Riedo, E. Structured and viscous water in subnanometer gaps. Phys. Rev. B 2007, 75 (11), 115415.

[16] Goldman, A. J.; Cox, R. G.; Brenner, H. Slow viscous motion of a sphere parallel to a plane wall-I Motion through a quiescent fluid. Chem. Eng. Sci. 1967, 22 (4), 637-651.

[17] Banerjee, A.; Kilm, K. D. Experimental verification of near-wall hindered diffusion for the Brownian motion of nanoparticles using evanescent wave microscopy. Phys. Rev. E 2005, 72 (4), 042101.

[18] Choi, C. K.; Margraves, C. H.; Kihm, K. D. Examination of near-wall hindered Brownian diffusion of nanoparticles: Experimental comparison to theories by Brenner (1961) and Goldman et al (1967). Phys. Fluids 2007, 19 (10), 103305.

[19] Eichmann, S. L.; Anekal, S. G.; Bevan, M. A. Electrostatically confined nanoparticle interactions and dynamics. Langmuir 2008, 24 (3), 714-721. 
[20] Kaji, N.; Ogawa, R.; Oki, A.; Horiike, Y.; Tokeshi M.; Baba, Y. Study of water properties in nanospace. Anal. Bioanal. Chem. 2006, 386 (3), 759-764.

[21] Hoang, H. T.; Segers-Nolten, I. M.; de Boer, M. J.; Berenschot, J. W.; Tas, N. R.; Haneveld, J.; Elwenspoek, M. C. Fabrication and interfacing of nanochannel devices for single-molecule studies. J. Micromech. Microeng. 2009, 19 (6), 065017.

[22] The concentration of the QD stock solution was $12 \mu \mathrm{M}$ as determined from absorbance spectroscopy using Beer-Lambert law [23]:

$A=\varepsilon c l$

Where $A$ is absorbance of the quantum-dot solution at $580 \mathrm{~nm}(0.28), \varepsilon$ is the extinction coefficient (223 $000 \mathrm{~L} \cdot \mathrm{mol}^{-1} \cdot \mathrm{cm}^{-1}$ at $\left.580 \mathrm{~nm}\right), c$ is the molar concentration (M) and $l$ is the pathlength $(0.1 \mathrm{~cm})$.

[23] Sun, J.; Goldys, E. M. Linear absorption and molar extinction coefficients in direct semiconductor quantum dots. J. Phys. Chem. C 2008, 112 (25), 9261-9266.

[24] Snijder-van As, M. I.; Rieger, B.; Joosten, B.; Subramaniam, V.; Figdor, C. G.; Kanger, J. S. A hybrid total internal reflection fluorescence and optical tweezers microscope to study cell adhesion and membrane protein dynamics of single living cells. J. Microsc. 2009, 233 (1), 84-92.

[25] ImageJ, Image processing and analysis in Java http://rsb.info.nih.gov/ij/.

[26] Matlab software from The Mathworks http://www.mathworks.com.

[27] Brown, R. A brief account of microscopical observations made in the months of June, July and August, 1827, on the particles contained in the pollen of plants; and on the general existence of active molecules in organic and inorganic bodies. Edinburgh New Philoso. J. 1828, 5, 358-371.

[28] Einstein, A. On the motion-required by the molecular kinetic theory of heat-of small particles suspended in a stationary liquid. Ann. Phys., Lpz. 1905, 17, 549-560.

[29] Einstein, A. Investigations on the Theory of the Brownian Movement, ed. By Furth, R., tr. by Cowper, A. D.; Dover publications, Inc.: NY 1926.

[30] Ray, D. S. Notes on Brownian Motion and Related Phenomena. arXiv: physics/9903033v2.

[31] In a nanochannel with volume $v=h \times w \times l=150.10^{-9} \times 20.10^{-6} \times 50.10^{-6}=15.10^{-17}$ $\mathrm{m}^{3}$ filled with a $12 \mathrm{nM}$ concentration solution, there are 1080 QDs to be expected. 
[32] Plecis, A.; Schoch, R. B.; Renaud, P. Ionic transport phenomena in nanofluidics: Experimental and theoretical study of the exclusion-enrichment effect on a chip. Nano Lett. 2005, 5 (6), 1147-1155.

[33] Garcia-Palacios, J. L. Introduction to the Theory of Stochastic Processes and Brownian Motion Problems. arXiv:cond-mat/0701242v1.

[34] Saxton, M. J. Single-particle tracking: the distribution of diffusion coefficients. Biophys. J. 1997, 72 (4), 1744-1753.

[35] From the Einstein-Stokes relation (equation 5.1), the diffusion coefficient of the QDs in bulk solution was calculated based on their radius and viscosity of media:

$$
D=\frac{R T}{6 \pi N_{A} \eta r}=\frac{8.31 \times 298}{6 \pi \times 6.023 \times 10^{23} \times 0.001 \times 12.5 \times 10^{-9}}=17\left(\mu m^{2} \cdot s^{-1}\right)
$$

[36] Lyon, W. A.; Nie. S. Confinement and detection of single molecules in submicrometer channels. Anal. Chem. 1997, 69 (16), 3400-3405.

[37] Pappaert, K.; Biesemans, J.; Clicq, D.; Vankrunkelsven, S.; Desmet, G. Measurements of diffusion coefficients in 1D micro- and nanochannels using shear-driven flows. Lab Chip 2005, 5 (10), 1104-1110.

[38] Durand, N. F. Y.; Bertsch, A.; Todorova, M.; Renaud P. Direct measurement of effective diffusion coefficients in nanochannels using steady-state dispersion effects. Appl. Phys. Lett. 2007, 91 (20), 203106.

[39] Ohshima, H.; Healy, T. W.; White, L. R. Sedimentation velocity and potential in a dilute suspension of charged spherical colloidal particles. J. Chem. Soc. Faraday Trans. 2 1984, 80 (10), 1299-1317.

[40] Cox, R. G. Electroviscous forces on a charged particle suspended in a flowing liquid. $J$. Fluid Mech. 1997, 338, 1-34. 


\section{Chapter 6}

\section{Conclusions and outlook}

In this chapter, a summary of fabrication and applications of nanochannels is presented. Nanochannels with the depth and the width in nanometer scale have been successfully fabricated using combination of standard techniques from micromachining. Fundamental studies such as channel wall deprotonation, water viscosity have been carried out to learn more about liquid properties in confining nanochannels. Prospective aspects of nanochannel fabrication and its applications will be given. 


\subsection{Conclusions}

Throughout this thesis, fabrication of nanochannels (NCs) and utilization of fabricated channels have been presented. In chapter two, we present NC devices and its interfacing fabricated using combination of surface, bulk and bond micromachining. Fabrication steps for 1D NCs were quite simple and straightforward, and reliably modified for different fundamental studies. 1D NC devices have been fabricated by bonding a bottom silicon substrate containing all structures (from nanotrenches to microtrenches then fluidic inlet ports) with a thin blank borofloat glass substrate as a cover. These devices with flexible configurations are suitable for using with an inverted microscope in combination with high numerical aperture (NA) lenses. Furthermore, 2D NCs with $30 \mathrm{~nm}$ height and $200 \mathrm{~nm}$ width have been presented in chapter two as well. By etching of a sacrificial layer, channels were formed by pulling-down of a thin-film capping layer to a substrate. Much effort was to integrate the fragile 2D NCs to inlet ports by deep reactive ion etching and to make channels transparent for optical observation by further oxidation of the polysilicon capping layer. Main achievement was to create a reliable process to obtain reproducible and complete 2D NCs ready for filling studies. Filling of fluorescence solution was carried out to confirm their function.

In chapter three, a new but simple approach has been developed to fabricate enclosed 2D NCs with both dimensions down to $20 \mathrm{~nm}$ on wafer scale. These fabricated NCs had welldefined cross-sections, and surrounded by the same (homogeneous) material (silicon oxide), which is favorable for many applications. Testing of the 2D NCs by filling with fluorescent solutions at relative low concentration has been carried out. By introducing 2D NCs as a confining media, the single-molecule level was expected to be achieved inside basedmicromachining NCs at higher concentrations compared to other methods such as near-field scanning optical microscopy, total internal reflection fluorescence microscopy and confocal microscope. We observed discrete fluorescent spots, however it was concluded that these were likely to be liquid pockets containing several individual molecules.

We explored a new phenomenon indicated by a decrease in the fluorescent activity of fluorescein during capillary filling, which has been presented in chapter four. The two observed fluorescent and nonfluorescent regions were explained by acidification of the solution due to deprotonation of the silanol groups from channel walls. A theoretical model has been established to explain the deprotonation mechanism by fitting to the data. This 
mechanism represented a unique way to titrate a solution without adding additional counter ions and to study the properties of a surface.

Furthermore, in chapter five, the mobility of $25 \mathrm{~nm}$ diameter quantum dots was measured by the combination of a $150 \mathrm{~nm}$ height $\mathrm{NC}$, a high NA lenses and a sensitive camera. Movements of single quantum dots inside 1D NCs followed Brownian motion. The movements in one dimension were characterized using Gaussian fitting while the movements in two dimensions were fitted by nonlinear least square regression fitting. The diffusion coefficient of single quantum dots in $16 \mathrm{nM}$ concentration has experimentally been determined by image investigation of their displacements. The diffusion coefficient values of single quantum dots moving inside NCs were found to be three times smaller than in the bulk solution. The deviation of the diffusion coefficients was explained by considering different effects such as electroviscous, conventional hydrodynamic, electrostatic interactions, etc. Among them electroviscous effect is the most likely, however still disputed.

\subsection{Outlook and recommendations}

Procedures for fabrication of NCs and integration of the fabricated NCs to macro world can apply for silicon substrates and glass substrates as well (appendices 6.1 and 6.2). Glass NCs are preferred for separation applications because of electrical isolation and optical transparency. Furthermore, 1D NC devices with confined spaces are very much attractive for fundamental and applied studies of fluid behavior.

In this thesis a few fundamental studies have been carried out to prove the possibilities of utilization of the fabricated 1D NCs. Nanofluidics transport behavior can be observed and analyzed based on deprotonation effects on fluorescent solutions happening inside NCs. The understanding of the effects in nanostructure surfaces (due to a high surface-to-volume ratio) on the solution $\mathrm{pH}$ and the resulting changes in surface potentials is of great significance especially in chemical analysis. This phenomenon occurs not only during liquid filling but also when there is changing of $\mathrm{pH}$ or ionic strength. This will be very important for the analysis of biological samples because of its complex matrix composition. The implications of these fundamental properties of silicon oxide NCs are important for analytical strategies and in particular the analysis of complex biological samples.

Mobility study should be further carried out with consideration of effects from channel dimensions and ionic strength of the solution. A theoretical model could be constructed to verify effects causing the deviation of diffusion coefficients of quantum dots. Moreover, 
single-molecule mobility indicates promising prospects for utilization of the NCs for various applications, like e.g. single-molecule position tracking at physiologically relevant concentrations. It helps to discover more information from individual molecules that is different from the collective molecules or bulk solutions (due to ensemble-averaged macroscopic parameters).

2D NC devices fabricated by micromachining techniques with both dimensions as small as $20 \mathrm{~nm}$ have offered many prospective applications in the new field of nanobiotechnology. 2D NCs have given very promising opportunities of new applications in nanoconfinement which are not available in the large systems. Fundamental studies in nanofluidics systems [1], DNA stretching and analysis [2-3], chemical analysis and synthesis [4], separation (chromatography) [5], and nanobiological fields [6-7] are very attractive applications for these channels.

More effort should be spent on creating 2D NCs with dimensions smaller than $10 \mathrm{~nm}$. These confined channels are in high demand; however it is very difficult to achieve due to difficulties in controlling the size of nanospaces and sealing the nanospaces without completely closing. Nanospaces could be narrower by reducing thickness of the silicon oxide layer, well defining the underetching areas and oxidizing the silicon layer (bottom of nanospaces). Furthermore, sealing process could be improved by precise control of the direction of evaporated materials.

\subsection{References}

[1] Hibara, A.; Tsukahara, T.; Kitamori, T. Integrated fluidic systems on a nanometer scale and the study on behavior of liquids in small confinement. J. Chromatogr. A 2009, 1216 (4), 673-683.

[2] Fan, Z. H.; Harrison, D. J. Micromachining of capillary electrophoresis injectors and separators on glass chips and evaluation of flow at capillary intersections. Anal. Chem. 1994, 66 (1), 177-184.

[3] Tegenfeldt, J. O.; Prinz, C.; Cao, H.; Huang, R. L.; Austin, R. H.; Chou, S. Y.; Cox, E. C.; Sturm, J. C. Micro- and nanofluidics for DNA analysis. Anal. Bioanal. Chem. 2004, $378(7), 1678-1692$.

[4] Gardeniers, H. J. G. E. Chemistry in nanochannel confinement. Anal. Bioanal. Chem. 2009, 394 (2), 385-397. 
[5] Detobel, F.; Fekete, V.; De Malsche, W.; De Bruyne, S.; Gardeniers, H.; Desmet, G. Estimation of surface desorption times in hydrophobically coated nanochannels and their effect on shear-driven and pressure-driven chromatography. Anal. Bioanal. Chem. 2009, 394 (2), 399-411.

[6] Craighead, H. Future lab-on-a-chip technologies for interrogating individual molecules. Nature 2006, 442 (7101), 387-393.

[7] Mannion, J. T.; Craighead. H. G. Nanofluidic structures for single biomolecule fluorescent detection. Biopolymers 2006, 85 (2), 131-143. 


\section{Appendix}

\section{Appendix 2.1. Fabrication of 1D nanochannel devices}

\begin{tabular}{|c|c|c|}
\hline Process description & Parameters & Cross section after process \\
\hline Process on a silicon wafer & $\begin{array}{l}\text { - Supplier: Okmetic } \\
\text { - DSP <110> silicon wafer } \\
\text { - Diameter: } 100 \mathrm{~mm} \\
\text { - Thickness: } 380 \mu \mathrm{m} \\
\text { - Type: } \mathrm{p}\end{array}$ & t. \\
\hline Oxidation & $\begin{array}{l}\text { - Furnace: Amtech Tempress Omega Junior } \\
\text { - Temperature: } 950^{\circ} \mathrm{C} \\
\text { - Gas: } \mathrm{O}_{2}\left(41 . \mathrm{min}^{-1}\right) \\
\text { - Time: } 7 \mathrm{~h}\end{array}$ & L. \\
\hline $\begin{array}{l}\text { Lithography (nanotrench } \\
\text { structures) }\end{array}$ & $\begin{array}{l}\text { - Suss Micro TECH Spinner (Delta20, } \\
\text { Spinning acceleration: } 4000 \mathrm{rpm} \cdot \mathrm{s}^{-1} \text {, } \\
\text { Spinning speed: } 4000 \mathrm{rpm}) \\
\text { - Electronic Vision Group } 20 \text { Mask Aligner } \\
\left.\text { (Hg lamp: } 12 \mathrm{~mW} \cdot \mathrm{cm}^{-2}\right) \\
\text { - Dehydration bake }\left(120^{\circ} \mathrm{C}\right): 5 \mathrm{~min} \\
\text { - HMDS spinning } \\
\text { - Olin } 907-12 \mathrm{spinning} \\
\text { - Prebake }\left(95^{\circ} \mathrm{C}\right): 60 \mathrm{~s} \\
\text { - Exposure time: } 3 \mathrm{~s} \\
\text { - After-exposure bake }\left(120^{\circ} \mathrm{C}\right): 60 \mathrm{~s} \\
\text { - Development time: } 60 \mathrm{~s}\end{array}$ & L. \\
\hline $\mathrm{SiO}_{2}$ etching & $\begin{array}{l}\text { - Wet-Bench } \\
\text { - BHF (VLSI): Merck } \\
\text { - Etch rate: } 60-80 \mathrm{~nm} . \mathrm{min}^{-1} \\
\text { - Time: } 3 \mathrm{~min}\end{array}$ & 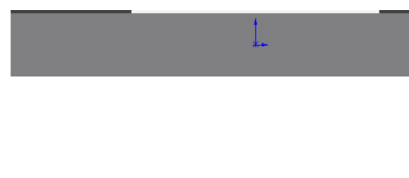 \\
\hline $\begin{array}{l}\text { Lithography (microtrench } \\
\text { structures) }\end{array}$ & $\begin{array}{l}\text { - Suss Micro TECH Spinner (Delta20, } \\
\text { Spinning acceleration: } 4000 \mathrm{rpm} \cdot \mathrm{s}^{-1} \text {, } \\
\text { Spinning speed: } 4000 \mathrm{rpm}) \\
\text { - Electronic Vision Group } 20 \text { Mask Aligner } \\
\left.\text { (Hg lamp: } 12 \mathrm{~mW} \cdot \mathrm{cm}^{-2}\right) \\
\text { - Dehydration bake }\left(120^{\circ} \mathrm{C}\right): 5 \mathrm{~min} \\
\text { - HMDS spinning } \\
\text { - Olin } 907-12 \mathrm{spinning} \\
\text { - Prebake }\left(95^{\circ} \mathrm{C}\right): 60 \mathrm{~s} \\
\text { - Exposure time: } 3 \mathrm{~s} \\
\text { - After-exposure bake }\left(120^{\circ} \mathrm{C}\right): 60 \mathrm{~s} \\
\text { - Development time: } 60 \mathrm{~s}\end{array}$ & 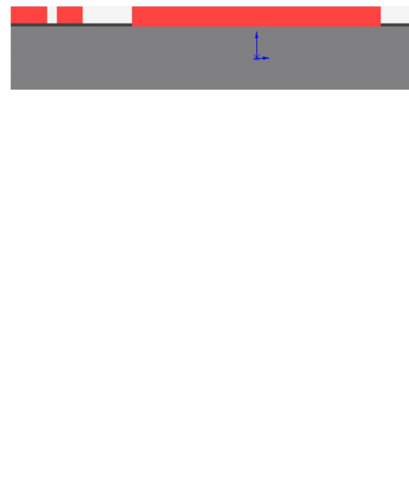 \\
\hline $\mathrm{SiO}_{2}$ etching & $\begin{array}{l}\text { - Wet-Bench } \\
\text { - BHF (VLSI): Merck } \\
\text { - Etch rate: } 60-80 \mathrm{~nm} \cdot \mathrm{min}^{-1} \\
\text { - Time: } 4 \text { min }\end{array}$ & L \\
\hline Silicon etching & $\begin{array}{l}\text { - Oxford Plasmalab } 100 \mathrm{ICP} \\
\text { - RIE procedure: Cryogenic process } \\
\text { - Temperature: }-110^{\circ} \mathrm{C} \\
\text { - } \mathrm{SF}_{6} \text { flow: } 120 \mathrm{sccm} \\
\text { - Pressure: } 10 \mathrm{Torr} \\
\text { - ICP power: } 600 \mathrm{~W} \\
\text { - He pressure: } 20 \mathrm{mbar} \\
\text { - Etching rate: } 4.7 \mu \mathrm{m} \cdot \mathrm{min}^{-1} \\
\text { - Time: } 40 \mathrm{~s}\end{array}$ & t. \\
\hline
\end{tabular}




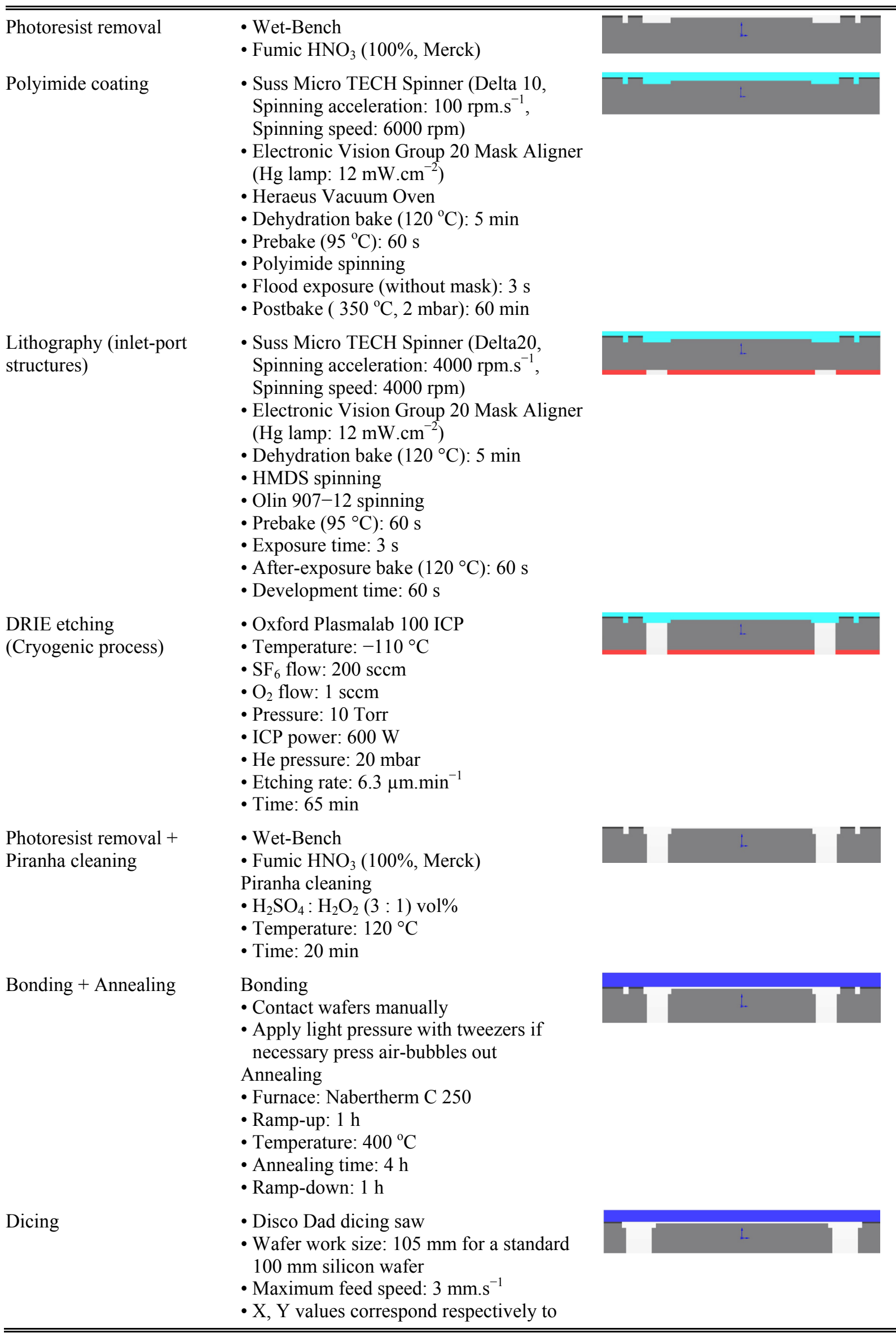


$\mathrm{Ch} 1$ and $\mathrm{Ch} 2$, and are determined by mask

layout

- Saw type: TC 300

- Select in blade menu: $2.187-12 \mathrm{~A}$

\section{Appendix 2.2. Fabrication of 2D nanochannel devices}

\begin{tabular}{|c|c|c|}
\hline Process description & Parameters & Cross section after process \\
\hline Select a silicon wafer & $\begin{array}{l}\text { - Supplier: Okmetic } \\
\text { - DSP }<100>\text { silicon wafer } \\
\text { - Diameter: } 100 \mathrm{~mm} \\
\text { - Thickness: } 525 \mu \mathrm{m} \\
\text { - Type: } \mathrm{p}\end{array}$ & \\
\hline Oxidation & $\begin{array}{l}\text { - Furnace: Amtech Tempress Omega Junior } \\
\text { - Temperature: } 950^{\circ} \mathrm{C} \\
\text { - Gas: } \mathrm{O}_{2}\left(41 . \mathrm{min}^{-1}\right) \\
\text { - Time: } 2 \mathrm{~h}\end{array}$ & \\
\hline $\begin{array}{l}\text { Lithography (sacrificial } \\
\text { layer structures) }\end{array}$ & $\begin{array}{l}\text { - Suss Micro TECH Spinner (Delta20, } \\
\text { Spinning acceleration: } 4000 \mathrm{rpm} . \mathrm{s}^{-1} \text {, } \\
\text { Spinning speed: } 4000 \mathrm{rpm}) \\
\text { - Electronic Vision Group } 20 \text { Mask Aligner } \\
\left.\text { (Hg lamp: } 12 \mathrm{~mW} \cdot \mathrm{cm}^{-2}\right) \\
\text { - Dehydration bake }\left(120^{\circ} \mathrm{C}\right): 5 \mathrm{~min} \\
\text { - HMDS spinning } \\
\text { - Olin } 907-12 \mathrm{spinning} \\
\text { - Prebake }\left(95^{\circ} \mathrm{C}\right): 60 \mathrm{~s} \\
\text { - Exposure time: } 3 \mathrm{~s} \\
\text { - After-exposure bake }\left(120^{\circ} \mathrm{C}\right): 60 \mathrm{~s} \\
\text { - Development time: } 60 \mathrm{~s}\end{array}$ & \\
\hline $\mathrm{SiO}_{2}$ etching & $\begin{array}{l}\text { - Elektrotech PF310/340 } \\
\text { - Electrode temperature: } 25^{\circ} \mathrm{C} \\
\text { - } \mathrm{CHF}_{3} \text { flow: } 25 \mathrm{sccm} \\
\text { - Pressure: } 10 \mathrm{~m} \text { Torr } \\
\text { - Power: } 75 \mathrm{~W} \\
\text { - Etchrate: } 30-40 \mathrm{~nm} \cdot \mathrm{min}^{-1} \\
\text { - Time: } 5 \mathrm{~min}\end{array}$ & \\
\hline Polysilicon deposition & $\begin{array}{l}\text { - Furnace: Amtech Tempress Omega Junior } \\
\text { - } \mathrm{SiH}_{4} \text { flow: } 50 \mathrm{sccm} \\
\text { - Pressure: } 200 \mathrm{mTorr} \\
\text { - Temperature: } 590^{\circ} \mathrm{C} \text {; } \\
\text { - Deposition rate: } 5.5-7.5 \mathrm{~nm} \cdot \mathrm{min}^{-1} \\
\text { - Time: } 7 \text { min }\end{array}$ & \\
\hline $\begin{array}{l}\text { Lithography (opening } \\
\text { window) }\end{array}$ & $\begin{array}{l}\text { - Suss Micro TECH Spinner (Delta20, } \\
\text { Spinning acceleration: } 4000 \mathrm{rpm} . \mathrm{s}^{-1} \text {, } \\
\text { Spinning speed: } 4000 \mathrm{rpm}) \\
\text { - Electronic Vision Group } 20 \text { Mask Aligner } \\
\left.\text { (Hg lamp: } 12 \mathrm{~mW} \cdot \mathrm{cm}^{-2}\right) \\
\text { - Dehydration bake }\left(120^{\circ} \mathrm{C}\right): 5 \mathrm{~min} \\
\text { - HMDS spinning } \\
\text { - Olin } 907-12 \mathrm{spinning} \\
\text { - Prebake }\left(95^{\circ} \mathrm{C}\right): 60 \mathrm{~s} \\
\text { - Exposure time: } 3 \mathrm{~s} \\
\text { - After-exposure bake }\left(120^{\circ} \mathrm{C}\right): 60 \mathrm{~s} \\
\text { - Development time: } 60 \mathrm{~s}\end{array}$ & \\
\hline
\end{tabular}




\begin{tabular}{|c|c|}
\hline Polysilicon etching & $\begin{array}{l}\text { - Elektrotech PF310/340 } \\
\text { - Electrode temperature: } 10^{\circ} \mathrm{C} \\
\text { - } \mathrm{CHF}_{3} \text { flow: } 25 \mathrm{sccm} \\
\text { - } \mathrm{O}_{2} \text { flow: } 5 \mathrm{sccm} \\
\text { - Pressure: } 10 \mathrm{mTorr} \\
\text { - Power: } 75 \mathrm{~W} \\
\text { - Etchrate: } 30 \mathrm{~nm} \cdot \mathrm{min}^{-1} \\
\text { - Time: } 2 \mathrm{~min}\end{array}$ \\
\hline Photoresist removal & $\begin{array}{l}\text { - Wet-Bench } \\
\text { - Fumic } \mathrm{HNO}_{3}(100 \% \text {, Merck })\end{array}$ \\
\hline $\mathrm{SiO}_{2}$ etching & $\begin{array}{l}\text { - Wet-Bench } \\
\text { - } 50 \% \text { HF (VLSI): Merck } \\
\text { - Etchrate: } 1 \mu \mathrm{m} \cdot \mathrm{min}^{-1} \\
\text { - Time: } 2 \text { min }\end{array}$ \\
\hline Channel form & $\begin{array}{l}\text { - Wet-Bench } \\
\text { - Quick dump rinse }<0.1 \mu \mathrm{S} \\
\text { - Spin drying }\end{array}$ \\
\hline Annealing + Oxidation & $\begin{array}{l}\text { - Furnace: Amtech Tempress Omega Junior } \\
\text { Annealing } \\
\text { - Temperature: } 1150{ }^{\circ} \mathrm{C} \\
\text { - Gas: } \mathrm{N}_{2}\left(11 . \mathrm{min}^{-1}\right) \\
\text { - Time: } 2 \mathrm{~h} \\
\text { - Ramp: } 10^{\circ} \mathrm{C} \cdot \mathrm{min}^{-1} \\
\text { Oxidation } \\
\text { - Temperature: } 950^{\circ} \mathrm{C} \\
\text { - Gas: } \mathrm{O}_{2}\left(41 . \mathrm{min}^{-1}\right) \\
\text { - Time: } 3 \mathrm{~h}\end{array}$ \\
\hline TEOS deposition & $\begin{array}{l}\text { - Furnace: Amtech Tempress Omega Junior } \\
\text { - Recipe: } \mathrm{N}_{2} \\
\text { - Bubbler: } 40{ }^{\circ} \mathrm{C} \\
\text { - Pressure: } 400 \mathrm{mTorr} \\
\text { - Temperature: } 700{ }^{\circ} \mathrm{C} \\
\text { - Deposition rate: } 7-13 \text { nm. } \text { min }^{-1} \\
\text { - Time: } 70 \text { min }\end{array}$ \\
\hline $\begin{array}{l}\text { Coating + Lithography } \\
\text { (inlet-port structures) }\end{array}$ & $\begin{array}{l}\text { Coating on front side } \\
\text { - Suss Micro TECH Spinner (Delta20, } \\
\left.\text { Spinning acceleration: } 4000{\mathrm{rpm} . \mathrm{s}^{-1} \text {, }} \text { Spinning speed: } 4000 \mathrm{rpm}\right) \\
\text { - Electronic Vision Group } 20 \text { Mask Aligner } \\
\left.\text { (Hg lamp: } 12 \mathrm{~mW} . \mathrm{cm}^{-2}\right) \\
\text { - Dehydration bake }\left(120^{\circ} \mathrm{C}\right): 5 \mathrm{~min} \\
\text { - HMDS spinning } \\
\text { - Olin } 907-12 \mathrm{spinning} \\
\text { - Prebake }\left(95^{\circ} \mathrm{C}\right): 60 \mathrm{~s} \\
\text { Lithography on back side } \\
\text { - HMDS spinning } \\
\text { - Olin } 907-12 \mathrm{spinning} \\
\text { - Prebake }\left(95^{\circ} \mathrm{C}\right): 60 \mathrm{~s} \\
\text { - Exposure time: } 3 \mathrm{~s} \\
\text { - After-exposure bake }\left(120^{\circ} \mathrm{C}\right): 60 \mathrm{~s} \\
\text { - Development time: } 60 \mathrm{~s}\end{array}$ \\
\hline
\end{tabular}




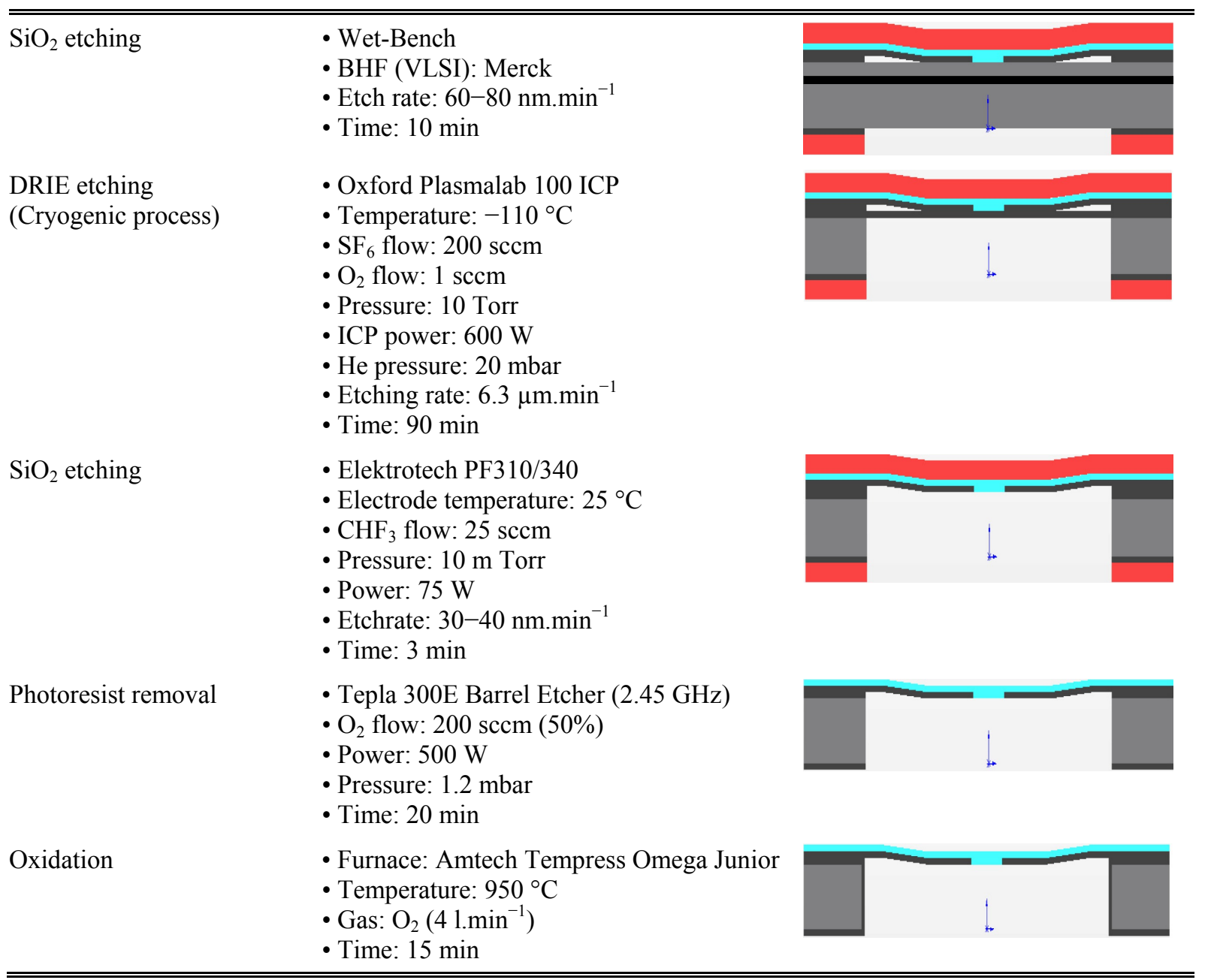

Appendix 2.3. Scanning confocal microscopy

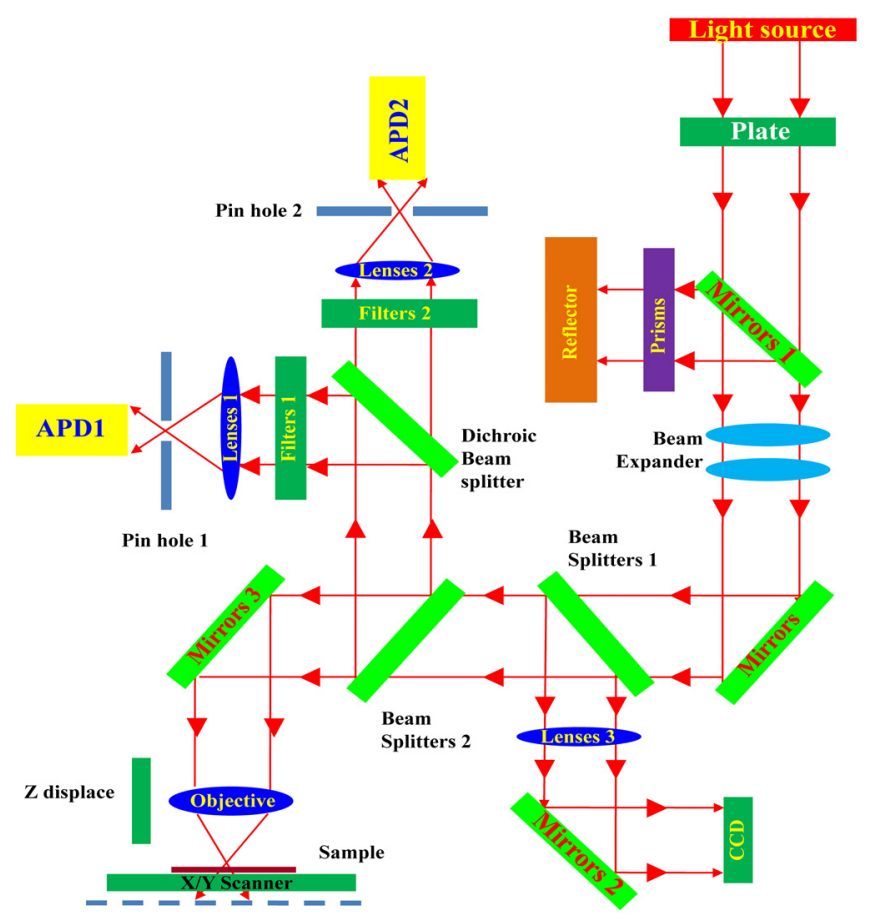

Figure A2.1. Principal scheme of scanning confocal microscopy. 
Appendix 3.1. Fabrication of 2D encapsulated nanochannel devices

\begin{tabular}{|c|c|c|}
\hline Process description & Parameters & Cross section after process \\
\hline Select a silicon wafer & $\begin{array}{l}\text { - Supplier: Okmetic } \\
\text { - DSP <100> silicon wafer } \\
\text { - Diameter: } 100 \mathrm{~mm} \\
\text { - Thickness: } 525 \mu \mathrm{m} \\
\text { - Type: } \mathrm{p}\end{array}$ & \\
\hline Oxidation & $\begin{array}{l}\text { - Furnace: Amtech Tempress Omega Junior } \\
\text { - Temperature: } 950{ }^{\circ} \mathrm{C} \\
\text { - Gas: } \mathrm{O}_{2}\left(41 . \mathrm{min}^{-1}\right) \\
\text { - Time: } 23 \mathrm{~min}\end{array}$ & \\
\hline SiRN deposition & $\begin{array}{l}\text { - Furnace: Amtech Tempress Omega Junior } \\
\text { - } \mathrm{SiH}_{2} \mathrm{Cl}_{2} \text { flow: } 70 \mathrm{sccm} \\
\text { - } \mathrm{NH}_{3} \text { flow: } 18 \mathrm{sccm} \\
\text { - Temperature: } 850{ }^{\circ} \mathrm{C} \\
\text { - Pressure: } 150 \mathrm{mTorr} \\
\text { - Deposition rate: } 3.9 \mathrm{~nm} \cdot \mathrm{min}^{-1} \\
\text { - Time: } 7 \text { min }\end{array}$ & \\
\hline $\begin{array}{l}\text { Lithography (nanotrench } \\
\text { structures) }\end{array}$ & $\begin{array}{l}\text { - Suss Micro TECH Spinner (Delta20, } \\
\text { Spinning acceleration: } 4000 \mathrm{rpm} \cdot \mathrm{s}^{-1} \text {, } \\
\text { Spinning speed: } 4000 \mathrm{rpm}) \\
\text { - Electronic Vision Group } 20 \text { Mask Aligner } \\
\left.\text { (Hg lamp: } 12 \mathrm{~mW} \cdot \mathrm{cm}^{-2}\right) \\
\text { - Dehydration bake }\left(120^{\circ} \mathrm{C}\right): 5 \mathrm{~min} \\
\text { - HMDS spinning } \\
\text { - Olin } 907-12 \mathrm{spinning} \\
\text { - Prebake }\left(95^{\circ} \mathrm{C}\right): 60 \mathrm{~s} \\
\text { - Exposure time: } 3 \mathrm{~s} \\
\text { - After-exposure bake }\left(120{ }^{\circ} \mathrm{C}\right): 60 \mathrm{~s} \\
\text { - Development time: } 60 \mathrm{~s}\end{array}$ & \\
\hline SiRN etching & $\begin{array}{l}\text { - Elektrotech PF310/340 } \\
\text { - Electrode temperature: } 10{ }^{\circ} \mathrm{C} \\
\text { - } \mathrm{CHF}_{3} \text { flow: } 25 \mathrm{sccm} \\
\text { - } \mathrm{O}_{2} \text { flow: } 5 \mathrm{sccm} \\
\text { - Pressure: } 10 \mathrm{mTorr} \\
\text { - Power: } 75 \mathrm{~W} \\
\text { - Etchrate } \mathrm{SiRN}: 50 \mathrm{~nm} \cdot \mathrm{min}^{-1} \\
\text { - Time: } 1 \mathrm{~min}\end{array}$ & \\
\hline Photoresist removal & $\begin{array}{l}\text { - Wet-Bench } \\
\text { - Fumic } \mathrm{HNO}_{3}(100 \%, \text { Merck })\end{array}$ & \\
\hline $\mathrm{SiO}_{2}$ etching & $\begin{array}{l}\text { - Wet-Bench } \\
\text { - } 1 \% \text { HF (VLSI): Merck } \\
\text { - Time: } 15 \mathrm{~min}\end{array}$ & \\
\hline $\mathrm{SiO}_{2}$ evaporation & $\begin{array}{l}\text { - BAK } 600 \\
\text { - Crucible: } 1\left(\mathrm{SiO}_{2}\right) \\
\text { - Voltage: } 10 \mathrm{kV} \\
\text { - Base pressure: }<10^{-6} \mathrm{mBar} \\
\text { - Density: } 2.7 \mathrm{~g} . \mathrm{cm}^{-3} \\
\text { - Tilt angle: } 20^{\circ} \\
\text { - Deposition rate: } 1-20 \text { A.s }^{-1}\end{array}$ & \\
\hline
\end{tabular}


Appendix 4.1. Filling images of Alexa and Bodipy

For supporting and comparing the deprotonation hypothesis, Alexa and Bodipy solutions were used to verify $p H$ effect from channel surfaces. Alexa with insensitive $p H$ and Bodipy with neutral charge were shown theirs relative independence of $p H$ (figure A4.1).
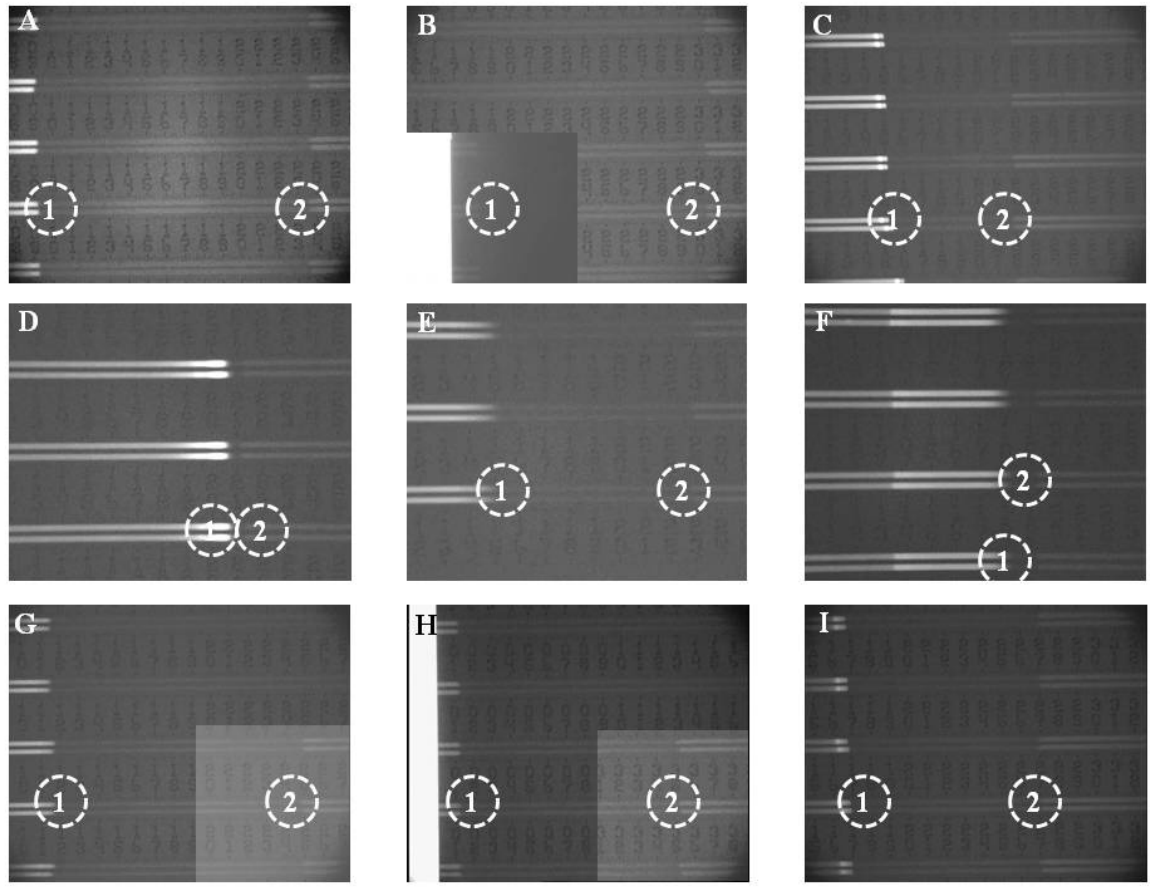

Figure A4.1. (1) Fluorescence front. (2) Liquid front. (A) Pure fluorescein. (B) Fluorescein + KCl. (C) Fluorescein + buffer. (D) Pure Alexa with both fluorescence and liquid meniscus; the distance between them is very small and about $0.1 \mathrm{~mm} .(E) \mathrm{Alexa}+\mathrm{KCl}$. (F) Alexa + buffer. (G) Pure Bodipy. (H) Bodipy $+\mathrm{KCl}$. (I) Bodipy + buffer.

Appendix 4.2. Process outline of 1D nanochannel devices for deprotonation studies

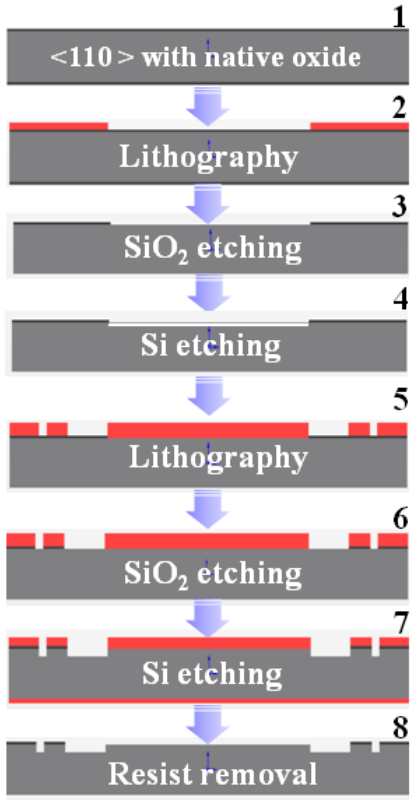

Borofloat glass wafer

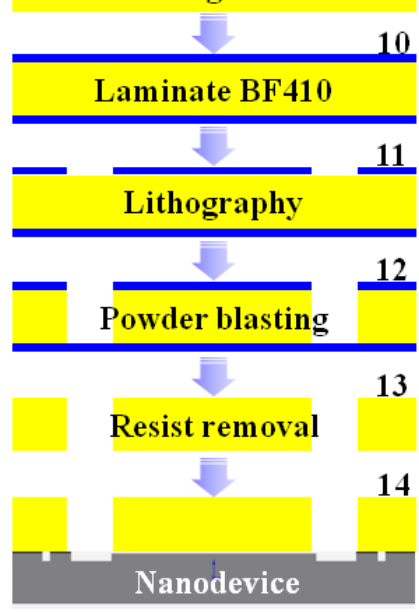

Figure A4.2. Process outline of $1 D$ nanochannel devices for deprotonation studies.

Appendix 4.3. Fabrication of $1 D$ nanochannel devices for deprotonation studies 


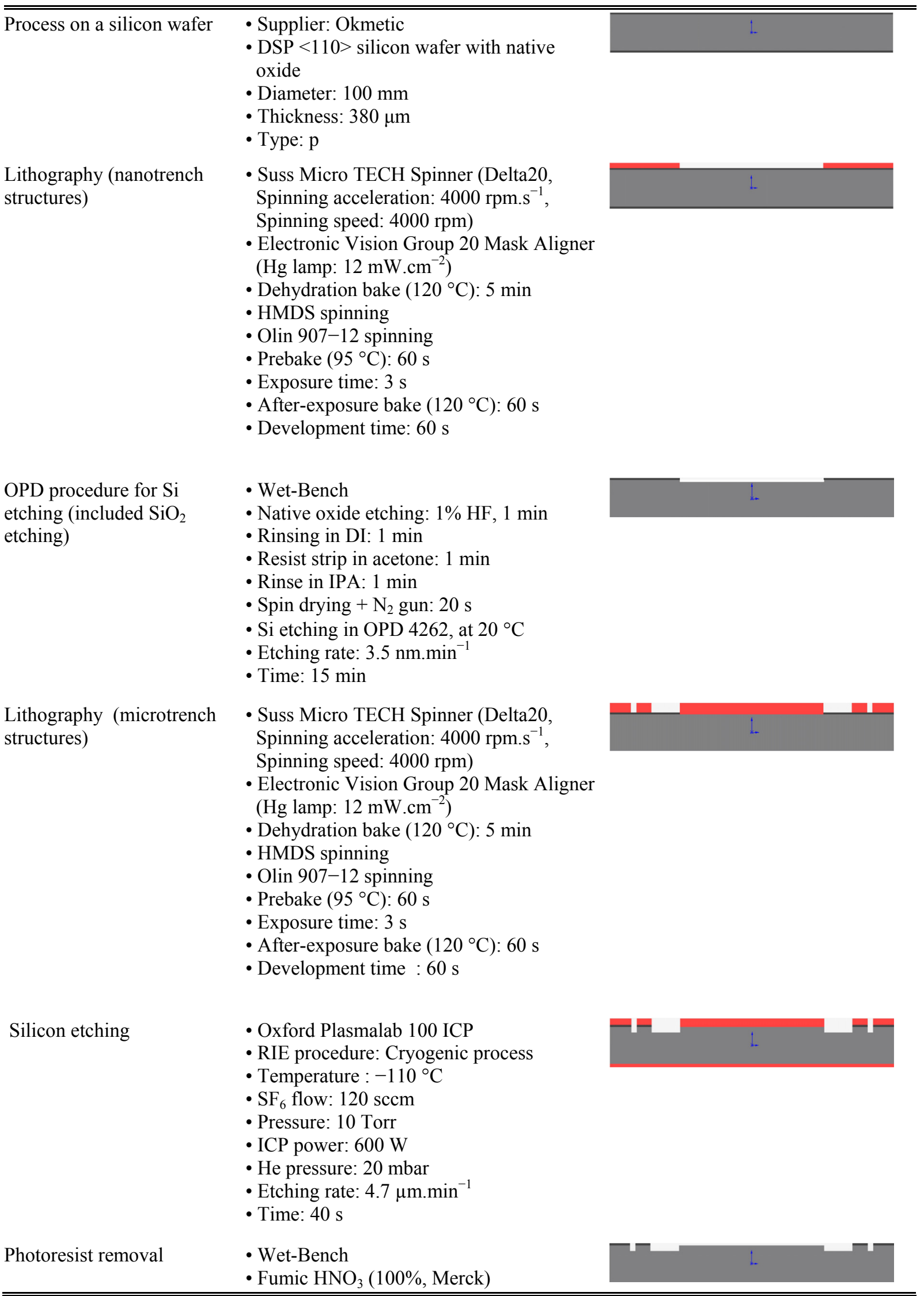




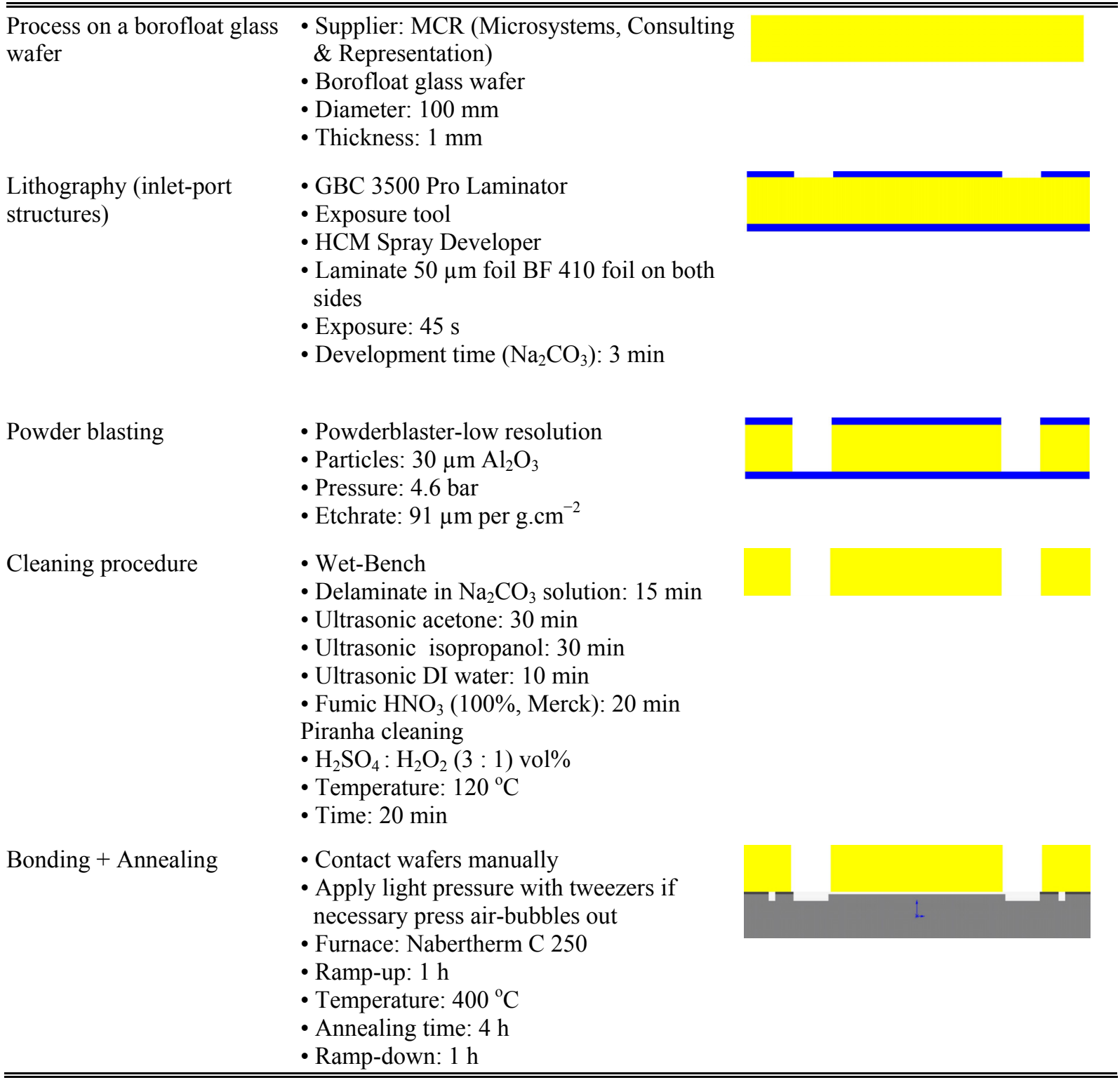

Appendix 4.4. Fluorescence experimental setup


Figure A4.3. (A) Systematic set-up of a fluorescence microscope. (B) Measurement set-up. 
Appendix 4.5. Raw data from a measurement with pure fluorescein

Table A4.1 shows raw data of a fluorescein solution filled in 1D nanochannels. Original times are the recorded times from the movie. Calculation was based on the off-set time which was supposed that the filling time was started at $0 \mathrm{~s}$.

Table A4.1. Raw data from a measurement of fluorescein filling

Original time

$$
\text { (s) }
$$

\begin{tabular}{|c|c|c|c|c|}
\hline 0 & 0 & 0 & 0 & - \\
\hline 19 & 2 & 0,54 & 1,5 & 0.640 \\
\hline 22 & 5 & 0,9 & 2,36 & 0.618 \\
\hline 25 & 8 & 1,18 & 2,94 & 0.599 \\
\hline 28 & 11 & 1,38 & 3,34 & 0.587 \\
\hline 35 & 18 & 1,78 & 4,34 & 0.590 \\
\hline 38 & 21 & 1,92 & 4,70 & 0.591 \\
\hline 41 & 24 & 2,04 & 5,00 & 0.592 \\
\hline 44 & 27 & 2,16 & 5,30 & 0.592 \\
\hline 47 & 30 & 2,26 & 5,62 & 0.598 \\
\hline 50 & 33 & 2,38 & 5,90 & 0.597 \\
\hline 53 & 36 & 2,48 & 6,04 & 0.589 \\
\hline 56 & 39 & 2,54 & 6,28 & 0.596 \\
\hline 59 & 42 & 2,68 & 6,50 & 0.588 \\
\hline 62 & 45 & 2,78 & 6,70 & 0.585 \\
\hline 65 & 48 & 2,86 & 6,88 & 0.584 \\
\hline 68 & 51 & 2,96 & 7,04 & 0.580 \\
\hline 71 & 54 & 3,04 & 7,24 & 0.580 \\
\hline 74 & 57 & 3,12 & 7,44 & 0.581 \\
\hline 77 & 60 & 3,2 & 7,64 & 0.581 \\
\hline 80 & 63 & 3,28 & 7,76 & 0.577 \\
\hline 83 & 66 & 3,36 & 7,92 & 0.576 \\
\hline 86 & 69 & 3,42 & 8,10 & 0.578 \\
\hline 89 & 72 & 3,48 & 8,26 & 0.579 \\
\hline 92 & 75 & 3,56 & 8,46 & 0.579 \\
\hline 95 & 78 & 3,62 & 8,52 & 0.575 \\
\hline 98 & 81 & 3,68 & 8,70 & 0.577 \\
\hline
\end{tabular}

*Meniscus ratio is defined by difference between liquid meniscus and fluorescein (FL) meniscus over liquid meniscus.

Liquid meniscus Meniscus ratio* $(\mathbf{m m})$

Appendix 5.1. Build matrix (convert text files to ASCII files named MAT files)

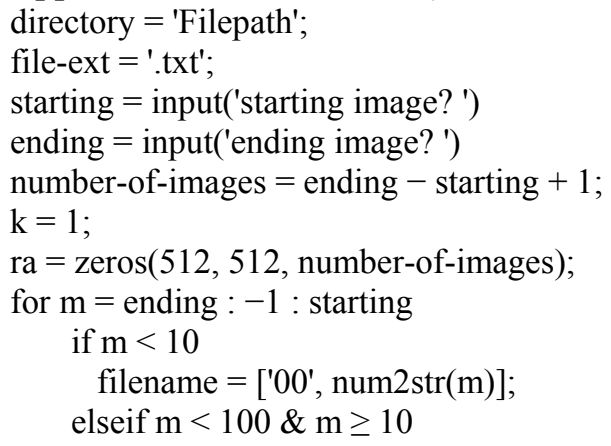

\% Example: 'D: \thesis \chapter5\filename.txt' $\%$ Starting image $=1$ $\%$ Ending image $=40$ $\%$ Write data file in ID directory $\%$ File names from 1 to 9 added "00" before 


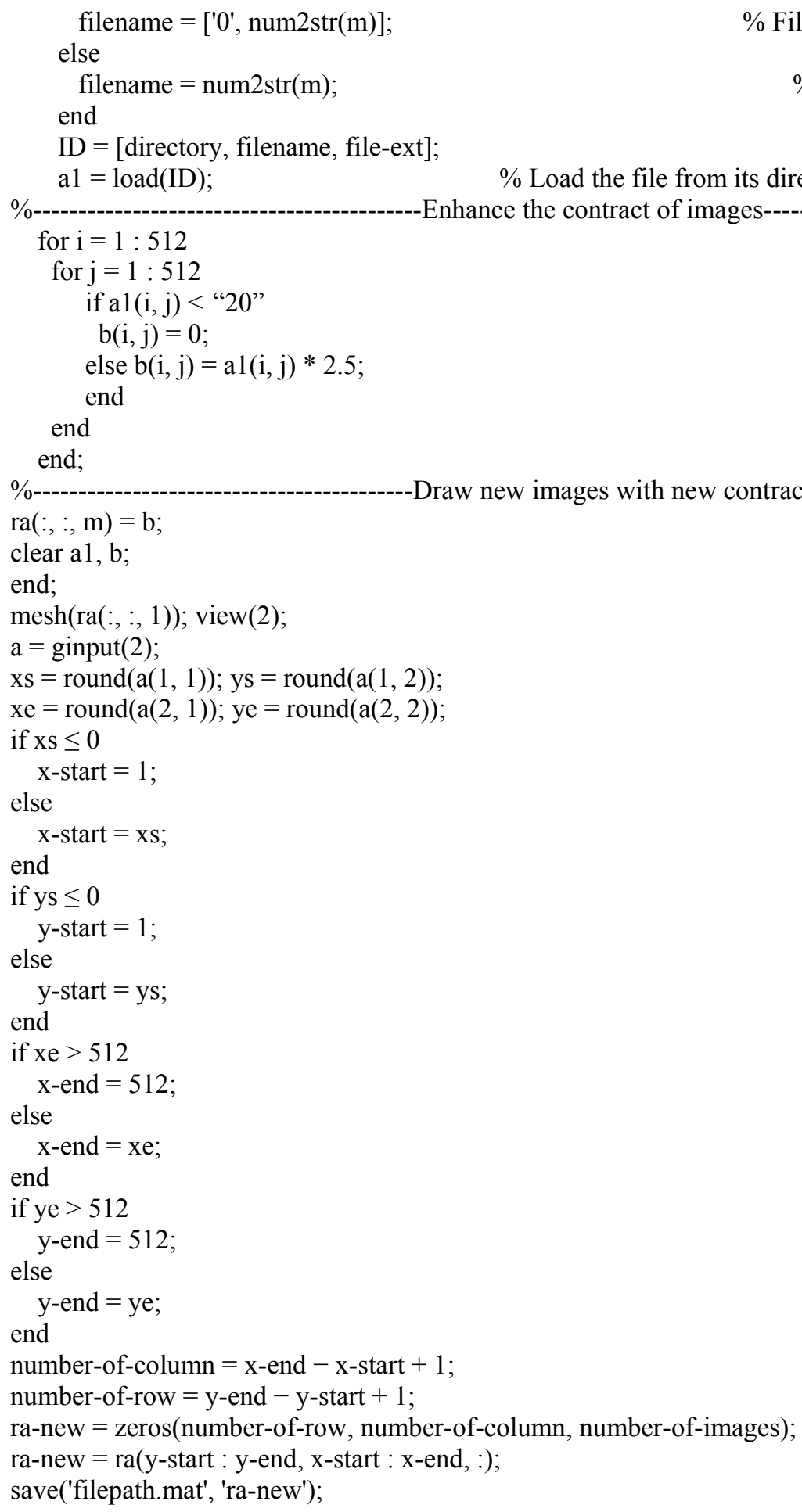

\section{Appendix 5.2. Quantum-dot tracking}

Positions of the single QD were manually determined from the Matlab images based on a window with three sequence images (figure A5.1). The middle was for the tracking image, the left for the previous image and the right for the coming image. It assisted to assure that the selected spot in the tracking image is corresponding to the spot from previous image. Then, positions were recorded as a set of coordinates $\left\{x_{i}, y_{i}\right\}$, where the index $i$ indicates the order of the image in a sequence and $1 \leq i \leq N_{s} ; N_{s}$ is number of images. $N_{s}$ was not too large (suggested $<100$ ) to prevent heating effect due to exciting laser beam. $N_{s}$ is normally 40 in our measurements. 

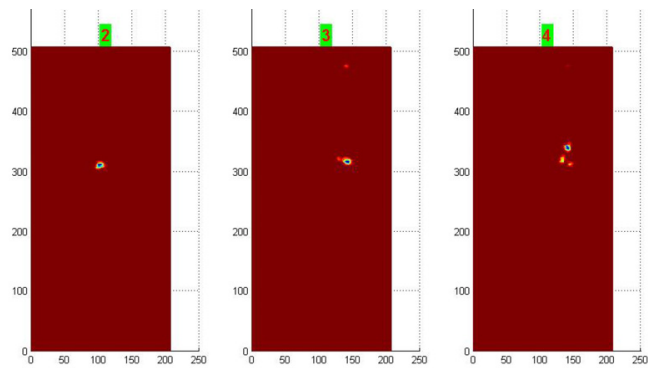

Figure A5.1. Determination of positions of quantum dots.






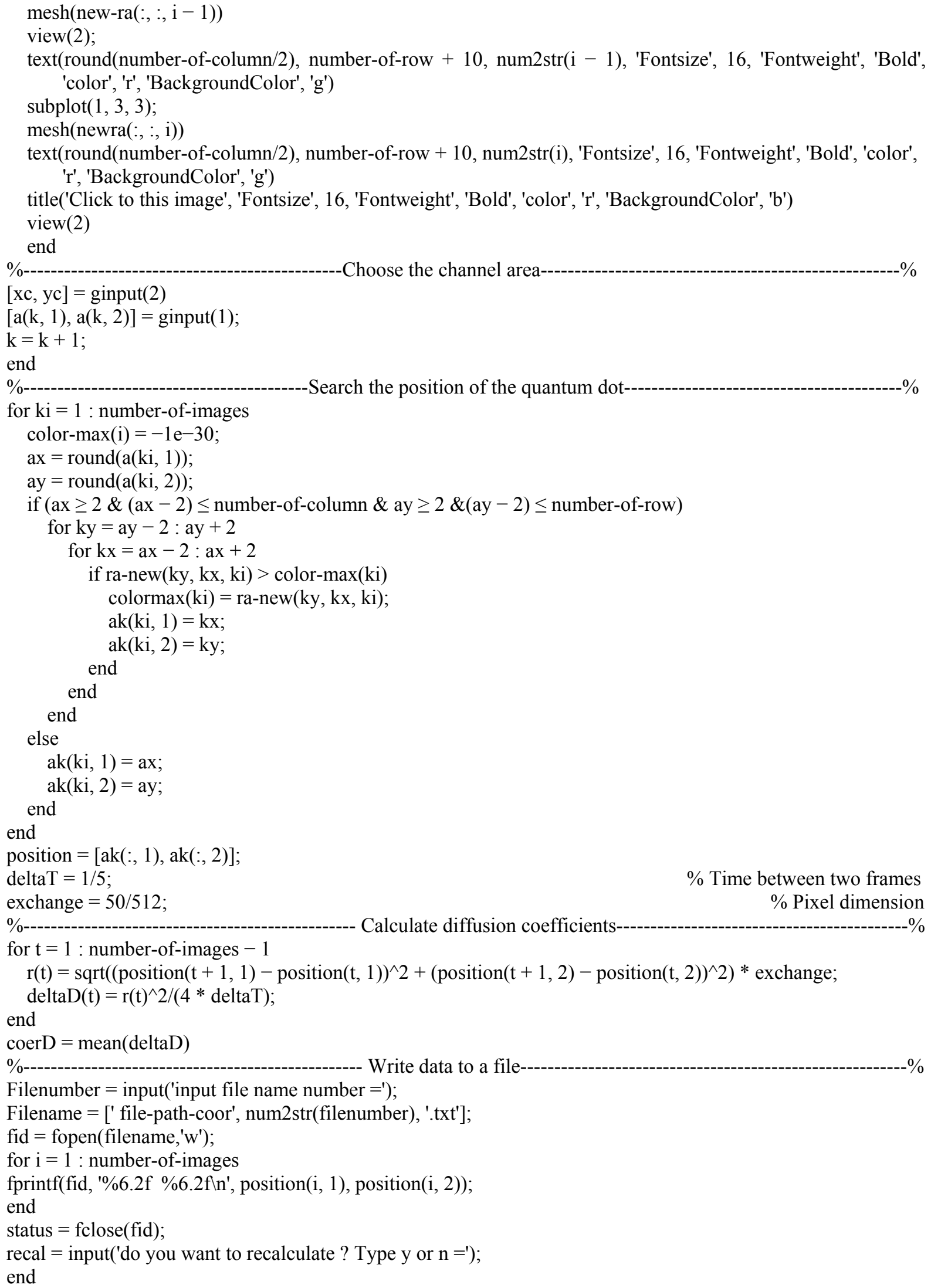

Appendix 5.3. Brownian motion (draw trajectories of a single quantum dot from one measurement) clear all;

deltaT $=1 / 5$;

exchange $=50 / 512$; 




Appendix 5.4a. Gaussian fitting (fit experimental data of one-dimensional movement histograms using Gaussian distribution)

deltaT $=1 / 5$;

exchange $=50 / 512$;

directory $=$ 'Folder-path-of-all-files';

dir-infol $=\operatorname{dir}($ directory);

file-quantities = length (dir-infol $)-2$;

$\operatorname{dir}$-info $=\operatorname{dir}$-infol $(3:$ end $)$

file-ext $=$ '.txt';

coordinate $=$ 'coor';

numb $=1$;

diffusion-coerf = zeros(file-quantities, 1 );

for $\mathrm{k}=1$ : file-quantities

for $\mathrm{i}=1:$ numb

filename $=$ num 2 str(in);

$\%$ Make string from input parameters

ID = [directory, 'l', dir-info(k).name, 'l',dir-info(k).name, coordinate, filename, file-ext]; $\operatorname{position}(:$, :, i) $=\operatorname{load}($ ID); end

$[\mathrm{r}, \mathrm{c}, \mathrm{la}]=\operatorname{size}($ position $)$;

\%------------------------------------------Calculate diffusion coefficients-

for $\mathrm{i}=1:$ numb

for $\mathrm{t}=1: \mathrm{r}-1$

$\operatorname{deltax}(t, i)=(\operatorname{position}(t+1,1, i)-\operatorname{position}(t, 1, i)) *$ exchange;

$\operatorname{deltay}(\mathrm{t}, \mathrm{i})=(\operatorname{position}(\mathrm{t}+1,2, \mathrm{i})-\operatorname{position}(\mathrm{t}, 2, \mathrm{i})) *$ exchange; 


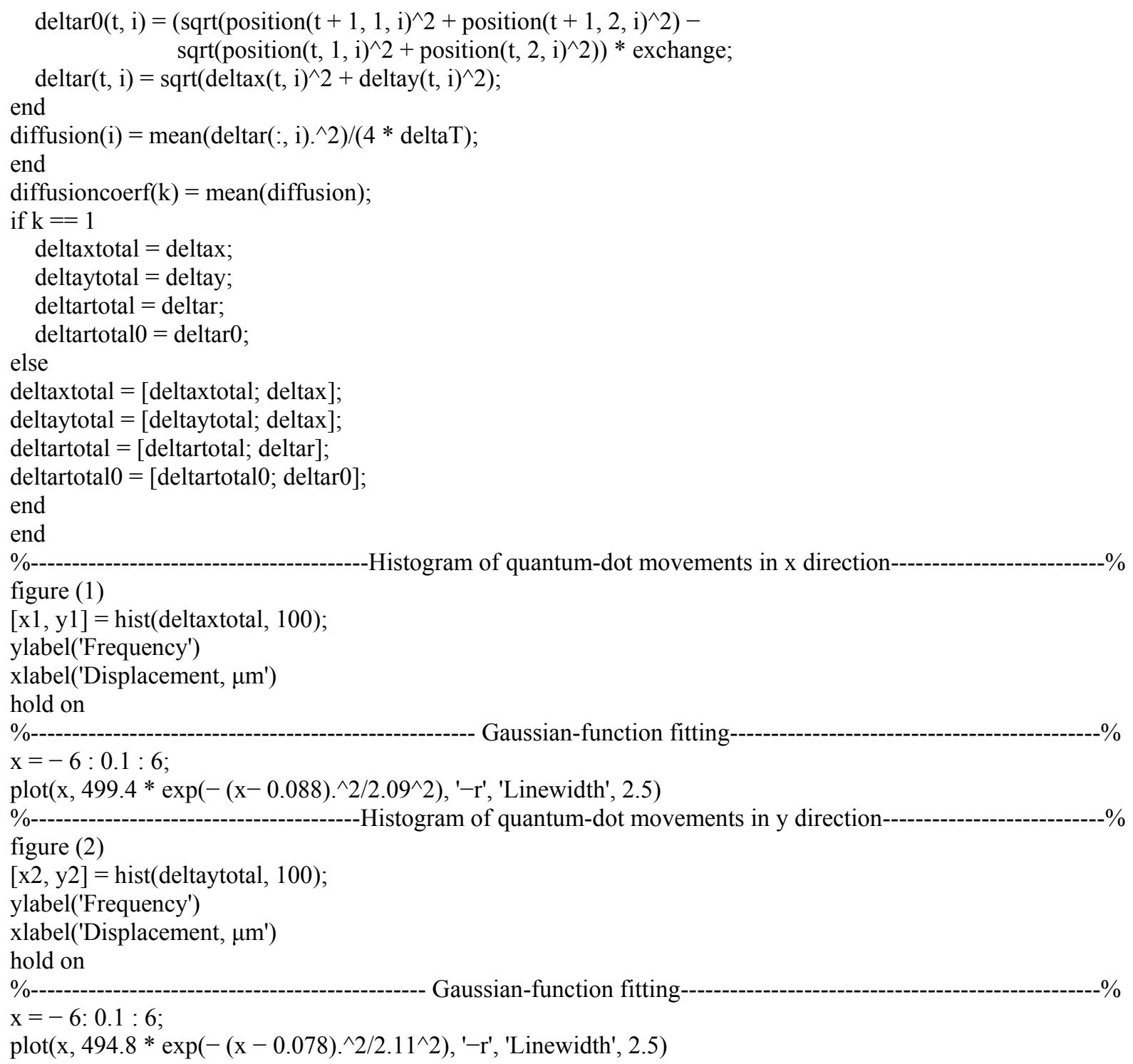

Appendix 5.4b. R-fitting (fit experimental data of two-dimensional movement histograms using with nonlinear least square regression function).

delta $=1 / 5$;

exchange $=50 / 512$;

directory $=$ 'Folder-path-of-all-files';

dir-infol $=\operatorname{dir}($ directory);

file-quantities $=$ length $(\operatorname{dir}-i n f o 1)-2$;

dir-info $=\operatorname{dir}$-info $1(3:$ end $)$;

file-ext $=$ '.txt';

coordinate $=$ 'coor';

numb $=1$;

diffusion-coerf = zeros(file-quantities, 1);

for $\mathrm{k}=1$ : file-quantities

for $\mathrm{i}=1:$ numb

filename $=$ num $2 \operatorname{str}($ in $)$;

ID = [directory, '\', dir-info(k).name,'’', dir-info(k).name, coordinate, filename, file-ext];

$\operatorname{position}(:$, :, i) $=\operatorname{load}($ ID);

end

$[\mathrm{r}, \mathrm{c}, \mathrm{la}]=\operatorname{size}($ position $)$;



for $\mathrm{i}=1:$ numb

for $\mathrm{t}=1: \mathrm{r}-1$ 


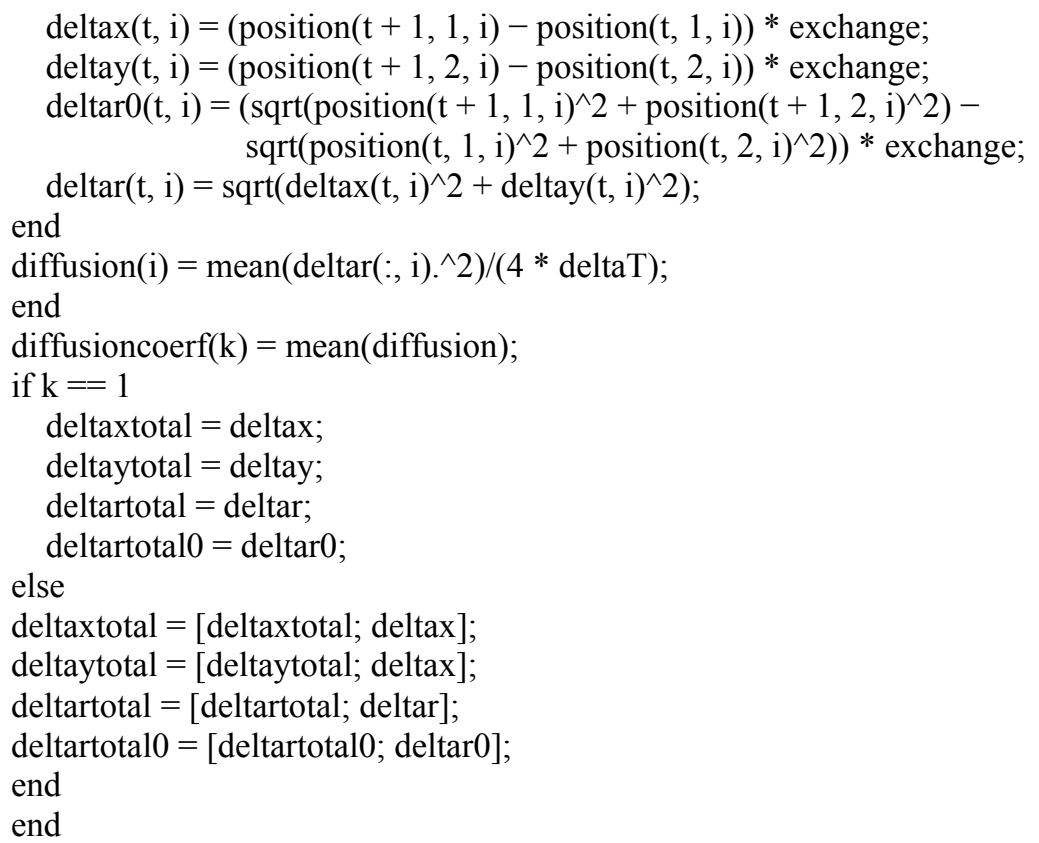

Appendix 5.5. MSD relation (determine the relation between MSD and interval times) clear all;

$\operatorname{deltaT}=1 / 5$

exchange $=50 / 512$;

number = 'filenumber';

directory $=$ ['filepath', number, 'limage', number, 'coor'];

file-ext $=$ '.txt';

numb $=$ input('number of files=');

for $\mathrm{i}=1:$ numb

filename $=$ num $2 \operatorname{str}(\mathrm{i})$

$\mathrm{ID}=[$ directory, filename, file-ext $] ; \quad \%$ Make string from input parameters

a1 $=\operatorname{load}($ ID);

$\%$ Load a file from its directory to memory and store in matrix a1

position $(:,,, \mathrm{i})=\mathrm{a} 1$;

end

$[\mathrm{r}, \mathrm{c}, \mathrm{la}]=\operatorname{size}($ position$)$;

timejump $=1$;

for $\mathrm{j}=1:$ numb

for $\mathrm{t}=1: \mathrm{r}-$ timejump

$\operatorname{deltarm}(\mathrm{t}, \mathrm{j})=\operatorname{sqrt}\left((\operatorname{position}(\mathrm{t}+\operatorname{timejump}, 1, \mathrm{j})-\operatorname{position}(\mathrm{t}, 1, \mathrm{j}))^{\wedge} 2+\right.$

$\left.(\operatorname{position}(\mathrm{t}+\text { timejump, } 2, \mathrm{j})-\operatorname{position}(\mathrm{t}, 2, \mathrm{j}))^{\wedge} 2\right) *$ exchange;

end 


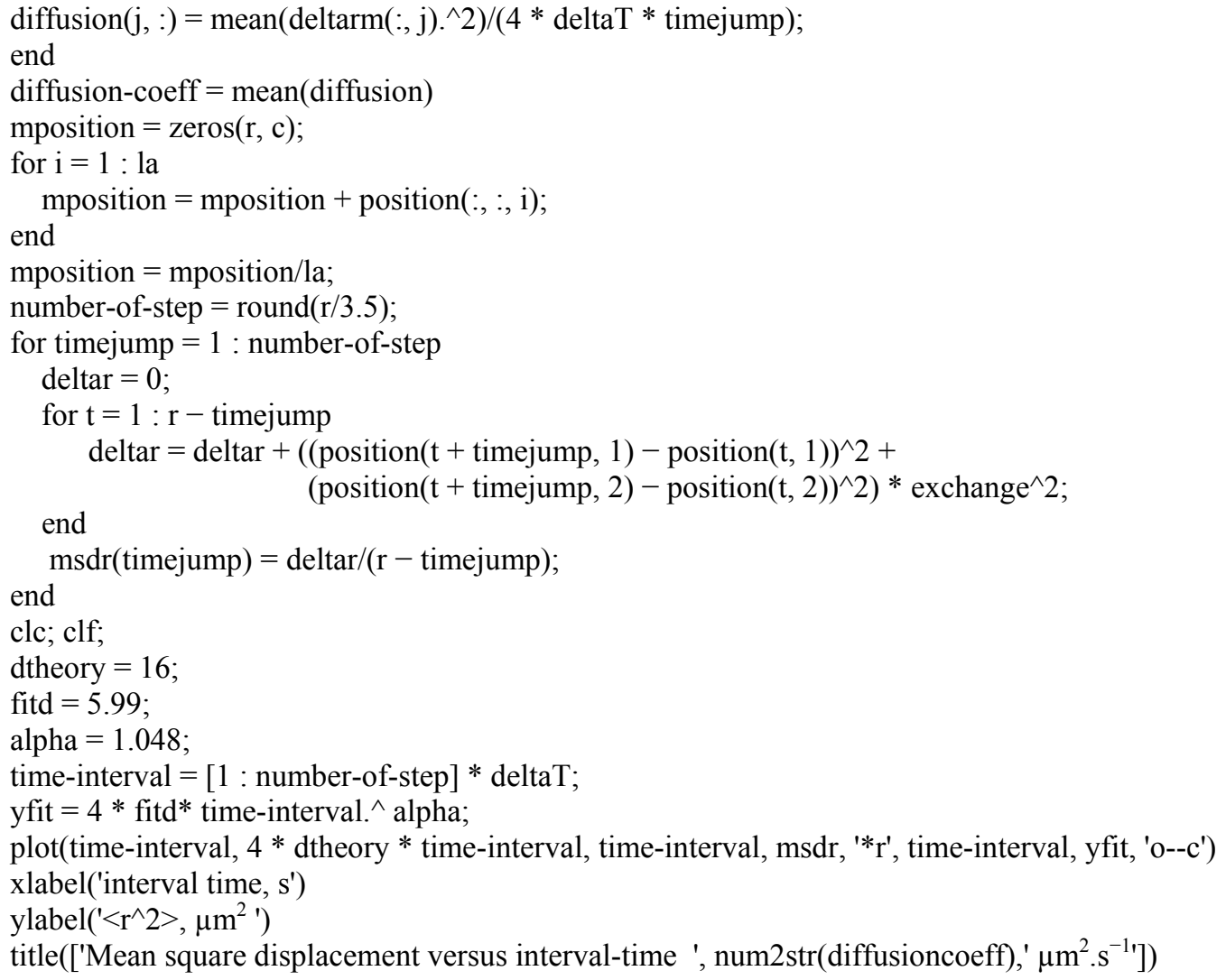

\section{Appendix 5.6. Distribution of diffusion coefficients}

time $=0.2$;

deltaT $=1 / 5$;

exchange $=50 / 512$;

directory = 'Folder-path-of-all-files';

dir-infol = $\operatorname{dir}($ directory $)$;

file-quantities $=$ length $($ dir-info 1$)-2$

$\operatorname{dir}$-info $=\operatorname{dir}$-infol $(3:$ end $)$

file-ext $=$ '.txt';

coordinate = 'coor';

numb $=1$;

diffusion-coerf $=$ zeros(file-quantities, 1$)$;

for $\mathrm{k}=1$ : file-quantities

for $\mathrm{i}=1:$ numb

filename $=$ num $2 \operatorname{str}($ in $)$;

$\%$ Make string from input parameters

ID = [directory, 'l', dir-info(k).name, 'l', dir-info(k).name, coordinate, filename, file-ext];

position(:, :, i) = load(ID); end

$[\mathrm{r}, \mathrm{c}, \mathrm{la}]=\operatorname{size}($ position $)$;

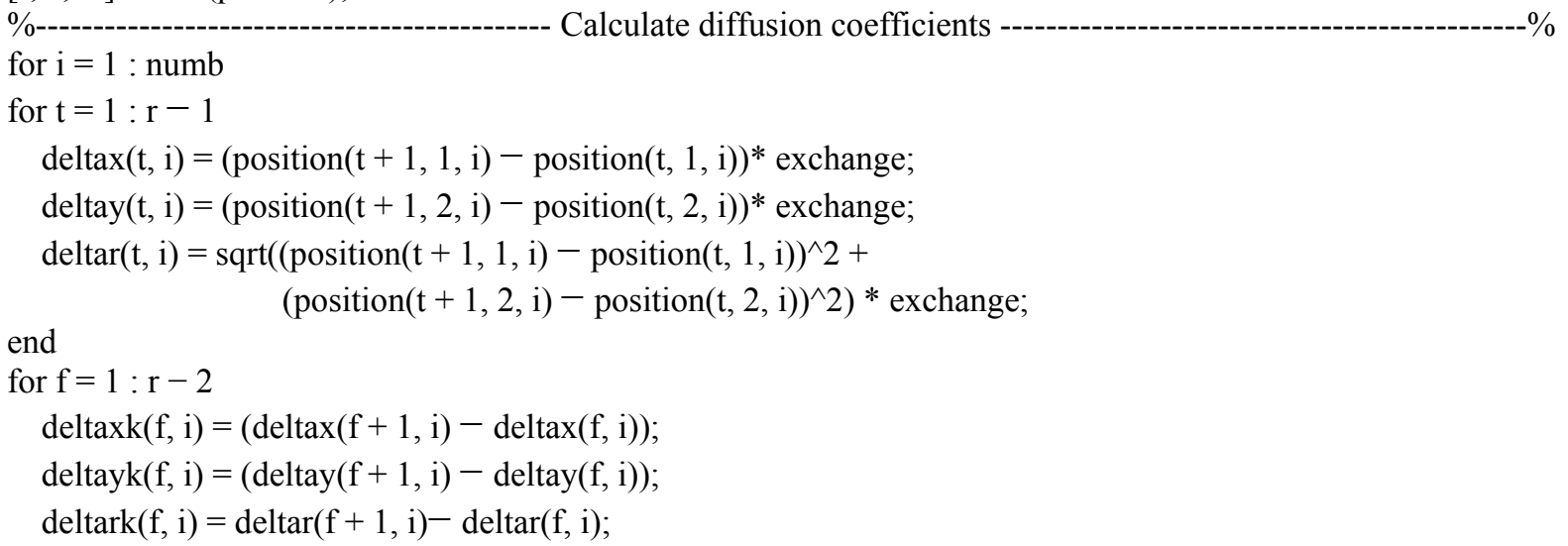


end

$\operatorname{diffusion} x(\mathrm{i})=\operatorname{mean}(\operatorname{deltax}(:, \mathrm{i}) . \wedge 2) /(2 * \operatorname{deltaT})$;

$\operatorname{diffusiony}(\mathrm{i})=\operatorname{mean}(\operatorname{deltay}(:, \mathrm{i}) . \wedge 2) /(2 * \operatorname{deltaT})$;

$\operatorname{diffusion}(\mathrm{i})=\operatorname{mean}\left(\operatorname{deltar}(:, \mathrm{i}) .^{\wedge} 2\right) /(4 * \operatorname{deltaT})$;

end

diffusion-coerf $(\mathrm{k})=$ mean(diffusion $)$;

diffusion-coerfx $(\mathrm{k})=$ mean $($ diffusionx $)$;

diffusion-coerfy $(\mathrm{k})=$ mean (diffusiony);

for $\mathrm{i}=1:$ numb

$\operatorname{mindl}(\mathrm{i})=\min (\operatorname{deltax}(:, \mathrm{i}))$;

$\operatorname{maxdl}(\mathrm{i})=\max (\operatorname{deltax}(:, \mathrm{i}))$;

numb-of-step $=\operatorname{size}($ hist $(\operatorname{deltax}(:, i)))$;

$\operatorname{pdf}(i,:)=\operatorname{hist}(\operatorname{deltax}(:, \mathrm{i}))$;

stepsize $(\mathrm{i})=(\operatorname{maxdl}(\mathrm{i})-\operatorname{mindl}(\mathrm{i})) /(\operatorname{numb}-\mathrm{of}-\operatorname{step}(1,2)-1)$;

$\operatorname{rdisp}(i,:)=\operatorname{mindl}(i): \operatorname{stepsize}(i): \operatorname{maxdl}(i)$;

end

end

$[\mathrm{dx}, \mathrm{cx}]=$ hist(diffusion-coerf $\mathrm{x}, 10)$;

$[\mathrm{dy}, \mathrm{cy}]=$ hist(diffusion-coerfy, 10);

$[\mathrm{d}, \mathrm{c}]=$ hist $($ diffusion-coerf, 10);

hist(diffusion-coerf, 10)

drxy $=$ mean (diffusion-coerf)

ylabel('Frequency')

xlabel('Diffusion coefficient $D_{R}, \mu m^{2} . s^{-1 \prime}$ )

pause(time)

hold on

$\mathrm{f}=16.572 * \exp \left(-((\mathrm{c}-5.461) / 2) .^{\wedge} 2\right)$;

$\operatorname{plot}\left(\mathrm{c}, \mathrm{f}, \mathrm{r}^{\prime}\right)$

\section{Appendix 5.7. Einstein-Stokes relation}

Following the state of dynamic equilibrium of particles, balance motion of particles was assumed to determine by the viscous force and a process diffusion produced by the thermal molecular movement. Stokes established a formula which was considered the force resisting the motion of sphere particles in liquids. The formula was derived for the flow of liquids with effect of viscosity $\mu$. Then the force $F_{p}$ gave the particles with radius $r$ and velocity $v_{p}$ :

$v_{p}=\frac{F_{p}}{6 \pi \mu r}$

Einstein related the force acting on the individual particles to a bulk property of suspended particles which was their osmotic pressure. The ideal gas equation for the osmotic pressure was used:

$P=\frac{R T}{N_{A}} \frac{n}{V}=\frac{R T}{N_{A}} C$

where $T$ is the temperature, $n$ - the number of particles, $N_{A}$ - the Avogadro number, $n / V$ - the number of moles per unit volume (with the same units as concentration $C$ ). In Brownian motion, the suspended particles were moving in such a way that dynamical equilibrium was always maintained between the viscous force and the osmotic force:

$F_{p} C=\frac{\partial P}{\partial x}$

Substitute the value for pressure in equation A5.2 we have the relation between viscous force and concentration gradient:

$F_{p} C=\frac{R T}{N_{A}} \frac{\partial C}{\partial x}$

Since there must be the dynamical equilibrium between the flow of particles in a viscous fluid and diffusion rate: 
$v_{p} C=D \frac{\partial C}{\partial x}$

Substitute $v_{p}$ from equation A5.1 in equation A5.5 we got:

$\frac{F_{p} C}{6 \pi \mu r}=D \frac{\partial C}{\partial x} \quad$ or $\quad F_{p} C=6 \pi \mu r D \frac{\partial C}{\partial x}$

By eliminating $F_{p}$ from equations A5.4 and equation A5.6 we had:

$\frac{R T}{N_{A}}=6 \pi \mu r D$

then diffusion coefficient was expressed:

$D=\frac{R T}{N_{A}} \frac{1}{6 \pi \mu r}$

\section{Appendix 5.8. Random movements of suspended particles in liquids}

Einstein examined the properties of the Brownian motion using statistical physics. There were $n$ suspended particles in a select system. An interval time $\tau$ was introduced which was shorter than the observation time but long enough to consider the motions of a single particle in two successive time intervals independently. In the interval time $\tau, x$ coordinate of the single particle could increase by $\Delta . \Delta$ had a different positive or negative value for each particle. The particles moved randomly without influence from external media. From the probability law, the number of particles $d n$ fell between positions $\left(\Delta_{x}, \Delta_{y}\right)$ and $\left(\Delta_{x}+d \Delta_{x}, \Delta_{y}+d \Delta_{y}\right)$ in the interval time $\tau$ :

$d n=\phi\left(\Delta_{x}, \Delta_{y}\right) d \Delta_{x} d \Delta_{y}$

The probability of the particle being somewhere was unity:

$\int_{-\infty}^{+\infty} \int_{-\infty}^{+\infty} \phi\left(\Delta_{x}, \Delta_{y}\right) d \Delta_{x} d \Delta_{y}=1$

Here $\phi\left(\Delta_{x}, \Delta_{y}, \tau\right)$ was the probability of the particle moving a distance $\Delta_{x}, \Delta_{y}$ in time $\tau$. $\phi$ only differed from zero value for very small values of $\Delta_{x}, \Delta_{y}$ and fulfilled the condition of an even function:

$\phi\left(\Delta_{i}\right)=\phi\left(-\Delta_{i}\right)$

where $i$ was $x$ or $y$.

The displacements of the particles were described by a probability distribution $p(x, y, t)$ that determined the number of particles presented at position $(x, y)$ and time $t$. The position at time zero was chosen as the origin of the coordinate system. The system was homogeneous so that $p(x, y, t)$ equals to $p(-x,-y, t)$. Then the distribution of the particles at time $t+\tau$, position $(x, y)$ was determined from a distribution at time $t$ and position $(x+\Delta x, y+\Delta y)$ :

$$
p(x, y, t+\tau)=\int_{-\infty}^{+\infty} \int_{-\infty}^{+\infty} p\left(x+\Delta_{x}, y+\Delta_{y}, t\right) \phi\left(\Delta_{x}, \Delta_{y}\right) d \Delta_{x} d \Delta_{y}
$$

Since $\tau$ was small, expand $p(x, y, t+\tau)$ we could write:

$$
p(x, y, t+\tau)=p(x, y, t)+\tau \frac{\partial p(x, y, t)}{\partial t}
$$

Using the Taylor expansion for small $\Delta_{x}$, and $\Delta_{y}$ we had:

$p\left(x+\Delta_{x}, y+\Delta_{y}, t\right)=p(x, y, t)+\left[\Delta_{x} \frac{\partial p}{\partial x}+\Delta_{y} \frac{\partial p}{\partial y}\right]+\frac{1}{2 !}\left[\Delta_{x}^{2} \frac{\partial^{2} p}{\partial x^{2}}+2 \Delta_{x} \Delta_{y} \frac{\partial p}{\partial x} \frac{\partial p}{\partial y}+\Delta_{y}^{2} \frac{\partial^{2} p}{\partial y^{2}}\right]+\ldots$

This expansion was brought in equation A5.11: 


$$
\begin{aligned}
p(x, y, t)+\tau \frac{\partial p}{\partial t}= & \int_{-\infty}^{+\infty} \int_{-\infty}^{+\infty} p(x, y, t) \phi\left(\Delta_{x}, \Delta_{y}, \tau\right) d \Delta_{x} d \Delta_{y}+\left[\int_{-\infty}^{+\infty} \int_{-\infty}^{+\infty} \Delta_{x} \frac{\partial p}{\partial x} \phi\left(\Delta_{x}, \Delta_{y}, \tau\right) d \Delta_{x} d \Delta_{y}+\right. \\
& \left.+\int_{-\infty}^{+\infty} \int_{-\infty}^{+\infty} \Delta_{y} \frac{\partial p}{\partial y} \phi\left(\Delta_{x}, \Delta_{y}, \tau\right) d \Delta_{x} d \Delta_{y}\right]+\left[\int_{-\infty}^{+\infty} \int_{-\infty}^{+\infty} \frac{\Delta_{x}^{2}}{2 !} \frac{\partial^{2} p}{\partial x^{2}} \phi\left(\Delta_{x}, \Delta_{y}, \tau\right) d \Delta_{x} d \Delta_{y}+\right. \\
& \left.+\int_{-\infty}^{+\infty} \int_{-\infty}^{+\infty} \frac{2 \Delta_{x} \Delta_{y}}{2 !} \frac{\partial^{2} p}{\partial x \partial y} \phi\left(\Delta_{x}, \Delta_{y}, \tau\right) d \Delta_{x} d \Delta_{y}+\int_{-\infty}^{+\infty} \int_{-\infty}^{+\infty} \frac{\Delta_{y}^{2}}{2 !} \frac{\partial^{2} p}{\partial y^{2}} \phi\left(\Delta_{x}, \Delta_{y}, \tau\right) d \Delta_{x} d \Delta_{y}\right]+\ldots
\end{aligned}
$$

Then we had:

$$
\begin{aligned}
& p(x, y, t)+\tau \frac{\partial p}{\partial t}=p \int_{-\infty}^{+\infty} \int_{-\infty}^{+\infty} \phi\left(\Delta_{x}, \Delta_{y}, \tau\right) d \Delta_{x} d \Delta_{y}+\left[\frac{\partial p}{\partial x} \int_{-\infty}^{+\infty} \int_{-\infty}^{+\infty} \Delta_{x} \phi\left(\Delta_{x}, \Delta_{y}, \tau\right) d \Delta_{x} d \Delta_{y}+\frac{\partial p}{\partial y} \int_{-\infty}^{+\infty} \int_{-\infty}^{+\infty} \Delta_{y} \phi\left(\Delta_{x}, \Delta_{y}, \tau\right) d \Delta_{x} d \Delta_{y}\right] \\
& +\left[\frac{\partial^{2} p}{\partial x^{2}} \int_{-\infty}^{+\infty} \int_{-\infty}^{+\infty} \frac{\Delta_{x}^{2}}{2 !} \phi\left(\Delta_{x}, \Delta_{y}, \tau\right) d \Delta_{x} d \Delta_{y}+2 \frac{\partial^{2} p}{\partial x \partial y} \int_{-\infty}^{+\infty} \int_{-\infty}^{+\infty} \frac{\Delta_{x} \Delta_{y}}{2 !} \phi\left(\Delta_{x}, \Delta_{y}, \tau\right) d \Delta_{x} d \Delta_{y}+\frac{\partial^{2} p}{\partial y^{2}} \int_{-\infty}^{+\infty} \int_{-\infty}^{+\infty} \frac{\Delta_{y}^{2}}{2 !} \phi\left(\Delta_{x}, \Delta_{y}, \tau\right) d \Delta_{x} d \Delta_{y}\right]+\ldots
\end{aligned}
$$

On the right-hand side of the above equation, the second, fourth... terms vanished because of

$\int_{-\infty}^{+\infty} \int_{-\infty}^{+\infty} \Delta_{x, y} \phi\left(\Delta_{x}, \Delta_{y}, \tau\right) d \Delta_{x} d \Delta_{y}=0$

Setting:

$$
D=\frac{1}{\tau} \int_{-\infty}^{+\infty} \int_{-\infty}^{+\infty} \frac{\Delta_{x}^{2}}{2 !} \phi\left(\Delta_{x}, \Delta_{y}, \tau\right) d \Delta_{x} d \Delta_{y}=\frac{1}{\tau} \int_{-\infty}^{+\infty} \int_{-\infty}^{+\infty} \frac{\Delta_{y}^{2}}{2 !} \phi\left(\Delta_{x}, \Delta_{y}, \tau\right) d \Delta_{x} d \Delta_{y}
$$

and considering only the first and the third terms with

$$
\int_{-\infty}^{+\infty} \int_{-\infty}^{+\infty} \phi\left(\Delta_{x}, \Delta_{y}, \tau\right) d \Delta_{x} d \Delta_{y}=1
$$

while the fifth, seventh... terms were very small compared with the previous terms, we got:

$$
\begin{aligned}
& p(x, y, t)+\tau \frac{\partial p}{\partial t}=p(x, y, t)+D\left(\frac{\partial^{2} p}{\partial x^{2}}+\frac{\partial^{2} p}{\partial y^{2}}\right) \\
& \frac{\partial p(x, y, t)}{\partial t}=D\left(\frac{\partial^{2} p}{\partial x^{2}}+\frac{\partial^{2} p}{\partial y^{2}}\right)
\end{aligned}
$$

As one dimension, we had:

$$
\frac{\partial p(x, t)}{\partial t}=D \frac{\partial^{2} p}{\partial x^{2}}
$$

Equation A5.12a and equation A5.12b were both expressions for the distribution of particles in position $R(x, y)$ and at time $t$. Equation A5.12a was of an integral form while equation A5.12b was a differential equation. Equation A5.12 was the Fick's second law and $D$ was diffusion coefficient of the particles.

\section{Appendix 5.9. Solving diffusion equation}

To determine the probability distribution as the function of time, equation A5.12 has been solved. With initial conditions: at $t=0$, all the particles were concentrated at a position $(x=0, y=0)$. This means that the probability function $p(x, y, t)$ was infinitive at this position and zero everywhere, and defined by Dirac delta function:

at $t=0, p(x, y, 0)=n \delta(x, y)$ 
with $\delta^{2}(x, y)=0, x^{2}+y^{2} \neq 0$

$\delta^{2}(x, y)=\infty, x^{2}+y^{2}=0$

and $\int_{-\infty}^{+\infty} \int_{-\infty}^{+\infty} \delta^{2}(x, y) d x d y=1$

$\delta^{2}(a x, b y)=\frac{1}{|a b|} \delta^{2}(x, y)$

$\delta^{2}(x, y)=\delta(x) \delta(y)$

The Dirac Delta function was given as Fourier representation:

$\delta(x, y)=\frac{1}{2 \pi} \int_{-\infty}^{+\infty} \int_{-\infty}^{+\infty} e^{i(u x+v y)} d u d v$

So that $p(x, y, t)$ was written:

$p(x, y, t)=\frac{1}{2 \pi} \int_{-\infty}^{+\infty} \int_{-\infty}^{+\infty} P(u, v, t) e^{i(u x+v y)} d u d v$

$P(u, v)$ represents $p(x, y)$ in frequency domain; $u, v$ are angular frequencies in $x, y$ directions. Putting Fourier transform in equation A5.12 we have:

$\frac{1}{2 \pi} \int_{-\infty}^{+\infty} \int_{-\infty}^{+\infty} e^{i(u x+v y)} \frac{\partial P(u, v, t)}{\partial t} d u d v=\frac{D}{2 \pi} \int_{-\infty}^{+\infty} \int_{-\infty}^{+\infty}-\left(u^{2}+v^{2}\right) e^{i(u x+v y)} P(u, v, t) d u d v$

therefore: $\frac{\partial P(u, v, t)}{\partial t}=-\left(u^{2}+v^{2}\right) D P(u, v, t)$

which can be solved: $\mathrm{P}(\mathrm{u}, \mathrm{v}, \mathrm{t})=\mathrm{P}(\mathrm{u}, \mathrm{v}, 0) \mathrm{e}^{-\left(\mathrm{u}^{2}+\mathrm{v}^{2}\right) \mathrm{Dt}}$

(A5.16)

Since $p(x, y, 0)=n \delta(x, y)$ and using the definition of $\delta(x, y)$ we have:

$$
\begin{aligned}
n \delta(x, y, t) & =\frac{n}{2 \pi} \int_{-\infty}^{+\infty} \int e_{-\infty}^{i(u x+v y)} d u d v \\
& =\frac{1}{2 \pi} \int_{-\infty}^{+\infty} \int_{-\infty}^{+\infty} e^{i(u x+v y)} n d u d v
\end{aligned}
$$

Fourier transform for $p(x, y, 0)$ :

$p(x, y, 0)=\frac{1}{2 \pi} \int_{-\infty}^{+\infty} \int_{-\infty}^{+\infty} e^{i(u x+v y)} P(u, v, 0) d u d v$

hence equation $\mathrm{A} 5.11$ becomes:

$n \delta(x, y, t)=\frac{1}{2 \pi} \int_{-\infty}^{+\infty} \int_{-\infty}^{+\infty} e^{i(u x+v y)} P(u, v, 0) d u d v$

comparison with equation A5.17 gives: $P(u, v, 0)=n$

Therefore, $P(u, v, t)=n \mathrm{e}^{-\left(\mathrm{u}^{2}+\mathrm{v}^{2}\right) \mathrm{Dt}}$ 
Replace $P(u, v, t)$ from equation A5.19 into equation A5.14 we get:

$p(x, y, t)=\frac{n}{2 \pi} \int_{-\infty}^{+\infty} \int_{-\infty}^{+\infty} e^{i(u x+v y)} e^{-\left(u^{2}+v^{2}\right) D t} d u d v$

Starting with the position vector $R(x, y)$ along $x, y$ directions and the vector $w(u, v)$ along $u, v$ directions, we have $R \times w=u x+v y$ then:

$$
\begin{aligned}
p(x, y, t) & =\frac{n}{2 \pi} e^{-\left(x^{2}+y^{2}\right) / 4 D t} \int_{-\infty-\infty}^{+\infty} \int e^{i(u x+v y)} e^{\left(\left(u^{2}+v^{2}\right) \sqrt{D t}\right)^{2}} e^{\left(x^{2}+y^{2}\right) / 4 D t} d u d v \\
& =\frac{n}{2 \pi} e^{-\left(x^{2}+y^{2}\right) / 4 D t^{+\infty}} \int_{-\infty-\infty}^{+\infty} \exp \left[-\left\{(w \sqrt{D t})^{2}+(-i r / 2 \sqrt{D t})^{2}+(-i(u x+v y))\right\}\right] d u d v \\
& =\frac{n}{2 \pi} e^{-\left(x^{2}+y^{2}\right) / 4 D t} \int_{-\infty-\infty}^{+\infty} \int_{-\infty}^{+\infty} \exp \left[-\{w \sqrt{D t}-i r / 2 \sqrt{D t}\}^{2}\right] d u d v \\
& =\frac{n}{2 \pi} e^{-\left(x^{2}+y^{2}\right) / 4 D t} \int_{-\infty-\infty}^{+\infty+\infty} \frac{1}{\sqrt{D t}} e^{-a^{2}} d a
\end{aligned}
$$

Putting: $a=w \sqrt{D t}-i r / 2 \sqrt{D t} ; \quad d a=\sqrt{D t} d u d v$

$$
\begin{aligned}
p(x, y, t) & =\frac{n}{2 \pi \sqrt{D t}} e^{-\left(x^{2}+y^{2}\right) / 4 D t} \sqrt{\pi} \\
& =\frac{n}{4 \pi D t} e^{-\left(x^{2}+y^{2}\right) / 4 D t}
\end{aligned}
$$

For one dimension, we obtain:

$$
p(x, t)=\frac{n}{\sqrt{4 \pi D t}} e^{-x^{2} / 4 D t}
$$

\section{Appendix 5.10. Derivation of diffusion coefficient}

We can calculate the displacements by:

$$
\begin{aligned}
<x^{2}+y^{2}> & =\frac{1}{n} \int_{-\infty}^{+\infty} \int_{-\infty}^{+\infty}\left(x^{2}+y^{2}\right) p(x, y, t) d x d y \\
& =\frac{1}{n} \int_{-\infty}^{+\infty} \int_{-\infty}^{+\infty}\left(x^{2}+y^{2}\right) e^{-\left(x^{2}+y^{2}\right) / 4 D t} d x d y
\end{aligned}
$$

Putting $\alpha=1 / 4 D t$

$$
\begin{aligned}
& =\sqrt{\frac{\alpha}{\pi}} \int_{-\infty}^{+\infty} \int_{-\infty}^{+\infty}\left(x^{2}+y^{2}\right) e^{-\left(x^{2}+y^{2}\right) / 4 D t} d x d y \\
& =-\sqrt{\frac{\alpha}{\pi}} \int_{-\infty}^{+\infty} \int_{-\infty}^{+\infty} \frac{\partial}{\partial \alpha} e^{-\left(x^{2}+y^{2}\right)} d x d y \\
& =\sqrt{\frac{\alpha}{\pi}} \times \frac{\partial}{\partial \alpha} \int_{-\infty}^{+\infty} \int_{-\infty}^{+\infty} e^{-\left(x^{2}+y^{2}\right)} d x d y \\
& =\sqrt{\frac{\alpha}{\pi}} \times \frac{\partial}{\partial \alpha} \int_{-\infty}^{+\infty} \int_{-\infty}^{+\infty} e^{-x^{2}} e^{-y^{2}} d x d y \\
& =-\sqrt{\frac{\alpha}{\pi}} \times \frac{\partial}{\partial \alpha} 2 \sqrt{\frac{\pi}{\alpha}}
\end{aligned}
$$




$$
\begin{aligned}
& =-2 \sqrt{\alpha} \times \frac{\partial}{\partial \alpha} \alpha^{-1 / 2} \\
& =-2 \sqrt{\alpha} \times\left(-\frac{1}{2} \alpha^{-3 / 2}\right) \\
& =\frac{1}{\alpha} \\
& =4 D t
\end{aligned}
$$

Then $<x^{2}+y^{2}>=4 D t$

In one-dimensional case: $\left\langle x^{2}>=2 D t\right.$

\section{Appendix 6.1. Nano-ITP chip, design and fabrication}

Effectively translating quantitative isotachophoresis (ITP) to the nano-chip format requires a sample of welldefined volume, to be interposed between a leading electrolyte (LE) and a trailing electrolyte (TE) on chip. Using NCs in the same way as a capillary, with timed and calibrated pressure steps ensuring quantitativeness is not feasible. Besides the challenge of delivering sufficient pressure on the NCs, dead volumes as a result of replacing electrolytes at the NC entrance, would be much larger than the envisioned sample of a few hundred femtoliters. Therefore a channel structure was employed incorporating T-junctions (figure A6.1). For the evaluation of NC height on ITP, chips were fabricated with $50 \mathrm{~nm}$ deep and $10 \mu \mathrm{m}$ wide.

Chip devices were made from borofloat glass wafers. In the bottom-side wafer, NCs and rulers, were made by wet chemical etching. The depth of the channels was measured with a Dektak 8 mechanical surface profiler (Veeco Instruments Inc. Plainview, USA). Access holes were powder-blasted in the bottom-side and top-side wafers. This is unconventional, but allows fluidic and electric interfacing from opposite sides. Thorough wafer cleaning to remove powder-blast particle residues was required and performed as follows. First, the wafers were sonicated for several hours in an ultrasonic bath of deionized water. Then the wafers were transferred in $100 \%$ $\mathrm{HNO}_{3}$ and left for $15 \mathrm{~min}$, followed by thorough rinsing with water and finally spin-drying. The wafers were aligned, contacted and fusion bonded at $600{ }^{\circ} \mathrm{C}$ for $4 \mathrm{~h}$ (for process outline see figure A6.4 and detail processing parameters in appendix 6.3).

Immediately prior to experiments, the wafers were preconditioned at $400{ }^{\circ} \mathrm{C}$ for $2 \mathrm{~h}$. This procedure improved reproducibility between measurements, removing organic compounds and water from the channels that accumulated from the air during storage.

Results of ITP in $50 \mathrm{~nm}$ deep channels are shown in figure A6.2. The sample plug was $0.2 \mathrm{pL}$, containing 10 attomoles of each amino acid, corresponding to a downscaling of 600,000 times relative to the $0.12 \mu \mathrm{L}$ of sample in the capillary setup. These preliminary results demonstrate focusing with ITP in $50 \mathrm{~nm}$ channels, but separation between the two labeled amino acids could not be observed. The surface area in the ITP graph



Figure A6.1. Schematic layout of the nanofluidic-ITP chip. A-F designate the access holes, approximately $1 \mathrm{~mm}$ in diameter, for placement of electrodes and fluidic access. The configuration of channels and access holes allows selection of different injection volumes. The separation channel $(A-F)$ is $3.5 \mathrm{~cm}$ in length. The insert shows a brightfield image of the injection area. The distance between where channels $D$ and E intersect with the separation channel is $400 \mu \mathrm{m}$. For the $50 \mathrm{~nm}$ deep $10 \mu \mathrm{m}$ wide, a length of $400 \mu \mathrm{m}$ corresponds to a volume of $0.2 \mathrm{pL}$. The ruler etched along the separation channel, has $20 \mu \mathrm{m}$ spacing between minor divisions, with the numbers at the major divisions indicating hundreds of microns. 

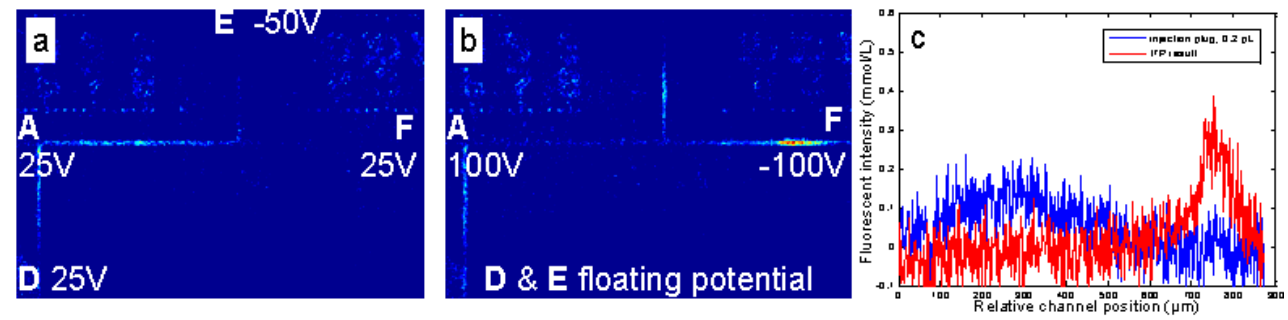

Figure A6.2. On-chip ITP results in $50 \mathrm{~nm}$ deep channels with $0.2 \mathrm{pL}$ of pretreated yeast biomatrix spiked with Glu-FITC and Phe-FITC. The white letters $A, D, E$ and $F$ designate the sample reservoirs (figure A6.1). Subfigure a shows a false-colored fluorescence image of the created stable sample injection plug, with LE present on the left (A) and TE to the right (F). Subfigure b shows the resulting ITP. Subfigures $a$ and $b$ were background corrected and filtered. Voltages indicated are those applied to create the stable sample plugs shown, and those to perform ITP, in subfigure $a$ and $b$ respectively. Subfigure c shows an overlay of the fluorescent intensities extracted from subfigures $a$ and $b$, scaled to concentration, with the $x$ axis indicating the relative position.

appeared to contain only $58 \%$ of the material in the plug. We speculate that part of the plug has entered the top channel, indicating a mistake in injection.

ITP in $50 \mathrm{~nm}$ deep channels was demonstrated to be feasible, for samples as small as $200 \mathrm{fL}$. ITP was achieved qualitatively as the corresponding intensities were near the detection limit of the setup. Also, lower electrical fields could be used for ITP, compared to the deeper channels.

With nano-ITP now being established as a feasible element of a future method for sub-cellular aliquots, integrating onchip sample extraction and developing interfacing with a powerful detector such as a mass spectrometer, will yield a method capable of elucidating a single-cell's metabolism. Detection limits however, will be critical if not fluorescence is used but for instance a mass spectrometer.

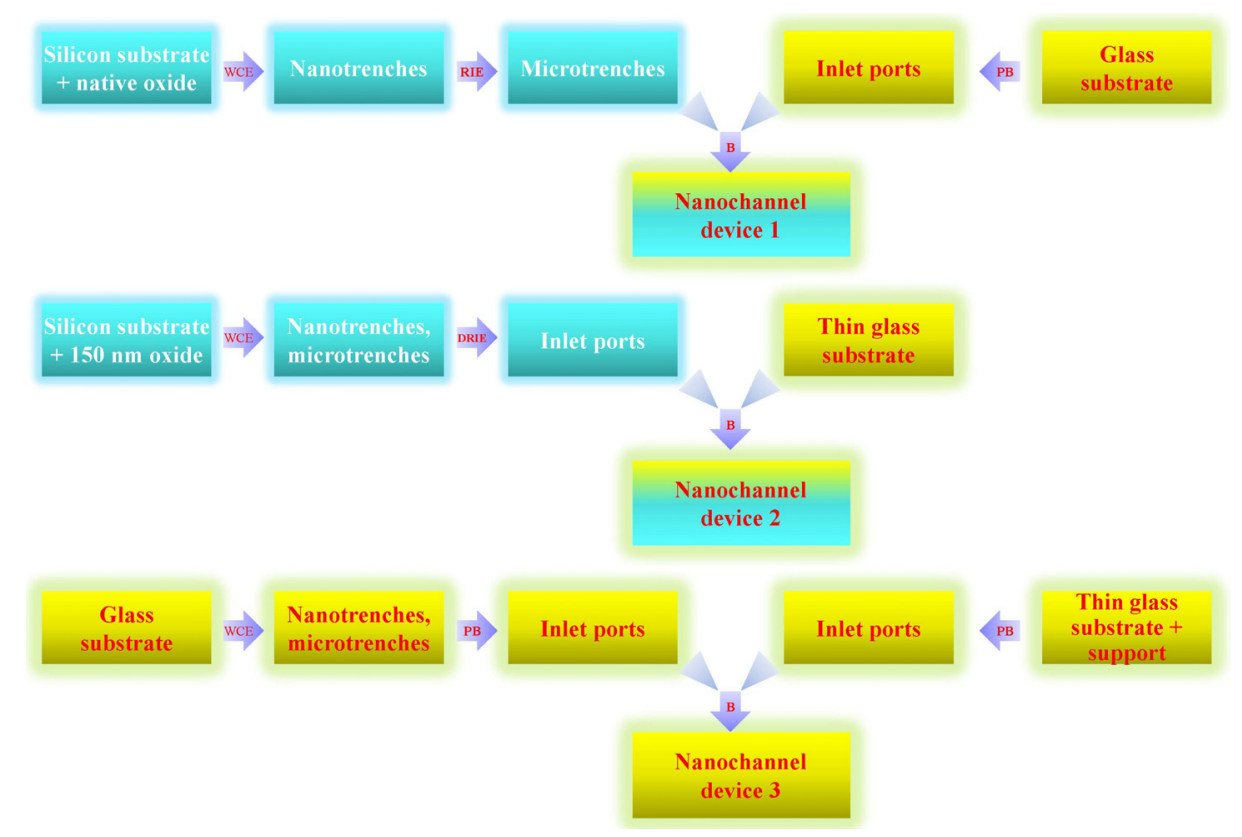

Figure A6.3. Fabrication scheme of $1 D$ nanochannel devices. WCE: wet chemical etching, RIE: reactive ion etching, DRIE: deep reactive ion etching, PB: powder blasting, B: bonding. 



Figure A6.4. Process outline of 1 D glass nanochannels (device 3).

Appendix 6.2. Modification and fabrication of 1D nanochannel devices

Figure A6.3 showed a scheme for fabrication of three types of NC devices. For deprotonation studies during fluorescence capillary filling, NC device 1 was fabricated by direct bonding of a silicon substrate containing nanotrenches and microtrenches and a glass substrate with inlet ports. NC device 2 was created by bonding of a silicon substrate with all features of nano/microtrenches and inlet ports with a thin glass substrate for mobility studies using a high numerical aperture (NA) lens. For separation studies, NC device 3 was formed on both glass substrates.

In this section the fabrication of the NC device 3 is discussed in details while fabrication of other devices has been presented in chapter 2 . The separation studies required an isolation device to control liquids into channels using high voltages. To meet this requirement, NCs were fabricated on glass substrates suitable for electric isolation and optical observation. Additionally, the fabricated channel device should have inlet ports on both glass substrates. Thus, micro/nanotrenches and inlet ports were first fabricated on a bottom glass substrate then bonded to a top substrate by thermal bonding. For using high NA lenses, the thin glass substrate $(170 \mu \mathrm{m}$ thickness) is required. However, structuring through-wafer inlet/outlet ports on rather thin glass substrates is not an easy task as the substrates broken often during processing. Because the substrate was too thin, thus fragile, it generated difficulties in handling of the substrate during processing steps such as cleaning, lithography and etching [5-6]. To prevent damage this thin substrate was temporarily bonded to a carrier silicon substrate (step 10, figure A6.4) using an Olin resist as an adhesive layer. The Olin resist was selected because it can be easily dissolving in a $\mathrm{HNO}_{3}$ solution to de-bond substrates. The lithography (step 11) and powder blasting procedures (step 12), as presented in chapter 2 were applied on the thin substrate together with its carrier. Then series of cleaning steps were used to clean substrates. The final cleaning step was extremely difficult because the thin substrate was even more fragile after structuring. The cleaning was performed in a rinsing bath in which water flow-up and nitrogen bubbles could be reduced. For drying a spinner with a slow speed or a nitrogen blow gun was used. Broad plastic tip tweezers were preferred use to handle this thin substrate. Even though, structuring in thin glass substrates was difficult we succeeded to fabricate inlet ports on these substrates. Techniques for fabrication of 1D NCs by combination of bulk and bond micromachining has been reported extensively during the last several years, however, a number of modifications in the fabrication process and selection of materials were still required to make the realized NCs suitable for different fundamental studies. 
Appendix 6.3. Fabrication of 1D glass nanochannel devices

\begin{tabular}{|c|c|c|}
\hline Process description & Parameters & Cross section after process \\
\hline $\begin{array}{l}\text { Process on a glass bottom } \\
\text { wafer }\end{array}$ & $\begin{array}{l}\text { - Supplier: MCR (Microsystems, Consulting } \\
\text { \& Representation) } \\
\text { - Borofloat glass wafer } \\
\text { - Diameter: } 100 \mathrm{~mm} \\
\text { - Thickness: } 1 \mathrm{~mm}\end{array}$ & \\
\hline $\begin{array}{l}\text { Lithography (microtrench } \\
\text { structures) }\end{array}$ & $\begin{array}{l}\text { - Suss Micro TECH Spinner (Delta20, } \\
\text { Spinning acceleration: } 4000 \mathrm{rpm} . \mathrm{s}^{-1} \text {, } \\
\text { Spinning speed: } 4000 \mathrm{rpm}) \\
\text { - Electronic Vision Group } 20 \text { Mask Aligner } \\
\left.\text { (Hg lamp: } 12 \mathrm{~mW} . \mathrm{cm}^{-2}\right) \\
\text { - Dehydration bake }\left(120^{\circ} \mathrm{C}\right): 5 \mathrm{~min} \\
\text { - Vapor HMDS: } 5 \mathrm{~min} \\
\text { - Olin } 907-12 \mathrm{spinning} \\
\text { - Prebake }\left(95^{\circ} \mathrm{C}\right): 60 \mathrm{~s} \\
\text { - Exposure time: } 3 \mathrm{~s} \\
\text { - After-exposure bake }\left(120{ }^{\circ} \mathrm{C}\right): 60 \mathrm{~s} \\
\text { - Development time: } 60 \mathrm{~s} \\
\text { - Postbake }\left(120^{\circ} \mathrm{C}\right): 30 \mathrm{~min} \\
\text { - Ozone annealing: } 5 \mathrm{~min}\end{array}$ & \\
\hline Glass etching & $\begin{array}{l}\text { - Wet-Bench } \\
\text { - BHF (VLSI): Merck } \\
\text { - Etchrate: } 23 \mathrm{~nm} \cdot \mathrm{min}^{-1} \\
\text { - Time: } 90 \mathrm{~min}\end{array}$ & \\
\hline Photoresist removal & $\begin{array}{l}\text { - Wet-Bench } \\
\text { - Fumic } \mathrm{HNO}_{3}(100 \% \text {, Merck })\end{array}$ & \\
\hline $\begin{array}{l}\text { Lithography (nanotrench } \\
\text { structures) }\end{array}$ & $\begin{array}{l}\text { - Suss Micro TECH Spinner (Delta20, } \\
\text { Spinning acceleration: } 4000 \mathrm{rpm} . \mathrm{s}^{-1} \text {, } \\
\text { Spinning speed: } 4000 \mathrm{rpm}) \\
\text { - Electronic Vision Group } 20 \text { Mask Aligner } \\
\left.\text { (Hg lamp: } 12 \mathrm{~mW} \cdot \mathrm{cm}^{-2}\right) \\
\text { - Dehydration bake }\left(120^{\circ} \mathrm{C}\right): 5 \mathrm{~min} \\
\text { - Vapor HMDS: } 5 \mathrm{~min} \\
\text { - Olin } 907-12 \mathrm{spinning} \\
\text { - Prebake }\left(95^{\circ} \mathrm{C}\right): 60 \mathrm{~s} \\
\text { - Exposure time: } 3 \mathrm{~s} \\
\text { - After-exposure bake }\left(120{ }^{\circ} \mathrm{C}\right): 60 \mathrm{~s} \\
\text { - Development time: } 60 \mathrm{~s} \\
\text { - Postbake }\left(120^{\circ} \mathrm{C}\right): 30 \mathrm{~min} \\
\text { - Ozone annealing: } 5 \mathrm{~min}\end{array}$ & \\
\hline Glass etching & $\begin{array}{l}\text { - Wet-Bench } \\
\text { - BHF (VLSI): Merck } \\
\text { - Etchrate: } 23 \text { nm.min }{ }^{-1} \\
\text { - Time: } 4 \text { min }\end{array}$ & \\
\hline Photoresist removal & $\begin{array}{l}\text { - Wet-Bench } \\
\text { - Fumic } \mathrm{HNO}_{3}(100 \%, \text { Merck })\end{array}$ & \\
\hline $\begin{array}{l}\text { Lithography (inlet-port } \\
\text { structures) }\end{array}$ & $\begin{array}{l}\text { - GBC } 3500 \text { Pro Laminator } \\
\text { - Exposure tool } \\
\text { - HCM Spray Developer } \\
\text { - Laminate } 50 \mu \mathrm{m} \text { foil BF } 410 \text { foil on both } \\
\text { sides } \\
\text { - Exposure: } 45 \mathrm{~s} \\
\text { - Development time }\left(\mathrm{Na}_{2} \mathrm{CO}_{3}\right): 3 \mathrm{~min}\end{array}$ & \\
\hline
\end{tabular}


Powder blasting + Cleaning procedure

Process on a top wafer

Lithography (inlet-port structures)

Powder blasting

Cleaning procedure

Bonding support wafer
- Powderblaster-low resolution

- Particles: $30 \mu \mathrm{m} \mathrm{Al} \mathrm{O}_{3}$

- Pressure: 4.6 bar

- Etchrate: $91 \mu \mathrm{m}$ per g.cm ${ }^{-2}$

Cleaning procedure

- Delaminate in $\mathrm{Na}_{2} \mathrm{CO}_{3}$ solution: $15 \mathrm{~min}$

- Ultrasonic acetone: $30 \mathrm{~min}$,

- Ultrasonic isopropanol: $30 \mathrm{~min}$

- Ultrasonic DI water: $10 \mathrm{~min}$

- Supplier: Mark Optics

- Borofloat glass wafer

- Diameter: $100 \mathrm{~mm}$

- Thickness: $170 \mu \mathrm{m}$

Preparation on a silicon

- Suss Micro TECH Spinner (Delta20, Spinning acceleration: $4000 \mathrm{rpm} . \mathrm{s}^{-1}$, Spinning speed: $4000 \mathrm{rpm}$ )

- Dehydration bake $\left(120^{\circ} \mathrm{C}\right): 5 \mathrm{~min}$

- Olin 907-12 spinning

- Stick the thin glass to the silicon wafer

- GBC 3500 Pro Laminator

- Exposure tool

- HCM Spray Developer

- Laminate $50 \mu \mathrm{m}$ foil BF 410 foil on both sides

- Exposure: $45 \mathrm{~s}$

- Development time $\left(\mathrm{Na}_{2} \mathrm{CO}_{3}\right): 3 \mathrm{~min}$

- Powderblaster-low resolution

- Particles: $30 \mu \mathrm{m} \mathrm{Al}_{2} \mathrm{O}_{3}$

- Pressure: 4.6 bar

- Etchrate: $91 \mu \mathrm{m}$ per g.cm ${ }^{-2}$

-Wet-Bench

- Delaminate in $\mathrm{Na}_{2} \mathrm{CO}_{3}$ solution: 15 min

- Ultrasonic acetone: $30 \mathrm{~min}$,

- Ultrasonic isopropanol: $30 \mathrm{~min}$

- Ultrasonic DI water: $10 \mathrm{~min}$

- Fumic $\mathrm{HNO}_{3}(100 \%$, Merck): 20 min

Piranha cleaning

- $\mathrm{H}_{2} \mathrm{SO}_{4}: \mathrm{H}_{2} \mathrm{O}_{2}(3: 1)$ vol\%

- Temperature: $120^{\circ} \mathrm{C}$

- Time: $20 \mathrm{~min}$

$\mathrm{KOH}(25 \%) \operatorname{dip}$

- Temperature: $75^{\circ} \mathrm{C}$

- Contact wafers manually

- Apply light pressure with tweezers if necessary press air-bubbles out

- Furnace: Nabertherm C 250

- Ramp-up: $1 \mathrm{~h}$

- Temperature: $550{ }^{\circ} \mathrm{C}$

- Annealing time: $4 \mathrm{~h}$

- Ramp-down: $1 \mathrm{~h}$
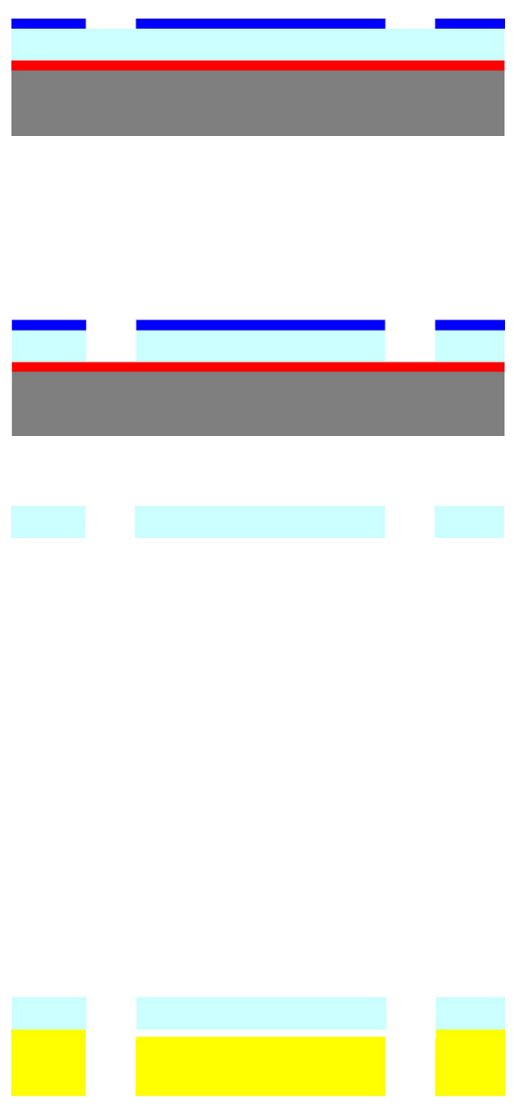


\section{Summary}

The most important motivation of this thesis is study the viscosity of water in confined nanospaces by measuring mobility of single nanoparticles. To perform mobility studies using a high numerical aperture (NA) lens from an inverted microscope, one-dimensional (1D) nanochannel devices were fabricated. Previously, our nanochannels were formed by bonding a silicon substrate to a conventional glass substrate of $1 \mathrm{~mm}$ thickness. With this thickness, processing the glass wafers is a quite straightforward procedure of micromachining. However, using the thick glass wafer brings some limitations and restrictions in observation using a NA lens, thus, applications of nanochannels. Therefore, 1D nanochannels were modified by direct bonding of a processed silicon wafer (containing nanochannels, microchannels and inlet/outlet ports), with a very thin glass wafer of $170 \mu \mathrm{m}$ thick. The through-wafer inlet ports were formed by deep reactive ion etching with a sufficient protection procedure to avoid damage of the fabricated nanochannels which are on the same silicon wafer. These fabricated 1D nanochannel devices have broad potential applications in physics, chemistry, biology and biomedicine. 1D nanochannels with the width still in micrometer scale were created by using standard optical lithography while nanometer scale in height can easily be obtained using etching in bulk substrates or in deposited layers.

We have developed a new and simple method to construct two-dimensional (2D) nanochannels using several common techniques of conventional microfabrication like underetching of a sacrificial layer, and vertically evaporation deposition. Encapsulated 2D nanochannels with both dimensions of height and width down to sub-20 $\mathrm{nm}$ regimes were directly obtained without requiring bonding. We test possibilities of conducting experiments in these really small 2D nanochannels by filling fluorescence solutions. Filling results proved that the fabricated channels were not leaking and that they can be used to study fluorescent solutions. These confined 2D nanochannels have potential toward single-molecule studies at high concentrations.

A large effort was spent to optimize the fabrication process to obtain reproducible and reliable 2D nanochannels developed from previous work. To obtain 2D nanochannel devices for confinement of small molecules, fabricated channels were made transparent for optical observation. Transparency was done by oxidation of the capping polysilicon layer to be transformed into silicon oxide. In addition, macro inlet and outlet ports were micromachined to integrate the fragile channels to outer-reservoirs to create filling paths into nanochannels without any damage of nanochannels. Filling experiments of solutions containing small 
fluorescence molecules (1.4 $\mathrm{nm}$ diameter) were conducted to confirm the functioning of fabricated nanochannels.

The above fabricated 1D nanochannels were used for studying of deprotonation during filling $50 \mathrm{~nm}$ depth silicon oxide channels with sodium fluorescein solutions using capillary pressure. Instead of fluorescence from all of the fluid in the filling channel a distinct bisection was observed, the fluid near the entrance fluoresces while the fluid near the front did not. The ratio between two sections was found to be constant in time and to be depended on several parameters including ionic strength, $\mathrm{pH}$ and the presence of a buffer. Using a model of electric double layer, this phenomenon can be effectively modeled as titration of the solution by protons released from silanol groups on channel walls. The $p H$ effect was further tested by using non- $p H$ dependent fluorescence molecules showing a very small distance of the bisection. This deprotonation effect proves an important role for analytical strategies and in particular the analysis of complex biological systems.

Mobility of single quantum-dot has been determined in 1D nanochannels. By tracking and analyzing images using a Matlab program, random movements of single quantum dots inside nanochannels could be measured and confirmed to perform as expected for the Brownian motion. Diffusion coefficient $(D)$ of individual quantum dots in 1D nanochannels was experimentally determined using either standard deviation of Gaussian distribution or slope of straight lines fitted to curves (mean square displacements versus interval times). The diffusion coefficient inside nanochannels appeared to be three times smaller than from bulk solutions. These results confirm and extend the Eichmann's measurements to smaller particles and further confinement. The observed reduce mobility cannot be explained by conventional hydrodynamic and electroviscous theories. Follow-up studies should concentrate on modeling of the electroviscous effect under conditions of double-layer overlap, and on experiments in which the dependence of the particle mobility on electrolyte concentration is measured. 


\section{List of abbreviations and symbols}

1D

2D

AFM

AL

CCD

$-\mathrm{COOH}$

DI

DRIE

DSP

EBL

EDL

Exp

FCS

FIB

FL

$\mathrm{Fl}^{2+}$

$\mathrm{FlH}_{2}$

HMDS

HRSEM

LPCVD

MSD

NA

$\mathrm{NC}(\mathrm{s})$

NIL

NSOM

OSP

PDF

PDMS

PECVD

$\mathrm{QD}(\mathrm{s})$

RIE

rpm

SEM

SFA

TEOS

TIFF

TIRFM

TMAH

Tris

WCE

$a_{H s+}$

A

A

$B_{S}$

$c$

$c_{i}$

$C_{\text {Diff }}$

$C_{D L}$ one-dimensional

two-dimensional

atomic force microscopy

Alexa Fluor 488

charge-coupled device

carboxyl group

deionized water

deep reactive ion etching

double side polished

electron beam lithography

electrical double layer

experiments

fluorescence correlation spectroscopy

focused ion beam

fluorescein sodium salt

charged fluorescein anion

uncharged fluorescein molecule

hexamethyldisilazane

high resolution scanning electron microscopy

low pressure chemical vapor deposition

mean square displacements

numerical aperture

nanochannel(s)

nanoimprint lithography

near-field scanning optical microscopy

single side polished

probability density function

polydimethylsiloxane

plasma enhanced chemical vapor deposition

quantum $\operatorname{dot}(\mathrm{s})$

reactive ion etching

rotations per minute

scanning electron microscopy

surface forces apparatus

tetra-ethyl-ortho-silicate

tagged image file format

total internal reflection fluorescence microscopy

tetra methyl-ammonium-hydroxide

2-amino-2-(hydroxymethyl) propane-1,3-diol

wet chemical etching

proton activity at the surface

channel area (chapter 2 and chapter 3)

absorbance (chapter 5)

required protons to titrate from $\mathrm{pH}_{B}$ to $\mathrm{pHpzc}$

concentration of solutions

concentration of components in solutions

capacitance of the diffuse layer

capacitance of the double layer
F.m ${ }^{-2}$

F. $\mathrm{m}^{-2}$ 


\begin{tabular}{|c|c|c|}
\hline$C_{\text {Stern }}$ & capacitance of the Stern layer & F.m ${ }^{-2}$ \\
\hline$D$ & diffusion coefficient & \\
\hline$d$ & distance between fluorescence front and water front (chapter 4) & \\
\hline$d$ & distance between particles and walls (chapter 5) & \\
\hline$D_{x}, D_{y}$ & diffusion coefficients during $x, y$ displacement & $\mu \mathrm{m}^{2} \mathrm{~s}^{-1}$ \\
\hline$D_{R}$ & diffusion coefficients during two-dimensional displacements & $\mu \mathrm{m}^{2} \mathrm{~s}^{-1}$ \\
\hline$E$ & Young's modulus & \\
\hline$e$ & electron charge & \\
\hline$F$ & Faraday constant & \\
\hline$F_{p}$ & forces on particles & \\
\hline$g$ & thickness of the sacrificial layer & \\
\hline$h$ & height of channels & \\
\hline$H^{+}$ & hydrogen ion or proton & \\
\hline$\left[H^{+}\right]$ & equilibrium concentration of $\mathrm{H}^{+}$ & \\
\hline$H_{S}^{+}$ & concentration of protons at the surface & \\
\hline$I$ & ionic strength & \\
\hline$K$ & Boltzmann constant & $1.38 \times 10^{-23}$ \\
\hline$K_{a 1}, K_{a 2}$ & $\begin{array}{l}\text { acid dissociation constants (acidity constant or acid-ionization } \\
\text { constant) }\end{array}$ & \\
\hline$l$ & pathlength (chapter 5) & \\
\hline$L$ & length of channels (chapter 4 ) & \\
\hline$L_{D}$ & length of dark zone & \\
\hline$L_{F l}$ & length of fluorescent zone & \\
\hline$m$ & mass of the particles & \\
\hline$n$ & number of particles & \\
\hline$N_{A}$ & Avogadro constant & $6.022 \times 10^{23}$ \\
\hline$N_{H_{\exp }^{+}}$ & amount of protons released per $\mathrm{m}^{2}$ of wall & \\
\hline$N_{H_{\text {theory }}^{+}}$ & theoretical amount of released protons & \\
\hline$N_{H_{\text {absorbed }}^{+}}$ & number of absorbed protons & \\
\hline$N_{H_{\text {released }}^{+}}$ & number of released protons & \\
\hline$n_{i}^{\infty}$ & bulk concentration & \\
\hline $\mathrm{n}^{0}$ & ionic strength in the bulk & \\
\hline$N_{s}$ & total number of $\mathrm{SiOH}$ sites per $\mathrm{m}^{2}$ (chapter 4 ) & $4.6 \times 10^{18}$ \\
\hline$N_{s}$ & number of steps (chapter 5) & \\
\hline$n_{\infty}$ & ionic concentration & \\
\hline$P$ & osmotic pressure & \\
\hline$p H$ & a measure of the acidity or basicity of a solution & \\
\hline $\mathrm{pH}_{\mathrm{B}}$ & measured bulk $p H$ of introduced solutions & \\
\hline$p H_{p z c}$ & $p H$ at point of zero charge of $\mathrm{SiO}_{2}$ & \\
\hline$p H_{S}$ & calculated $p H$ at the surface & \\
\hline$p K a$ & dissociation constants & \\
\hline$P(u, v)$ & represents $p(x, y)$ in frequency domain & \\
\hline$p(x, y)$ & probability distribution in scalar domain & \\
\hline$p z c$ & point of zero charge & \\
\hline$q$ & elementary charge & $1.602 \times 10^{-19}$ \\
\hline
\end{tabular}




\begin{tabular}{|c|c|c|}
\hline$R$ & gas constant & \\
\hline$r$ & radius of the particles & \\
\hline$R(x, y)$ & vector position & \\
\hline$T$ & temperature & \\
\hline$t$ & time & \\
\hline$t_{c}$ & thickness of the capping layer & \\
\hline$t_{E D L}$ & thickness of electrical double layer & \\
\hline$t_{s}$ & thickness of the sacrificial layer & \\
\hline$u, v$ & angular frequencies & \\
\hline$V$ & volume (chapter 2) & \\
\hline$V$ & potential (chapter 4) & \\
\hline$v_{p}$ & velocity of the particles & \\
\hline$V(x)$ & potential & \\
\hline$w$ & width of channels & \\
\hline$w(u, v)$ & vector position & \\
\hline$x$ & position at $x$-axis at time $t$ & \\
\hline$x_{o}$ & position at $x$-axis at time $t=0$ & \\
\hline$x_{1}$ & position of water front, $\mathrm{mm}$ & \\
\hline$x_{2}$ & position of fluorescence front, $\mathrm{mm}$ & \\
\hline$y$ & position at $y$-axis at time $t$ & \\
\hline$y_{o}$ & position at $y$-axis at time $t=0$ & \\
\hline$Z_{i}$ & ionic valence & \\
\hline & $\begin{array}{l}\text { Greek letters } \\
\text { gas liquid surface tension }\end{array}$ & N.m ${ }^{-1}$ \\
\hline$\gamma_{a}$ & $\begin{array}{l}\text { gas liquid surtace tension } \\
\text { adhesion energy }\end{array}$ & \\
\hline $\begin{array}{l}\gamma_{a} \\
\Delta P\end{array}$ & $\begin{array}{l}\text { adhesion energy } \\
\text { pressure gradient }\end{array}$ & \\
\hline$\Delta_{x}, \Delta_{y}$ & displacements & \\
\hline$\delta(x, y)$ & Dirac Delta function & \\
\hline$\varepsilon$ & relative permittivity of water (in presence of salt), chapter 4 & \\
\hline$\varepsilon$ & extinction coefficient (chapter 5) & \\
\hline$\varepsilon_{0}$ & permittivity of free space & 80 \\
\hline$\eta$ & viscosity of solvent & $8.854 \times 10^{-12}$ \\
\hline$\Theta^{-}$ & the fraction of the negatively charged surface groups & $\mathrm{C}^{2} \cdot \mathrm{N}^{-1} \mathrm{~m}^{-2}$ \\
\hline$\theta$ & contact angle & \\
\hline$\kappa$ & Debye length or Debye-Huckel parameter & \\
\hline$\lambda(x, y)$ & average displacements & \\
\hline$\mu$ & viscosity of liquids (chapter 4 ) & \\
\hline$\mu$ & mobility of the particle (chapter 5) & \\
\hline$\mu_{0}$ & viscosity of water & \\
\hline$\sigma$ & standard deviation & \\
\hline$\sigma_{D L}$ & charge of the double layer & \\
\hline$\sigma_{0}$ & surface charge & \\
\hline$\tau$ & interval time & \\
\hline$\Phi_{2}$ & potential at the Stern plane & \\
\hline$\phi_{2}$ & potential & \\
\hline$\phi(x, y)$ & probability function & \\
\hline$\Psi_{0}$ & surface potential & \\
\hline & electrostatic potential & \\
\hline$\widetilde{\psi}_{p}$ & dimensionless surface potential & \\
\hline
\end{tabular}




\section{List of figures and tables}

Figure 1.1. Definition of nanochannels.

Figure 1.2. Brief description of fabrication of nanochannels (A) Bulk micromachining. (B) Spacer layer etching technique. (C) Sacrificial layer etching technique.

Figure 1.3. Brief description of fabrication of nanochannels using combination of bulk and bond micromachining (left images) and surface and bond micromachining (right images).

Figure 2.1. Process outline for fabrication of 1D nanochannel devices.

Figure 2.2. (A) Schematic of the experimental set-up. (B) An artist's drawing of a 1D nanochannel device. (C) SEM cross section of $20 \mu \mathrm{m}$ width nanochannel bonded between a silicon wafer and a thin glass wafer.

Figure 2.3. Process outline for fabrication of 2D nanochannel devices.

Figure 2.4. SEM cross-sectional images of $2 \mathrm{D}$ nanochannels fabricated with different thickness. (A) $30 \mathrm{~nm}$ and (B) $50 \mathrm{~nm}$.

Figure 2.5. Cross-sectional SEM images of $2 \mathrm{D}$ nanochannels during processing with two etching possibilities of the sacrificial layer.

Figure 2.6. Blinking behavior of individual quantum dots visualized inside 1D nanochannels (150 $\mathrm{nm}$ height and $20 \mu \mathrm{m}$ width).

Figure 2.7. 1D nanochannels filled with different concentrations of Alexa 488 in water.

Figure 2.8. (A) A preserved nanochannel with $500 \mathrm{~nm}$ TEOS protection layer. (B) A confocal fluorescence image of $4 \mu \mathrm{M}$ Alexa Fluor 488 solution in 2D nanochannels. (C) An artist's drawing of a 2D nanochannel device. (D), (E) Optical microscope images of inlet holes.

Figure 3.1. Process outline for fabrication of 2D nanochannels.

Figure 3.2. Cross-sectional SEM images of an encapsulated channel (20 $\mathrm{nm}$ height and 40 nm width).

Figure 3.3. Cross-sectional SEM image to present a small difference of ca. $5 \mathrm{~nm}$ between the designed arrived positions and the as-deposited positions of the evaporated $\mathrm{SiO}_{2}$.

Figure 3.4. Fluorescence intensity images of fluorescent molecules filled in the nanochannels.

Figure 4.1. Typical image of fluorescence observed in nanochannels during filling.

Figure 4.2. Sequence fluorescence images during filling of a pure fluorescein sodium solution into $50 \mathrm{~nm}$ height and $20 \mu \mathrm{m}$ width nanochannels.

Figure 4.3. Chip layout seen from the top.

Figure 4.4. Axial cross-section of a filling nanochannel.

Figure 4.5. Position of the meniscus and the fluorescent front versus the square root of time for experiments.

Figure 4.6. Schematic representation of potential $V$ versus the distance $x$ from the silicon oxide wall.

Figure 4.7. Theoretical amount of deprotonated silanol groups per $\mathrm{nm}^{2}$ as a function of $\mathrm{pH}$.

Figure 4.8. Results of the experiments, $N_{H_{\text {exp }}^{+}}$, fitted with the model, $N_{H_{\text {theory }}^{+}}$.

Figure 5.1. (A) Fluorescence images of single quantum dots observed in a $150 \mathrm{~nm}$ high and $20 \mu \mathrm{m}$ wide nanochannel. (B) Surface plots which indicate fluorescence intensity of a single quatum dot performing the Brownian motion inside the confined nanochannel.

Figure 5.2. (A) A trajectory of a quantum dot inside a $150 \mathrm{~nm}$ high and $20 \mu \mathrm{m}$ wide nanochannel. (B), (C) Histograms of $x, y$ displacements of 65 trajectories. (D) Histogram of $\mathrm{R}$ displacements $R^{2}=x^{2}+y^{2}$.

Figure 5.3. Displacements determination methods for moving positions from 1 to $N_{s}$.

Figure 5.4. Mean square displacements of the first ten steps of ten trajectories in $150 \mathrm{~nm}$ 
high and $20 \mu \mathrm{m}$ wide nanochannels.

Figure 5.5. Distribution of diffusion coefficient values of quantum dots in nanochannels (150 $\mathrm{nm}$ high and $20 \mu \mathrm{m}$ wide) with 65 measurements .

Figure A2.1. Principal scheme of scanning confocal microscopy.

Figure A4.1. Images of filling Alexa and Bodipy.

Figure A4.2. Process outline of 1D nanochannel devices for deprotonation studies.

Figure A4.3. (A) Systematic set-up of a fluorescence microscope. (B) Measurement setup.

Figure A5.1. Determination of positions of quantum dots.

Figure A6.1. Schematic layer of the nanofluidic-ITP chip.

Figure A6.2. On-chip ITP results in $50 \mathrm{~nm}$ deep channels with $0.2 \mathrm{pL}$ of pretreated yeast.

Figure A6.3. Fabrication scheme of 1D nanochannel devices.

Figure A6.4. Process outline of 1D glass nanochannels.

Table 2.1. Overview of 1D nanochannel fabrication methods.

Table 2.2. Overview of 2D nanochannel fabrication methods.

Table 4.1. Composition of the solution, the height $(h)$ of the channel, and the measured $p H$ for the various experiments.

Table 4.2. Constants and parameters used in fitting the data.

Table 5.1. Diffusion coefficient values in $\mu \mathrm{m}^{2} \mathrm{~s}^{-1}$.

Table A4.1. Raw data from a measurement of fluorescein filling. 


\section{Publications}

Journal papers

[1] Janssen, K. G. H.; Hoang, H. T.; Floris, J.; de Vries, J.; Tas, N. R.; Eijkel, J. C. T.; Hankemeier, T. Solution titration by wall deprotonation during capillary filling of silicon oxide nanochannels. Anal. Chem. 2008, 80 (21), 8095-8101.

[2] Hoang, H. T.; Segers-Nolten, I. M.; Berenschot, J. W.; de Boer, M. J.; Tas, N.R.; Haneveld, J.; Elwenspoek, M. C. Fabrication and interfacing of nanochannel devices for single-molecule studies. J. Micromech. Microeng. 2009, 19 (6), 065017.

[3] Hoang, H. T.; Segers-Nolten, I. M.; Tas, N. R.; van Honschoten, J. W.; Subramaniam, V.; Elwenspoek, M. C. Analysis of single quantum-dot mobility inside 1D nanochannel devices. Nanotechnology 2011, 22, 275201.

[4] Hoang, H. T.; Tong, H. D.; Segers-Nolten, I. M.; Tas, R. N.; Subramaniam, V.; Elwenspoek, M. C. Wafer-scale thin encapsulated two-dimensional nanochannels and its application toward visualization of single molecules. J. Colloid Interf. Sci. 2012, 367 (1), $455-459$.

\section{Conference papers}

[5] Hoang, H. T.; Jansen, H. V.; Tas, N. R.; Elwenspoek. M. C. The microfabrication of and study on nanochannels. NanoImpuls Day, Delft University of Technology, The Netherlands 2004.

[6] Hoang, H. T.; Jansen, H. V.; Tas, N. R.; Elwenspoek. M. C. The microfabrication of and study on nanochannels. $I^{\text {st }}$ International Nanofluidics Workshop, Boekelo, The Netherlands 2005.

[7] Floris, J; Hoang, H. T.; Eijkel, J. C. T.; Tas, N. R. The influence of channel wall deprotonation on fluorescein intensity during capillary filling of $\mathrm{SiO}_{2}$ nanochannels. $I^{\text {st }}$ International Nanofluidics Workshop, Boekelo, The Netherlands 2005.

[8] Hoang, H. T.; Berenschot, E.; Tas, N. R.; Elwenspoek; M. C. Fabrication of access holes to 2D nanochannels for single molecules experiment. Nano2Life, University of Twente, Enschede, The Netherlands 2005.

[9] Hoang, H. T.; Berenschot, E.; Tas, N. R.; Elwenspoek; M. C. Fabrication of access holes to $2 \mathrm{D}$ nanochannels for single molecules experiment. The $9^{\text {th }}$ Annual European Conference on Micro and Nanoscale Technology for the Biosciences-Nanotech, Montreux, Switzerland 2005. 
[10] Hoang, H. T.; Berenschot, E.; Tas, N. R.; Elwenspoek; M.C. Fabrication of access holes to 2D nanochannels for single molecules experiment. NanoNed/MicroNed Symposium I, Groningen, The Netherlands 2005.

[11] Hoang, H. T.; de Boer, M.; Berenschot, E.; Tas, N. R.; Elwenspoek; M. C. Fabrication of nanochannels and their applications. Users' Committee Meeting, Utretch, The Netherlands 2006.

[12] Hoang, H.; Segers-Nolten, I.; Tas, N.; De Boer, M.; Subramaniam, V.; Elwenspoek, M. Fabrication of 1D nanochannels with thin glass wafers for single molecule studies. NanoNed/MicroNed Symposium II, Eindhoven University of Technology, Eindhoven, The Netherlands 2006.

[13] Janssen, K.; Hoang, H.; Tas, N.; Tjaden, U.; Eijkel, J.; van den Berg, A.; Hankemeier, T. Nanoscale electrophoretic separation for single cell metabolomics. NanoNed/MicroNed Symposium II, Eindhoven University of Technology, Eindhoven, The Netherlands 2006.

[14] Hoang, H.; Segers-Nolten, I.; Tas, N. R.; de Boer, M. J.; Subramaniam, V.; Elwenspoek, M. C. Fabrication of 1D nanochannels with thin glass wafers for single molecule studies. Oral presentation at $10^{\text {th }}$ Annual NSTI Nanotechnology Conference and Trade Show- NSTI Nanotech, Santa Clara, CA, USA 2007, Technical Proceedings 3, $260-263$.

[15] Janssen, K. G. H.; Hoang, H. T.; Tas, N. R.; Eijkel, J. C. T.; Hankemeier, T. Proton release from siliconoxide walls during capillary filling of nanochannels. $22^{\text {nd }}$ International Symposium on Microscale Bioseparations and Methods for Systems Biology, MSB the Freie Universität Berlin, Germany 2008.

[16] Janssen, K. G. H.; Jiajie, L.; Hoang, H. T.; Tas, N. R.; van der Linden, H. J.; Hankemeier, T. Downscaling quantitative isotachophoresis: limits at the sub-picoliter scale. $14^{\text {th }}$ International Conference on Miniaturized Systems for Chemistry and Life Sciences, Groningen, The Netherlands 2010, 1730-1732.

\section{Other publications}

[17] Tong, H. D.; Gielens, F. C.; Hoang, H. T.; Gardeniers, J. G. E.; Jansen, H. V.; Nijdam, W.; van Rijn, C. J. M.; Elwenspoek, M. C. Thin, strong and defect free microfabricated palladium composite membranes for hydrogen separation. Proceeding of International Conference on Microreaction Technology, IMRET 7, Lausanne, Switzerland 2003, $343-345$. 
[18] Tong, H. D.; Gielens, F. C.; Hoang, H. T.; Jansen, H. V.; Elwenspoek, M. C. Preparation of a dual sputtering $\mathrm{Pd}-\mathrm{Cu}$ alloy film and its application in hydrogen separation. Proceeding of MME Conference, Delft, The Netherlands 2003, 127-130.

[19] Tong, H. D.; Gielens, F. C.; Hoang, H. T.; Berenschot, J. W.; de Boer, M. J.; Gardeniers, J. G. E.; Jansen, H. V.; Nijdam, W.; van Rijn, C. J. M.; Elwenspoek, M. C. A hydrogen separation module based on wafer-scale micromachined palladium-silver alloy membranes. $12^{\text {th }}$ International Conference on Solid-State Sensors, Actuators and Microsystems, TRANSDUCERS, Boston, MA, USA 2003.

[20] Hoang, H. T.; Tong, H. D.; Gielens, F. C.; Jansen, H. V.; Elwenspoek, M. C. Fabrication and characterization of dual sputtered $\mathrm{Pd}-\mathrm{Cu}$ alloy films for hydrogen separation membranes. Mater. Lett. 2004, 58 (3-4), 525-528. 


\section{Acknowledgements}

This thesis is the result of the research work carried out in the Transducers Science and Technology (TST) Group, University of Twente, known as MicMec. I would like to express my great gratitude to everyone who has given me support and encouragement in completely different ways to fulfill this thesis.

I acknowledge the funding from NanoNed program through Nanofluidics flagship for supporting through the project TET 6644 "Machining technologies for nanochannels and interfacing". The NanoNed program has brought extremely wonderful opportunities to share experiences during many scientific activities such as annual meetings and symposiums.

I would like to express my deeply thank to the members of the Graduation Committee for their comments and presence.

I would especially like to thank my promotor, Professor Miko Elwenspoek to allow me working in TST group. Becoming a MicMec's member is a great chance to promote my scientific career. Thank you very much for supporting me all the way to make this thesis. Without your help, this thesis would have never been completed.

I owe great gratitude to my first daily supervisor, Dr. Henri Jansen. Thank you very much for choosing me to work for the project. Further, your guiding in my first year as a $\mathrm{PhD}$ student is extremely tremendous importance to me. I always think about one of our proverb "Everything has a difficult beginning". You help me set stable stones for my $\mathrm{PhD}$ research. Thank you so much, Henri!

I am grateful to thank my daily supervisor, Dr. Niels Tas for your stimulating advice during carrying research and writing this thesis. Thank you very much for your overwhelming patience and kind support, especially in the most difficult period of my time in the Netherlands. Through your dedication to editing my thesis and your support in making sure I have finally finished this work, it is all possible.

It is my true pleasure to work during the research cooperation among the TST group and the BIOS Lab-on-a-chip Group, University of Twente and the Analytical BioSciences Group, Leiden University to conduct experiments and analysis data for deprotonation. I wish to express my sincerely thank to Professor Albert van den Berg, Professor Jan Eijkel and Professor Thomas Hankemeier for your valuable comments during our meetings. Our cooperation has enormous prospective which proves by the wonderful article appeared in 
Analytical Chemistry journal. I would like to dedicate my great appreciate to Kjeld Janssen. It is my great delight to work with you through cooperation for deprotonation study. Your model is a breakthrough that deprotonation story is brought up to a perceivable state. I have never forgotten our valuably exchanged discussions and meetings in the Twente University and Leiden University.

My huge thanks come to Professor Vinod Subramaniam for your significant support and advices to establish experiment trends in cooperated activities between the TST Group and NanoBioPhysics Group, University of Twente. My special thank goes for Dr. Ine SegersNolten. You are the kindest person I have ever met. Thank you very much for your massive support during conducting the mobility experiments. My project would have never reached the target of mobility measurement without your help. I also would like to thank Dr. Hans Kanger and Dr. Marieke Snijder-van As to openly share your expertise of microscopy.

I really appreciate the unlimited support from my colleagues in Institute of Engineering Physics, Hanoi University of Technology (HUT), Vietnam. I would like to address my thanks to Professor Nguyen Duc Chien and Professor Do Tran Cat who strongly support me for abroad studying. All my close colleagues in Department of General Physics, HUT are thanked for your warm help during my coming-back time in Vietnam.

My big thank goes to my close friend, Dr. Tong Duy Hien. Thank you so much for introducing me the University of Twente from which I have had a chance to work in very high scientific environment. Thank for our cooperation in fabrication of 2D encapsulated nanochannels, it is proved by the excellent result. More than that, spending with your family in the Netherlands avoids my missing of our country. Thank you very much for everything you did for me.

I really appreciate technical help from Meint de Boer, Erwin Berenschot during fabrication of devices. Without your help, there would not have any channels fabricated. Of course, I never forget their unconditional support from $\mathrm{MESA}^{+}$cleanroom staffs. I must have very tough time running up and down without your assistant. I still remember you all with your blue suits, thank you very much the "Blue team". I would like to thank Mark Smithers for taking of SEM images.

There are some people in our group that I had opportunities to directly work with. I am really glad about your contributions to my research. One of these is Dr. Jeroen Haneveld. Thank you for sharing experience during fabrication of nanochannels. Your experience has 
significantly shortened the procedures to complete nanochannel devices. The second person, I am quite happy to work with, is Dr. Joost van Honschoten who I had discussions about calculations of Brownian motion of single quantum dots. Thank you very much for your willing support when it needed. My thanks are for Jan Floris and Jeroen de Vries for carrying deprotonation experiments inside nanochannels. It is glad to have you carrying out your assignments with us. Your contribution of collect and analysis data is excellent job. Finally, I like to thank Mai Thi Anh Dao for helping to carry out wetting experiment which improved filling procedure for nanochannels.

In short form of this paper, I hardly express my faithful thanks to everyone who has helped me all along to make this thesis. I am delighted to thank you, all the TST members for creating so many wonderful scientific and social activities. I enjoyed it very much and it made my experiences in Twente University definitely unforgettable. My special thanks to Prof. Gijs Krijnen, Dr. Leon Abelmann, Dr. Remco Wiegerink, Dr. Theo Lammerink, Dr. Vitaly Svetovoy, Satie, Susan, Ingrid, Dick, Henk, Pino, Johnny, Thijs, Rik, Hans, Kechun, Martin, Ton, John, Deladi, Louis, Duy, Imran, Boudewijn, Doekle, Marcus, Marcel, Dennis, Yiping, Berker, Shahina, Sandeep, Ram, Nima, Ahmad, Hammad, Hadi, Narges, Mubassira, Maryana etc...

I want to give my massive thank to Laura Vargas and Natalie Brunets who totally understand my concern about balance between working and raising children. Having Natalie as my roommate is really wonderful, our conversion about family, life in Ukraine and Vietnam is never going to end.

This thesis would not have been written without the support and encouragement of my friends in Twente University (Tom, Cuong, Kim-Van Anh, Hieu-Lam, Tu-An, Thang-Mai, Giang-Chi, Duy-Chi, Phuong-Ha, Long, Nhung, Trung-Thanh, Minh, Hao, Son, So, Nhi, Huong, Chau, Tan, Lan Anh) and in the Netherlands (Binh-Hien, Monique-Jeroen, Gerry, Zoe). I personally wish to thank my best friends Le Ly and Minh Huyen and my family in Vietnam for their frequent care and regarding to us.

My distinguished thank comes for my lovely Mum for upbringing me. I have realized that it is very hard for you when I decided to go for studying in the Netherlands. I really appreciate your understanding and your care to avoid anxiousness for me.

This thesis is devoted to my kind Dad. Thank you so much for support and believe me all the way. From heaven, you are probably happy that I finished and achieved a doctoral degree. 
Most of all my loving thanks go to my beloved husband, Duy Ha for your extreme patience, critical appraisal, and gracious support along the way of making this thesis. You are back me and help me to promote my career. I truly appreciate that. My dedicated thank to my sweetheart daughter, Hoang Anh (Mika) for her unfailing love and enthusiastic support. Working and having you in Enschede with me is a kind of fascinated experiences I have ever spent. You help me to balance them and enjoy our life in the Netherlands. I am really greatful about your big effort to understand my work of making tiny channels.

Hoang Thi Hanh

Vienna, $18^{\text {th }}$ December 2011 


\section{Biography}

Hanh Thi Hoang was born in Hungyen, Vietnam. She has gained an engineering degree in Chemical Department, Hanoi University of Technology, Hanoi, Vietnam in 1995.

In 1997, she graduated Master in International Training Institute for Material Science (ITIMS), Vietnam. After that she has worked as assistant teacher in Institute of Engineering Physics, Hanoi University of Technology, Vietnam.

In 2002 she received a one-year training scholarship from the Vietnamese government and worked for the "Membrane project" in Transducers Science and Technology Group, University of Twente, the Netherlands.

Since 2004, she started her $\mathrm{PhD}$ position in the Transducers Science and Technology Group with "Machining technologies for nanochannels and interfacing" project funded by NanoNed program. She successfully fabricated 1D and 2D nanochannel devices for studying water viscosity in these confined channels. 